\title{
Evaluating Contaminant Flux from the Vadose Zone to the Groundwater in the Hanford Central Plateau: SX Tank Farm Case Study
}

\section{September 2015}

\author{
M.J. Truex \\ M. Oostrom \\ G.V. Last \\ C.E. Strickland \\ G.D. Tartakovsky
}




\title{
DISCLAIMER
}

This report was prepared as an account of work sponsored by an agency of the United States Government. Neither the United States Government nor any agency thereof, nor Battelle Memorial Institute, nor any of their employees, makes any warranty, express or implied, or assumes any legal liability or responsibility for the accuracy, completeness, or usefulness of any information, apparatus, product, or process disclosed, or represents that its use would not infringe privately owned rights. Reference herein to any specific commercial product, process, or service by trade name, trademark, manufacturer, or otherwise does not necessarily constitute or imply its endorsement, recommendation, or favoring by the United States Government or any agency thereof, or Battelle Memorial Institute. The views and opinions of authors expressed herein do not necessarily state or reflect those of the United States Government or any agency thereof.

\author{
PACIFIC NORTHWEST NATIONAL LABORATORY \\ operated by \\ BATTELLE \\ for the \\ UNITED STATES DEPARTMENT OF ENERGY \\ under Contract DE-AC05-76RL01830
}

Printed in the United States of America
Available to DOE and DOE contractors from the Office of Scientific and Technical Information, P.O. Box 62, Oak Ridge, TN 37831-0062; ph: (865) 576-8401 fax: $(865) 576-5728$
email: reports $a$ adonis.osti.gov
Available to the public from the National Technical Information Service 5301 Shawnee Rd., Alexandria, VA 22312 ph: (800) 553-NTIS (6847)

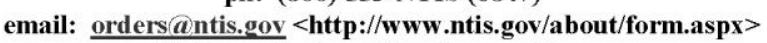 Online ordering: http://www.ntis.gov


PNNL-23737

RPT-DVZ-AFRI-026

\title{
Evaluating Contaminant Flux from the Vadose Zone to the Groundwater in the Hanford Central Plateau: SX Tank Farm Case Study
}

\author{
M.J. Truex \\ M. Oostrom \\ G.V. Last \\ C.E. Strickland \\ G.D. Tartakovsky
}

September 2015

Prepared for

the U.S. Department of Energy

under Contract DE-AC05-76RL01830

Pacific Northwest National Laboratory

Richland, Washington 99352 



\section{Executive Summary}

At the U.S. Department of Energy's (DOE's) Hanford Site, contaminants were discharged to the subsurface through engineered waste sites in the Hanford Central Plateau. Additional waste was released through waste storage tank leaks. Much of the contaminant inventory is still present within the unsaturated vadose zone sediments. The nature and extent of future groundwater contaminant plumes and the growth or decline of current groundwater plumes beneath the Hanford Central Plateau are a function of the contaminant flux from the vadose zone to the groundwater. In general, contaminant transport is slow through the vadose zone and it is difficult to directly measure contaminant flux in the vadose zone. Predictive analysis, supported by site characterization and monitoring data, was applied using a structured, systems-based approach to estimate the future contaminant flux to groundwater in support of remediation decisions for the vadose zone and groundwater (Truex and Carroll 2013). The SX Tank Farm was used as a case study because of the existing contaminant inventory in the vadose zone, observations of elevated moisture content in portions of the vadose zone, presence of a limited-extent groundwater plume, and the relatively large amount and wide variety of data available for the site. Although the SX Tank Farm case study is most representative of conditions at tank farm sites, the study has elements that are also relevant to other types of disposal sites in the Hanford Central Plateau.

A structured approach to estimating future contaminant flux to the groundwater was applied. This approach centers on using a systems-based, conceptual model to guide the study. The approach is initiated by considering the environmental and engineering setting of the site, gathering available data and information as is typically done for a tradition conceptual site model. An important part of this step is considering the lines of evidence provided by different types of data and any limitations for use of the data. The conceptual model is then refined by evaluating key elements of the environmental setting, considering potential controlling features and processes and relevant boundary conditions in the context of water and contaminant flux through the vadose zone. This refinement takes place as an integrated evaluation of data, unsaturated flow phenomena, and predictive analyses to investigate the role of different driving forces for contaminant flux at the site. Sensitivity analyses are conducted as part of this investigation to help assess the importance of different elements within the range of certainty of the data. Refinement also includes comparing the results of predictive analyses to available characterization and monitoring data. The refinement process identifies a range of contaminant flux conditions that reasonably bound the variation in data and provide an estimate for future contaminant flux to groundwater. Results for contaminant flux estimates can then be explained in terms of the conceptual model and the key controlling features and processes. This approach also provides a means to investigate how types of mitigation strategies - in this example, use of a surface infiltration barrier-may impact the future contaminant flux.

The SX Tank Farm contains fifteen 1-million gallon single-shell underground storage tanks. Ten of the 15 tanks in the SX Tank Farm have been officially designated as leakers. Eight of the tanks are believed to have released liquids to the subsurface and a groundwater plume appears to originate near the southern perimeter of the SX Tank Farm. 
For the SX Tank Farm case study, the following conclusions were reached based on the contaminant flux analysis. These conclusions provide the technical foundation supporting estimates of contaminant flux at the site. Key elements of the refined conceptual model for the SX Tank Farm are summarized in Figure ES.1.

- The leak volumes were small with respect to attenuation of advective flow in the vadose zone and do not drive long-term flux. The change in surface recharge following tank farm construction imposed a much larger hydraulic driving force on the vadose zone than the tank leaks.

- Even though massive amounts of water were discharged at sites in the vicinity of the SX Tank Farm (e.g., 216-U Pond), these discharges did not significantly impact water and contaminant flow beneath the SX Tank Farm and do not need to be considered in setting the boundary conditions for SX Tank Farm subsurface flow and transport analyses.

- The imposed recharge change in 1953, with an estimated impact of changing the surface recharge from about $3.5 \mathrm{~mm} / \mathrm{yr}$ to about $92 \mathrm{~mm} / \mathrm{yr}$, propagated changes in the vadose zone flow conditions. Changes in the surface recharge resulted in changes in the water flux into the groundwater about 50 years after the surface change occurred such that current conditions in the vadose zone are at steady state with respect to the imposed $92 \mathrm{~mm} / \mathrm{yr}$ recharge rate. This recharge rate controls the water flux throughout the vadose zone beneath the SX Tank Farm regardless of subsurface sediment properties, unless there is a localized source of higher water inflow (e.g., a water-line leak).

- In the presence of a water-line leak, localized conditions can be created that intersect vadose zone contamination and accelerate contaminant transport into the groundwater. The Tc-99 plume at the south end of the SX Tank Farms cannot be explained without imposing a localized water-line leak near the SX-115 tank. When a leak is simulated, the Tc-99 plume and contaminant arrival times at downstream wells can be reasonably replicated. It appears that the water-line leak adjacent to the SX115 has created the only accelerated contaminant flux condition at the SX Tank Farm. The other contaminant plumes would be expected to develop based on recharge-driven flux.

- While contaminants released from the tanks were initially advectively transported due to the leak, vadose zone processes quickly dissipated these conditions and the increased recharge rate became the controlling factor for water flux toward the groundwater. Unsaturated flow properties and the increased relative importance of molecular contaminant diffusion delay the contaminant flux compared to the water flux. Thus, in the absence of localized water-line leaks enhancing advective transport, while the increased recharge front is estimated to have reached the water table at present, the contaminant front from leaks is expected to occur in the future.

- The contaminant flux profile is related to the amount of contaminant concentration decreases caused by vadose zone flow and transport processes, contaminant-specific sorption, and decay properties (which are significant for Cs-137), and the recharge-driven water flux. Because the radioactive decay of Cs-137 is relatively fast, even with moderate sorption to sediments, Cs-137 is predicted to decay before being discharged to the groundwater. In contrast, Tc-99 has a long half-life and minimal sorption and is predicted to enter the groundwater. 
- Because leak volumes are relatively small and recharge controls the water flux through the vadose zone, contaminant plumes from individual tanks are not expected to co-mingle significantly in the vadose zone.

- Because recharge controls the contaminant flux conditions, a surface infiltration barrier can reduce the future contaminant flux to groundwater. However, it takes time for the effects of a barrier to propagate in the vadose zone and impact the water and associated contaminant flux to the groundwater. Although emplacement of a barrier will reduce the magnitude of future contaminant fluxes, these fluxes may result in groundwater concentrations exceeding standards over much longer periods.

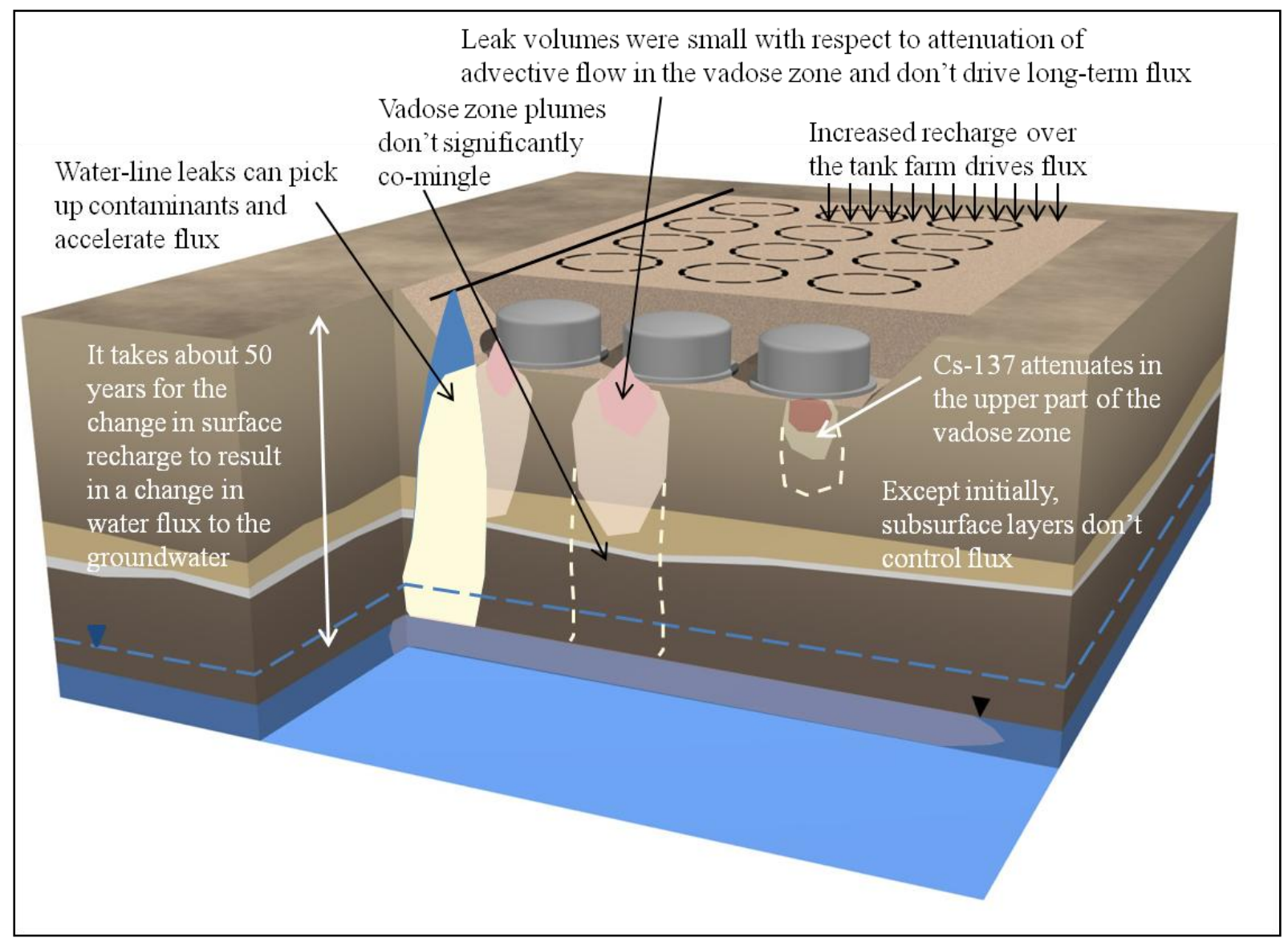

Figure ES.1. Synthesized conceptual model for the SX Tank Farm showing key conclusions related to future contaminant flux estimates.

Based on the contaminant flux analyses in the study, in the absence of any mitigation measures, the Tc-99 flux to groundwater from the SX-115 tank is expected to increase over the next 40 years before it starts to decline. Groundwater contamination from other tank leaks is expected to occur over the next 10-20 years with a peak contaminant flux in 60-100 years (depending on the individual tank leak). Installation of a surface infiltration barrier can delay the initial contaminant flux and decrease the magnitude of the peak flux, causing a lower overall contaminant flux over a much longer period of time. The magnitude and duration of contaminant flux are both important aspects when evaluating remediation alternatives. 
The analysis presented herein was conducted as a case study using SX Tank Farm data. The intent is to provide an example of a structured approach to estimating future contaminant flux to groundwater along with providing a technical foundation for the flux estimates. Key portions of the SX Tank Farm and associated water and contaminant sources (i.e., Tc-99 and Cs-137) were examined, but the analysis was not comprehensive for all SX Tank Farm contaminants. While the structured approach to estimating future contaminant flux is transferrable to other tank farms and waste disposal sites, specific conclusions with respect to contaminant flux at the SX Tank Farms are not necessarily applicable at other sites.

The contaminant flux analysis is important to provide input to remediation decisions, but also to focus characterization. For instance, only a few elements were shown to control the contaminant flux at the SX Tank Farm. Additional information about non-controlling features will not improve these estimates. Thus, characterization can be focused on gathering information that decreases uncertainty in these flux estimates, if needed to support a remedy decision, or on aspects related to evaluation and implementation of remediation alternatives. For the SX Tank Farm, the future contaminant flux estimates are fairly well bounded by the available information. This type of study may also be useful in communicating and discussing remediation decisions by demonstrating that uncertainty in some parameters (e.g., leak volumes and duration, detailed hydraulic property distributions) do not significantly impact the estimates of future contaminant flux. 


\section{Acknowledgments}

This document was prepared by the Deep Vadose Zone Applied Field Research Initiative at Pacific Northwest National Laboratory. Funding for this work was provided by the U.S. Department of Energy

(DOE), Richland Operations Office. The Pacific Northwest National Laboratory is operated by Battelle Memorial Institute for DOE under Contract DE-AC05-76RL01830. 



\section{Acronyms and Abbreviations}

\begin{tabular}{|c|c|}
\hline $3 \mathrm{D}$ & three-dimensional \\
\hline bgs & below ground surface \\
\hline $\mathrm{CCU}$ & Cold Creek Unit \\
\hline $\mathrm{Ci}$ & curie(s) \\
\hline $\mathrm{cm}$ & centimeter(s) \\
\hline cpm & counts per minute \\
\hline cps & counts per second \\
\hline $\mathrm{CY}$ & calendar year \\
\hline $\mathrm{d}$ & $\operatorname{day}(\mathrm{s})$ \\
\hline DOE & U.S. Department of Energy \\
\hline ERT & Electrical Resistivity Tomography \\
\hline $\mathrm{ft}$ & foot(feet) \\
\hline $\mathrm{g}$ & $\operatorname{gram}(\mathrm{s})$ \\
\hline gal & gallon(s) \\
\hline $\mathrm{h}$ & hour(s) \\
\hline $\mathrm{K}_{\mathrm{d}}$ & distribution coefficient \\
\hline $\mathrm{kg}$ & kilogram(s) \\
\hline kgal & 1000 gallon \\
\hline $\mathrm{L}$ & liter(s) \\
\hline $\mathrm{m}$ & meter(s) \\
\hline M & molar \\
\hline $\mathrm{m}^{2}$ & square meter(s) \\
\hline $\mathrm{m}^{3}$ & cubic meter(s) \\
\hline $\min$ & minute(s) \\
\hline $\mathrm{mL}$ & milliliter(s) \\
\hline $\mathrm{mm}$ & millimeter(s) \\
\hline mo & $\operatorname{month}(\mathrm{s})$ \\
\hline $\mathrm{pCi}$ & picocurie(s) \\
\hline PNNL & Pacific Northwest National Laboratory \\
\hline psi & pounds per square inch \\
\hline QA & quality assurance \\
\hline SIM & Soil Inventory Model \\
\hline SST & single-shell tank \\
\hline STOMP & Subsurface Transport Over Multiple Phases \\
\hline WMA & Waste Management Area \\
\hline yr & year(s) \\
\hline
\end{tabular}





\section{Contents}

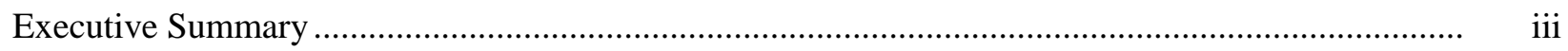

Acknowledgments......................................................................................................... vii

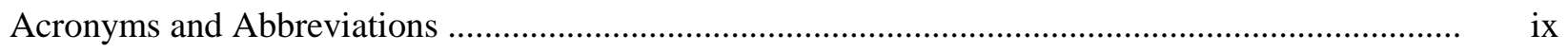

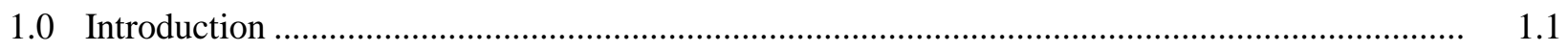

2.0 SX Tank Farm Background and Conceptual Model.................................................................... 2.1

2.1 Natural and Anthropogenic Driving Forces …………................................................... 2.2

2.2 Site Hydrogeology ......................................................................................... 2.3

2.3 Physical, Hydrologic, and Geochemical Properties ............................................................ 2.6

2.4 Vadose Zone Contaminant and Moisture Distributions ................................................... 2.8

2.5 Groundwater Impacts ............................................................................................ 2.13

2.6 Waste and Water Releases to the Vadose Zone at the SX Tank Farm................................ 2.19

2.7 Conceptual Model Summary ................................................................................. 2.20

3.0 Evaluation Approach for Future Contaminant Flux to Groundwater .......................................... 3.1

3.1 Integrated Assessment Approach ................................................................................... 3.1

3.2 Numerical Model Configuration ……………………................................................ 3.2

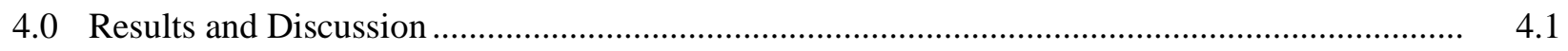

4.1 Assessment of Controlling Features and Processes ............................................................ 4.1

4.2 Estimation of Tc-99 Contaminant Flux into Groundwater............................................... 4.15

4.2.1 Base Case Model ........................................................................................... 4.15

4.2.2 Effects of Suspected Water Line Leak ………………………………………..... 4.27

4.2.3 Effects of Barrier Emplacement ......................................................................... 4.34

4.2.4 Effects of Lower Permeability in the Cold Creek Unit ........................................... 4.39

4.2.5 Effects of Tank Leak Rates and Duration ............................................................... 4.45

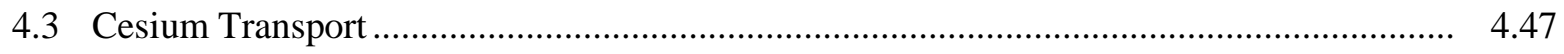

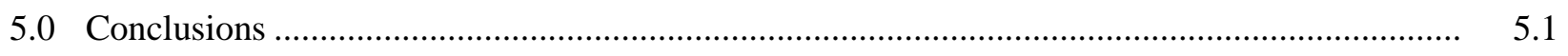

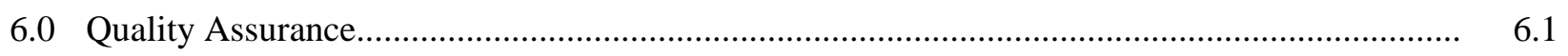

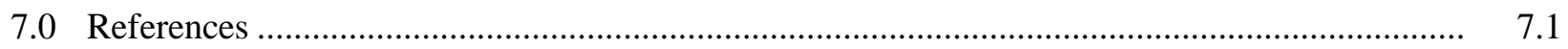

Appendix A - SX Tank Farm Operational Background Information................................................ A.1

Appendix B - SX Tank Leak Source Term Estimates ......................................................................... B. $\quad$ B.1 


\section{Figures}

2.1. SX Tank Farm and surrounding facilities ................................................................... 2.2

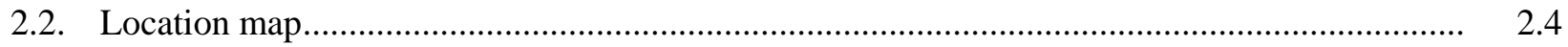

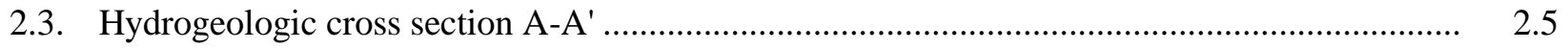

2.4. Hydrogeologic cross section $B-B^{\prime}$.............................................................................. 2.5

2.5. Area most likely indicative of increased soil moisture and electrolyte concentrations............... 2.9

2.6. Cross-sectional view of the "below $0.8 \mathrm{log}$ ohm-meter" contour area that is most likely indicative of increased soil moisture and electrolyte concentrations ............................. 2.10

2.7. Moisture content and Tc-99 distribution for borehole 299-W23-234 ................................... 2.11

2.8. Moisture content and Tc-99 distribution for the 241-SX-108 slant borehole ........................... 2.12

2.9. Comparison of acid-extractable Tc-99 for the 41-09-39 (well 299-W23-234) and C3082 boreholes.

2.10. Composite hydrograph and high-volume effluent discharges near the SX Tank Farm ............. 2.14

2.11. 200-UP-1 operable unit groundwater contaminant plume map ............................................ 2.16

2.12. Temporal concentrations of Tc-99 in groundwater observed at well 299-W23-19 ................. 2.17

2.13. Temporal concentrations of Tc-99 in groundwater observed at well 299-W22-39 ................. 2.17

2.14. Temporal concentrations of Tc-99 in groundwater observed at well 299-W22-46 ................. 2.18

2.15. Temporal concentrations of Tc-99 in groundwater observed at well 299-W22-49 ................. 2.18

2.16. Temporal concentrations of Tc-99 in groundwater observed at well 299-W22-50 ................. 2.19

2.17. Data available for evaluating vadose zone contamination and contaminant flux for

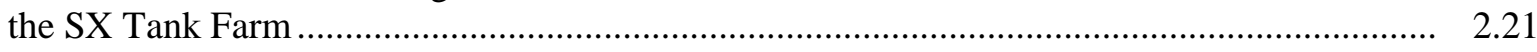

3.1. Sediment zonation for the SX-108 numerical model domain. .............................................. 3.6

3.2. Sediment zonation for SX Tank Farm numerical model domain.......................................... 3.6

3.3. Water lines at southern end of SX Tank Farm with suspected water-line leak location............ 3.7

3.4. Simulated water saturation in 1944 when disposal into U-10 was initiated.............................. 3.7

3.5. Simulated water saturation in 1985 when disposal into U-10 was terminated.......................... 3.8

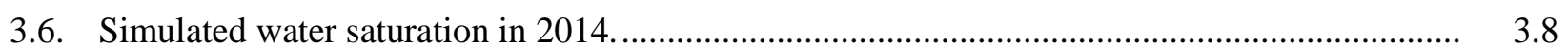

3.7. Simulated water saturation in 1985 , when disposal into U-10 was terminated, for a reduced hydraulic conductivity of the Cold Creek Units............................................. 3.9

3.8. Simulated water saturation in 2014 for reduced hydraulic conductivity in the

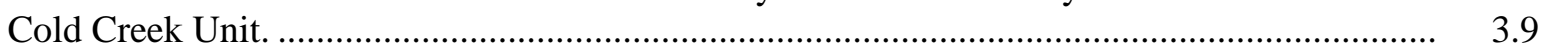

4.1. Aqueous saturation in 1953 for the SX-108 Base Case simulation ........................................ 4.5

4.2. Aqueous saturation after the second leak (1967) for the SX-108 Base Case simulation.

4.3. Dimensionless Tc-99 concentrations after the second leak (1967) for the SX-108

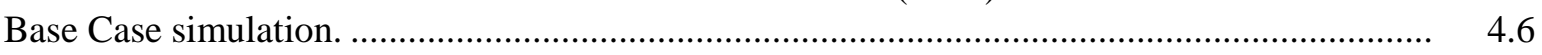

4.4. Aqueous saturation after the third leak (1968) for the SX-108 Base Case simulation ................ 4.6 
4.5. Dimensionless Tc-99 concentrations after the third leak (1968) for the SX-108

Base Case simulation.

4.6. Aqueous saturation in 1980 for the SX-108 Base Case simulation.

4.7. Dimensionless Tc-99 concentrations in 1980 for the SX-108 Base Case simulation...

4.8. Aqueous saturation in 2014 for the SX-108 Base Case simulation ..

4.9. Dimensionless Tc-99 concentrations in 2014 for the SX-108 Base Case simulation.

4.10. Aqueous saturation in 2100 for the SX-108 Base Case simulation

4.11. Dimensionless Tc-99 concentrations in 2100 for the SX-108 Base Case simulation.

4.12. Aqueous saturation in 2100 for the SX-108 Barrier simulation.

4.10

4.13. Dimensionless Tc- 99 concentrations in 2100 for the SX-108 Barrier simulation

4.14. Aqueous saturation in 4000 for the SX-108 Barrier simulation.

4.15. Dimensionless Tc-99 concentrations in 4000 for the SX-108 Barrier simulation

4.16. Groundwater recharge for the SX-108 simulations.

4.17. Tc-99 mass discharge into groundwater for the SX-108 simulations over the period 1953-2450.

4.18. Tc-99 mass discharge into groundwater for the SX-108 simulations over the period 1953-3950.

4.19. Tc-99 cumulative mass discharge into groundwater for the SX-108 simulations over the period 1953-2450.

4.20. Tc-99 cumulative mass discharge into groundwater for the SX-108 simulations over the period 1953-3950.

4.21. Aqueous saturation in 1953 for the Base Case simulation (transect through tank centers).

4.22. Aqueous saturation at of the SX-113 leak in 1962 for the Base Case simulation (transect through tank centers).

4.23. Dimensionless Tc-99 concentration at the end of the SX-115 leak in 1962 for the Base Case simulation (transect through tank centers)

4.24. Aqueous saturation at the end of the SX-115 leak in 1965 for the Base Case simulation (transect through tank centers).

4.25. Dimensionless Tc-99 concentration at the end of the SX-115 leak in 1965 for the Base Case simulation (transect through tank centers).

4.26 Aqueous saturation at the end of the SX-115 leak in 1965 for the Base Case simulation (transect $8 \mathrm{~m}$ south of tank centers).

4.27. Dimensionless Tc-99 concentration at the end of the SX-115 leak in 1967 for the Base Case simulation (transect $8 \mathrm{~m}$ south of tank centers).

4.28. Aqueous saturation in 1980 for the Base Case simulation (transect through tank centers).

4.29. Dimensionless Tc-99 concentration in 1980 for the Base Case simulation (transect through tank centers).

4.30. Dimensionless Tc-99 concentration in 1980 for the Base Case simulation (transect $8 \mathrm{~m}$ south of tank centers).

4.31. Aqueous saturation in 2014 for the Base Case simulation (transect through tank centers). 
4.32. Dimensionless Tc- 99 concentration in 2014 for the Base Case simulation (transect through tank centers).

4.33. Dimensionless Tc-99 concentration in 2014 for the Base Case simulation (transect $8 \mathrm{~m}$ south of tank centers).

4.34. Aqueous saturation in 2100 for the Base Case simulation (transect through tank centers)

4.35. Dimensionless Tc-99 concentration in 2100 for the Base Case simulation (transect through tank centers).

4.36. Dimensionless Tc-99 concentration in 2100 for the Base Case simulation (transect $8 \mathrm{~m}$ south of tank centers)

4.37. Groundwater recharge for the Base Case simulation.

4.38. Tc-99 mass discharge into groundwater for the Base Case simulation.

4.39. Tc-99 cumulative mass discharge into groundwater for the Base Case simulation.

4.40. Tc-99 well concentrations for the Base Case simulation.

4.41. Aqueous saturation at the end of the SX-115 leak in 1965 for the Water Line Leak simulation (transect $8 \mathrm{~m}$ south of tank centers)

4.42. Aqueous saturation in 1980 for the Water Line Leak simulation (transect $8 \mathrm{~m}$ south of tank centers)

4.43. Aqueous saturation in 2000 for the Water Line Leak simulation (transect $8 \mathrm{~m}$ south of tank centers).

4.44. Dimensionless Tc-99 concentration in 1980 for the Water Line Leak simulation (transect $8 \mathrm{~m}$ south of tank centers).

4.45. Dimensionless Tc-99 concentration in 2000 for the Water Line Leak simulation (transect $8 \mathrm{~m}$ south of tank centers)

4.46. Groundwater recharge for the Base Case and Water Line Leak simulation

4.47. Comparison of Tc-99 mass discharge into groundwater for the Base Case and Water Line Leak simulation.

4.48. Tc-99 mass discharge into groundwater for the Water Line Leak simulation

4.49. Tc-99 cumulative mass discharge into groundwater for the Water Line Leak simulation.

4.50. Comparison of Tc-99 well concentrations for the Base Case and Water Line Leak simulation.

4.51. SX-115 Tc-99 mass discharge into groundwater for the three Water Line Leak simulations and the Base Case.

4.52. Aqueous saturation in 2100 for the Water Line Leak with Barrier simulation (transect through tank centers).

4.53. Dimensionless Tc-99 concentration in 2100 for the Water Line Leak with Barrier simulation (transect through tank centers).

4.54. Tc-99 mass discharge for the Water Line Leak with Barrier simulation for $1953-2250$

4.55. Tc-99 mass discharge for the Water Line Leak with Barrier simulation for $1953-2950$. 
4.56. Tc-99 cumulative mass discharge for the Water Line Leak with Barrier simulation for 1953-2250.

4.57. Tc-99 cumulative mass discharge for the Water Line Leak with Barrier simulation for 1953-2950.

4.58. Tc-99 well concentrations for the Water Line Leak with Barrier simulation for $1953-2250$.

4.59. Tc-99 well concentrations for the Water Line Leak with Barrier simulation for 1953-2950.

4.60. Aqueous saturation in 1953 for the Reduced CCU Ksat simulation (transect through tank centers).

4.61. Aqueous saturation at the end of the SX-115 leak in 1965 for the Reduced CCU Ksat simulation (transect $8 \mathrm{~m}$ south of tank centers).

4.62. Dimensionless Tc-99 concentration at the end of the SX-115 leak in 1965 for the Reduced CCU Ksat simulation (transect $8 \mathrm{~m}$ south of tank centers)

4.63. Aqueous saturation in 1980 for the Reduced CCU Ksat simulation (transect $8 \mathrm{~m}$ south of tank centers).

4.64. Dimensionless Tc-99 concentration in 1980 for the Reduced CCU Ksat simulation (transect $8 \mathrm{~m}$ south of tank centers)

4.65. Aqueous saturation in 2014 for the Reduced CCU Ksat simulation (transect $8 \mathrm{~m}$ south of tank centers).

4.66. Dimensionless Tc-99 concentration in 2014 for the Reduced CCU Ksat simulation (transect $8 \mathrm{~m}$ south of tank centers)

4.67. Dimensionless Tc-99 concentration in 2100 for the Reduced CCU Ksat simulation (transect through tank centers).

4.68. Dimensionless Tc-99 concentration in 2100 for the Reduced CCU Ksat simulation (transect $8 \mathrm{~m}$ south of tank centers)

4.69. Comparison of Tc-99 mass discharge into groundwater for Base Case and Reduced CCU Ksat simulation

4.70. Comparison of Tc-99 well concentrations for Base Case and Reduced CCU Ksat simulation...

4.71. Comparison of Tc-99 well concentrations for Base Case and Reduced Leak Duration simulation.

4.72. Comparison of Tc-99 well concentrations for Base Case and Increased Leak Volume simulation.

4.73. Dimensionless Cs-137 concentration at the end of the 1965 SX-115 leak

4.74. Dimensionless Cs-137 concentration in 1980.

4.75. Dimensionless Cs-137 concentration in 2014.

4.76. Dimensionless Cs-137 concentration in 2100.

5.1. Synthesized conceptual model for the SX Tank Farm showing key conclusions related to future contaminant flux conclusions. 


\section{Tables}

2.1. Lithofacies descriptions for the major geologic units of the Hanford Central Plateau .............. $\quad 2.7$

2.2. Summary of Tank Leak Events from the SX Tank Farm.................................................... 2.20

3.1. Sediment hydraulic properties used in the numerical models............................................... 3.4

3.2. Description of SX-108 scoping simulations..................................................................... 3.4

3.3. Description of SX Tank Farm numerical simulations ......................................................... 3.5

3.4. Released Tc- 99 activity, waste volumes, and Tc-99 concentrations used in

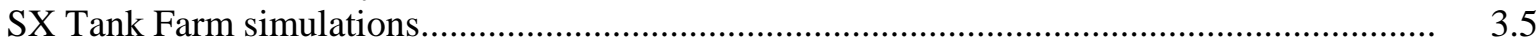




\subsection{Introduction}

At the U.S. Department of Energy (DOE) Hanford Site, contaminants were discharged to the subsurface through engineered waste sites in the Hanford Central Plateau. Additional waste was released through waste storage tank leaks. As a result of these previous tank leaks and waste-site discharges, the vadose zone beneath the Hanford Central Plateau has become contaminated. Some of the contamination has begun to migrate into the groundwater, creating groundwater contamination plumes. However, much of the contaminant inventory is still present within the unsaturated vadose zone sediments. The nature and extent of future groundwater contaminant plumes and the growth or decline of current groundwater plumes beneath the Hanford Central Plateau are a function of the contaminant flux from the vadose zone to the groundwater. Contaminant movement is slow through the vadose zone and it is difficult to directly measure contaminant flux in the vadose zone. However, predictive analysis, supported by site characterization and monitoring data, can be applied to estimate the future contaminant flux to groundwater in support of remediation decisions for the vadose zone and groundwater.

This report provides an analysis of future contaminant flux to groundwater using the 241-SX Tank Farm (hereafter SX Tank Farm) as a case study site. Following the general framework presented by Truex and Carroll (2013), this report integrates available data, knowledge of vadose zone flow and transport processes, and predictive analysis to provide these estimates. The approach and results provide a template for use in evaluating contaminant flux to groundwater and the use of site data to support this evaluation. The SX Tank Farm was selected as a case study because of the existing contaminant inventory in the vadose zone, observations of elevated moisture content in portions of the vadose zone, presence of a limited-extent groundwater plume, and the relatively large amount and wide variety of data available for the site. Although the SX Tank Farm case study is most representative of conditions at tank farm sites, the study has elements that are also relevant to other types of disposal sites in the Hanford Central Plateau.

The study steps through the process of generating a conceptual model in the context of estimating contaminant flux to groundwater and examining the data supporting this conceptual model. Coupling the available lines of evidence with numerical modeling analysis is then applied to evaluate controlling features and processes and to make estimates of future contaminant flux to groundwater. The study also evaluates the type of existing or new data that can be used in support of these contaminant flux estimates. 



\subsection{SX Tank Farm Background and Conceptual Model}

The SX Tank Farm contains fifteen 1-million gallon single-shell underground storage tanks, and a myriad of waste transfer piping systems, diversion boxes, pump pits, valve pits, ventilation/condenser systems, emergency cooling-water tanks, and other waste management facilities (Williams 2001). Ten of the 15 tanks in the SX Tank Farm have been officially designated as leakers (Williams 2001). Eight of the tanks are believed to have released liquids to the subsurface, and a groundwater plume appears to originate near the site's southern perimeter (Johnson and Field 2010; CHPRC 2014). Additional information about the SX Tank Farm is provided in Appendix A and is summarized below.

SX Tank Farm was one of the many waste management facilities constructed to support REDOX (S Plant) operations to separate plutonium and uranium from irradiated nuclear fuel rods. The 241-SX Tank Farm (Figure 2.1) was constructed in two stages from 1953 to 1955 (Williams 2001). Routing of liquid waste from REDOX to the SX Tank Farm was done via underground pipelines and diversion boxes with selected underground piping interconnected via jumpers. The 15 tanks were arranged in five, threetank cascades (Williams 2001), with the first tank in each cascade receiving the waste that would then overflow into the second tank and finally into the third tank. Over the years, various transfer piping systems (including pump pits, valve pits, and diversion boxes) have been installed/modified to enable waste transfer between tanks, tank farms, and the 242-S evaporator. A number of liquid waste disposal facilities are located adjacent to the SX Tank Farm and need to be considered with respect to vadose zone and groundwater contamination in the area (Figure 2.1).

Elements of a conceptual model for the SX Tank Farm and the associated conceptual model data/information are provided in the following sections, and more detailed information is compiled in Appendix A. The final section provides a synthesized conceptual model, along with a discussion of key conceptual model elements that need to be considered in an evaluation of contaminant flux. This synthesized conceptual model and associated questions were used to guide the subsequent data analysis and predictive assessments presented in later sections. 

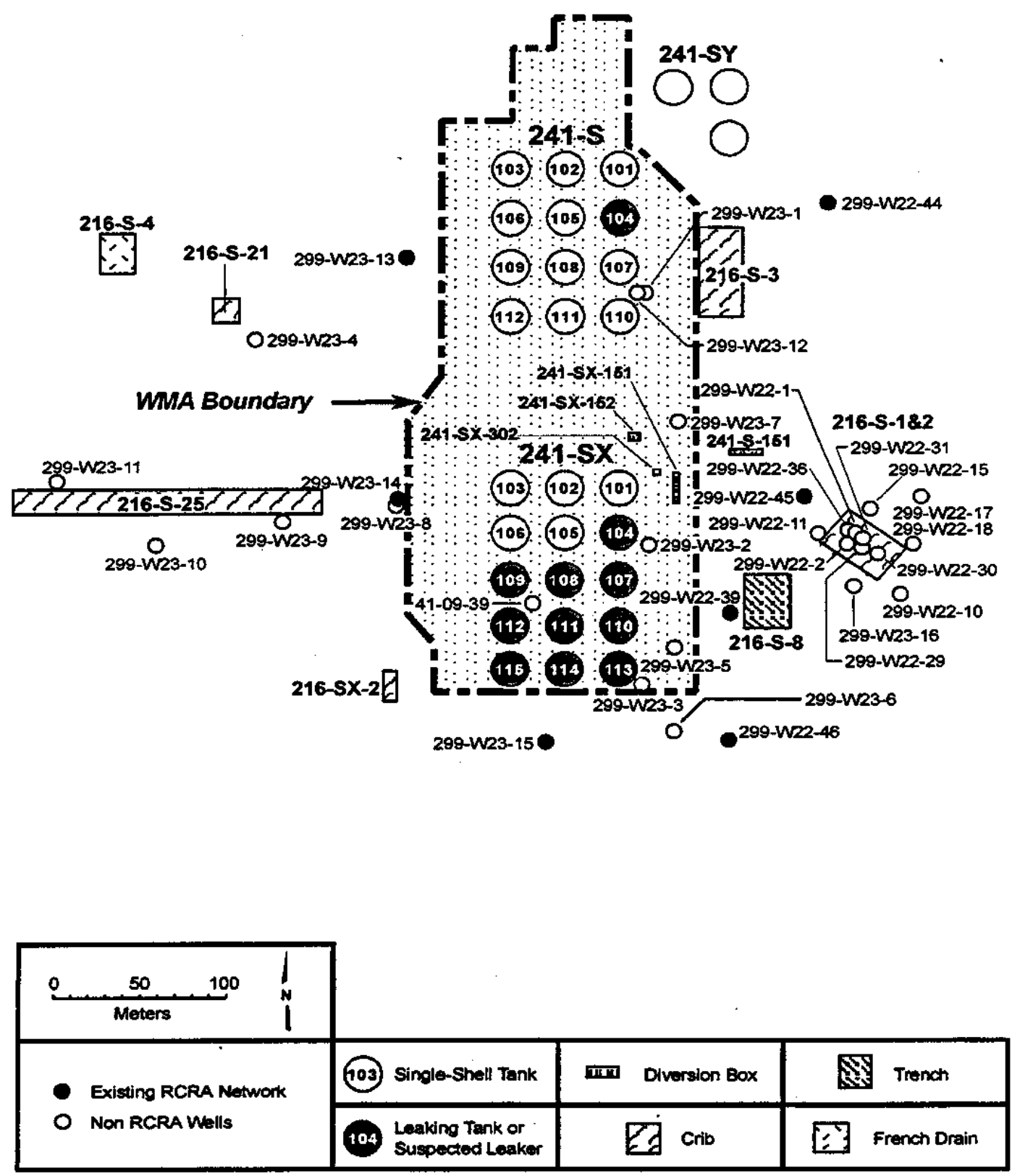

Figure 2.1. SX Tank Farm and surrounding facilities (after Wood et al. 1999).

\subsection{Natural and Anthropogenic Driving Forces}

Anderson (2001) described two sources of water to the single-shell tanks (SST) farms-normal precipitation events, and catastrophic events (both natural and anthropogenic). Fayer and Keller (2007) and Last et al. (2006a) suggested that the best estimate for recharge (the flux of water reaching [i.e., recharging] the water table) beneath a graveled surface (such as that covering the SX Tank Farm) is 92 $\mathrm{mm} / \mathrm{yr}$. Others have rounded this estimate to $100 \mathrm{~mm} / \mathrm{yr}(10 \mathrm{~cm} / \mathrm{yr})$ (DOE 2005; DOE/RL 2012). Anderson (2001) reported that extreme/catastrophic events could occur in conjunction with winter seasonal conditions, when the frozen ground surface is covered with snow, and then a warm southerly 
Chinook wind causes rapid melting. This could result in ponding of water in topographically low areas leading to local areas of increased infiltration within the tank farm.

Anthropogenic water used during normal and off-normal tank farm operations and/or water-line leaks could provide another source of water to drive contamination deeper into the vadose zone and eventually to the groundwater. Anderson (2001) reported that existing site water lines present two separate leak scenarios: 1) everyday leakage from the water lines and 2) leaks from major line ruptures. He noted that old water lines leak over time as a result of soil settlement, deterioration, and operations. He further noted that there have been no leak volume estimates or tests for tank farm water lines, but that "the volume is considered to be substantial." For comparison, he noted that leakage estimates for large water lines outside of the tank farms ranged from about 14 to $140 \mathrm{gal} / \mathrm{min}$ (53 to $530 \mathrm{~L} / \mathrm{min}$ ). In addition to everyday water-line leaks, Anderson (2001) noted that approximately four major water-line breaks are expected to occur in the 200-East or 200-West Areas each year. One such water-line break occurred in 1996 in the vicinity of the 241-S and 241-SY Tank Farms, where Anderson (2001) reported a release of $550,000 \mathrm{gal}$ in 2 hours $(17,350 \mathrm{~L} / \mathrm{m})$.

\subsection{Site Hydrogeology}

The geology underlying the SX Tank Farm, and the associated physical and geochemical properties, control moisture and contaminant movement through the vadose zone to groundwater. Of particular interest are the interrelationships between the coarser and finer-grained facies, and the degree of contrast in their physical and geochemical properties (Serne et al. 2008a). Information about the hydrogeologic stratigraphy comes primarily from the interpretation of borehole data. There are 124 borings and wells within the confines of the SX Tank Farm. Fifty-six of these have geologic contact information.

Four principal suprabasalt geologic units underlie the SX Tank Farm and surrounding area. These include (in descending order) Holocene surficial deposits (primarily of anthropogenic origin, i.e., backfill), the Hanford formation, the Cold Creek Unit (CCU), and the Ringold Formation Figure 2.2 through Figure 2.4). Additional information and the average geologic contact elevation and thicknesses for each of the major geologic units are provided in Appendix A. 


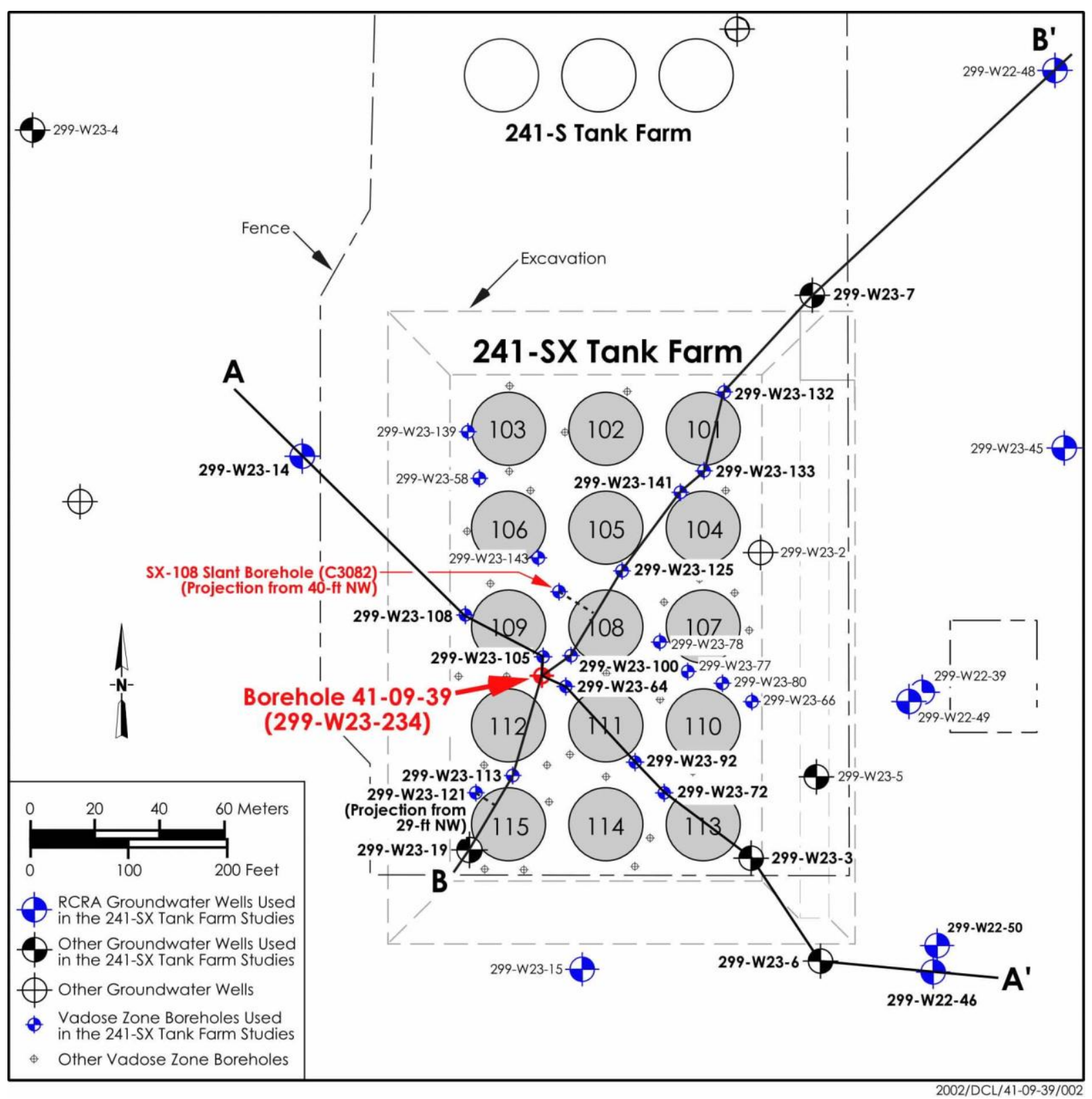

Figure 2.2. Location map (from Serne et al. 2008a). 


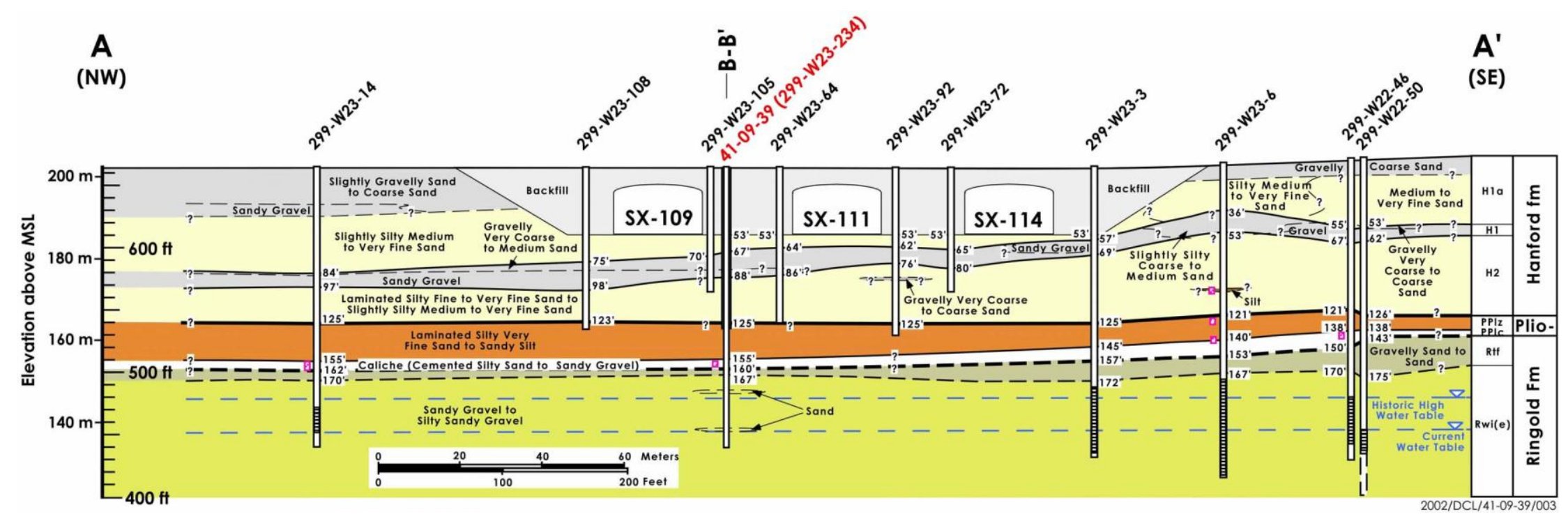

in

Figure 2.3. Hydrogeologic cross section A-A' (from Serne et al 2008a).

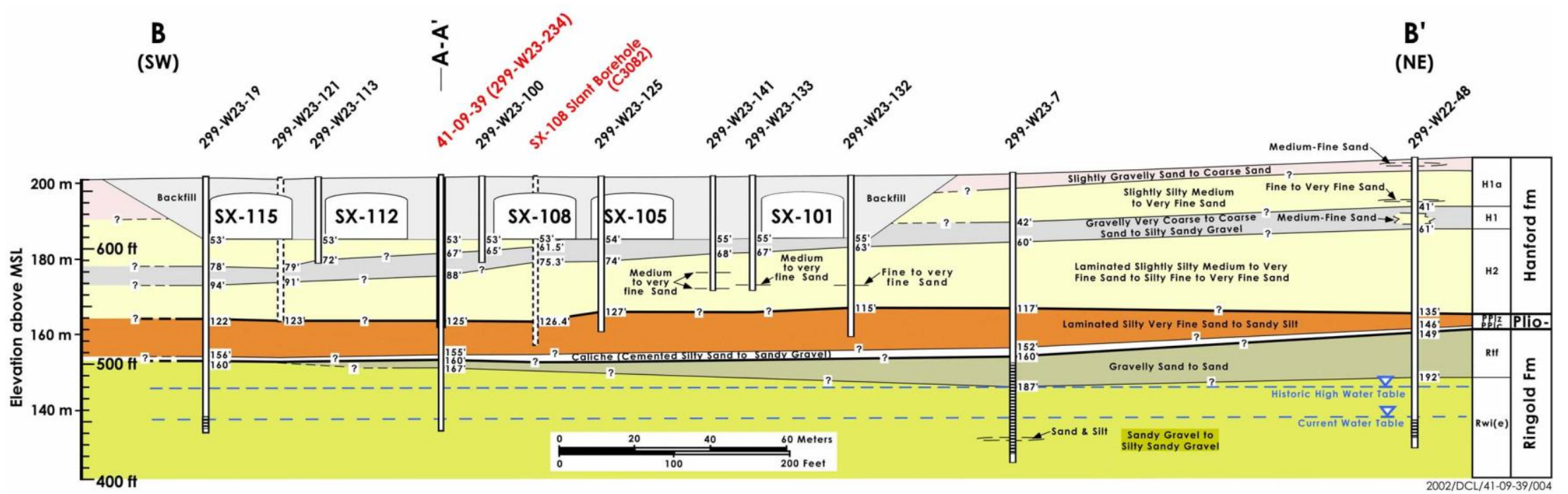

Figure 2.4. Hydrogeologic cross section B-B' (from Serne et al. 2008a). 


\subsection{Physical, Hydrologic, and Geochemical Properties}

Truex et al. (2013) subdivided the major lithostratigraphic units into discrete lithofacies, containing similar physical properties and hydrologic conditions. This same approach was extended to the entire SX Tank Farm. Table 2.1 identifies the average particle-size and calcium carbonate content data for each of the lithofacies, based on data from the ROCSAN database using Folk-Wentworth grain-size divisions. Each of these lithofacies was matched to a hydraulic property soil class taken from Last et al. (2006a). Appendix A includes the van Genuchten model (van Genuchten 1980) parameters for each hydraulic property class, which are important for predictive analysis of vadose zone flow and transport. 
Table 2.1. Lithofacies descriptions for the major geologic units of the Hanford Central Plateau (adapted from Truex et al. 2013).

\begin{tabular}{|c|c|c|c|c|c|c|c|c|}
\hline Lithostratigraphic Unit & $\begin{array}{c}\text { Lithofacies } \\
\text { Code }\end{array}$ & Lithofacies Description & $\begin{array}{l}\text { Number of } \\
\text { ROCSAN } \\
\text { Samples } \\
\end{array}$ & $\begin{array}{c}\text { Average } \\
\% \\
\text { Gravel } \\
\end{array}$ & $\begin{array}{l}\text { Average } \\
\% \text { Sand } \\
\end{array}$ & $\begin{array}{c}\text { Average } \\
\text { \% Mud } \\
\text { (Silt + Clay) } \\
\end{array}$ & $\begin{array}{c}\text { Average } \mathrm{CaCO}_{3} \\
\text { wt. \% (no. of } \\
\text { samples) } \\
\end{array}$ & $\begin{array}{c}\text { Representative } \\
\text { Hydraulic Property } \\
\text { Class } \\
\text { (Last et al. 2006a) } \\
\end{array}$ \\
\hline \multirow{3}{*}{ Backfill } & Bf-(m)[f]S & Slightly silty fine SAND & 48 & 2.9 & 84.3 & 12.8 & $1.5(44)$ & Hfs_2W \\
\hline & $B f-[c-f] S$ & Coarse to fine SAND & 31 & 4.3 & 88.1 & 7.5 & $1.3(22)$ & Hcs_2W \\
\hline & Bf-(m)gS & $\begin{array}{l}\text { Slightly silty, gravelly SAND } \\
\end{array}$ & 6 & 22.9 & 67.3 & 9.8 & $1.3(6)$ & Hgs_2W \\
\hline \multirow[t]{3}{*}{ Hanford formation, H1a unit } & H1a-[m-f]S & Medium to fine SAND & 26 & 2.0 & 91.7 & 6.4 & $1.3(15)$ & Hcs_2W \\
\hline & H1a-(m)[f]S & Slightly silty fine SAND & 57 & 1.4 & 84.3 & 14.3 & $1.4(50)$ & Hfs_2W \\
\hline & H1a-m[f-vf]S & Silty fine to very fine SAND & 23 & 1.2 & 73.3 & 24.4 & $1.6(21)$ & Hss_2W \\
\hline \multirow[t]{5}{*}{ Hanford formation, H1 unit } & H1-msG & Silty sandy GRAVEL & 29 & 49.3 & 44.5 & 6.2 & $1.3(21)$ & Hg_2W \\
\hline & H1-g[vc-c]S & $\begin{array}{l}\text { Gravelly very coarse to coarse } \\
\text { SAND }\end{array}$ & 57 & 17.6 & 75.6 & 6.8 & $1.4(39)$ & Hgs_2W \\
\hline & H1-(g)[c]S & Slightly gravelly coarse SAND & 30 & 5.2 & 87.8 & 6.9 & $1.2(25)$ & Hcs_2W \\
\hline & H1-(g)m[vf]S & $\begin{array}{l}\text { Slightly gravelly muddy very } \\
\text { fine SAND }\end{array}$ & 8 & 10.1 & 67.7 & 22.3 & $1.3(6)$ & Hss_2W \\
\hline & $\mathrm{H} 1-(\mathrm{m})[\mathrm{m}] \mathrm{S}$ & $\begin{array}{l}\text { Slightly muddy medium } \\
\text { SAND }\end{array}$ & 18 & 3.6 & 83.1 & 13.3 & $1.3(17)$ & Hfs_2W \\
\hline \multirow[t]{3}{*}{ Hanford formation, $\mathrm{H} 2$ unit } & $\mathrm{H} 2-[\mathrm{m}-\mathrm{vf}] \mathrm{S}$ & Medium to very fine SAND & 55 & 0.9 & 92.2 & 6.9 & $1.6(20)$ & \multirow[b]{2}{*}{ Hfs_2W } \\
\hline & $\mathrm{H} 2-(\mathrm{m})[\mathrm{m}-\mathrm{vf}] \mathrm{S}$ & $\begin{array}{l}\text { Slightly muddy medium to } \\
\text { very fine SAND }\end{array}$ & 134 & 1.3 & 83.8 & 15.0 & $1.5(75)$ & \\
\hline & $\mathrm{H} 2-\mathrm{m}[\mathrm{f}-\mathrm{vf}] \mathrm{S}$ & $\begin{array}{l}\text { Muddy fine to very fine } \\
\text { SAND }\end{array}$ & 72 & 2.1 & 73.3 & 24.5 & $1.4(35)$ & Hss_2W \\
\hline \multirow{2}{*}{$\begin{array}{l}\text { Cold Creek Unit silt (Fine-grained, } \\
\text { laminated to massive) }\end{array}$} & CCUz-m[vf]S & Muddy very fine SAND & 28 & 0.3 & 62.4 & 37.3 & $2.1(16)$ & \multirow{2}{*}{$\mathrm{PPlz}$} \\
\hline & CCUz-sM & Sandy MUD & 7 & 0.0 & 42.6 & 57.4 & $3.0(7)$ & \\
\hline \multirow{2}{*}{$\begin{array}{l}\text { Cold Creek Unit caliche (Fine to } \\
\text { coarse-grained, calcium carbonate } \\
\text { cemented) }\end{array}$} & CCUcal-sM & $\begin{array}{l}\text { Sandy MUD to muddy } \\
\text { gravelly very fine SAND }\end{array}$ & 3 & 4.6 & 45.8 & 49.6 & $3.9(3)$ & \multirow[b]{2}{*}{ PPlc } \\
\hline & $\begin{array}{l}\text { CCUcal- } \\
(\mathrm{m}) \mathrm{g}[\mathrm{m}] \mathrm{S} \text { to } \\
\mathrm{msG}\end{array}$ & $\begin{array}{l}\text { Slightly silty gravelly medium } \\
\text { SAND to muddy, sandy } \\
\text { GRAVEL }\end{array}$ & 4 & 14.2 & 65.5 & 2.3 & $4.5(4)$ & \\
\hline \multirow[t]{2}{*}{$\begin{array}{l}\text { Ringold Formation, member of } \\
\text { Taylor Flat }\end{array}$} & Rtf-(m)g[m]S & $\begin{array}{l}\text { Slightly silty, gravelly medium } \\
\text { SAND }\end{array}$ & 5 & 16.2 & 69.6 & 14.2 & $0.0(5)$ & \multirow{2}{*}{ Hfs_2W } \\
\hline & Rtf-(m) $[\mathrm{m}] \mathrm{S}$ & $\begin{array}{l}\text { Slightly silty coarse to medium } \\
\text { SAND }\end{array}$ & 5 & 0.9 & 85.3 & 13.8 & $0.7(5)$ & \\
\hline \multirow{2}{*}{$\begin{array}{l}\text { Ringold Formation, member of } \\
\text { Wooded Island, unit e }\end{array}$} & Rwi(e)-sG & Sandy GRAVEL & 12 & 41.1 & 55.3 & 3.6 & $0.2(12)$ & \multirow{2}{*}{$\mathrm{Rg} \_2 \mathrm{~W}$} \\
\hline & Rwi(e)-msG & Silty Sandy GRAVEL & 15 & 32.4 & 57.9 & 9.8 & $0.3(15)$ & \\
\hline
\end{tabular}




\subsection{Vadose Zone Contaminant and Moisture Distributions}

Levitt and Henderson (2009) presented surface-to-surface electrical resistivity data collected to identify low resistivity response for evaluation as potential areas of contamination in the SX Tank Farm area. They presented a comparison between the $0.8 \mathrm{log}$ ohm-meter contour lines from their modeling results at various depths beneath the SX Tank Farm. While they state that "These contours do not represent the interpreted boundary of possible subsurface contamination or increased soil moisture," they selected this contour to represent the high gradient between highly conductive and moderately conductive responses, with the values below $0.8 \mathrm{log}$ ohm-meters likely to provide the highest confidence in locating increased soil moisture and electrolyte concentrations. Figure 2.5and Figure 2.6 illustrate the plan view and cross-sectional view of the highly conductive area represented by the $0.8 \log$ ohm-meter contours of Levitt and Henderson (2009). Contaminant distribution data from beneath the SX Tank Farm are available from 3 characterization boreholes (C3082, 299-W23-234, and 299-W23-19), as well as 11 direct push boreholes, 8 inside the tank farm (C7154, C7156, C7158, C7168, C7170, C7172, C7178, C7180, C7184, C7186, and C7192), and 3 (C7154, C7156, C7158) just outside the western perimeter of the tank farm. These data suggest that mobile constituents (such as nitrate) have co-mingled to form one vadose zone plume, consistent with the soil electrical resistivity data presented by Levitt and Henderson (2009).

Two of the characterization boreholes are located near the center of this co-mingled plume and indicate that the leading edge of mobile tank waste constituents (e.g., sodium, nitrate, and technetium) beneath tank SX-108 may have stopped at a depth of about $45.7 \mathrm{~m}(150 \mathrm{ft})$, at the contact between the Cold Creek Unit silt zone (CCUz) and the Cold Creek Unit caliche zone (CCUc) (Serne et al. 2008a;

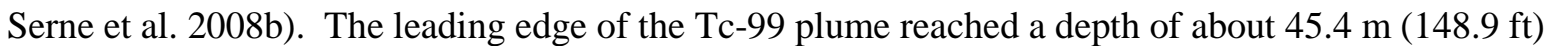
beneath tank SX-108 (Serne et al. 2008b) and 41.4 m (136 ft), beneath tank SX-109 (Serne et al. 2008a).

Moisture and Tc-99 concentration data are available from four boreholes (299-W23-234, C3082, and dual boreholes C7185/C7186; highlighted in red in Figure 2.5 and Figure 2.6). Figure 2.7 and Figure 2.8 illustrate moisture and Tc-99 concentration data from Serne et al. 2008a (borehole 299-W23-234) and Serne et al. 2008b (241-SX-108 slant borehole C3082), respectively. A comparison of the depth profile of acid-extractable Tc-99 in these two boreholes is shown in Figure 2.9. These figures illustrate that the highest Tc-99 concentrations are located at depths between 24 and $43 \mathrm{~m}$ (80 and $140 \mathrm{ft})$, within the Hanford formation $\mathrm{H} 2$ unit and the CCU.

Some mobile constituents, such as nitrate and sodium, followed a pattern similar to that of Tc-99, while others (such as chromium and I-129) appeared to be slightly retarded, staying within the footprint of the Tc-99 plume described above. Other less mobile contaminants (such as Cs-137) are even more retarded, confined well within the Tc-99 plume. 


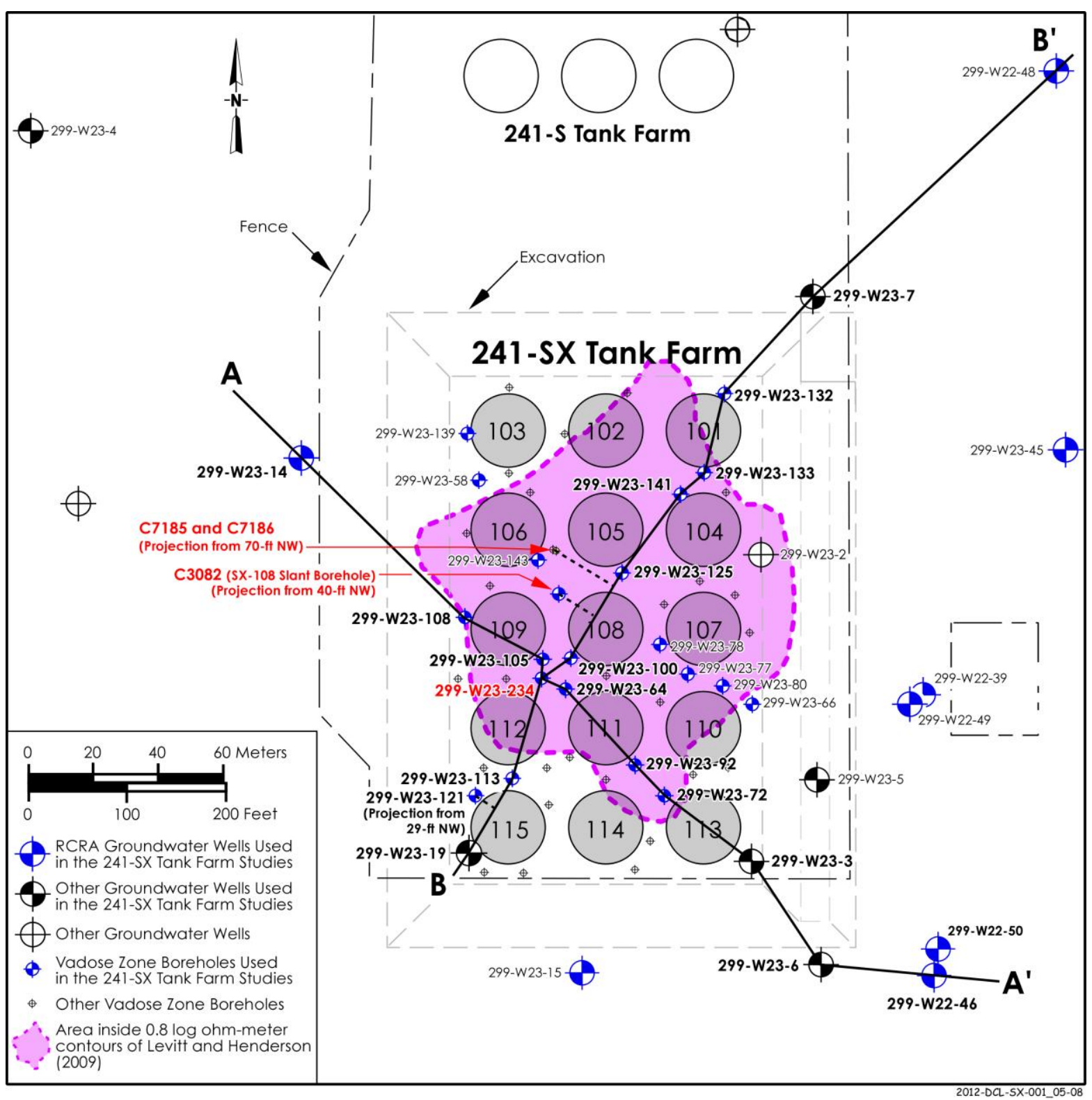

Figure 2.5. Area most likely indicative of increased soil moisture and electrolyte concentrations (after Levitt and Henderson [2009] and Truex et al. [2013]). 


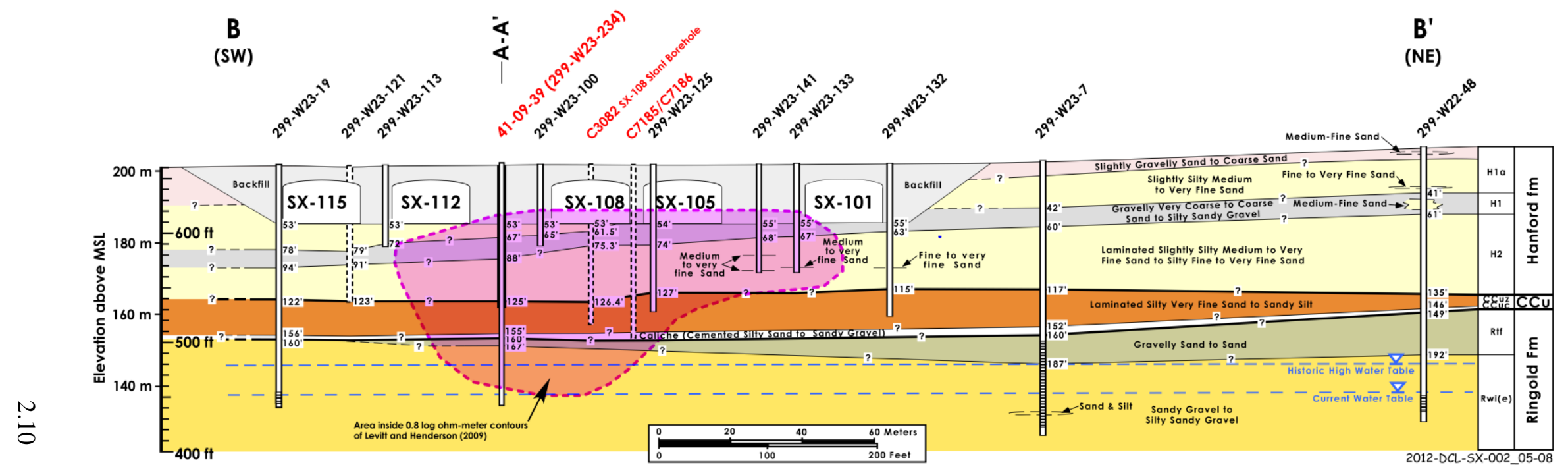

Figure 2.6. Cross-sectional view of the "below 0.8 log ohm-meter" contour area that is most likely indicative of increased soil moisture and electrolyte concentrations (highlighted in pink) (after Truex et al. 2013). 


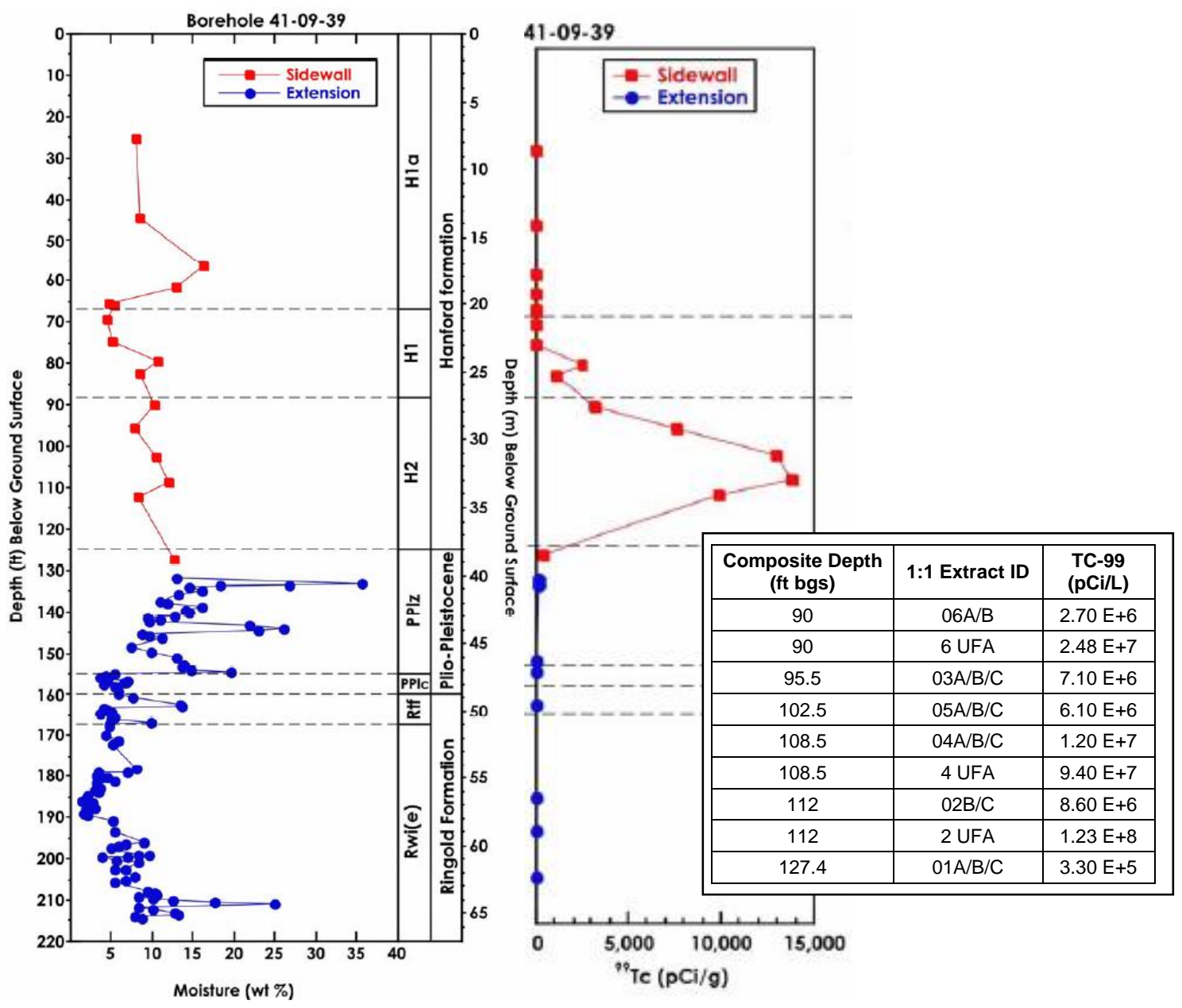

Figure 2.7. Moisture content and Tc-99 distribution for borehole 299-W23-234 (after Serne et al. 2008a). 

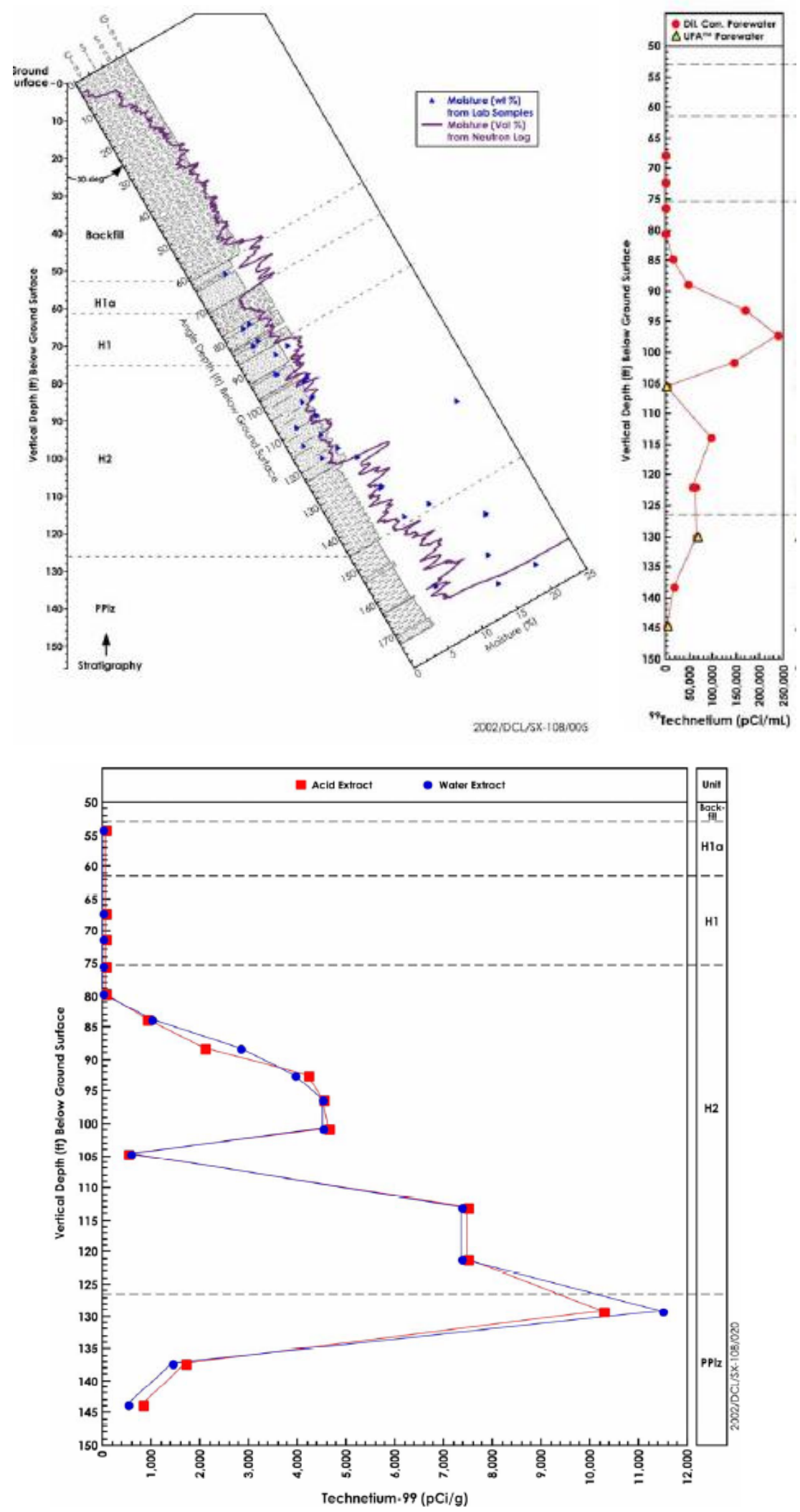

Figure 2.8. Moisture content and Tc-99 distribution for the 241-SX-108 slant borehole (after Serne et al. 2008b). 


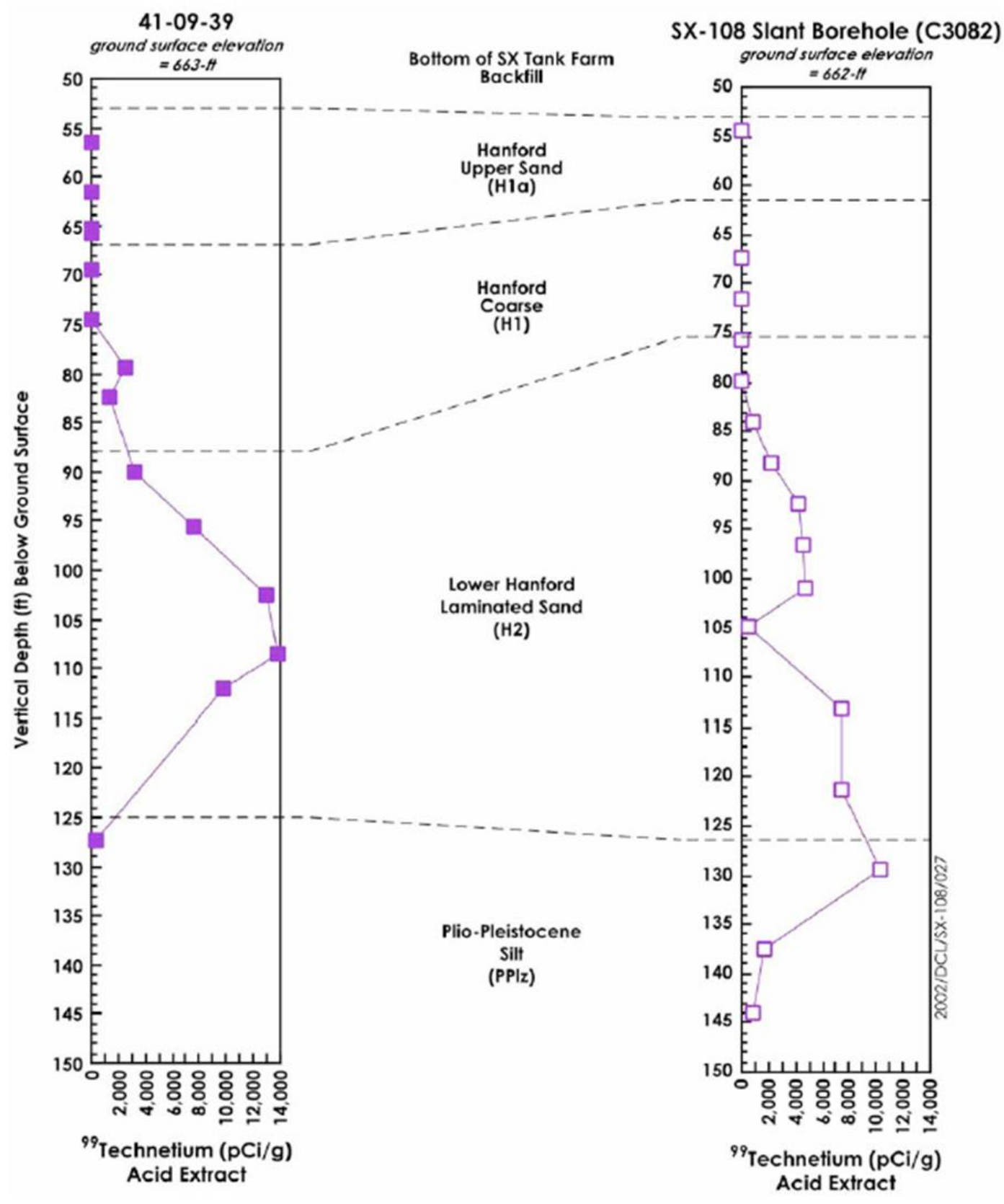

Figure 2.9. Comparison of acid-extractable Tc-99 for the 41-09-39 (well 299-W23-234) and C3082 boreholes (after Serne et al. 2008b).

\subsection{Groundwater Impacts}

High-volume liquid effluent discharges to nearby ponds and cribs created a groundwater mound beneath the 241-SX Tank Farm, where water levels increased at least $22 \mathrm{~m}$ (72 ft) (Hartman 2000). In 1988, production activities on the Hanford Site began to close, resulting in dramatic decreases in wastewater disposal and subsequent decreases in water table elevation. Figure 2.10 shows a composite hydrograph of water levels in comparison to effluent discharges from major high-volume effluent disposal sites near the 241-SX Tank Farm. 


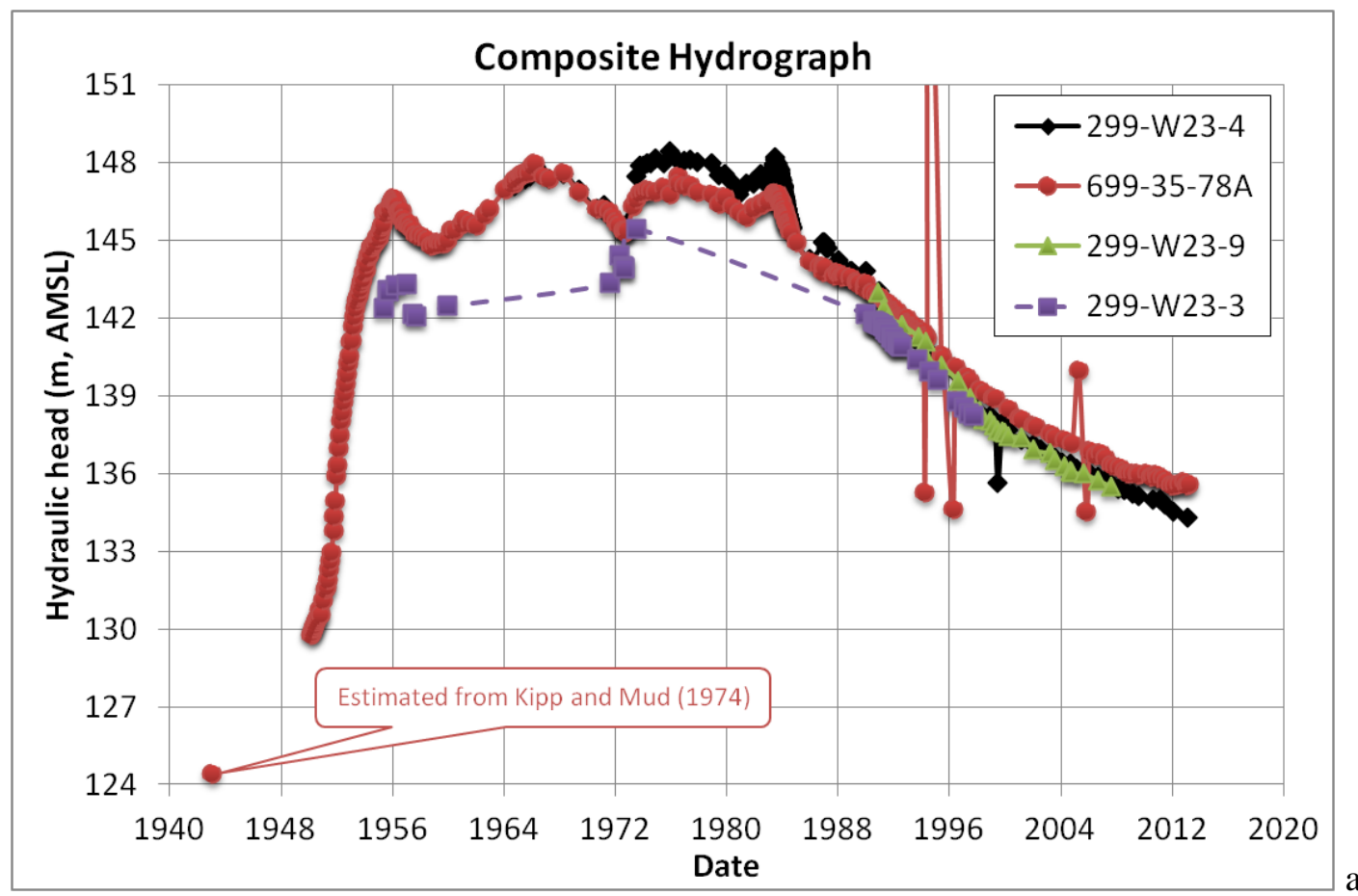

a)

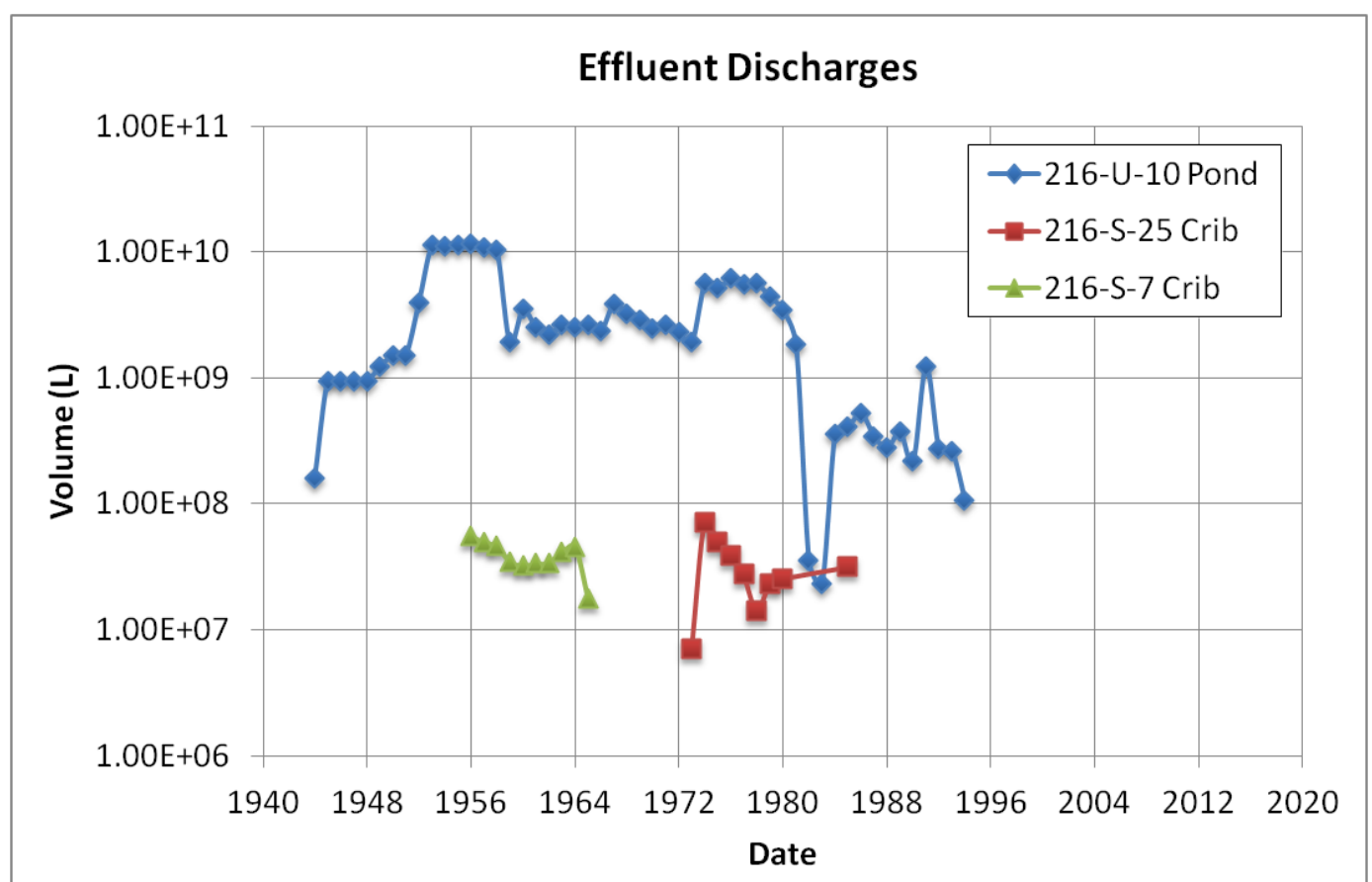

b)

Figure 2.10. Composite hydrograph (a) and high-volume effluent discharges (b) near the SX Tank Farm (Extracted via the Environmental Dashboard Application and the Soil Inventory Model, Corbin et al. 2005). 
Figure 2.11 shows the major groundwater contaminant plumes emanating from the 200-West Area. According to the Record of Decision for Interim Remedial Action Hanford 200 Area Superfund Site 200UP-1 Operable Unit dated September 2012 (EPA/Ecology/DOE 2012), those contaminant plumes attributed, at least in part, to the SX Tank Farm include the following:

- a widespread nitrate plume originating from U Plant and S Plant cribs and SX Tank Farm

- a chromium (total and hexavalent) plume associated with SX Tank Farm and a dispersed chromium (total and hexavalent) plume in the southeast corner of the operable unit that originated from an S Plant crib

- five separate Tc-99 plumes associated with Waste Management Area (WMA) U, U Plant cribs, and the SX Tank Farm

- a small I-129 plume that is now interpreted to occur beneath the SX Tank Farm.

In addition to groundwater plumes attributed to the SX Tank Farm, there are

- a uranium plume originating from U Plant cribs

- a widespread I-129 plume originating from U Plant and S Plant cribs

- a widespread tritium plume originating from S Plant cribs

- a widespread carbon tetrachloride plume originating from operation of Plutonium Finishing Plant (Z Plant) facilities.

In particular, Tc-99 concentrations occur above the $900 \mathrm{pCi} / \mathrm{L}$ cleanup level downgradient of the SX Tank Farm (Johnson and Field 2010). The temporal profile for wells where the primary observations of Tc-99 contamination have been observed are shown in Figure 2.12 through Figure 2.16. Nitrate, chromium, and I-129 plumes have also been observed and attributed to the SX Tank Farm (Johnson and Field 2010; CHPRC 2014; DOE/RL 2013). 


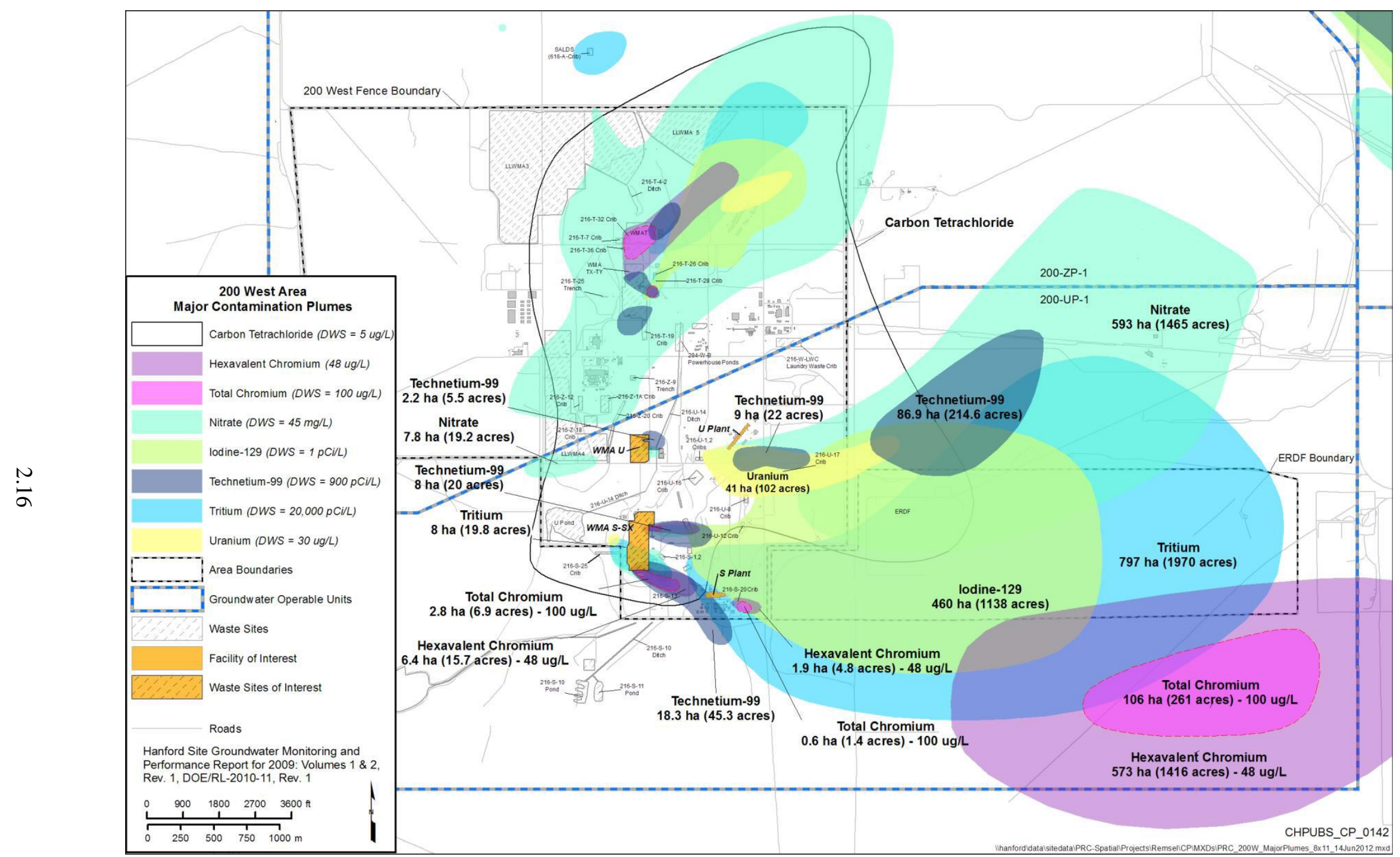

Figure 2.11. 200-UP-1 operable unit groundwater contaminant plume map (from Record of Decision for Interim Remedial Action Hanford 200 Area Superfund Site 200-UP-1 Operable Unit dated September 2012 [EPA/Ecology/DOE 2012]). 


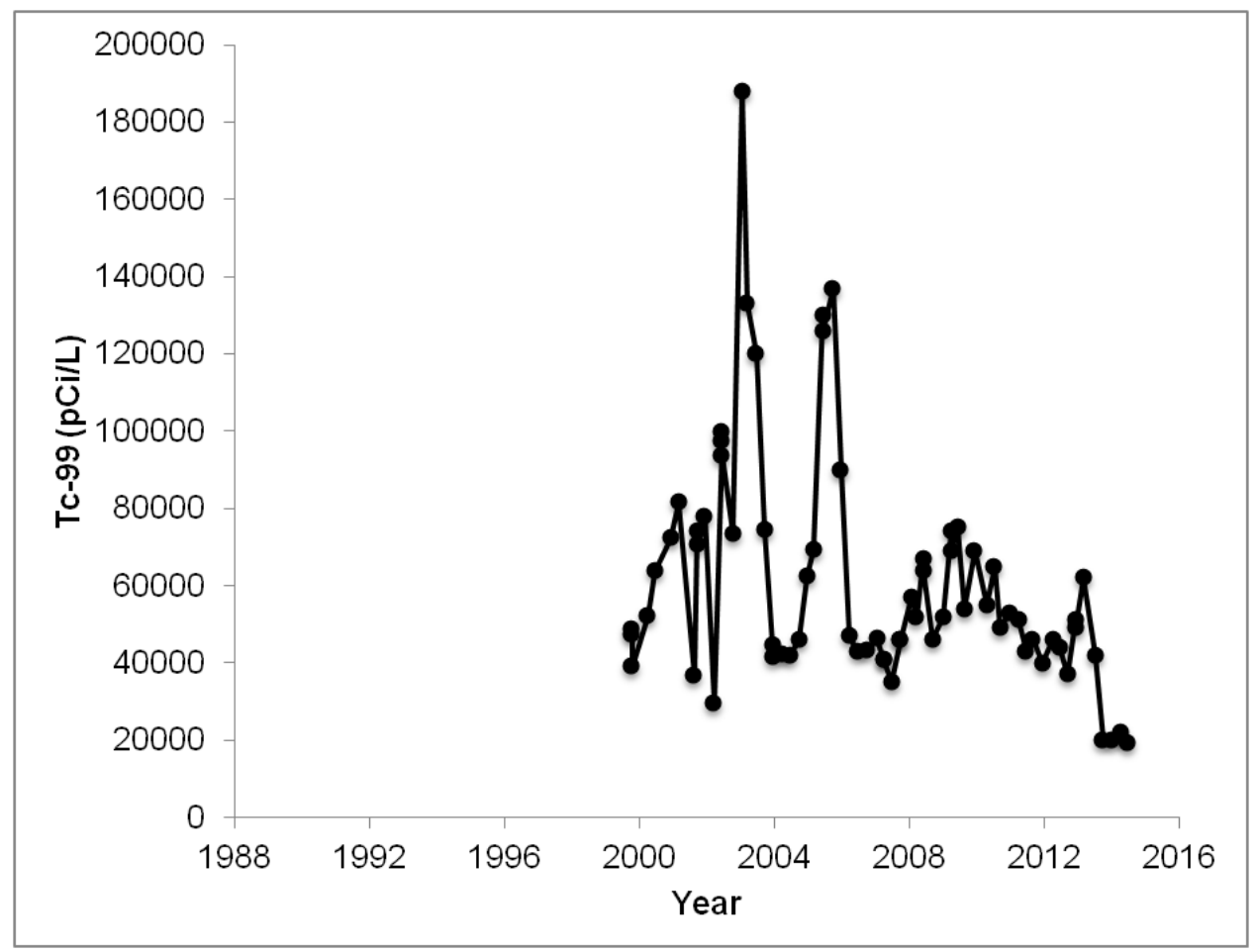

Figure 2.12. Temporal concentrations of Tc-99 in groundwater observed at well 299-W23-19.

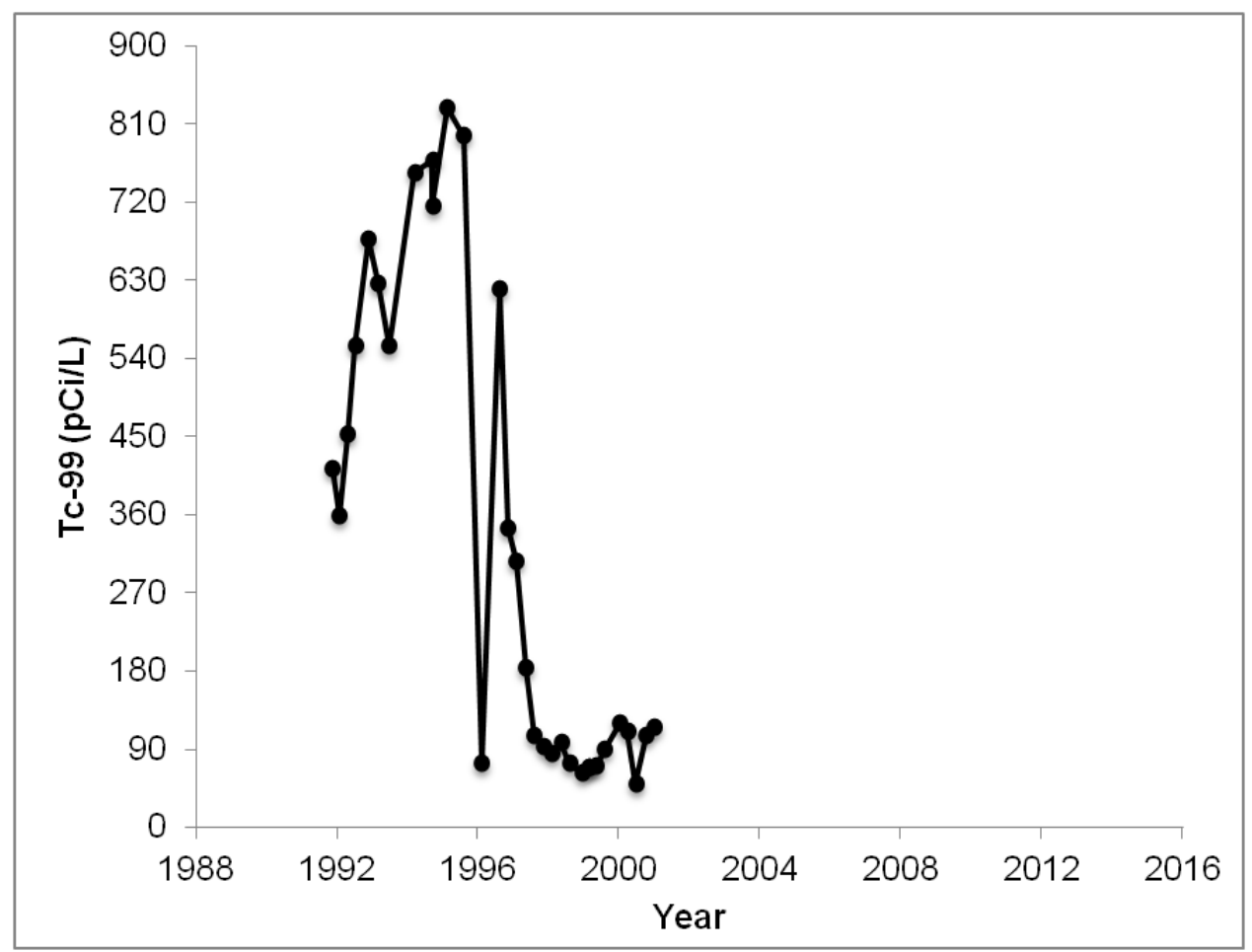

Figure 2.13. Temporal concentrations of Tc-99 in groundwater observed at well 299-W22-39. 


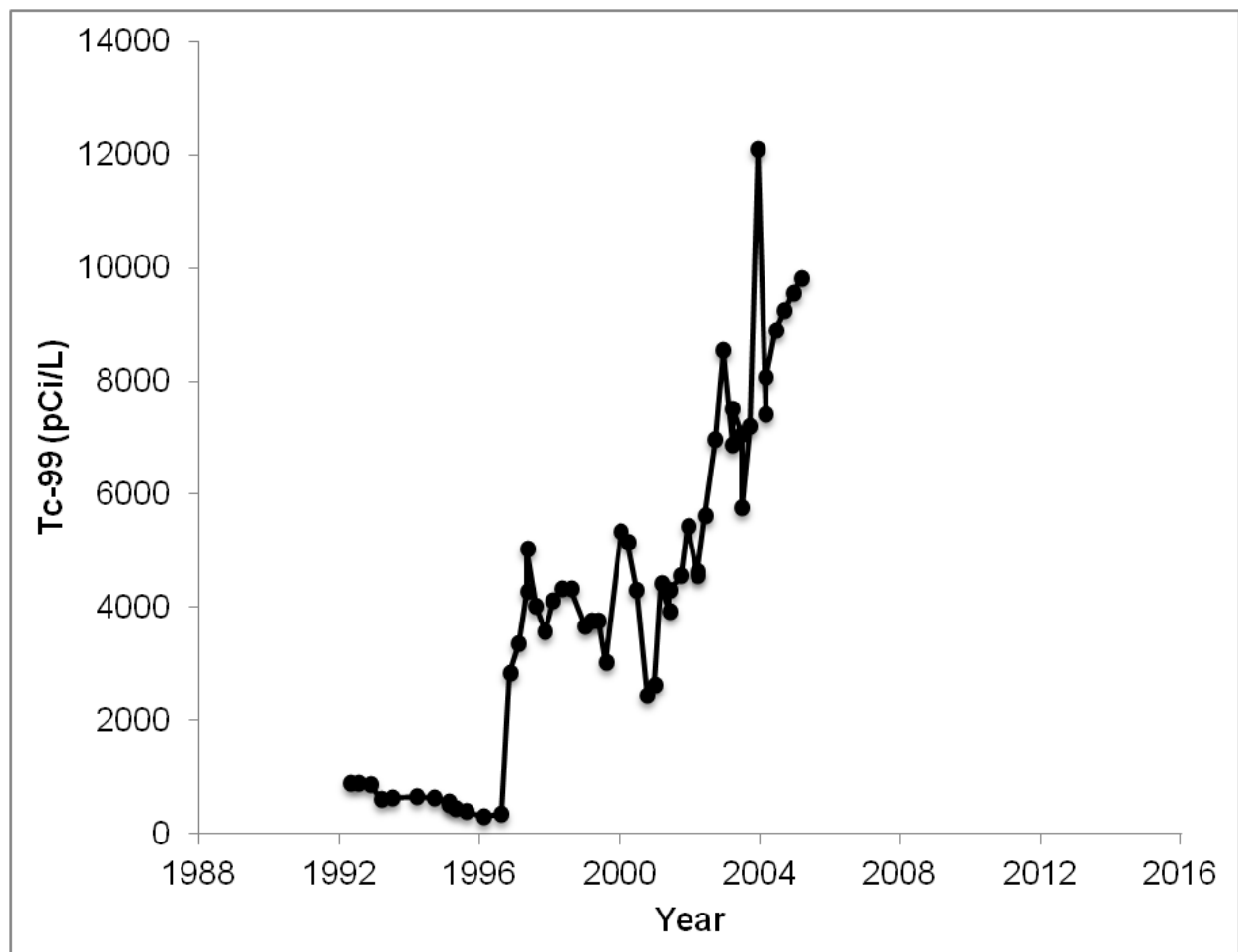

Figure 2.14. Temporal concentrations of Tc-99 in groundwater observed at well 299-W22-46.

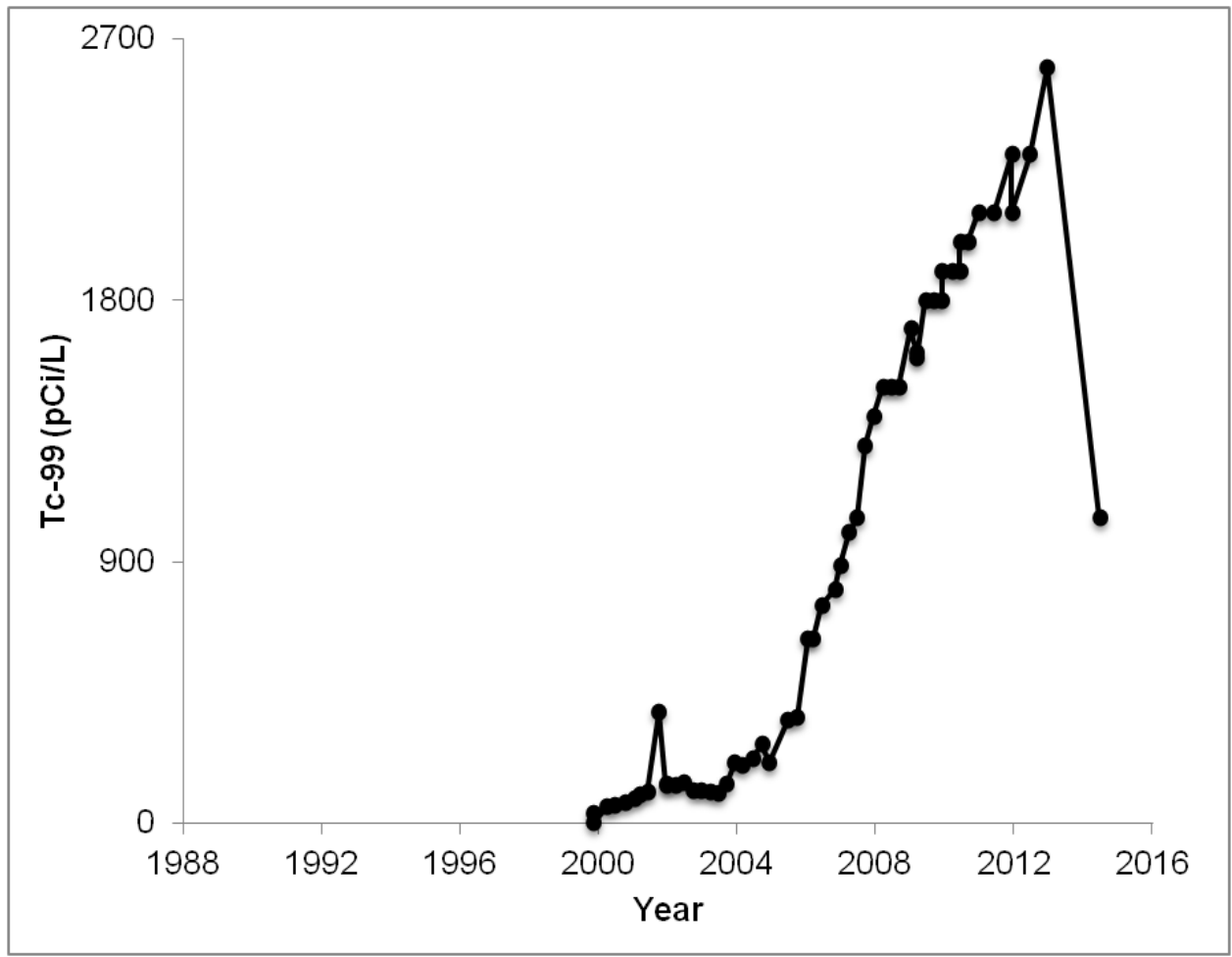

Figure 2.15. Temporal concentrations of Tc-99 in groundwater observed at well 299-W22-49. 


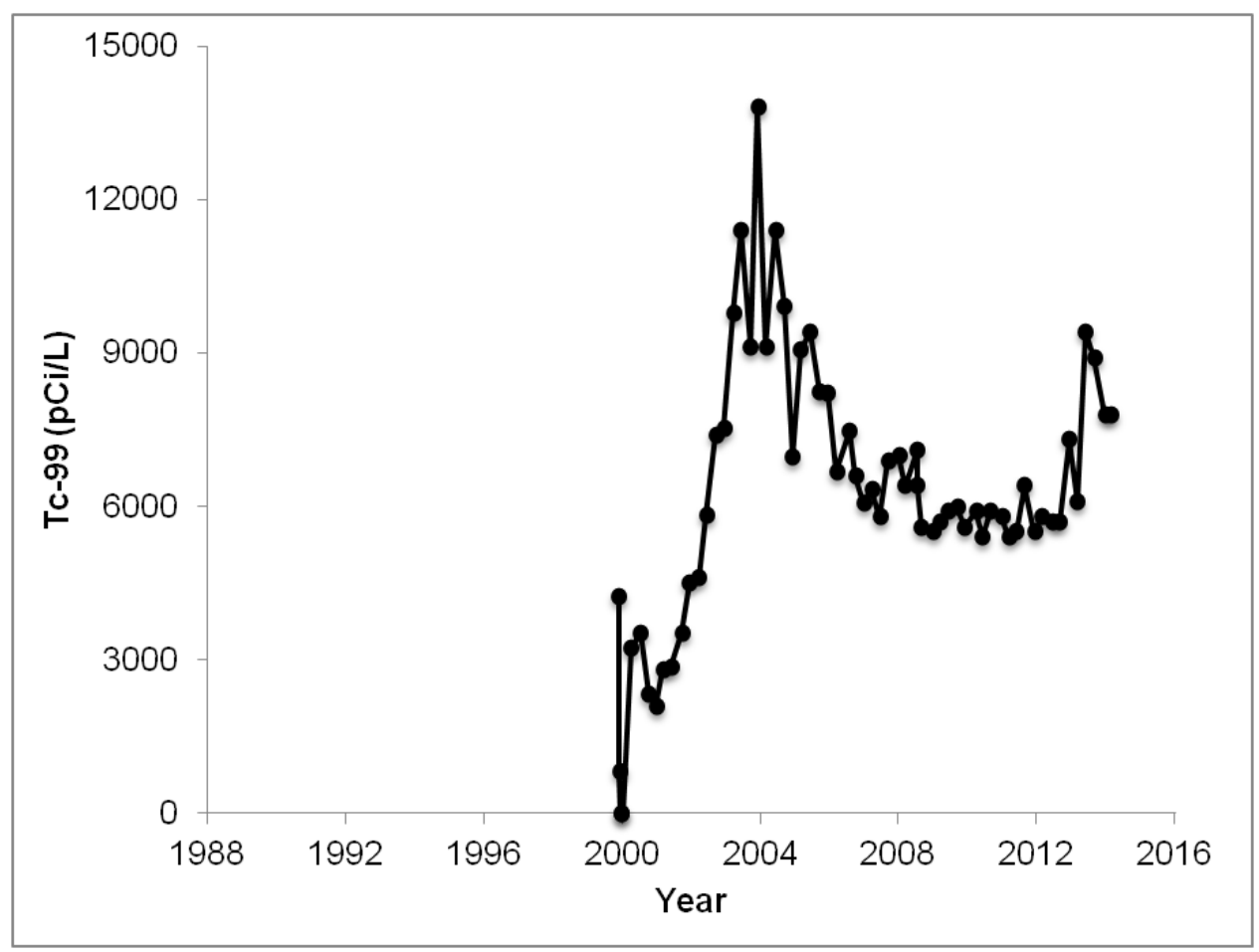

Figure 2.16. Temporal concentrations of Tc-99 in groundwater observed at well 299-W22-50.

\subsection{Waste and Water Releases to the Vadose Zone at the SX Tank Farm}

A summary of tank leak estimates from eight high-level waste SSTs in the SX Tank Farm-241-SX$107,-108,-109,-111,-112,-113,-114$, and -115 -is provided Table 2.2. Note that only a portion of the suspected leaking tanks in Figure 2.1 have been confirmed as leaking. The tank leak information is based primarily on the analysis of waste loss events by Johnson and Field (2010), and location/cause analyses conducted by Girardot and Harlow (2014). Appendix B provides more detailed estimates for each tank leak event, including timing, duration, release rate, and location. Water releases are described by Anderson (2001) and discussed in more detail in Section 2.1. 
Table 2.2. Summary of Tank Leak Events from the SX Tank Farm.

\begin{tabular}{|c|c|c|c|c|c|}
\hline $\begin{array}{c}\text { Tank } \\
\text { Release Events }\end{array}$ & $\begin{array}{c}\text { Total Duration } \\
\text { (days) }\end{array}$ & $\begin{array}{l}\text { Total Volume } \\
\text { (gal) }\end{array}$ & $\begin{array}{c}\text { Total Volume } \\
\text { (L) }\end{array}$ & $\begin{array}{c}\text { Average } \\
\text { Release Rate } \\
(\mathrm{L} / \mathrm{d})\end{array}$ & $\begin{array}{c}\text { Total Cs-137 } \\
\text { Inventory }(\mathrm{Ci}, \text { decay } \\
\text { corrected to } \\
9 / 30 / 2010)\end{array}$ \\
\hline SX-107 & 60 (min.) & 3,400 (min.) & 12,900 (min.) & 33 (min.) & $5.40+3(\mathrm{~min})$ \\
\hline Mar-Aug '64 & 365 (best) & 6,400 (best) & 24,200 (best) & 66 (best) & $1.16 \mathrm{E}+04$ (best) \\
\hline Mar-Sep ‘68 & 395 (max.) & $23,000(\max )$ & $78,100(\max )$ & 1,300 (max.) & $2.86 \mathrm{E}+4(\max )$ \\
\hline SX-108 & 487 (min.) & 50,700 (min.) & 192,000 (min.) & 122 (min.) & $6.35 \mathrm{E}+3(\mathrm{~min})$ \\
\hline Jul '64-Jun '65 & 1190 (best) & 76,100 (best) & 288,000 (best) & 242 (best) & $2.79 \mathrm{E}+04$ (best) \\
\hline Mar '66-Mar '67 & 1580 (max.) & $102,000(\max )$ & $384,000(\max )$ & 788 (max.) & $8.89 \mathrm{E}+4(\max )$ \\
\hline \multicolumn{6}{|l|}{ Mar '67-Aug '68 } \\
\hline SX-109 & 60 (min.) & 310 (min.) & 1,200 (min.) & 2.3 (min.) & $4.90 \mathrm{E}+2(\mathrm{~min})$ \\
\hline Jan-Feb '65 & 487 (best) & 1,000 (best) & 3,800 (best) & 7.8 (best) & $1.84 \mathrm{E}+03$ (best) \\
\hline Mar '65-Jun '66 & 516 (max.) & $<10,000(\max )$ & $<37,900(\max )$ & 632 (max.) & $9.59 \mathrm{E}+3(\max )$ \\
\hline SX-111 & 27 (min.) & 500 (min.) & 1,900 (min.) & 44 (min.) & $1.59 \mathrm{E}-1(\mathrm{~min})$ \\
\hline \multirow[t]{2}{*}{ Apr-May '74 } & 27 (best) & 2,800 (best) & 11,000 (best) & 100 (best) & $1.46 \mathrm{E}+00$ (best) \\
\hline & 43 (max.) & $2,800(\max )$ & $11,000(\max )$ & 100 (max.) & $1.83 \mathrm{E}+3(\max )$ \\
\hline SX-112 & 16 (min.) & 1,000 (min.) & 3,790 (min.) & 62.1 (min.) & $2.07 \mathrm{E}+1(\mathrm{~min})$ \\
\hline Oct' $58-$ Sep '59 & 16 (best) & 27,000 (best) & 102,000 (best) & 6,380 (best) & $1.53 \mathrm{E}+4$ (best) \\
\hline Jan '69 & 426 (max.) & $44,000(\max )$ & 167,000 (max.) & 6,380 (max.) & $1.70 \mathrm{E}+5(\max )$ \\
\hline SX-113 & 5 (min.) & 15,000 (min.) & 56,800 (min.) & 1,620 (min.) & $7.29 \mathrm{E}+0$ (min) \\
\hline May-Jun '58 & 12 (best) & 15,000 (best) & 56,800 (best) & 4,730 (best) & $3.30 \mathrm{E}+3$ (best) \\
\hline Nov '62 & 40 (max.) & $65,000(\max )$ & 208,000 (max.) & 30,300 (max.) & $1.23 \mathrm{E}+4(\max )$ \\
\hline SX-114 & 14 (min.) & 43 (min.) & 163 (min.) & 1.36 (min.) & 0 (min.) \\
\hline \multirow[t]{2}{*}{ Jul-Aug ' 72} & 52 (best) & $<2,000$ (best) & $<7,570$ (best) & $>146$ (best) & $1.05 \mathrm{E}+03$ (best) \\
\hline & 120 (max.) & 2,000 (max.) & 7,570 (max.) & 540 (max.) & $1.05 \mathrm{E}+03(\max )$ \\
\hline SX-115 & 6 (min.) & 50,000 (min.) & 189,000 (min.) & 15,750 (min.) & $8.53 \mathrm{E}+3(\mathrm{~min})$ \\
\hline Feb-Mar '65 & 12 (best) & 51,000 (best) & 193,000 (best) & 16,080 (best ) & $1.34 \mathrm{E}+04$ (best) \\
\hline Mar ‘65 & 12 (max.) & $52,300(\max )$ & $198,000(\max )$ & 33,000 (max.) & $1.46 \mathrm{E}+4(\max )$ \\
\hline
\end{tabular}

\subsection{Conceptual Model Summary}

As discussed in the above sections, a variety of data are available to develop a conceptual model for the SX Tank Farm. Figure 2.17 summarizes the spectrum of data available at the SX Tank Farm. Each type of data provides input to some element of the conceptual model and subsequent assessment of contaminant flux to groundwater. However, the nature and quality of each data type need to be assessed as the data are interpreted to support the conceptual model. 


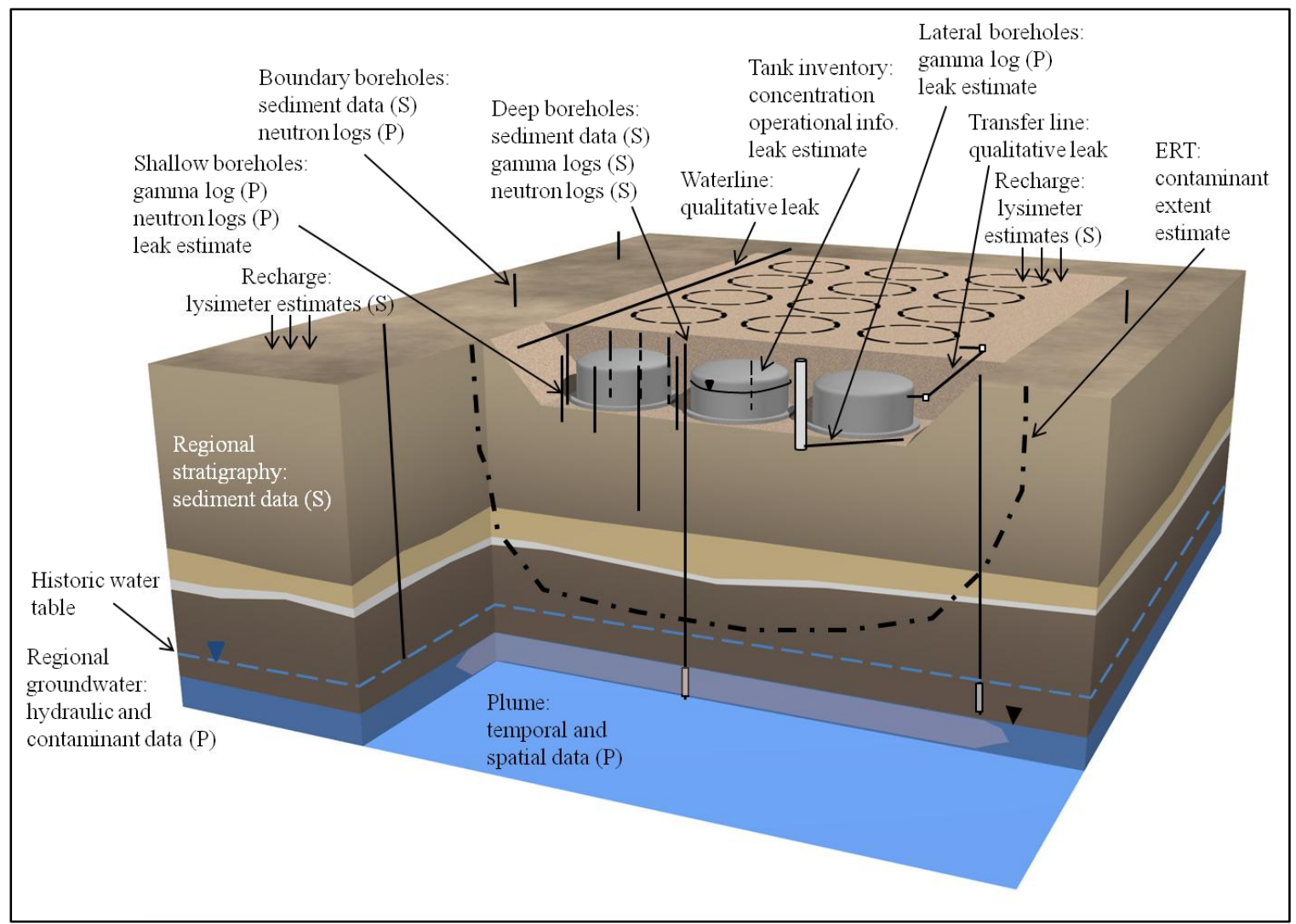

Figure 2.17. Data available for evaluating vadose zone contamination and contaminant flux for the SX Tank Farm. An "S" symbol after the data type indicates a single time point is available. A "P" symbol indicates that data are available for periodic or multiple time points.

Conceptual model elements and associated data from Figure 2.17 are discussed below with respect to the type, quantity, quality, and location of data available and how these data support the technical basis for the conceptual model.

- Recharge

- Data from lysimeter studies are used to establish recharge values for different surface conditions. These data are documented and commonly accepted for use in establishing recharge rates in the Hanford Central Plateau (Section 2.1).

- Contaminant and Water Releases/Discharges (leak estimates)

- Contaminant release information from tanks or transfer lines is documented as part of Hanford Site operations and source term studies. Several efforts have compiled this information for use in establishing source terms in the Hanford Central Plateau. Use of this information should consider the ranges in the estimates provided (Section 2.6).

- Water-line leaks are often poorly documented as part of Hanford Site operations, and are generally not quantitative in nature. Typically, evidence of a leak is discovered and the leak is corrected. At that time, some estimate of the nature and extent of the leak may be qualitatively made. Thus, use of this information should consider the ranges in the estimates provided (Section 2.6). 
- Subsurface Evidence of Tank Farm Leaks

- Shallow vertical boreholes and lateral boreholes beneath some of the tanks are logged for gamma radiation as a means to provide evidence for the location and extent of leaks. Neutron logging is also conducted in the vertical boreholes. These data have historically provided information about leaks, but are limited in quantifying the extent and exact location of the leak due to spacing of the wells. It is also difficult to track leak movement because of the mixture of gamma-emitting radionuclides and differences in decay rates. Interpretation of neutron logging is also limited due to the construction of some wells. However, the information has been useful in combination with other information in describing and bounding estimates of leaks (Section 2.6). The sensitivities of both the gamma and neutron measurement systems are dependent on a number of factors including borehole casing and completion materials and diameters. Several different borehole completion geometries have been used for the monitoring wells and can significantly affect the results obtained from the geophysical logs. In particular, the use of cement severely affects the neutron-neutron probe response due to the high hydrogen content of the cement. Drywells generally used 6-in.-diameter carbon steel casing. Completion materials used in the annulus between the drilled borehole and the casing were typically cement grout; however, in some cases the materials were not documented. Many drywells used a dual casing completion with a smaller diameter casing grouted inside an outer casing.

- Vadose Zone Contamination

- Data about the contaminant nature and extent in the vadose zone are available from shallow and deep vertical boreholes and lateral boreholes beneath the tank farm. Some of these data are from geophysical borehole logs, as described above for leak evidence from shallow and lateral boreholes. Geophysical logging is also applied for deep boreholes, but typically only once (during drilling). However, sediment samples have been retrieved from a number of deep boreholes and provide information about the vertical distribution of contamination in relation to the profile of sediment physical, chemical, and moisture conditions at the borehole location. Detailed reports are available to describe this information. Use of this information must consider the limited spatial density in the lateral direction and the single time point available for sediment collection and analysis.

- Because the vadose zone contamination is from fluids with high ionic strength, the electrical resistivity of the subsurface can provide information about the distribution of the contamination. Electrical Resistivity Tomography (ERT) can be applied to provide an estimate of contaminant distribution in three dimensions based on the distribution of decreased electrical resistivity from the presence of contamination. However, ERT is sensitive to the presence of metallic infrastructure. Thus, use of ERT is challenging in tank farms, although recent advances in data inversion may help reduce the interference from known metallic infrastructure (Johnson and Wellman 2013). For the SX Tank Farm, ERT information is considered as only a general guide for zones of potential contamination, but not representative of actual contaminant distribution.

- Vadose Zone Moisture

- Vadose zone moisture data are available from shallow and deep vertical boreholes. Some of these data are from neutron logs as described above for leak evidence from shallow and lateral 
boreholes. Neutron logging is also applied for deep boreholes, but typically only once during drilling, though some wells surrounding the SX Tank Farm have neutron data from multiple surveys over time. However, sediment samples have been retrieved from a number of deep boreholes and provide information about the vertical distribution of moisture in relation to the profile of contaminants and sediment physical, and chemical conditions at the borehole location. Detailed reports are available to describe this information. Use of this information must consider the limited spatial density in the lateral direction and the single time point available for sediment collection and analysis. Use of the neutron logging data must also consider that the data may not be calibrated to determine absolute moisture content and may only represent relative moisture content at the borehole location.

- Subsurface Vadose Zone Sediment Properties

- Vadose zone sediment properties are based on data from analysis of sediment samples and geophysical log data. No significant field-scale data are available for sediment properties in the vadose zone. Properties from sediment samples within the SX Tank Farm are available and need to be considered in the context of the broader set of regional data from sediment samples that are used to estimate the properties for defined stratigraphic units and facies within the subsurface. While estimates of properties are available in multiple documents for the Hanford Central Plateau, site-specific variations in these properties need to be considered.

- Boundary Conditions

- It is important to determine whether disposal of water or contaminants outside the SX Tank Farm influence the contaminant flux beneath the tank farm. Thus, data for contaminant and water releases/discharges, contaminant and moisture distribution, and the distribution of subsurface properties for the surrounding area are important. The types of data described above are available outside the SX Tank Farm. Use of these data needs to consider the temporal and spatial density of the data. However, this information is useful as input to evaluate the appropriate moisture and contaminant conditions for the lateral boundaries for studying the contaminant flux at the SX Tank Farm. Key features are the U Pond and nearby waste sites and the observed moisture and contaminant distributions at these sites and between these sites and the SX Tank Farm.

- Groundwater Conditions

- Groundwater monitoring provides regional data and data local to the SX Tank Farm to describe the groundwater elevation as a function of time. These data are generally well documented and provide fairly long-term groundwater trend information. Interpolation is required for some time periods at specific locations.

- Hydraulic testing has been applied in multiple studies for the unconfined aquifer in the Hanford Central Plateau. While estimates for aquifer properties are available in multiple documents for the Hanford Central Plateau, site-specific variations in these properties need to be considered.

- Groundwater Plumes

- In most cases, groundwater plumes are expressions of vadose zone contaminant flux. Regional and local groundwater monitoring provide well documented information about groundwater plumes for some constituents. Historic information prior to about the 1980s is lacking for some 
constituents like Tc-99 and I-129. Use of this information needs to consider the temporal and spatial density of the data.

Although the data in this section represent a baseline conceptual model for the SX Tank Farms, integration of these data with additional assessments is needed to develop a conceptual model appropriate to support estimates of contaminant flux (Truex and Carroll 2013). This integrated approach to estimating contaminant flux and development of a refined conceptual model are presented in Sections 3.0 and 4.0. 


\subsection{Evaluation Approach for Future Contaminant Flux to Groundwater}

This study uses a conceptual model approach to examine the controlling elements with respect to contaminant flux to groundwater. Numerical modeling is used in conjunction with available data and the conceptual model as an integrated approach to evaluate these controlling elements and to estimate future contaminant flux to groundwater.

\subsection{Integrated Assessment Approach}

An initial step in the assessment was to identify potential controlling elements of contaminant flux based on the conceptual model and evaluate the nature and magnitude of these elements based on vadose zone transport knowledge and, where needed, numerical modeling. The following potential controlling elements were identified for the SX Tank Farm. Efforts to determine the impact of these potential controlling elements were then used to provide justification for the predictive analysis method to estimate future contaminant flux to groundwater.

- Recharge is a key element because it is recognized as a major driving force for vadose zone transport, and presence of the tank farm and supporting facilities has significantly altered recharge compared to pre-Hanford conditions. Assessment of recharge includes both the large areally extensive recharge (e.g., tank-farm scale and larger) and the impact of localized recharge features such as how the tanks affect the spatial distribution of water infiltration. Key questions are:

- Is recharge the dominant controlling factor for water flux (and associated contaminant flux)?

- Is the transport of a leak underneath a tank different than a leak along the side of a tank?

- Water discharges to the subsurface are another key element. There are several aspects to this issue. One aspect is the historical disposal of very large water volumes (containing some contamination) that occurred in facilities surrounding SX Tank Farm, notably the U Pond, and the potential for its impact on the vadose zone beneath the tank farm. Another aspect is relatively large, focused water leaks such as from water lines present in and around the SX Tank Farm. Contaminated water leaks such as from the tanks or transfer lines and equipment is another key factor that introduced the primary contaminants of concern into the vadose zone at the SX Tank Farm. Key questions are:

- Does water disposed outside the tank farm boundary migrate beneath the tank farm and impact contaminant flux? Does lateral water flow on a large scale need to be considered?

- Can a focused large and/or relatively long-duration water leak quickly drive contaminants to the groundwater and what size/duration would this leak have to be to be significant given the size and properties of the vadose zone at the SX Tank Farm?

- Are the volumes of waste released from the tanks significant with respect to quickly driving contaminants to the groundwater?

- Should we expect individual vadose zone plumes from leaks or will individual leaks consolidate into broader plumes? 
- Subsurface hydrogeologic properties and specific features can be important with respect to water and contaminant flux under transient water flux conditions. Porous media properties and contrasts in these properties must be considered with respect to lateral spreading for a transient water addition. The CCU is a major sediment feature that must be considered along with the other major and minor sediment units and the contrasts between these units. A key questions is:

- How much influence do major and minor sediment features have on contaminant flux to the groundwater in the short and long term?

Based on the evaluation of the controlling elements for contaminant flux, predictions were made to bound the range and expected temporal profile of contaminant flux to groundwater. This evaluation also identified where additional information could be applied to improve confidence in the estimates or to decrease the range of the estimate. In addition, the impact of selected mitigation options was considered in a scoping-level assessment to demonstrate how options targeting controlling elements may reduce the contaminant flux. Potential monitoring elements to verify contaminant flux conditions over time were also discussed.

\subsection{Numerical Model Configuration}

The water mode of the STOMP (Subsurface Transport Over Multiple Phases) simulator (White and Oostrom 2006) was used to simulate vadose zone aqueous phase flow and contaminant transport. The applicable governing equations are the component mass-conservation equation for water and the solute transport equation, which are solved using a total-variation diminishing scheme.

A three-dimensional (3D) model was constructed to represent the subsurface configuration of the SX-108 tank, as shown in Figure 3.1. This local SX-108 model was used to investigate controlling features and processes for flow and transport in the vicinity of a single tank. The SX-108 model comprises a domain of $61 \mathrm{~m}$ in the $x$ direction (west to east), $61 \mathrm{~m}$ in the $y$ direction (south to north), and $84 \mathrm{~m}$ in the $z$ direction (bottom to top). The 84-m vertical length ranges from $123.5 \mathrm{~m}$ at the bottom of the domain to $207.5 \mathrm{~m}$ at the top surface. The domain was discretized into $51 \times 51 \times 91$ grid cells for a total of 236,691 nodes. Standard refinement procedures were used to obtain a discretization yielding converged mass fluxes across the water table.

To conduct full SX Tank Farm subsurface simulations, another 3D model was constructed, as shown in Figure 3.2. The SX Tank Farm model consists of three sub-models representing the SX-115-114-113, the SX-112-111-110, and the SX-109-108-107 west-to-east tank sequences. The SX-112-111-110 and the SX-109-108-107 sequence models represent an area of $160 \times 50 \times 84 \mathrm{~m}$ and are discretized using 150 $\times 46 \times 91$ grid cells for a total of 627,900 nodes. The SX-115-114-113 sequence model represents an area of $160 \times 81 \times 84 \mathrm{~m}$ and is discretized using $150 \times 61 \times 91$ grid cells for a total of 832,650 nodes. This model was larger in the y direction to include the area south of the SX Tank Farm to ensure that the well locations W23-15, W22-80, W22-46, and W22-50 (Figure 2.5) are part of the domain. In the x direction, the model extends $30 \mathrm{~m}$ beyond the east fence of the SX Tank Farm. For these three models, standard refinement procedures similar to those of the local SX-108 model were used to obtain the final discretized domains yielding converged mass fluxes across the water table.

The numerical models were configured with eight geologic sediment layers according to information from Last et al. (2009). Sediment property hydraulic values are listed in Table 3.1. The water-retention 
values (Last et al. 2006a) are for the van Genuchten saturation-water pressure constitutive model (van Genuchten 1980) and the water relative permeability is computed using the Mualem (1976) relation. The parameter values listed in Table 3.1 are used in the base case simulations for both the local SX-108 and the SX Tank Farm models. For all layers, longitudinal and transverse dispersivity values $(0.3$ and $0.03 \mathrm{~m}$, respectively) similar to those used by Zhang et al. (2005) were used for the simulations.

Descriptions of the conducted simulations for the local SX-108 and SX Tank Farm are listed in

Table 3.2 and, respectively. The leak volumes and periods are presented in Table 2.2. Tc-99 and Cs-137 concentrations are obtained by dividing the best estimate inventories (Table 2.2 for Cs-137 and

Table 3.4 for Tc-99, see also Appendix B) for each tank by the total leak volumes in Table 2.2. For the simulations considering the effects of a water-line leak, the assumed location of the leak is toward the south of SX-115, as shown in Figure 3.3. The groundwater Darcy flow velocity was assumed to be 10 $\mathrm{m} / \mathrm{yr}$ (Johnson and Chou 2001) and was imposed through a constant flux (Neumann) boundary condition at the west side of the computational domains, in combination with a constant pressure (Dirichlet) boundary condition at the east side of the domains to indicate the water table position.

Each simulation consists of two components: 1) a pre-tank construction simulation to obtain steadystate initial conditions for the transport simulation, and 2) a post-tank construction transport simulation starting in 1953. The simulation to acquire the initial conditions started with unit hydraulic gradient conditions from the water table to the surface and was allowed to run for 10,000 years to establish steadystate conditions. For the pre- and post-construction periods, the respective recharge rates were assumed to be 3.5 and $92 \mathrm{~mm} / \mathrm{yr}$ for the SX Tank Farm (Fayer et al. 2010). The increase in the recharge rate is due to the removal of vegetation within the tank farm area. For the area outside the tank farm (e.g., the area to the right of the sloped backfill in Figure 3.2), the recharge rate was kept constant at $3.5 \mathrm{~mm} / \mathrm{yr}$ for both the pre- and post-construction periods.

The use of a pre-construction simulation, where a constant recharge rate determines the initial watersaturation distribution for a post-construction transport simulation, is only acceptable for systems where no additional water has migrated through the domain boundary conditions. This is a potential concern for the SX Tank Farm because it is surrounded by several Hanford waste facilities where large water volumes have been discharged into the subsurface (Last et al. 2006b). Of these adjacent sites, the U-10 pond was considered to be the most likely site from which fluids might have migrated to the SX Tank Farm subsurface due its relative proximity to the SX Tank Farm $(\sim 600 \mathrm{~m})$ and the large volumes of water $(\sim 2.0 \mathrm{e} 9 \mathrm{~L})$ that have been disposed between 1944 and 1985 . To investigate the potential of U-10 water migrating to the SX Tank Farm, 3D radial scoping simulations were conducted using the layered system and waste-site configuration shown in Figure 3.4. For the simulation using hydraulic properties from Table 3.1, water saturations in 1985 and 2014 are shown in Figure 3.5 and Figure 3.6, respectively. These plots show that most of the U-10 wastewater primarily moved vertically downward with limited lateral spreading during the disposal period, and rapid drainage thereafter. For conservative conditions, using permeabilities for the CCU that are a factor 100 less than those listed in Table 3.1, the maximum water spreading in 1985 is shown in Figure 3.7. At these conditions, considerably more water had moved in a lateral direction, but the SX Tank Farm subsurface was clearly not affected. Subsequent drainage between 1985 and 2014 has completely removed the potential of U-10 water to reach the tank farm (Figure 3.8). Based on the results from these scoping simulations it was decided that the choice of boundary conditions for the computational tank farm domain was justified. 
Table 3.1. Sediment hydraulic properties used in the numerical models.

\begin{tabular}{lcccccc}
\hline Sediment & $\begin{array}{c}\text { van } \\
\text { Genuchten } \alpha \\
(1 / \mathrm{cm})\end{array}$ & $\begin{array}{c}\text { van } \\
\text { Genuchten } n\end{array}$ & $\begin{array}{c}\text { Residual } \\
\text { Saturation } \\
\left(\mathrm{m}^{3}{ }^{\text {liquid }} /\right. \\
\left.\mathrm{m}^{3} \text { por space }\right)\end{array}$ & $\begin{array}{c}\text { Horizontal } \\
K_{\text {sat }}(\mathrm{cm} / \mathrm{s})\end{array}$ & $\begin{array}{c}\text { Vertical } \\
K_{\text {sat }}(\mathrm{cm} / \mathrm{s})\end{array}$ & $\begin{array}{c}\text { Porosity } \\
(-)\end{array}$ \\
\hline Backfill & $1.02 \times 10^{-2}$ & 2.177 & 0.118 & $7.77 \times 10^{-5}$ & $1.73 \times 10^{-5}$ & 0.323 \\
Hanford H1a & $1.02 \times 10^{-2}$ & 2.177 & 0.118 & $7.77 \times 10^{-5}$ & $1.73 \times 10^{-5}$ & 0.323 \\
Hanford H1 & $7.90 \times 10^{-3}$ & 2.223 & 0.133 & $6.17 \times 10^{-4}$ & $8.87 \times 10^{-5}$ & 0.335 \\
Hanford H2 & $1.02 \times 10^{-2}$ & 2.177 & 0.118 & $7.77 \times 10^{-5}$ & $1.73 \times 10^{-5}$ & 0.323 \\
Cold Creek Silt & $5.28 \times 10^{-3}$ & 2.249 & 0.097 & $9.18 \times 10^{-5}$ & $3.38 \times 10^{-5}$ & 0.420 \\
Cold Creek & $1.11 \times 10^{-2}$ & 1.740 & 0.185 & $1.39 \times 10^{-3}$ & $5.13 \times 10^{-4}$ & 0.340 \\
Carbonate & & & & & & \\
Ringold Taylor & $1.37 \times 10^{-2}$ & 1.671 & 0.120 & $2.24 \times 10^{-4}$ & $5.01 \times 10^{-5}$ & 0.300 \\
$\begin{array}{l}\text { Flats } \\
\text { Ringold Wooded }\end{array}$ & $1.37 \times 10^{-2}$ & 1.671 & 0.120 & $2.24 \times 10^{-4}$ & $5.01 \times 10^{-5}$ & 0.300 \\
Island Unit e & & & & & & \\
\hline
\end{tabular}

Table 3.2. Description of SX-108 scoping simulations.

\begin{tabular}{|c|c|}
\hline Simulation Name & Description \\
\hline Base Case & $\begin{array}{l}\text { Hydraulic data from Table } 3.1 \text { and leak information from Table } 2.2 . \\
\text { Recharge is } 92 \mathrm{~mm} / \mathrm{yr} \text { after } 1953 .\end{array}$ \\
\hline Barrier & $\begin{array}{l}\text { Same as Base Case but with barrier on SX Tank Farm after 2020. Recharge } \\
\text { through barrier is } 0.5 \mathrm{~mm} / \mathrm{yr} \text {. }\end{array}$ \\
\hline Center Leaks & As Base Case but with the leaks originating from tank bottom center. \\
\hline Reduced Leak Duration & $\begin{array}{l}\text { As Base Case but with all three leak periods (Table } 2.2 \text { ) reduced by a factor } \\
\text { of } 10 \text {. The leak rates were increased by the same factor to keep inventory the } \\
\text { same. }\end{array}$ \\
\hline Increased Leak Volume & $\begin{array}{l}\text { As Base Case but with leak volumes increased by a factor of } 2 . \text { The } \\
\text { contaminant concentrations were reduced by the same factor to keep } \\
\text { inventory the same. }\end{array}$ \\
\hline Reduced CCU Ksat & $\begin{array}{l}\text { As Base Case but with hydraulic conductivity of CCUs reduced by a factor of } \\
100 \text { in all directions. }\end{array}$ \\
\hline Reduced Ksat & $\begin{array}{l}\text { As Base Case but with hydraulic conductivity of all units reduced by a factor } \\
\text { of } 10 \text { in all directions. }\end{array}$ \\
\hline Reduced Recharge & As Base Case but with a recharge rate of $46 \mathrm{~mm} / \mathrm{yr}$ after 1953 . \\
\hline Unchanged Recharge & As Base Case but with recharge kept at pre-construction rate of $3.5 \mathrm{~mm} / \mathrm{yr}$. \\
\hline
\end{tabular}


Table 3.3. Description of SX Tank Farm numerical simulations

\begin{tabular}{|c|c|}
\hline Simulation Name & Description \\
\hline Base Case & $\begin{array}{l}\text { Hydraulic data from Table } 3.1 \text { and leak information from Table } 2.2 . \\
\text { Recharge is } 92 \mathrm{~mm} / \mathrm{yr} \text { after } 1953 .\end{array}$ \\
\hline Water Line Leak & $\begin{array}{l}\text { Same as Base Case but with water-line leak of } 1,000 \mathrm{~L} / \mathrm{d} \text { from a } 10-\mathrm{m} \text {-long } \\
\text { section at the suspected leak location south of SX-115. The leak duration is } \\
\text { from } 1960-2001 \text {. }\end{array}$ \\
\hline $\begin{array}{l}\text { Water Line Leak } \\
\text { /Reduced Leak Duration }\end{array}$ & As Water Line Leak simulation but with leak period from 1980 to 2001. \\
\hline $\begin{array}{l}\text { Water Line Leak } \\
\text { /Reduced Line Length }\end{array}$ & $\begin{array}{l}\text { As Water Line Leak simulation but with leak emanating from a 1-m-long } \\
\text { section. }\end{array}$ \\
\hline $\begin{array}{l}\text { Water Line Leak with } \\
\text { Barrier }\end{array}$ & $\begin{array}{l}\text { As Water Line Leak simulation with barrier on SX Tank Farm after } 2020 \text {. } \\
\text { Recharge through barrier is } 0.5 \mathrm{~mm} / \mathrm{yr} \text {. }\end{array}$ \\
\hline Reduced CCU Ksat & $\begin{array}{l}\text { As Base Case but with hydraulic conductivity of CCUs reduced by a factor of } \\
100 \text { in all directions. }\end{array}$ \\
\hline Reduced Leak Duration & $\begin{array}{l}\text { As Base Case but with all leak periods from all tanks (Table } 2.2) \text { reduced by } \\
\text { a factor of } 10 \text {. The leak rates were increased by the same factor to keep each } \\
\text { tank inventory the same. }\end{array}$ \\
\hline Increased Leak Volume & $\begin{array}{l}\text { As Base Case but with leak volumes from all tanks increased by a factor of } 2 \text {. } \\
\text { The contaminant concentrations were reduced by the same factor to keep } \\
\text { each tank inventory the same. }\end{array}$ \\
\hline
\end{tabular}

Table 3.4. Released Tc- 99 activity, waste volumes, and Tc-99 concentrations used in SX Tank Farm simulations.

\begin{tabular}{cccc}
\hline Tank & $\begin{array}{c}\text { Total Volume } \\
(\mathrm{L})\end{array}$ & $\begin{array}{c}\text { Tc-99 Inventory } \\
(\mathrm{Ci})\end{array}$ & $\begin{array}{c}\text { Tc-99 } \\
\text { Concentration } \\
(\mathrm{pCi} / \mathrm{L})\end{array}$ \\
\hline SX-107 & 24,200 & 4.87 & $2.012 \mathrm{e} 8$ \\
SX-108 & 288,000 & 11.70 & $4.063 \mathrm{e} 7$ \\
SX-109 & 3,800 & 0.77 & $2.026 \mathrm{e} 8$ \\
SX-111 & 11,000 & 0.63 & $5.727 \mathrm{e} 7$ \\
SX-112 & 102,000 & 6.45 & $6.324 \mathrm{e} 7$ \\
SX-113 & 56,800 & 1.49 & $2.623 \mathrm{e} 7$ \\
SX-114 & 7,570 & 0.16 & $2.153 \mathrm{e} 7$ \\
SX-115 & 193,000 & 4.53 & $2.347 \mathrm{e} 7$ \\
\hline
\end{tabular}




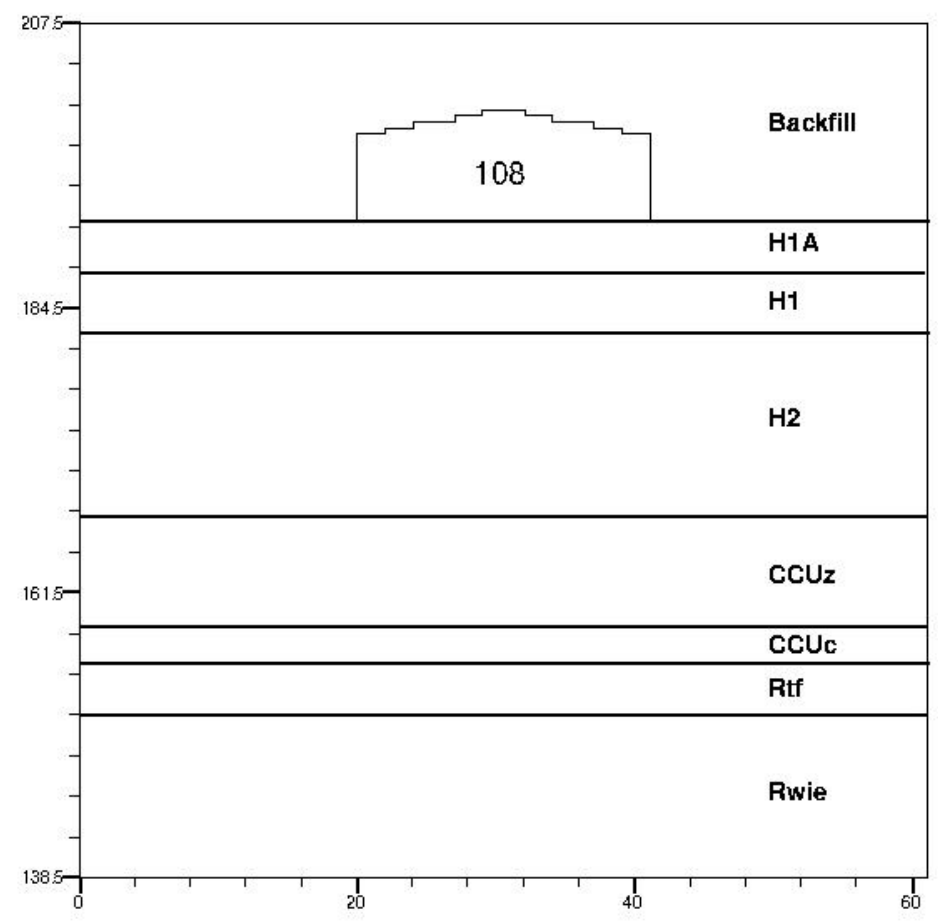

Figure 3.1. Sediment zonation for the SX-108 numerical model domain.

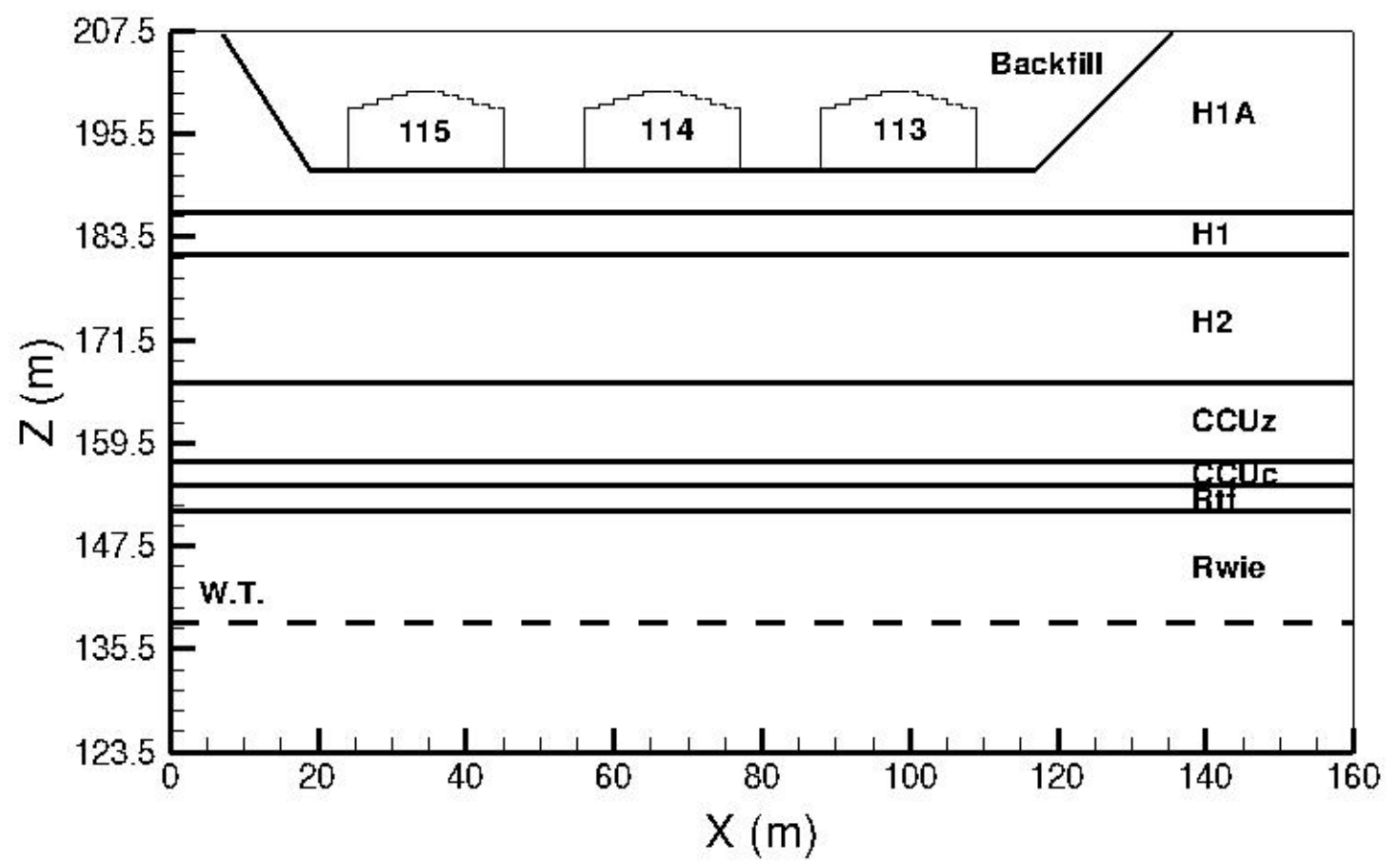

Figure 3.2. Sediment zonation for SX Tank Farm numerical model domain. 


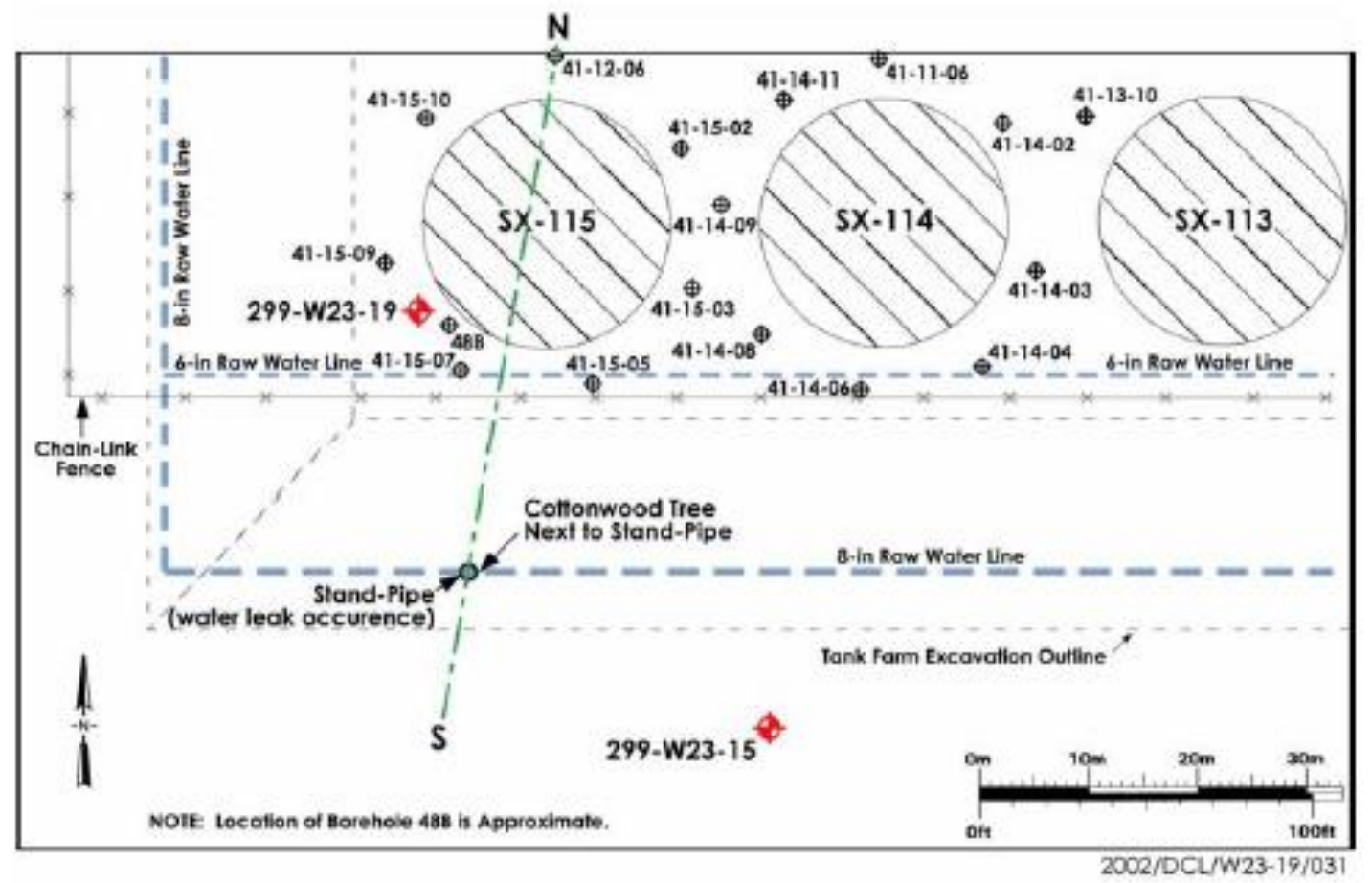

Figure 3.3. Water lines at southern end of SX Tank Farm with suspected water-line leak location (from Johnson and Chou 2002).

\section{Aqueous Saturation: $\quad 0.150 .250 .350 .450 .550 .650 .750 .850 .95$}

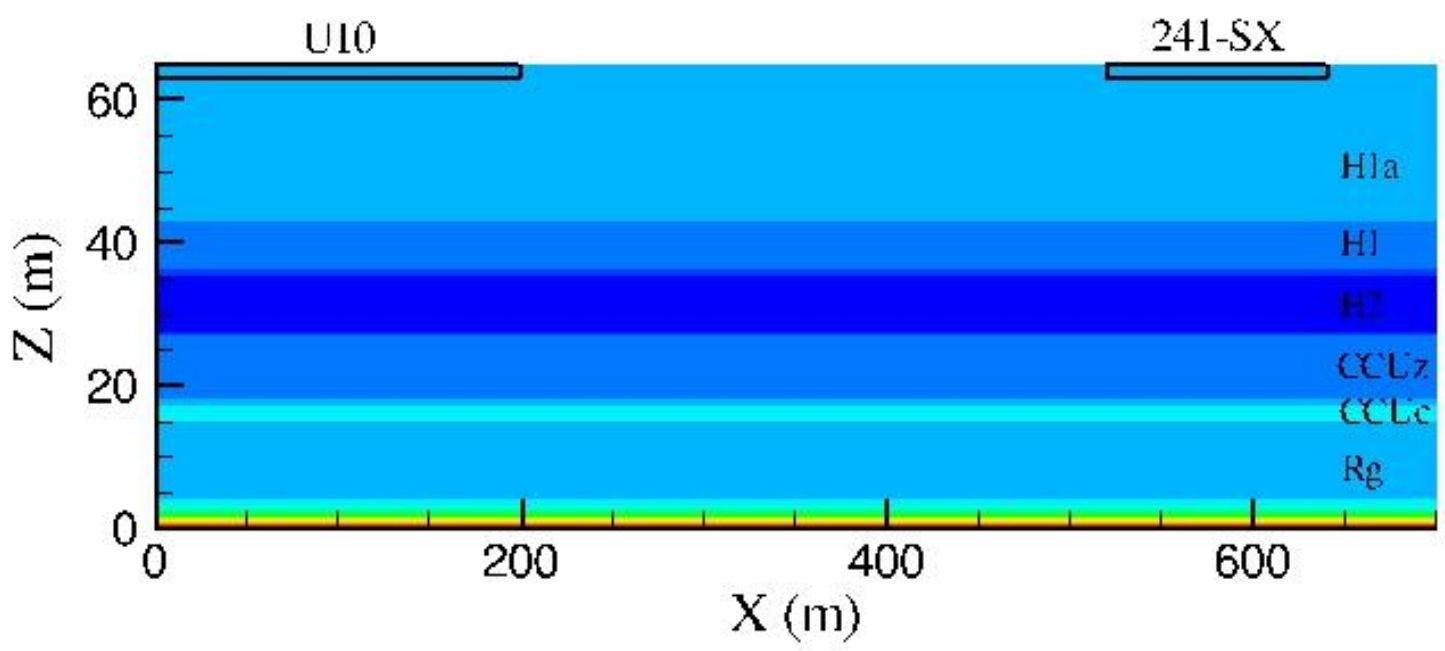

Figure 3.4. Simulated water saturation in 1944 when disposal into U-10 was initiated. 
Aqueous Saturation: 0.150 .250 .350 .450 .550 .650 .750 .850 .95

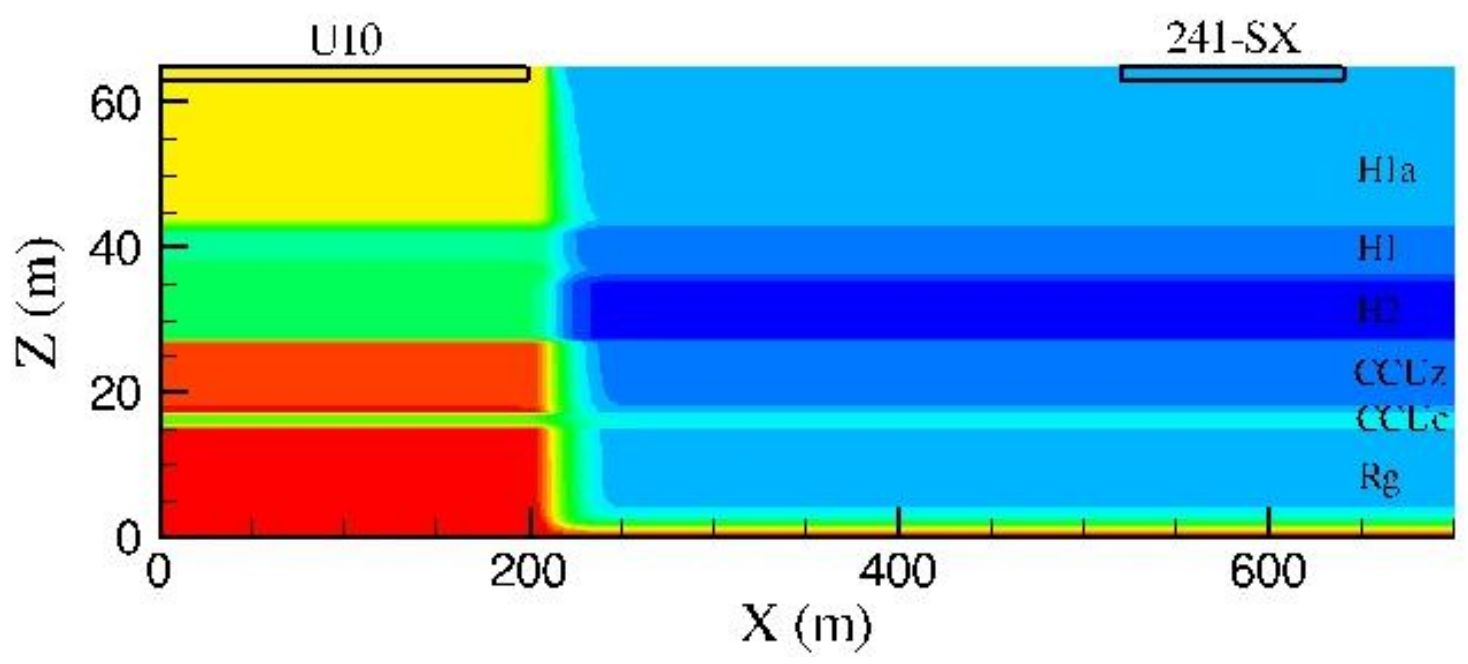

Figure 3.5. Simulated water saturation in 1985 when disposal into U-10 was terminated.

Aqueous Saturation: $\quad 0.150 .250 .350 .450 .550 .650 .750 .850 .95$

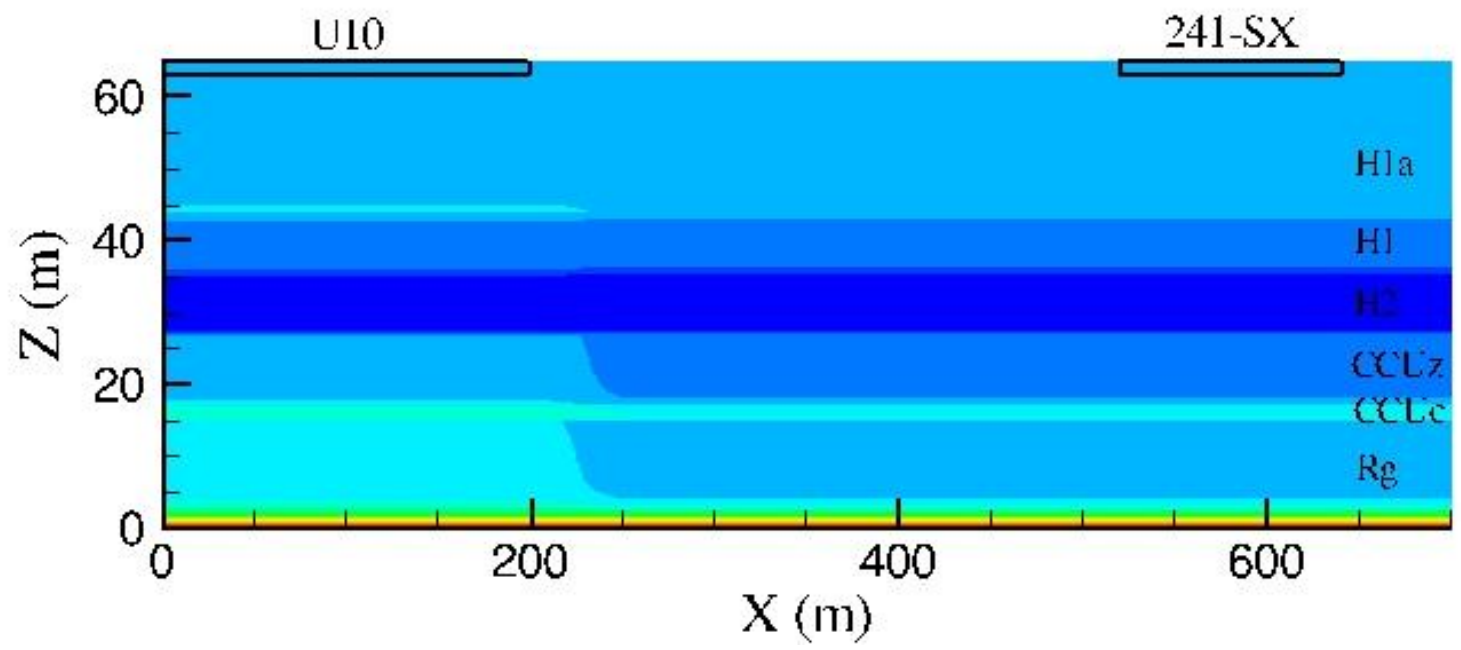

Figure 3.6. Simulated water saturation in 2014 . 


\section{Aqueous Saturation: 0.150 .250 .350 .450 .550 .650 .750 .850 .95}

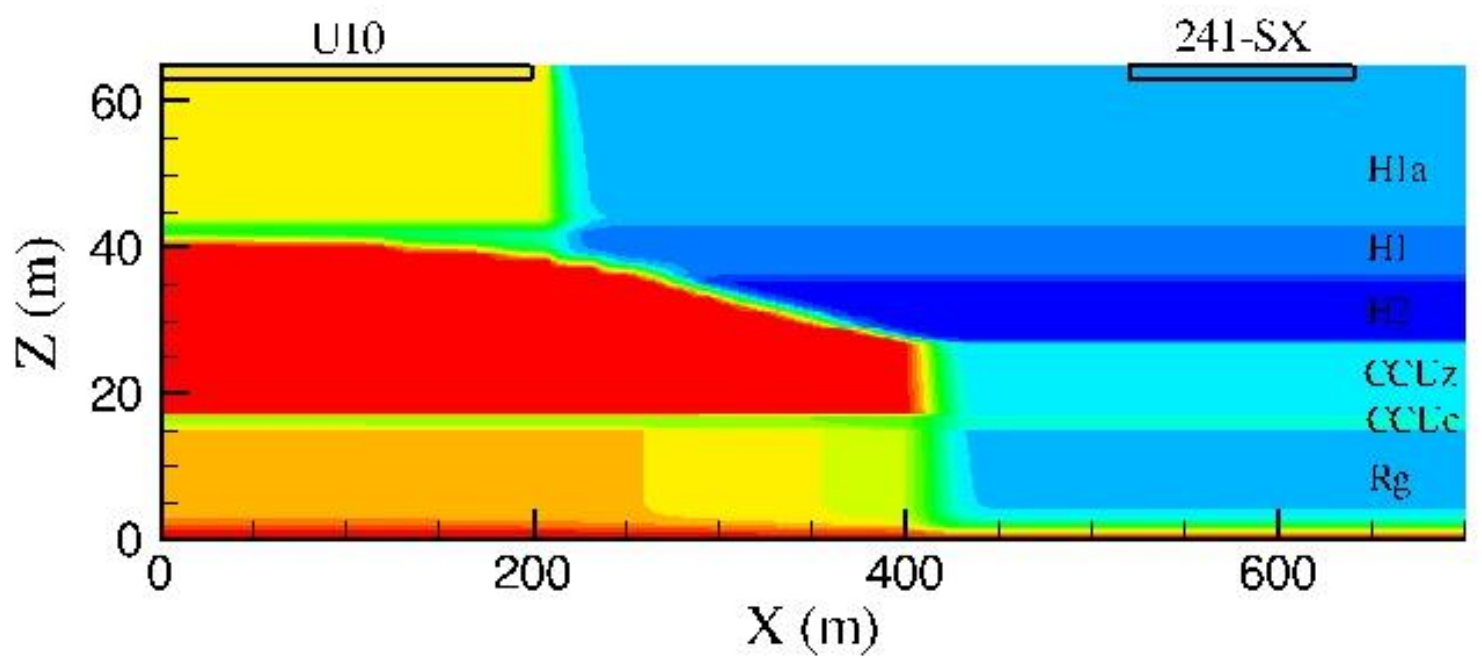

Figure 3.7. Simulated water saturation in 1985 , when disposal into U-10 was terminated, for a reduced hydraulic conductivity of the Cold Creek Units.

Aqueous Saturation: $\quad 0.150 .250 .350 .450 .550 .650 .750 .850 .95$

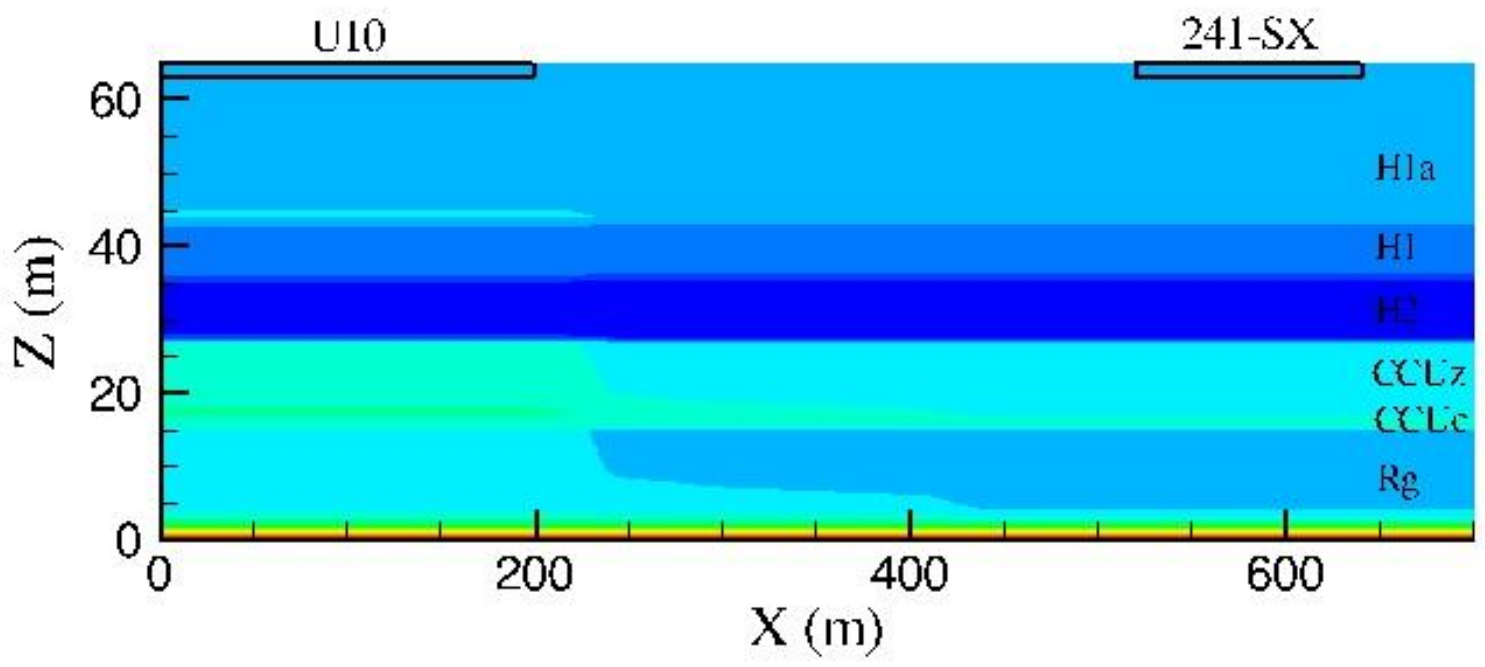

Figure 3.8. Simulated water saturation in 2014 for reduced hydraulic conductivity in the Cold Creek Unit. 



\subsection{Results and Discussion}

In Section 4.1, results are presented for a series of simulations investigating several potential controlling features and processes for the SX-108 configuration (Figure 3.1). The main goal of these simulations was to determine which factors significantly affect contaminant flux to groundwater. Section 4.2 presents SX Tank Farm (Figure 3.2) simulations that were conducted to improve the site conceptual model. In particular, the effects of a potential water-line leak and future surface barrier emplacement were investigated. The emphasis in these two sections is on the mobile Tc-99 contaminant. The nature of Cs-137 subsurface transport is significantly different that the transport for Tc-99 due to its potential for sorption and its relatively short half-life of 30 years. A discussion of Cs-137 subsurface transport is presented in Section 4.3.

\subsection{Assessment of Controlling Features and Processes}

A series of simulations was conducted investigating several potential controlling features and processes for the layered SX-108 subsurface configuration (Figure 3.1). Descriptions of these simulations are presented in Table 3.1. The SX-108 tank is of particular interest because it is the tank in the SX Tank Farm with the largest released Tc-99 activity $(11.7 \mathrm{Ci}$ ) - almost $40 \%$ of estimated total released activity $(30.55 \mathrm{Ci})$ at the SX Tank Farm. The released activity occurred in the form of three suspected leaks (Appendix B): a small 9,000 L leak between July 1964 and June 1965 originating from the bottom center of the tank, a large 217,000 L leak from the bottom southwest portion of the tank between March 1966 and March 1967, and a moderate size leak (62,500 L) directly following the second leak between April 1968 and August 1968.

The simulated water saturation and Tc-99 concentration distributions over time are presented in Figure 4.1 through Figure 4.11 for the Base Case (

Table 3.2). The initial water-saturation plot in 1953 (Figure 4.11) shows water saturations above the CCUc between 0.2 and 0.4 , with gradually higher saturations between this tighter layer and the water table. Right after the second leak in 1967 (Figure 4.2), several changes are notable compared to the conditions in 1953: 1) the leaked aqueous phase is clearly visible near the west side of the tank with increased saturations into the upper part of the $\mathrm{H} 2 ; 2$ ) at the east side of the tank it can be seen that the front of the water from the increased recharge ( $92 \mathrm{~mm} / \mathrm{yr}$ after vs. $3.5 \mathrm{~mm} / \mathrm{yr}$ before 1953) has migrated into the $\mathrm{H1}$ a; and 3) as a result of the increased recharge, water saturations on top of the tank have increased considerably. The Tc-99 concentrations at the same time (Figure 4.3) show that the contaminant has primarily migrated with the leaked fluid, indicating that during this leak period, the major transport mechanism was advection. This result is expected, because water saturations near the leak location increased to values larger than 0.9. After the third and final leak in 1968, the tank fluids have penetrated further into the $\mathrm{H} 2$ layer and, as a result of capillarity, unsaturated water flow leads to horizontal water movement in the H1a and H1 layers (Figure 4.4). Because the leak rate during the third leak was smaller than during the second leak, water saturations near the leak location decreased in 1968. As shown in Figure 4.5, the reduced leak rate was still sufficient to transport Tc-99 downward and laterally.

In the period after the spill, the initially higher water saturations observed in Figure 4.4 rapidly dissipate in all directions due to capillary action and an associated reduction in relative permeability. 
Figure 4.6 shows that in 1980, increased water saturations resulting from the two larger leaks are only visible toward the bottom of the H2. As can be seen on the east side of the tank, increased water saturations due to the enhanced recharge rate are only a few meters above the water front related to the leaks. Of interest is that between the end of the leaks in 1968 and 1980, downward Tc-99 transport (Figure 4.7) slows compared to vertical water migration. Although a fraction of the water entering the domain through the assumed recharge rate of $92 \mathrm{~mm} / \mathrm{yr}$ is used to increase the water saturation (water storage) in the subsurface layers due to the lower capillary pressure associated with the enhanced recharge rate, the effective Darcy velocity of the infiltrating water is relatively close to the recharge rate. In contrast, the Tc-99 concentrations continue to decrease due to dilution with the recharge water and molecular diffusion. During this phase, water migrating downward beyond the Tc-99 plume contains increasingly less contaminant as it moves toward the water table. This is an interesting and somewhat counter-intuitive observation because it implies that wastewater originally containing large amounts of Tc-99 and recharge water that has migrated through the contaminant plume, will eventually leave all contaminant behind on its way to the water table. The observed behavior in the simulation was described by Truex and Carroll (2013) for a constant recharge rate. For the SX Tank Farm, where the recharge rate considerably increased after 1953, the difference in water and contaminant transport rates might not be as pronounced as for a constant recharge condition. However, it still appears to be a key feature of Tc-99 contaminant behavior in relatively large vadose zones.

Predictions for the present time (2014) show that infiltrating water has reached the water table (Figure 4.8). Despite the relatively high recharge rate, the Tc-99 plume is lagging behind and most of the contaminant is located in the $\mathrm{H} 2$ and the CCU. The predicted location is consistent with field observations for the SX Tank Farm (Figure 2.7, Figure 2.8, and Figure 2.9). Figure 34 suggests that so far, no Tc-99 has migrated to the water table under the Base Case assumptions. The predicted plume in Figure 4.9 has become largely asymmetric due to the larger effects of recharge on the part of the plume that is not under the SX-108 tank. In that zone, the Tc-99 has migrated downward faster than in the zone below the tank where the flow rates are considerably lower. In the latter zone, the Tc-99 plume is obviously more persistent because of the smaller advective transport component. Given the predicted 2014 plume shape shown in Figure 4.9, it should be noted that it originated from a leak at the bottom southwest portion of the tank and not from a center-tank leak. Over time, contaminant mass has migrated toward the center as a result of primarily molecular diffusion and this mass is less affected by recharge than the outer part of the plume because of the influence of the waste tank on localized water flow conditions.

The simulated water-saturation plot for 2100 (Figure 4.10) is similar to the one for 2014 (Figure 4.8), indicating that the SX-108 subsurface is currently under steady-state conditions with the current recharge conditions. The contaminant plume in 2100 has decreased in size with the majority of the remaining mass being located directly below the center of the tank and in the Ringold Formation above the water table (Figure 4.11). The predicted plumes in Figure 4.9 for 2014 and Figure 4.11 for 2100 suggest that the vast majority of the Tc-99 inventory will migrate across the water table in that period. In 2500, more than 99.9\% of the original leaked Tc-99 mass (results not shown) has been removed from the vadose zone.

The water saturation and contaminant plots for the other simulations do not differ greatly from the Base Case simulation plots in 1980 or later, except for the simulations where the recharge rate was different. Examples for the Barrier simulation ( 
Table 3.2) are shown in Figure 4.12 through Figure 4.15. In Figure 4.12, the water saturations in 2100 are considerably smaller than for the Base Case (Figure 4.10), especially in the layers above the CCUc unit. The contaminant plume at this time (Figure 4.13) is far more pronounced than for the Base Case (Figure 4.11). The reduction in the site recharge rate due to the barrier keeps the Tc-99 in the subsurface much longer due to drier conditions. A reduction of the recharge rate from 92 to $0.5 \mathrm{~mm} / \mathrm{yr}$ significantly reduces the advective flux component across the water table. The steady-state watersaturation conditions in year 4000 are shown in Figure 4.14. At this point in time, there is still considerable Tc-99 in the subsurface (Figure 4.15). This plume is comparable in appearance to the Base Case plume in 2100 (Figure 4.11).

The results of the local SX-108 tank scoping simulations (

Table 3.2) are compared in Figure 4.16 through Figure 4.20. The effective average groundwater recharge (water flux across the water table in millimeters per year) is presented in Figure 4.16. The plot shows that for all simulations, except for the ones with a modified recharge, an increase in the groundwater recharge (water flux across the water table) from 3.5 to $92 \mathrm{~mm} / \mathrm{yr}$ occurred in about the year 2000 for a condition where the surface recharge was increased by this amount in 1953. The closeness of the lines indicates that the effects of permeability, leak volume, and leak duration times on water flow were relatively small. For the cases with modified leak volume, leak location, and leak duration, the maximum groundwater recharge rate was obtained within a few days of the Base Case. For the cases where the permeability was lowered, the groundwater recharge rate change was delayed by less than 8 years compared to the Base Case. The difference between the lower permeability cases and the Base Case is primarily due to the additional time it takes to account for the increased water storage associated with the increased surface recharge rate and resulting lower capillary pressure in the sediment. As mentioned before, the simulations where the surface recharge rate was reduced resulted in considerably delayed water arrival at the water table. For the Barrier simulation, with a surface recharge rate reduced to $0.5 \mathrm{~mm} / \mathrm{yr}$ in 2020, the decline in groundwater recharge becomes apparent after 2040 as the vadose zone starts to drain to account for the increasing sediment capillary pressures due to the surface recharge lowering. According to Figure 4.16, it will take until about 2300 before steady-state conditions are obtained in the vadose zone. The results for the Reduced Recharge (surface recharge at $46 \mathrm{~mm} / \mathrm{yr}$ ) demonstrate, as expected, a later arrival time at the water table. Of course, no changes in the groundwater recharge rate were observed for the Unchanged Recharge simulation, where the surface recharge rate was kept at $3.5 \mathrm{~mm} / \mathrm{yr}$.

In Figure 4.17 and Figure 4.18, the Tc-99 mass flux across the water table is plotted as function of time. The only difference between the two figures is the time on the $\mathrm{x}$-axis. Figure 4.19 shows that the breakthrough curves for the simulations with unmodified surface recharge are rather similar. For all of these simulations, the arrival times are between 2020 and 2030, and the maximum concentrations occur between 2060 and 2080. In addition, more than $99 \%$ of the total mass will migrate into the groundwater by 2150 . For these simulations with a constant $92 \mathrm{~mm} / \mathrm{yr}$ surface recharge rate, the contaminant arrival times are approximately 20 years delayed compared to the rapid change in groundwater recharge occurring around the year 2000 (Figure 4.16). As discussed before, dilution due to the addition of recharge water in combination with molecular diffusion are largely responsible for this difference.

The proximity of the breakthrough curves for the constant recharge simulations indicates that variables such as leak duration and leak volume (for a given inventory) have a minor effect on transport behavior in the SX-108 subsurface. Even though the leak volumes for the SX-108 are considerable, totaling 
$\sim 288,000 \mathrm{~L}$, they are relatively small compared to the recharge volumes for the computational domain $(\sim 342,000 \mathrm{~L}$ each year). In combination with the relatively large vadose zone, the considerable surface recharge volumes reduce the effects of leak duration and volumes, even considering the extent to which the leak duration and volumes were varied in this scoping study (

Table 3.2). It is therefore not surprising that leak volumes and duration, even when varied in these scoping simulations, are not controlling features in determining flux to groundwater.

The observation that the leak location is also not a controlling feature for this particular tank is, interestingly enough, related to the leak volumes. Although the leak volumes are small compared to the domain recharge volumes over time, a leak volume of $\sim 288,000$ L emanating from the center of the tank is large enough to result in an initial contaminant plume of considerable dimensions. A large fraction of this initial plume is accessible to recharge water and available for downward advective migration. If the contaminant mass had been part of a smaller volume (higher initial concentrations), the initial plume would be less extensive and more persistent, because recharge water would have less access to the smaller plume. The limited access of recharge water is because of the influence of the waste tank on localized water flow conditions. However, the likelihood of a centrally located major leak, in combination with considerably smaller leak volumes, is small (Appendix B).

In addition to the leak features (volume, duration, and location), an assumed reduced permeability of the sediment only has a small effect on contaminant arrival times at the water table. A reduction in permeability, compared to the Base Case, increases the water pressures that are required to conduct the recharge water. In turn, this results in higher water saturations in the sediments and increased molecular diffusion coefficients. The net result for contaminant transport is that the Tc-99 arrives somewhat later at the water table and that the mass fluxes are smaller. However, Figure 4.19 shows that the overall effect is minor and comparable in magnitude to the effect of having the leaks originate from the bottom center of the tank.

The simulations with a modified surface recharge rate have a large effect on the mass flux into groundwater. As was also shown in Figure 4.12 through Figure 4.15, emplacement of a barrier in 2020 reduces the predicted maximum mass flux and will cause considerable tailing of the contaminant mass transfer into the groundwater. The effects of the tailing on downstream well concentrations is discussed in the next section. For the Reduced Recharge simulation, predicted arrival times are increased by approximately 100 years. For the Unchanged Recharge simulation, the Tc-99 does not arrive until about the year 3000 and the pulse lasts for at least 1,000 years. It should be noted that this simulation was not considered a viable option for the site, but was included to demonstrate the large influence that surface recharge rates have on contaminant transfer. Of all the variables investigated, the surface recharge rate appears to be the major controlling feature for future mass flux to the water table at this site.

The cumulative mass of Tc-99 migrating into the groundwater is presented in Figure 4.19 and Figure 4.20. Again, the only difference between the two plots is the time extent of the x-axis. The plots show the integrated mass fluxes from Figure 4.17 and Figure 4.18, respectively. Figure 4.19 shows that for the simulations without the modified surface recharge rates, most of the released Tc-99 mass (11.6 Ci) is no longer in the vadose zone by 2150 . The responses for the modified recharge simulations were delayed. For the simulation with the emplaced barrier, only $60 \%$ of the inventory is removed by 2150 and in 4000 , more than $10 \%$ is still predicted to be in the subsurface. 


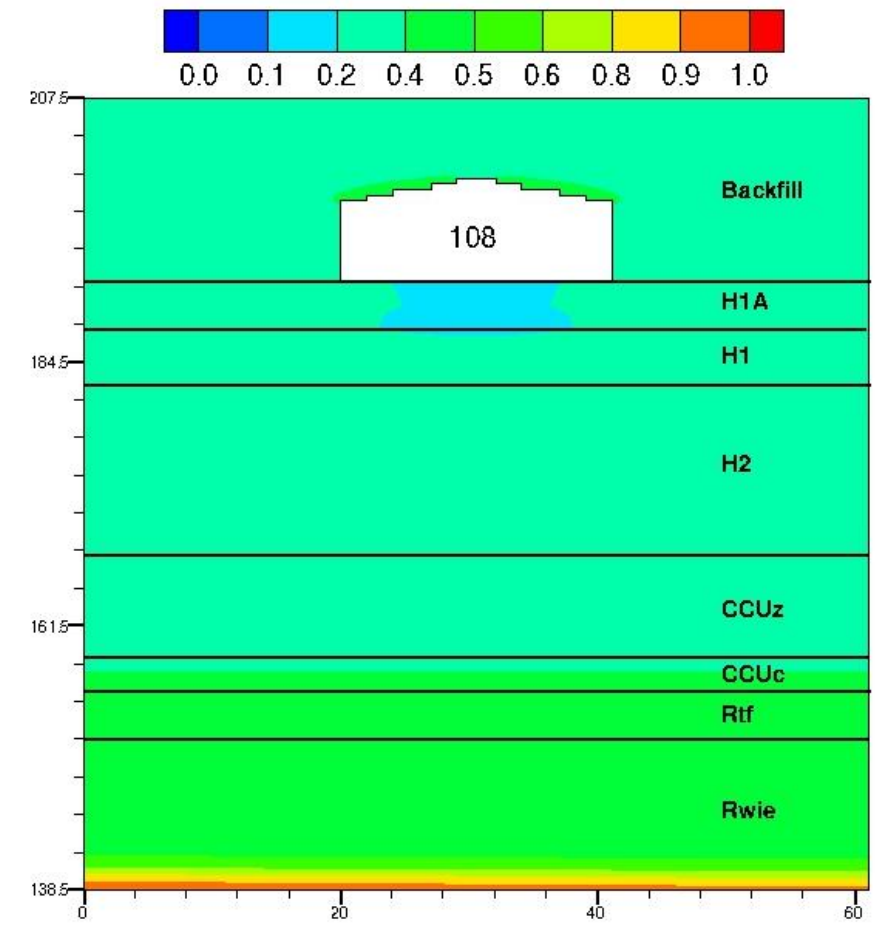

Figure 4.1. Aqueous saturation in 1953 for the SX-108 Base Case simulation.

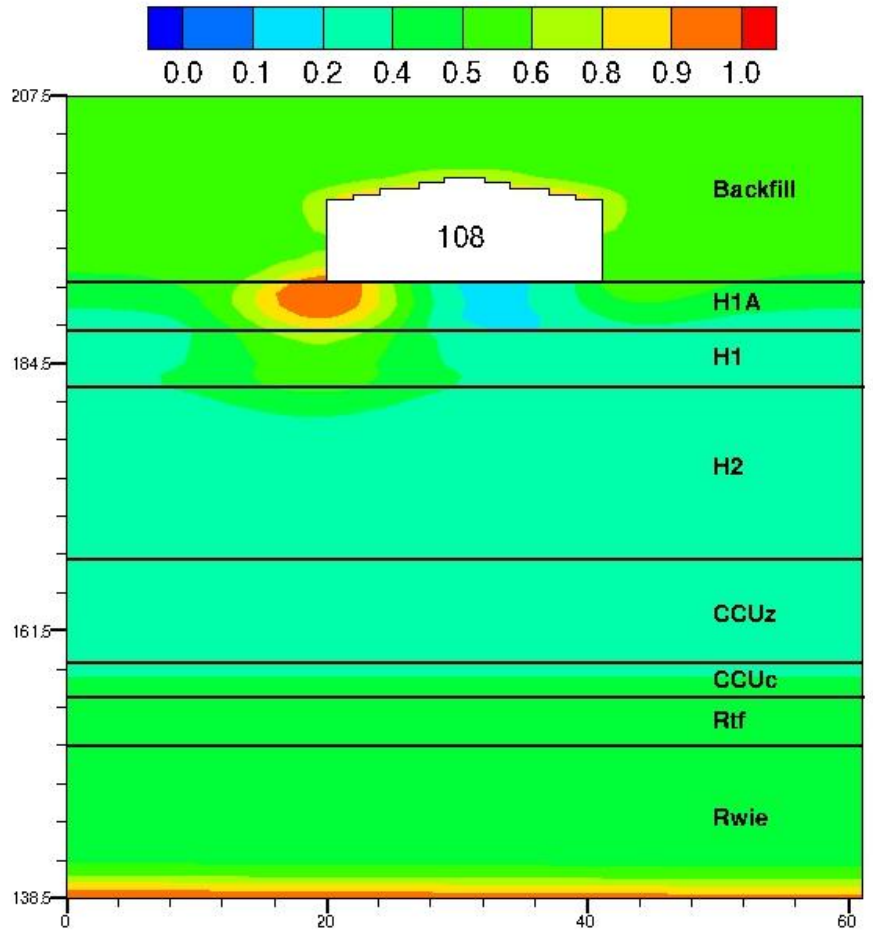

Figure 4.2. Aqueous saturation after the second leak (1967) for the SX-108 Base Case simulation. 


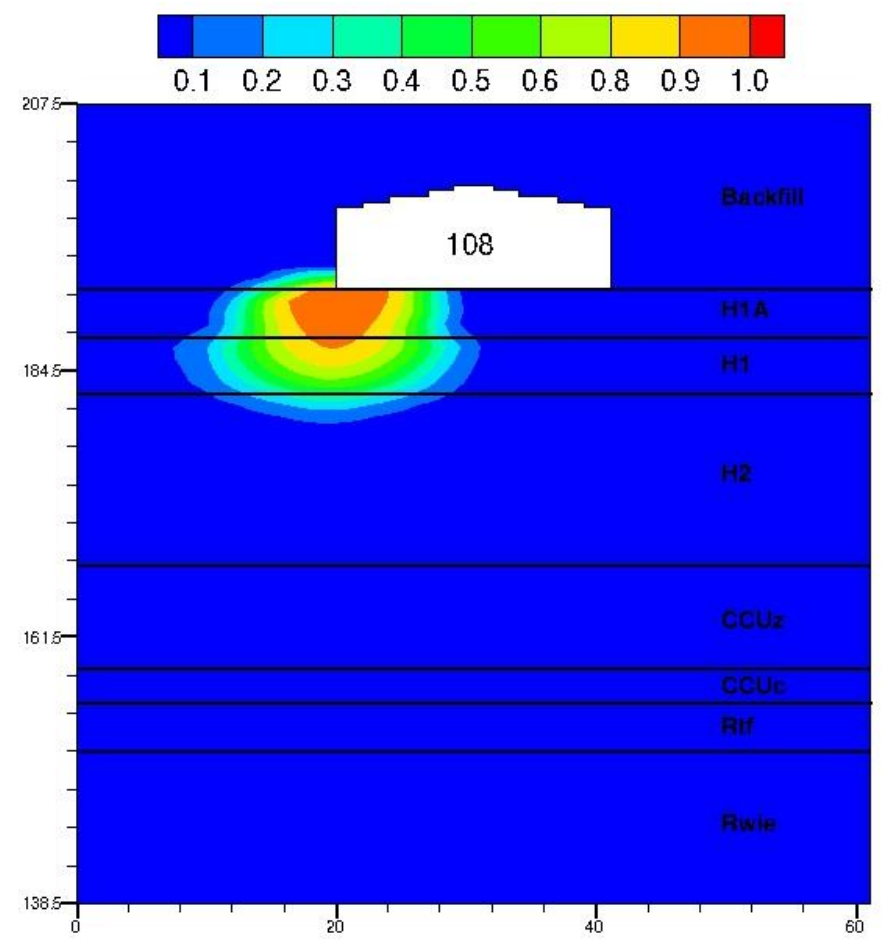

Figure 4.3. Dimensionless Tc-99 concentrations after the second leak (1967) for the SX-108 Base Case simulation.

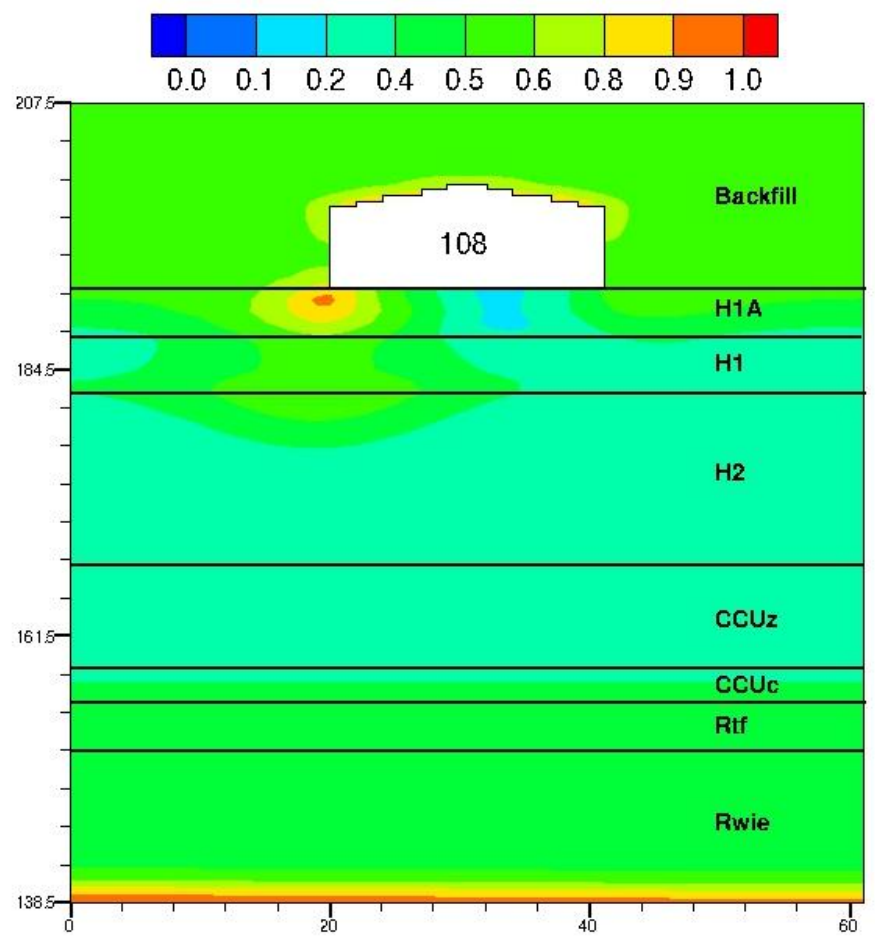

Figure 4.4. Aqueous saturation after the third leak (1968) for the SX-108 Base Case simulation. 


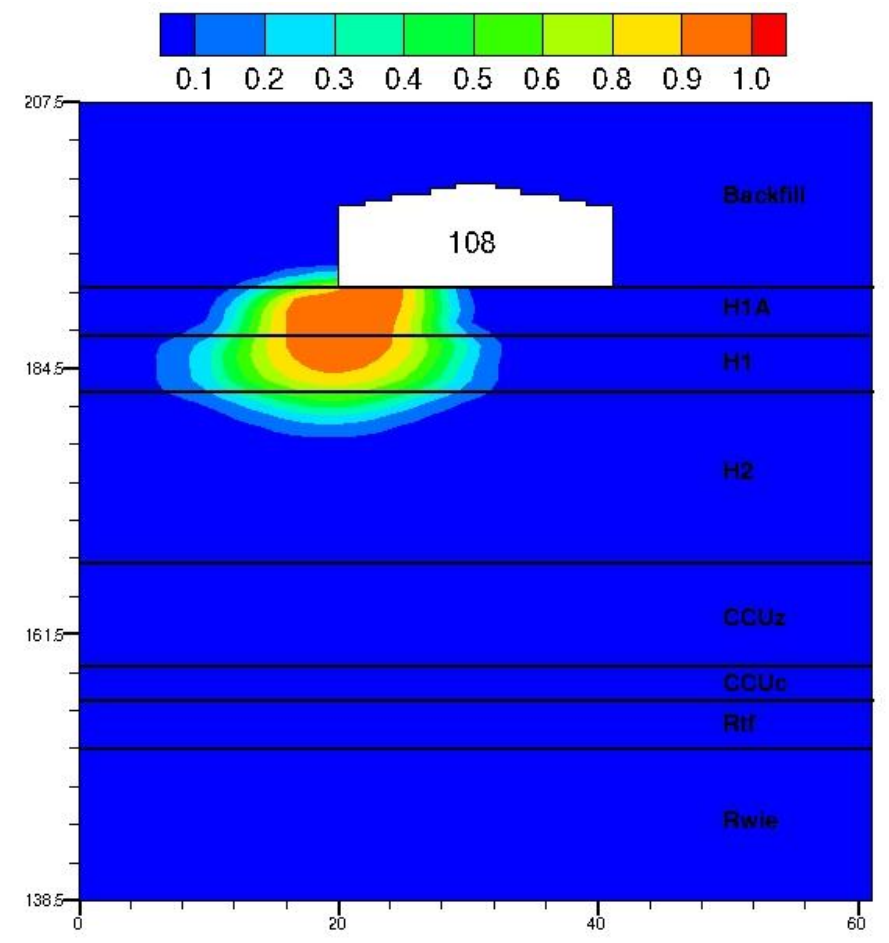

Figure 4.5. Dimensionless Tc-99 concentrations after the third leak (1968) for the SX-108 Base Case simulation.

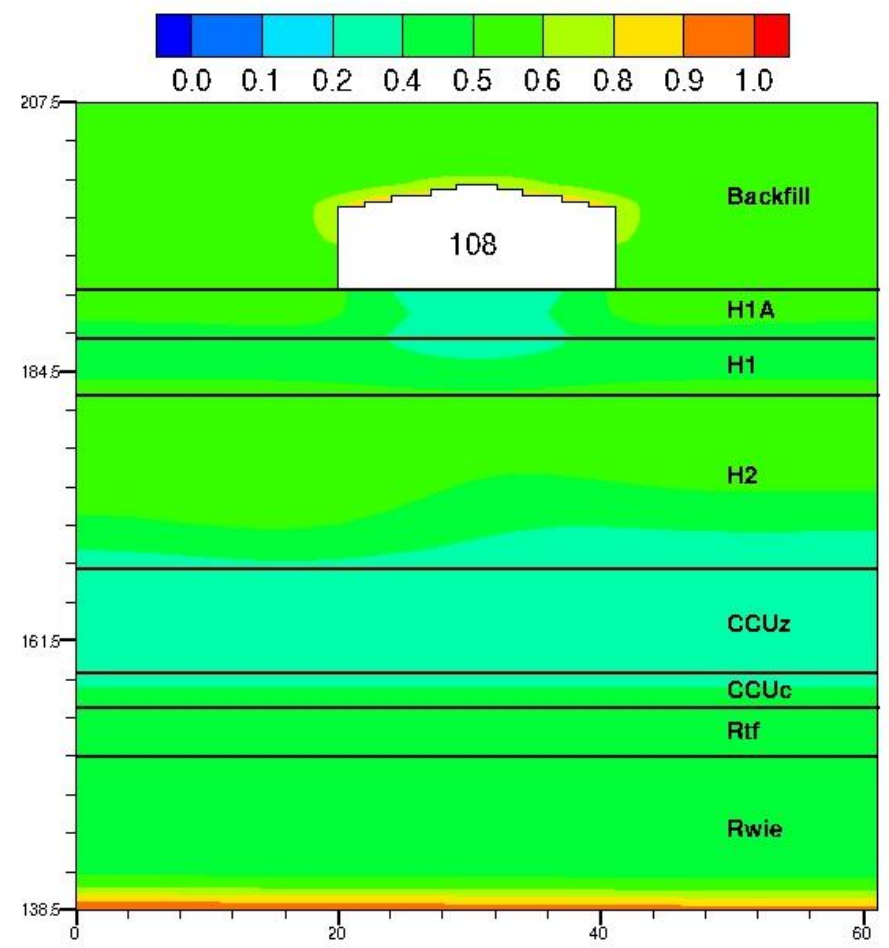

Figure 4.6. Aqueous saturation in 1980 for the SX-108 Base Case simulation. 


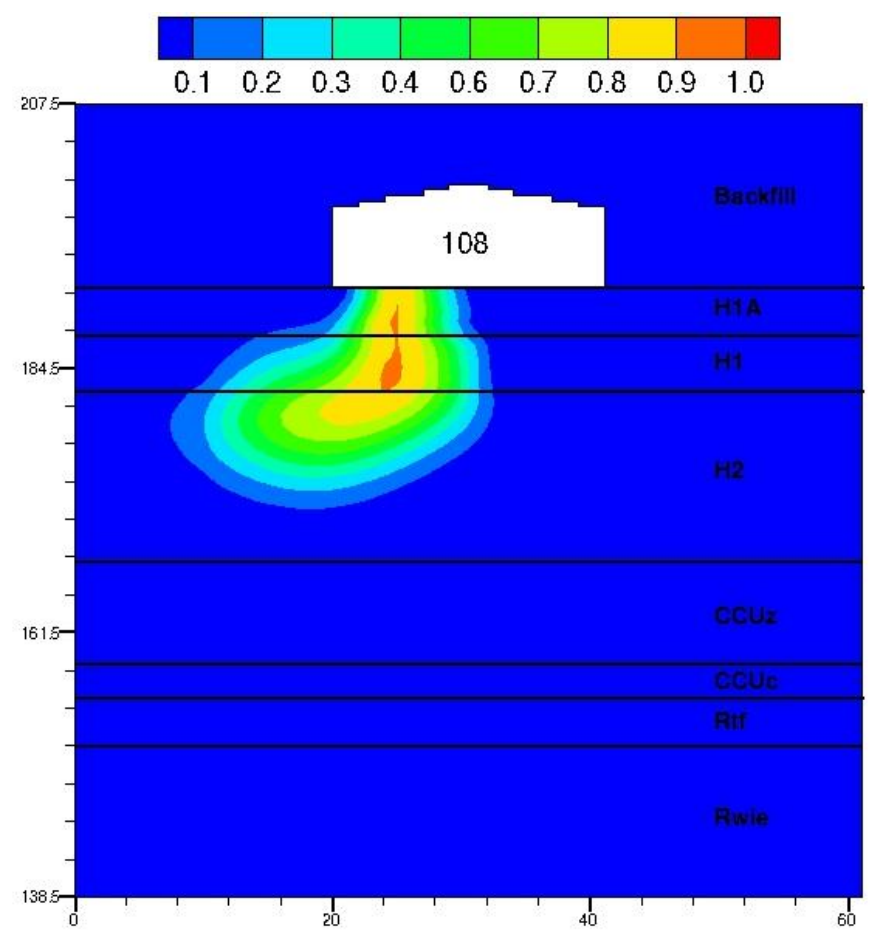

Figure 4.7. Dimensionless Tc-99 concentrations in 1980 for the SX-108 Base Case simulation.

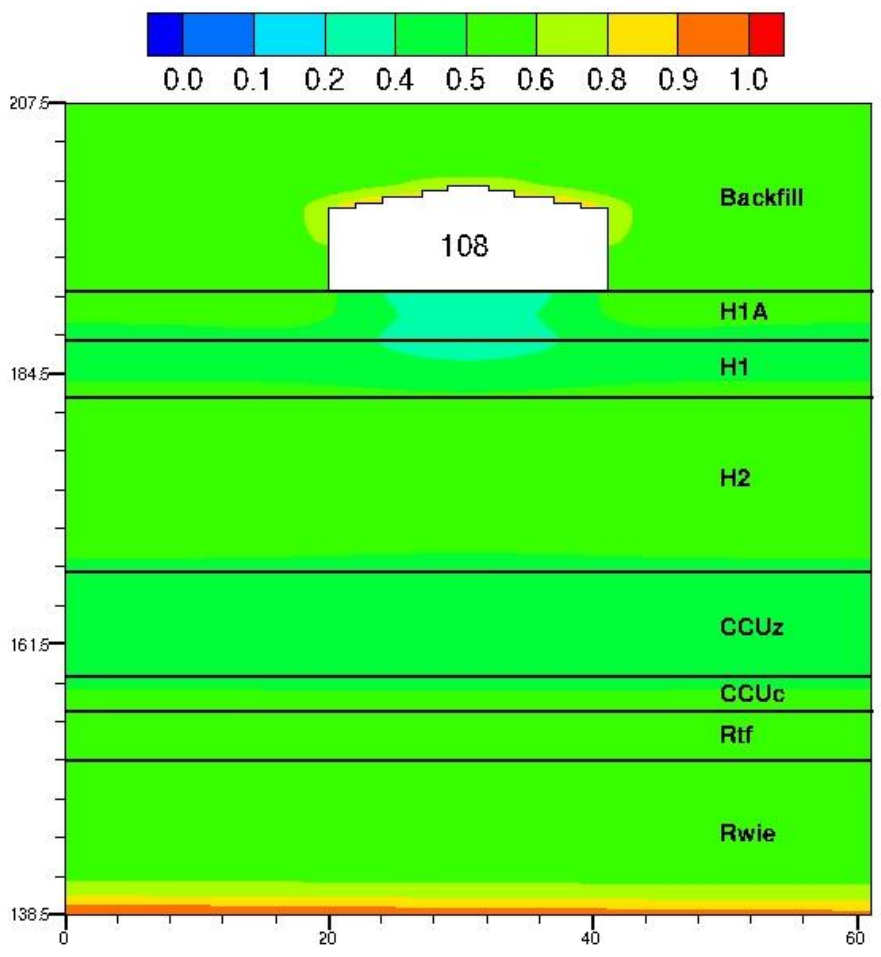

Figure 4.8. Aqueous saturation in 2014 for the SX-108 Base Case simulation. 


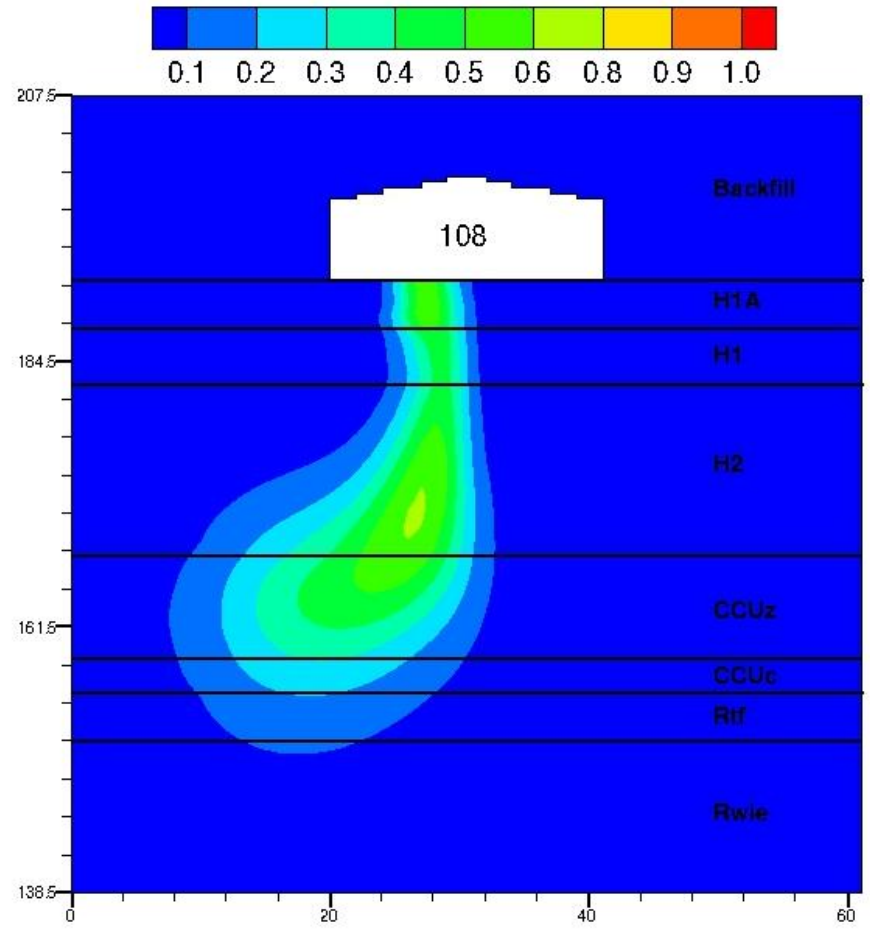

Figure 4.9. Dimensionless Tc-99 concentrations in 2014 for the SX-108 Base Case simulation.

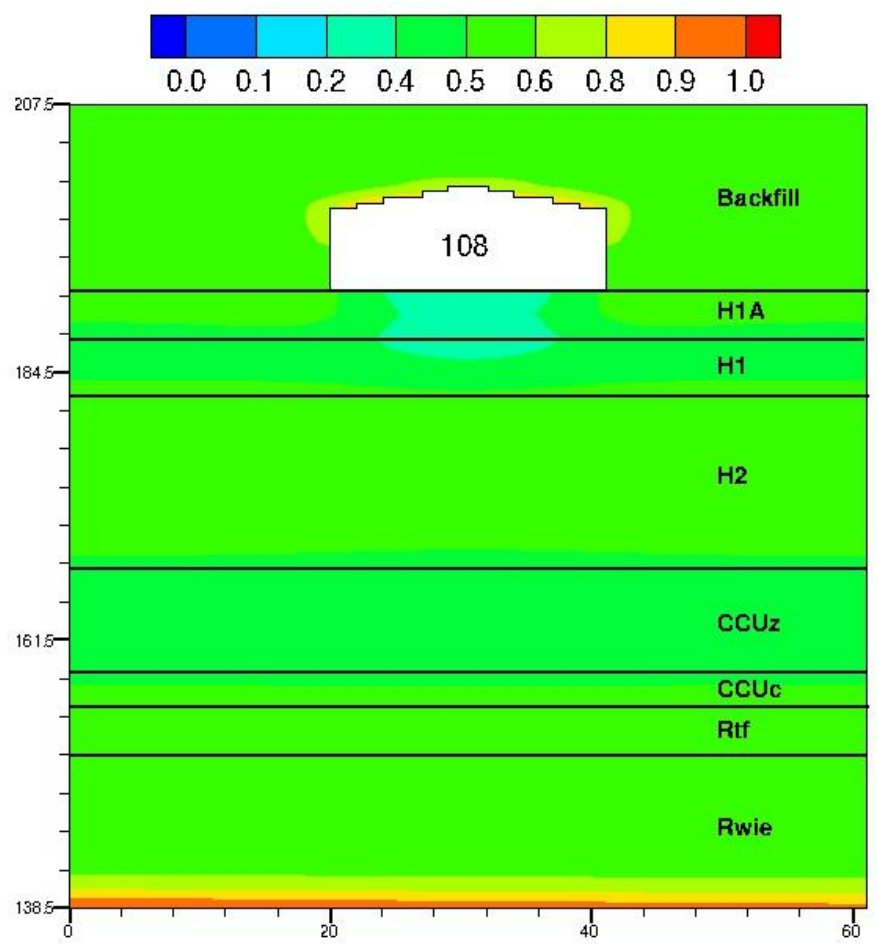

Figure 4.10. Aqueous saturation in 2100 for the SX-108 Base Case simulation. 


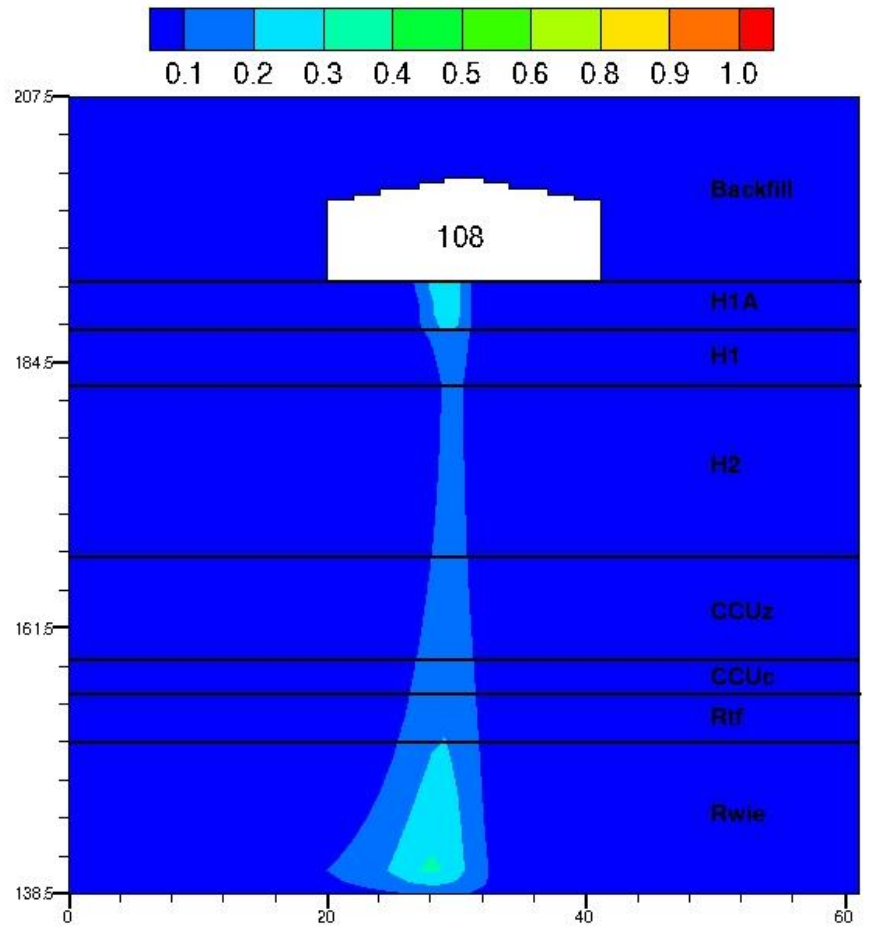

Figure 4.11. Dimensionless Tc-99 concentrations in 2100 for the SX-108 Base Case simulation.

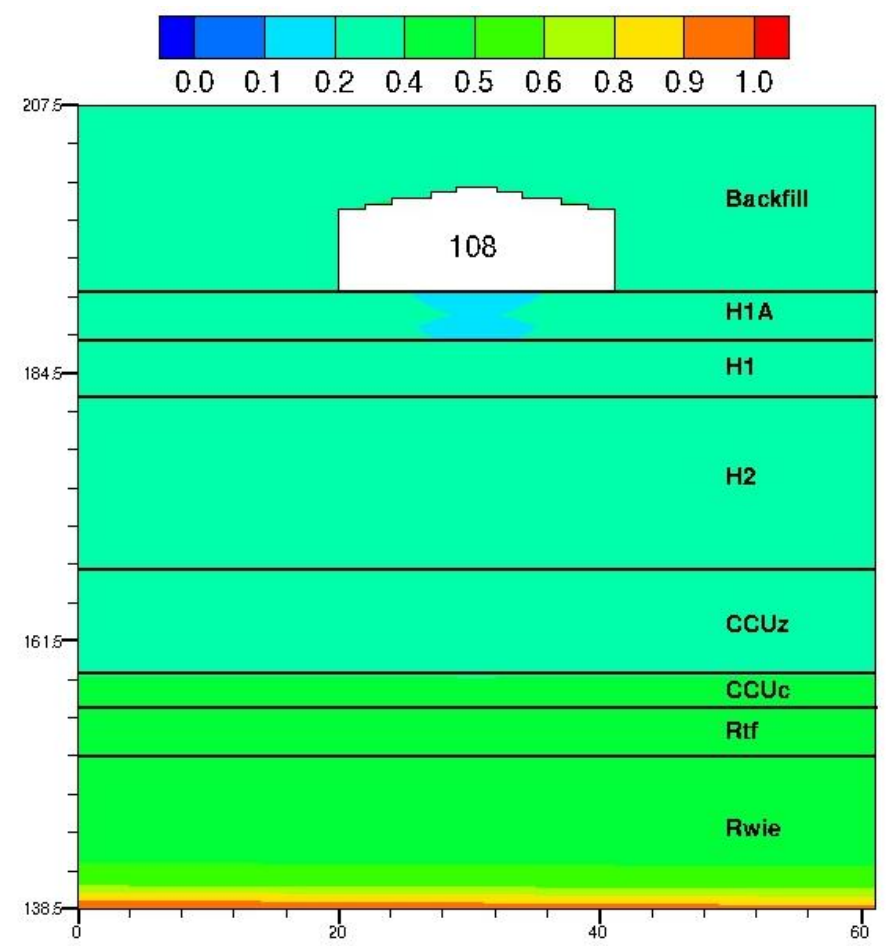

Figure 4.12. Aqueous saturation in 2100 for the SX-108 Barrier simulation. 


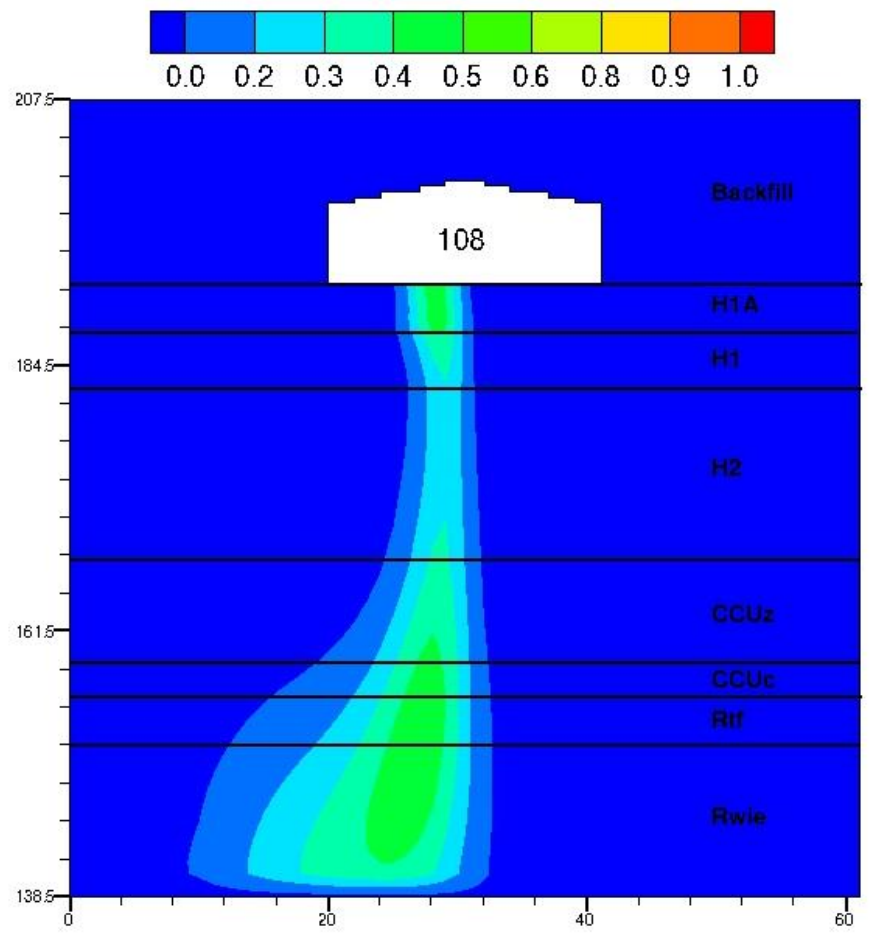

Figure 4.13. Dimensionless Tc-99 concentrations in 2100 for the SX-108 Barrier simulation.

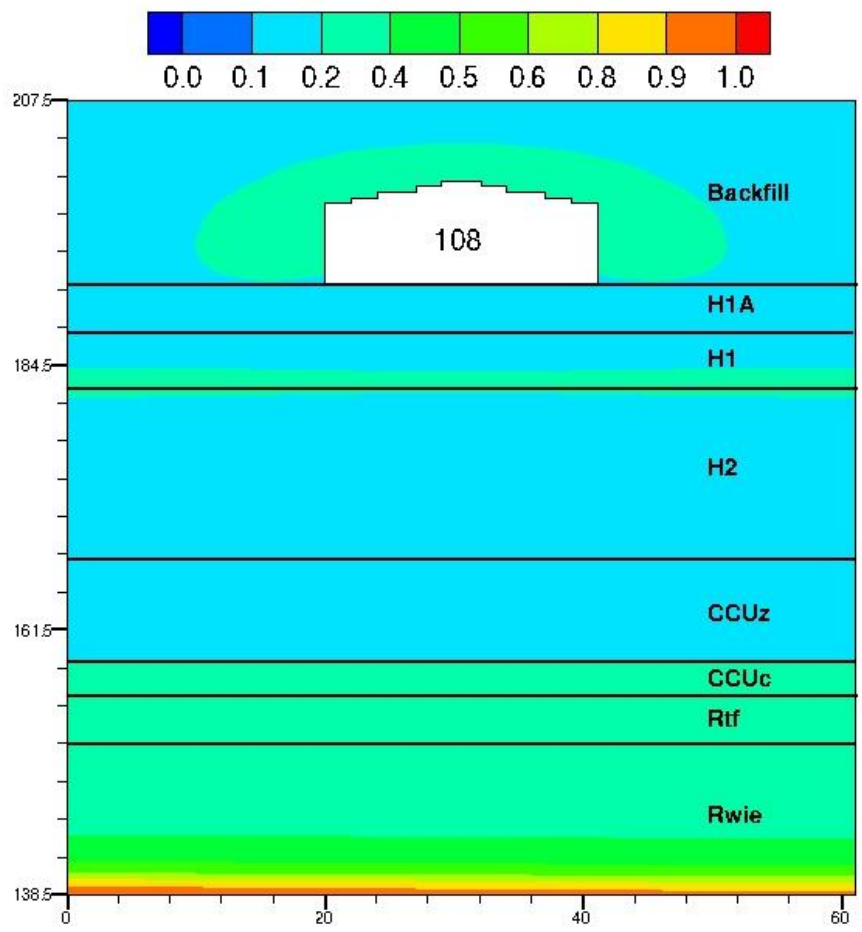

Figure 4.14. Aqueous saturation in 4000 for the SX-108 Barrier simulation. 


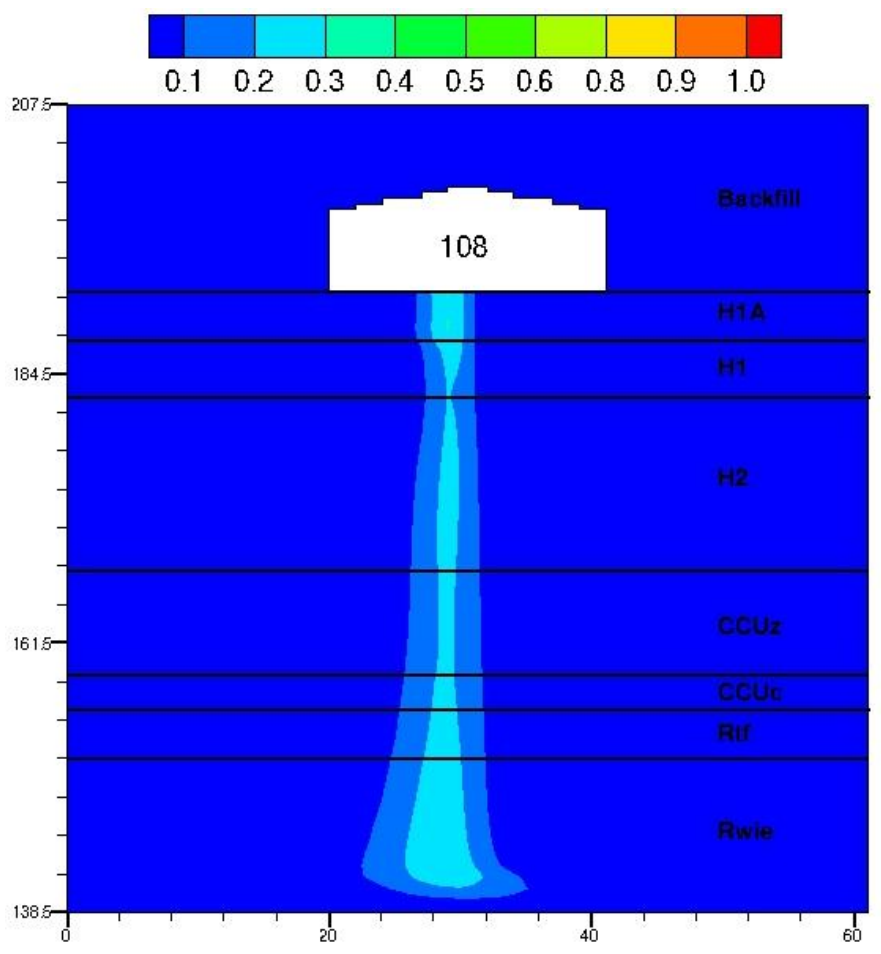

Figure 4.15. Dimensionless Tc- 99 concentrations in 4000 for the SX-108 Barrier simulation.

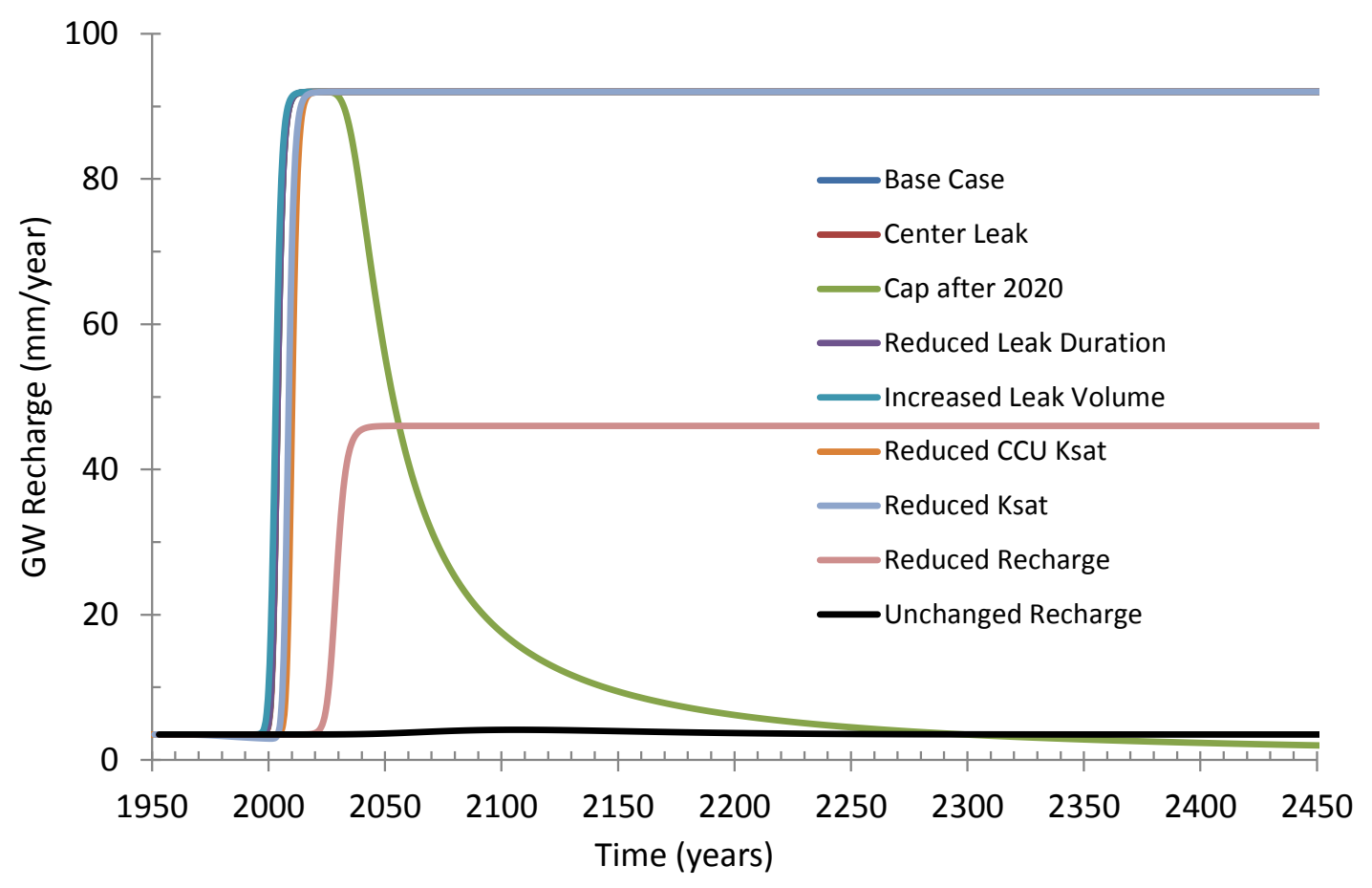

Figure 4.16. Groundwater recharge $(\mathrm{mm} / \mathrm{yr})$ for the $\mathrm{SX}-108$ simulations. 


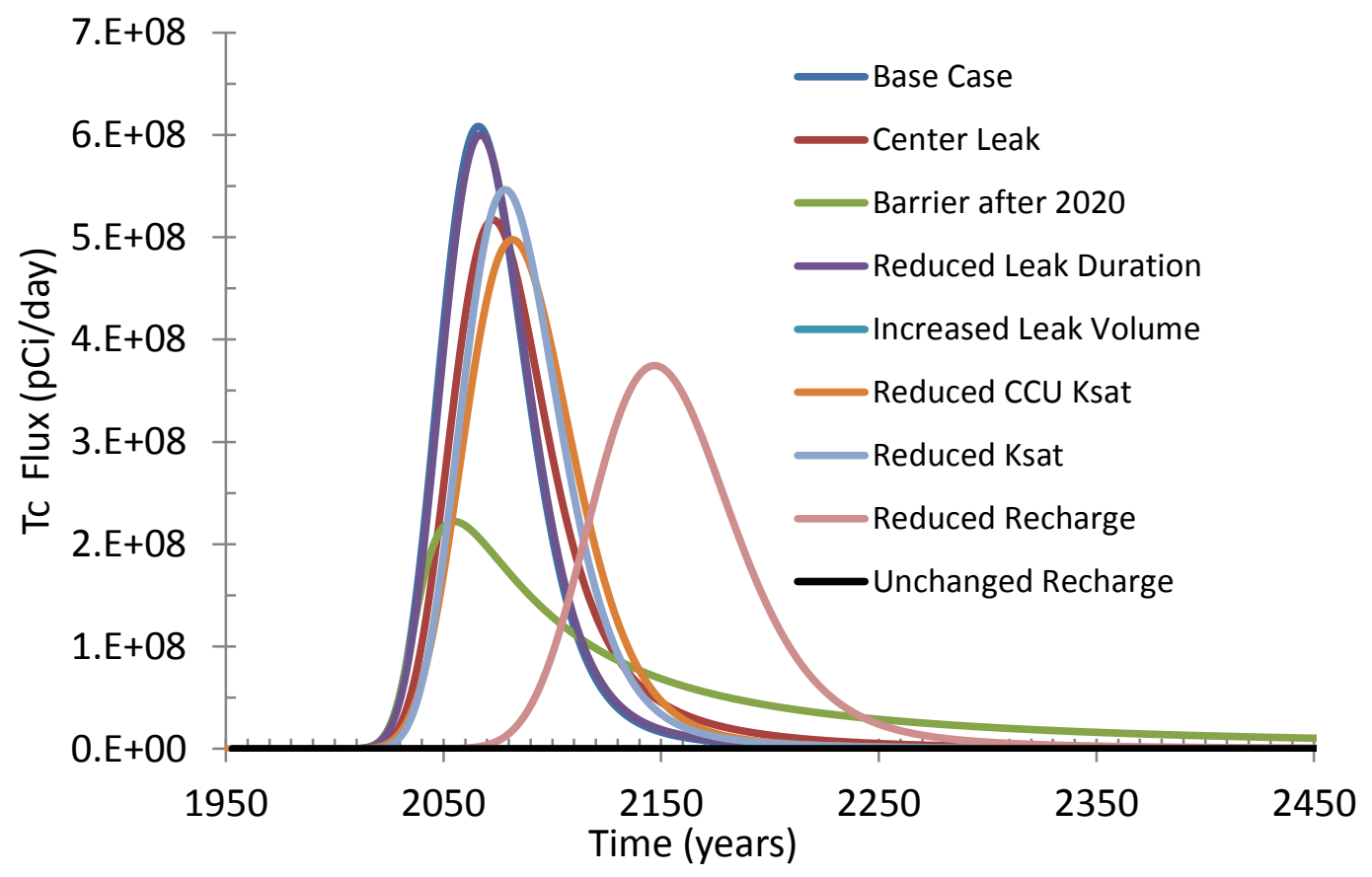

Figure 4.17. Tc-99 mass discharge (pCi/d) into groundwater for the SX-108 simulations over the period 1953-2450.

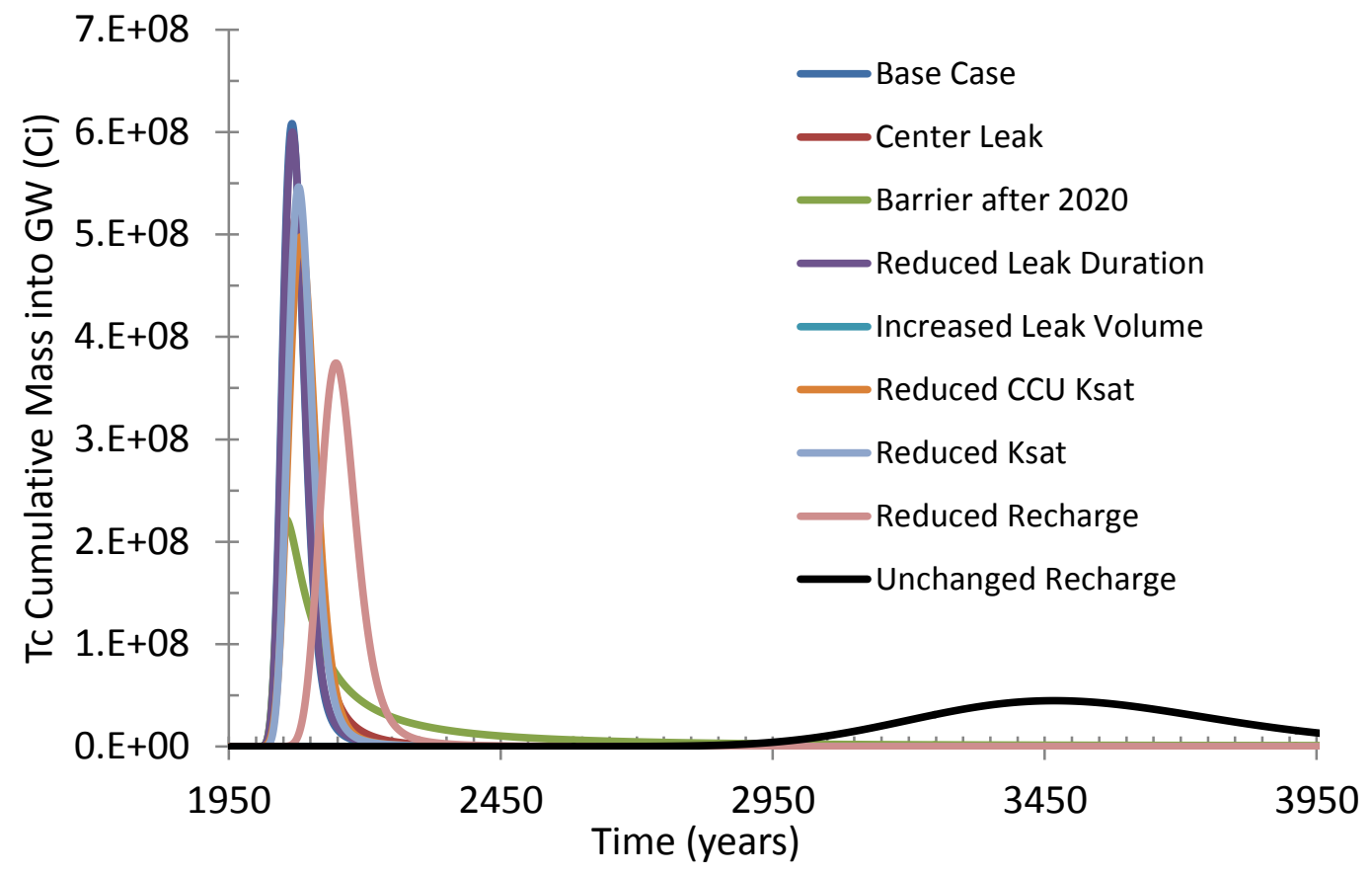

Figure 4.18. Tc-99 mass discharge (pCi/d) into groundwater for the $\mathrm{SX}-108$ simulations over the period 1953-3950. 


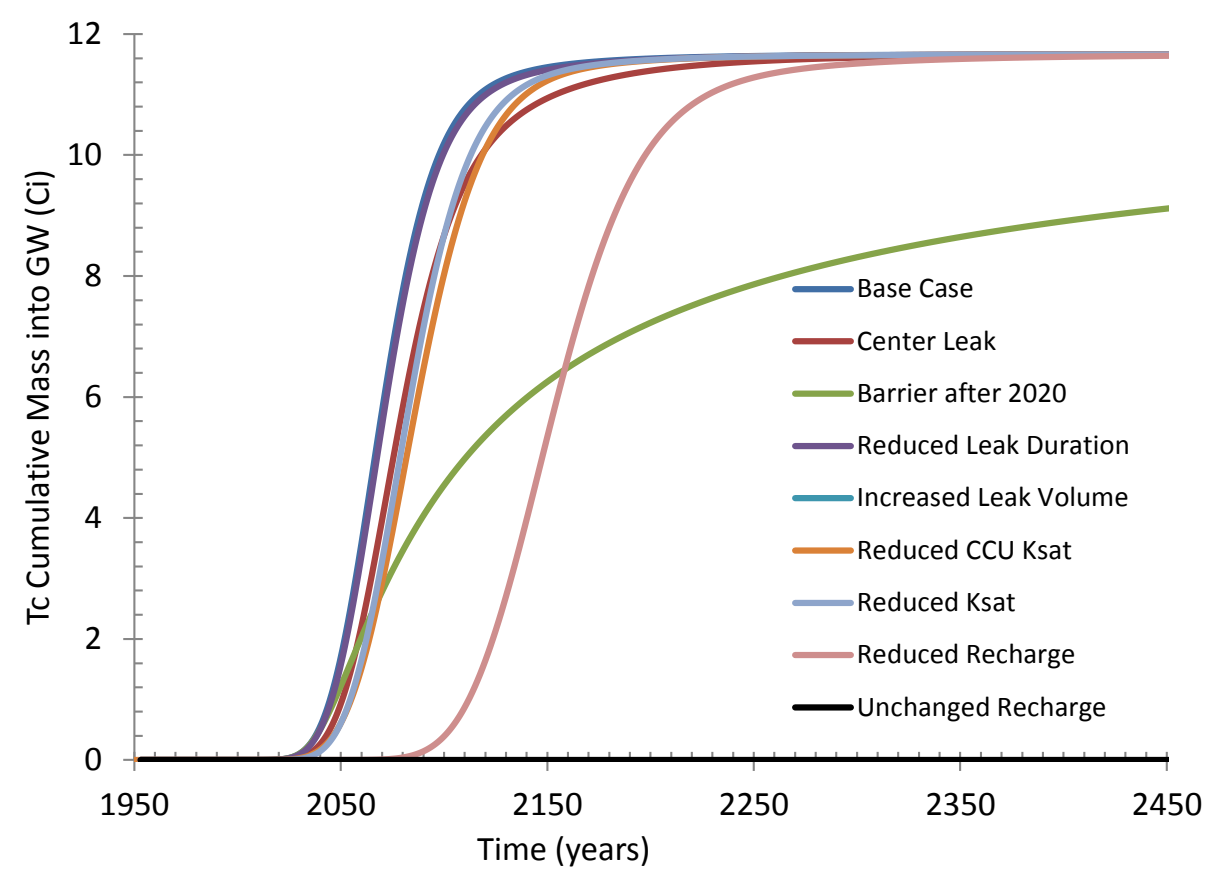

Figure 4.19. Tc-99 cumulative mass discharge (Ci) into groundwater for the SX-108 simulations over the period 1953-2450.

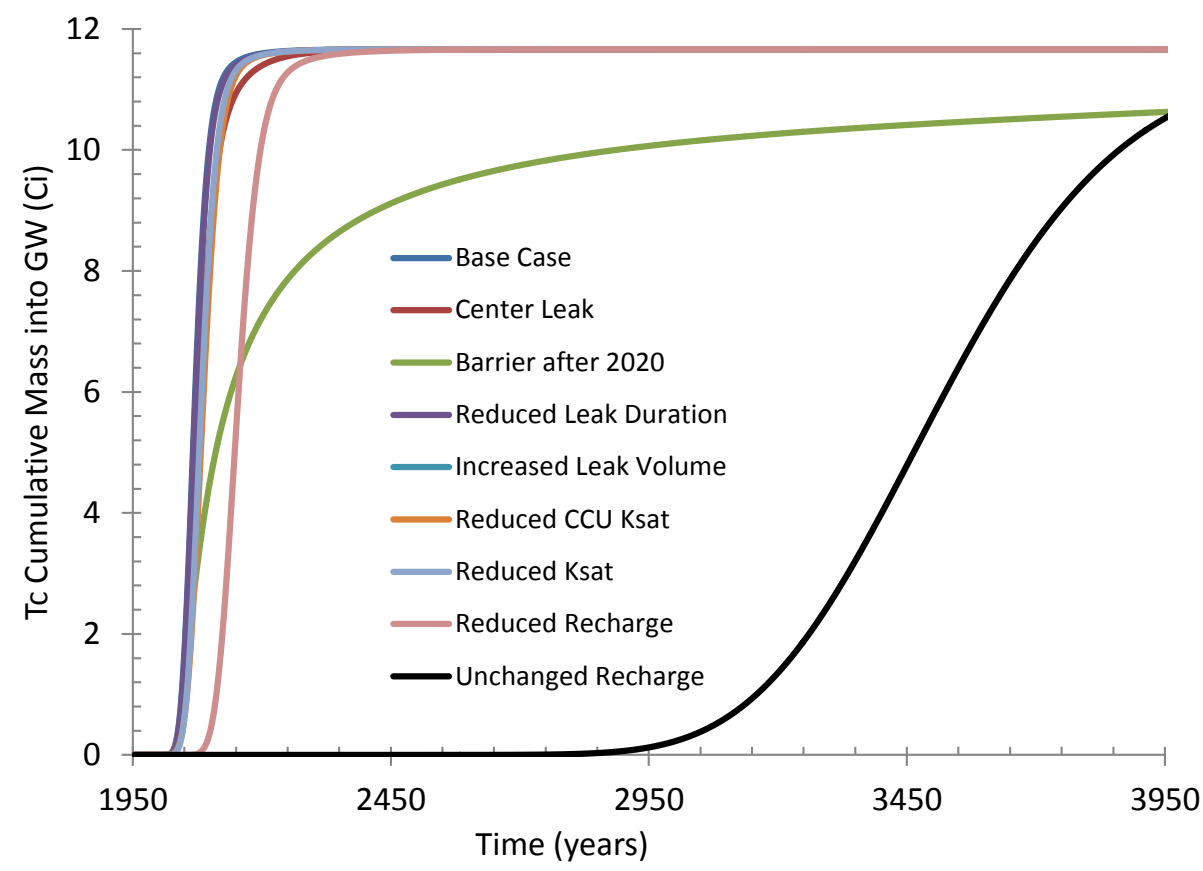

Figure 4.20. Tc-99 cumulative mass discharge (Ci) into groundwater for the SX-108 simulations over the period 1953-3950. 


\subsection{Estimation of Tc-99 Contaminant Flux into Groundwater}

In this section, Tc-99 contaminant mass fluxes resulting from SX Tank Farm simulations are presented for the cases listed in. In addition, predictions are computed for well concentrations and predicted trends are compared with field observations. First, the results of the Base Case model are presented, followed by a discussion of the effects of a suspected water-line leak south of the SX-115, emplacing a barrier, and a reduced permeability of the CCU.

\subsubsection{Base Case Model}

Flow and transport in the subsurface of the SX Tank Farm for the Base Case are illustrated using transects through the SX-115-114-113 tank sequence. The transect selection for this demonstration allows for a comparison of plots with those obtained using results from the Water Line Leak simulation (Section 4.2.2) and the Water Line Leak with Barrier simulation (Section 4.2.3). In addition, the two wells where considerable Tc-99 concentrations have been measured, W22-46 and W22-50 (Figure 2.14 and Figure 2.16), are located downstream of this tank sequence at the east side of the tank farm fence.

For each of the three tanks, contaminant leaks have been documented (Appendix B). The SX-113 tank released $1.44 \mathrm{Ci}$ of Tc-99 in 56,800 L liquid waste from the bottom center over 12 days between November 2 and November 14, 1962. In the period from February 24 to March 8, 5.12 Ci were leaked from the southwest edge of the SX-115 tank bottom in 193,000 L of liquid waste. A relative small amount $(0.163 \mathrm{Ci})$ originated from the southern sidewall of the SX-114 tank in 7,570 L of waste solution between July 10 and August 31, 1972. The total released activity for this sequence was therefore $6.72 \mathrm{Ci}$. To put this amount into context, recall that the mass released from the SX-108 tank only was $11.6 \mathrm{Ci}$.

The initial water-saturation levels are shown in Figure 4.21. The saturation distribution above the water table is similar to the one obtained for the distribution in the local SX-108 domain (Figure 4.1). The water saturations at the end of the SX-113 tank leak in 1962 are presented in Figure 4.22 and the associated Tc-99 concentrations in Figure 4.23. In 1965, after the SX-115 tank leak, water migration away from the leak location below the SX-113 tank has already substantially reduced the water saturations (Figure 4.24). The initial increase in water saturation below the SX-115 tank is also visible in this figure. The Tc-99 concentration plot after the SX-115 leak (Figure 4.25) shows a laterally and vertically growing plume below the SX-113 tank and a rather small contaminated zone below the SX-115 tank. The appearance of the water saturation and contaminant distribution is a strong function of the transect location in relation to where the actual leaks occurred. To illustrate this, water saturations and Tc-99 concentrations are shown in Figure 4.26 and Figure 4.27, respectively, for the vertical transect through the SX-115 leak location, 8 m south of the tank centers. Compared to Figure 4.24, showing saturations for a transect through the tank centers, the zone with elevated water saturations is much larger, as is the contaminant plume size. In contrast, the contaminant plume below the SX-113 tank is much smaller than in Figure 4.25 because that particular leak originated at the bottom center of the tank. No plots are presented demonstrating the leak below the SX-114 tank because the leak size was too small to show any meaningful changes.

Water-saturation levels in 1980 are shown in Figure 4.28. Compared to the end of the 1965 leak (Figure 4.24), no water-saturation effects from the SX-115 leak are visible anymore at this time and the infiltrating recharge water has arrived near the H2-CCUz interface. Tc-99 concentrations for both 
transects are shown in Figure 4.29 and Figure 4.30, demonstrating a downward extension that is already smaller than the vertical extent of the surface infiltration water in Figure 4.28. The plume below the center of the SX-113 tank is migrating relatively slowly because the contaminant was leaked in 1962 within a relatively small leak volume. As a result, the initial plume after the leak was narrow and was most protected from downward migration recharge water. Through diffusion, the contaminant moves out laterally over time and is picked up by downward-moving recharge water when it is transported close enough to the edge of the tank.

In 2014, steady-state flow conditions have been obtained (Figure 4.31). At that time, the contaminant plume from the SX-113 tank is still mostly symmetric and has migrated to within the CCUz unit (Figure 4.32). The information provided in Figure 4.32 and Figure 4.33 show that SX-115 plume is not symmetric and that the lower plume has arrived in the upper Ringold sediment. The asymmetric shape is associated with how the recharge water has interacted with the plume over time. The plume development process for this tank is similar to the SX-108 tank and is described in the previous section. As is shown by the water saturation (Figure 4.34) and contaminant distributions in Figure 4.35 and Figure 4.36, both unsaturated contaminant plumes have mostly disappeared by the year 2100, with some contaminant left between the center of the tank bottoms and the water table. In practical terms, the plume development over time for the SX-115 tank in this Base Case simulation is similar to what was observed for the local SX-108 Base Case simulation. The main reasons for the similarity in behavior are the identical relative leak locations and comparable leak volumes.

A qualitative analysis of fluxes and concentrations at observation wells is provided in Figure 4.37 through Figure 4.40. Figure 4.37 shows the groundwater recharge rate for the whole SX Tank Farm, indicating that at the water table, the groundwater recharge rate changed from 3.5 to $92 \mathrm{~mm} / \mathrm{yr}$ between 2000 and 2007. For a condition with the higher surface recharge initiated in 1953, it took about 54 years for the new steady-state conditions to establish in the unsaturated zone. The Tc-99 fluxes into the groundwater from each of the leaking tanks are shown in Figure 4.38. The plots show that for all tanks, most of the contaminants are predicted to migrate to the groundwater between approximately 2020 and 2150, with some notable tailing afterwards. For the tanks with the largest released activity (SX-107, -108, 112, and -115) the maximum fluxes are obtained between 2065 and 2085. It can be concluded that although the absolute flux numbers might differ, the general flux behavior for these tanks is quite similar. The cumulative mass discharge, presented in Figure 4.39, confirms that the vast majority (>95\%) of the leak contaminant has migrated into the groundwater by 2150 . For all tanks, the released activity from the leaks is transported into the groundwater within $0.0001 \%$ during the simulation, which lasted 10,000 years. This low percentage indicates an excellent numerical mass balance for a non-sorbing component like Tc-99.

Predicted well concentrations over time are shown in Figure 4.40. For W23-19, located inside the tank farm fence just a few meters from the SX-115 tank, Tc-99 is predicted to arrive in approximately 2020. This arrival time is considerably later than indicated by field observations (Figure 2.12). The contaminant arriving at wells W22-46 and W22-50, located downstream of the SX-115-114-113 tank sequence, is primarily originating from the SX-115 tank and the breakthrough behavior at these two wells also indicate that the bulk of the Tc-99 arrives after 2020. However, for both the W22-46 and W22-50, field observations show that contaminant is already arriving at these locations (Figure 2.14 and Figure 2.16). Because the majority of the contaminant arriving at the wells comes from the SX-115 tank, it can 
be concluded vadose zone transport for the Base Case simulation is not fast enough below this tank. The scoping study presented in Section 4.1 for the SX-108 tank has showed that reasonable variations in leak volumes, duration, and location likely cannot be used to sufficiently increase vadose zone contaminant transport to hasten arrival times at these wells. For that to occur, another feature, not directly related to the tanks, has to be responsible. In the next section, the effect of a water-line leak on transport below the SX-115 tank is discussed.

In Figure 4.40, the largest predicted concentrations are in well W22-39 located downstream of the SX-108 tank, which had the largest released activity. Well W22-49 is downstream of the SX-112 tank, explaining the relatively high predicted contaminant concentrations in the future. For both the W22-39 and W22-49, the simulated concentration behavior to date is consistent with field observations (Figure 2.13 and Figure 2.15). The curves for the downstream wells show considerable tailing, which is the result of transverse mixing because these wells are not on the same streamlines in the groundwater directly downgradient from the major leakers.
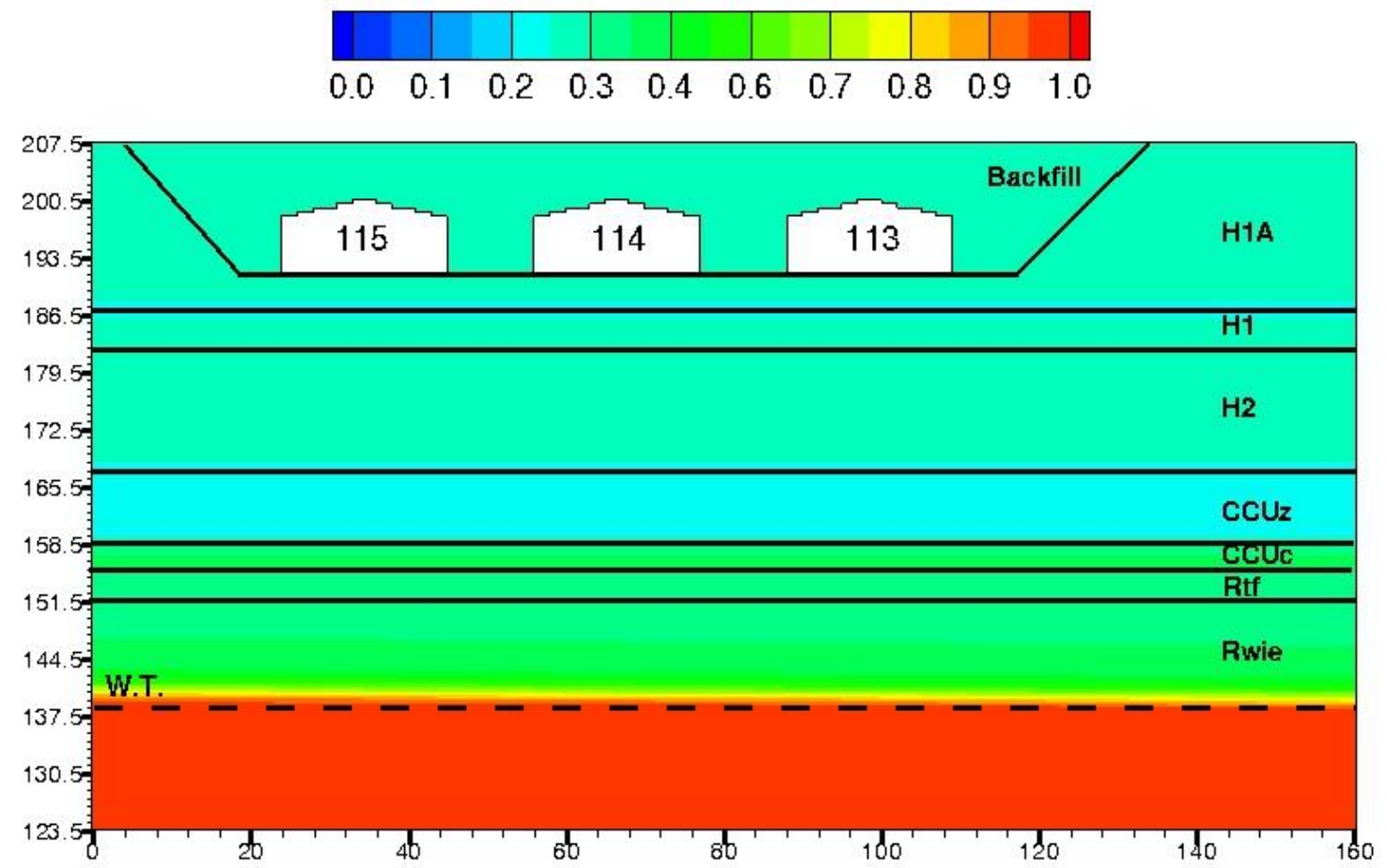

Figure 4.21. Aqueous saturation in 1953 for the Base Case simulation (transect through tank centers). 

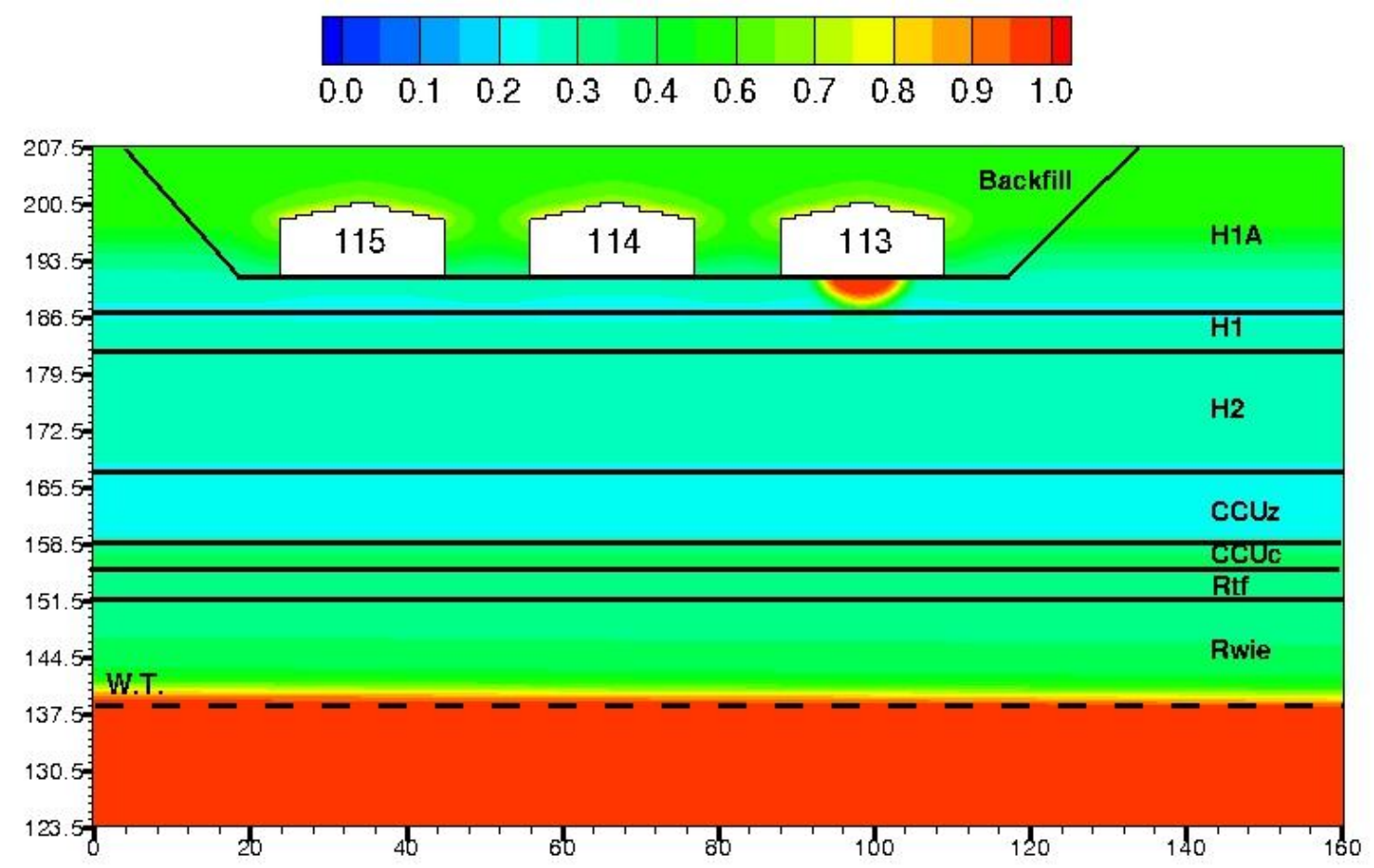

Figure 4.22. Aqueous saturation at of the SX-113 leak in 1962 for the Base Case simulation (transect through tank centers).

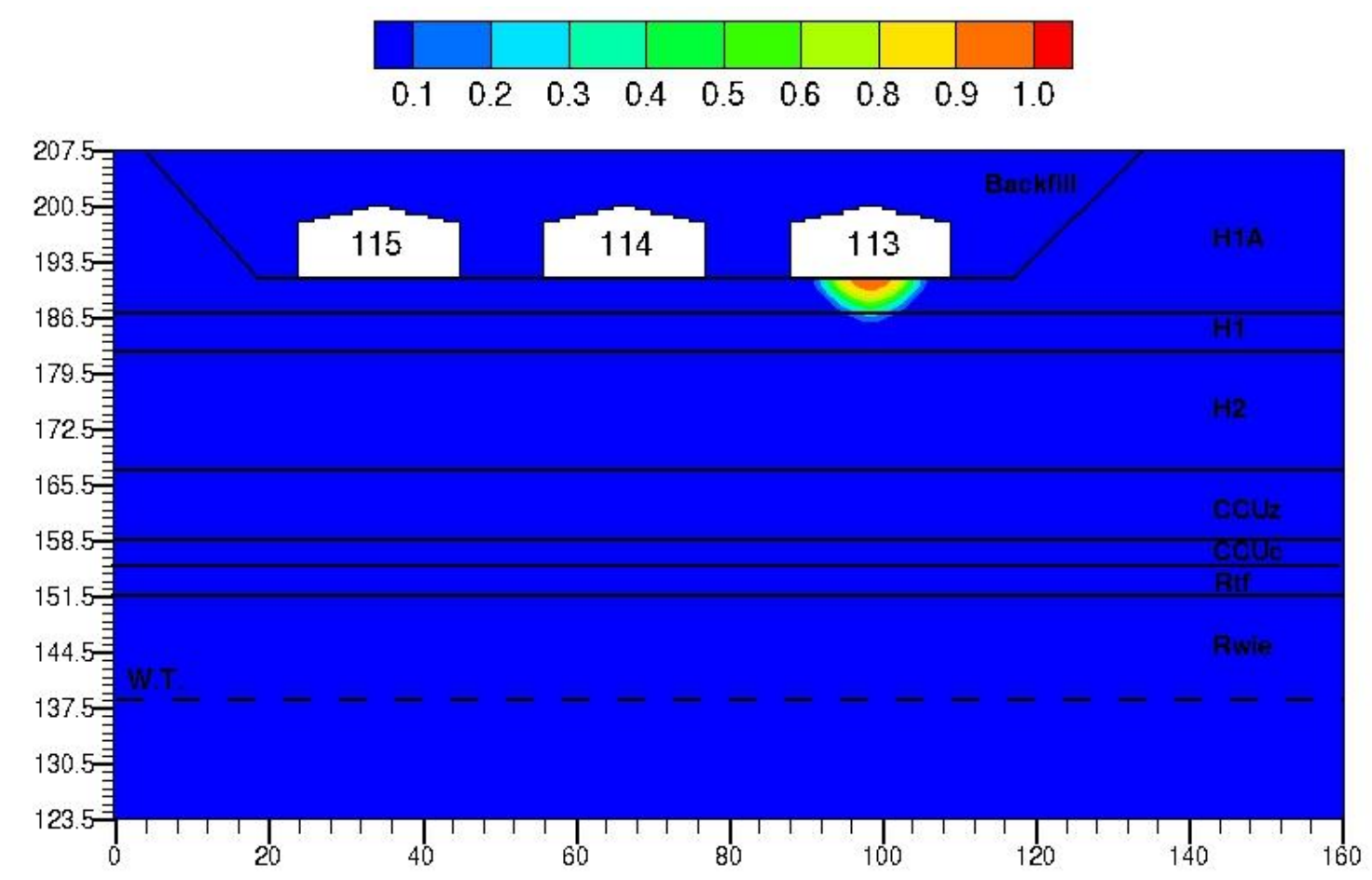

Figure 4.23. Dimensionless Tc-99 concentration at the end of the SX-115 leak in 1962 for the Base Case simulation (transect through tank centers). 

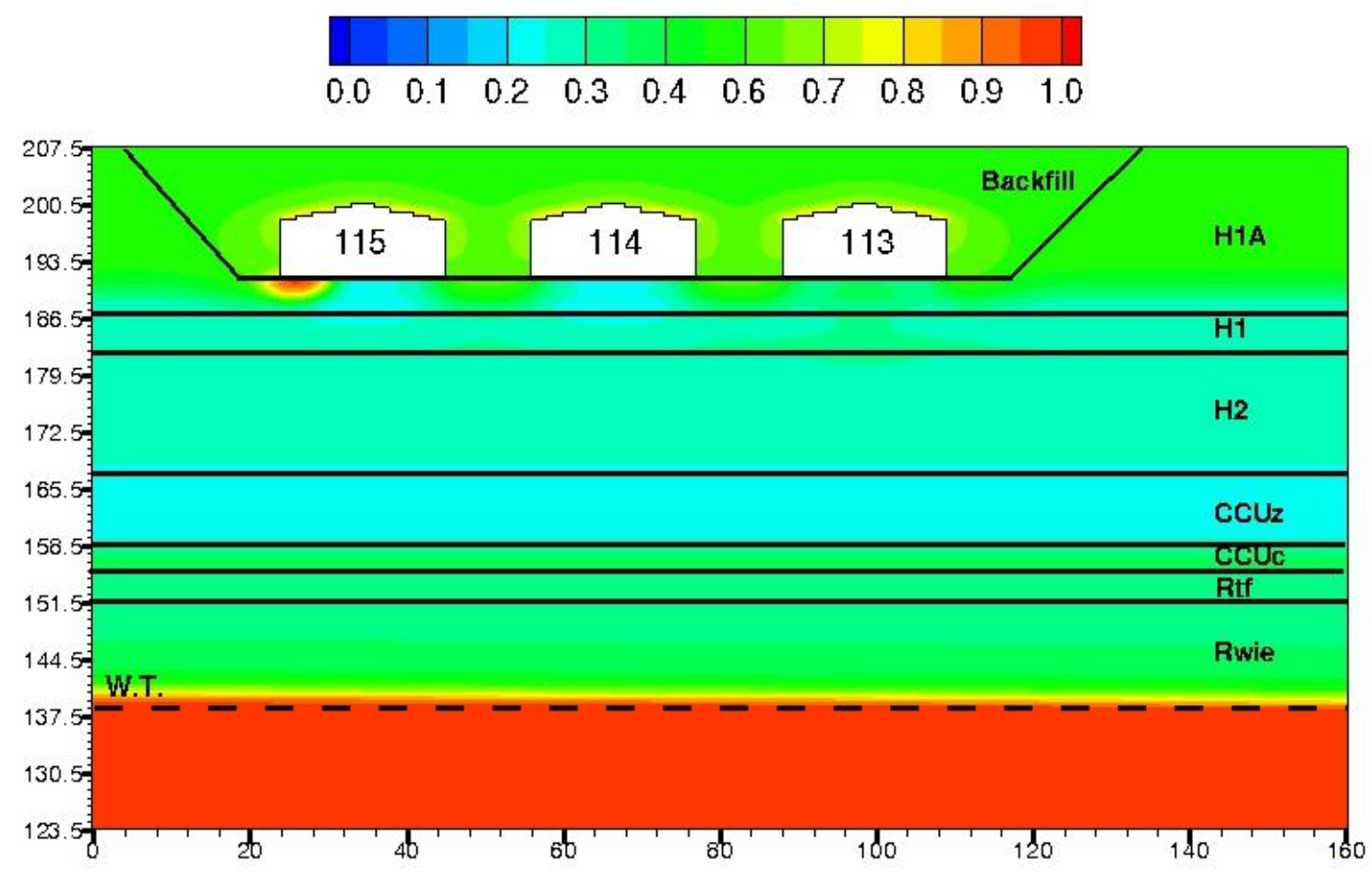

Figure 4.24. Aqueous saturation at the end of the SX-115 leak in 1965 for the Base Case simulation (transect through tank centers).
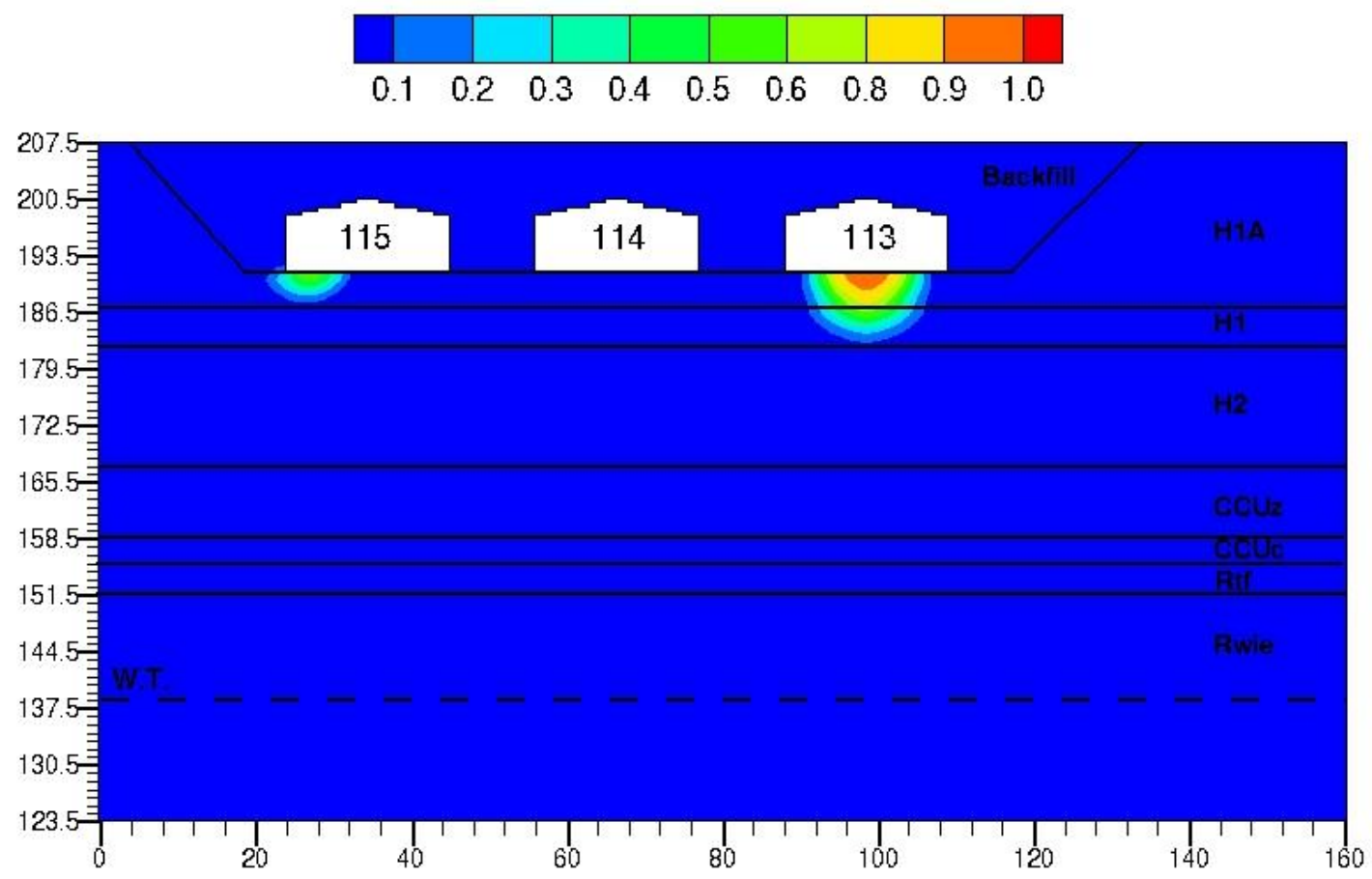

Figure 4.25. Dimensionless Tc-99 concentration at the end of the SX-115 leak in 1965 for the Base Case simulation (transect through tank centers). 

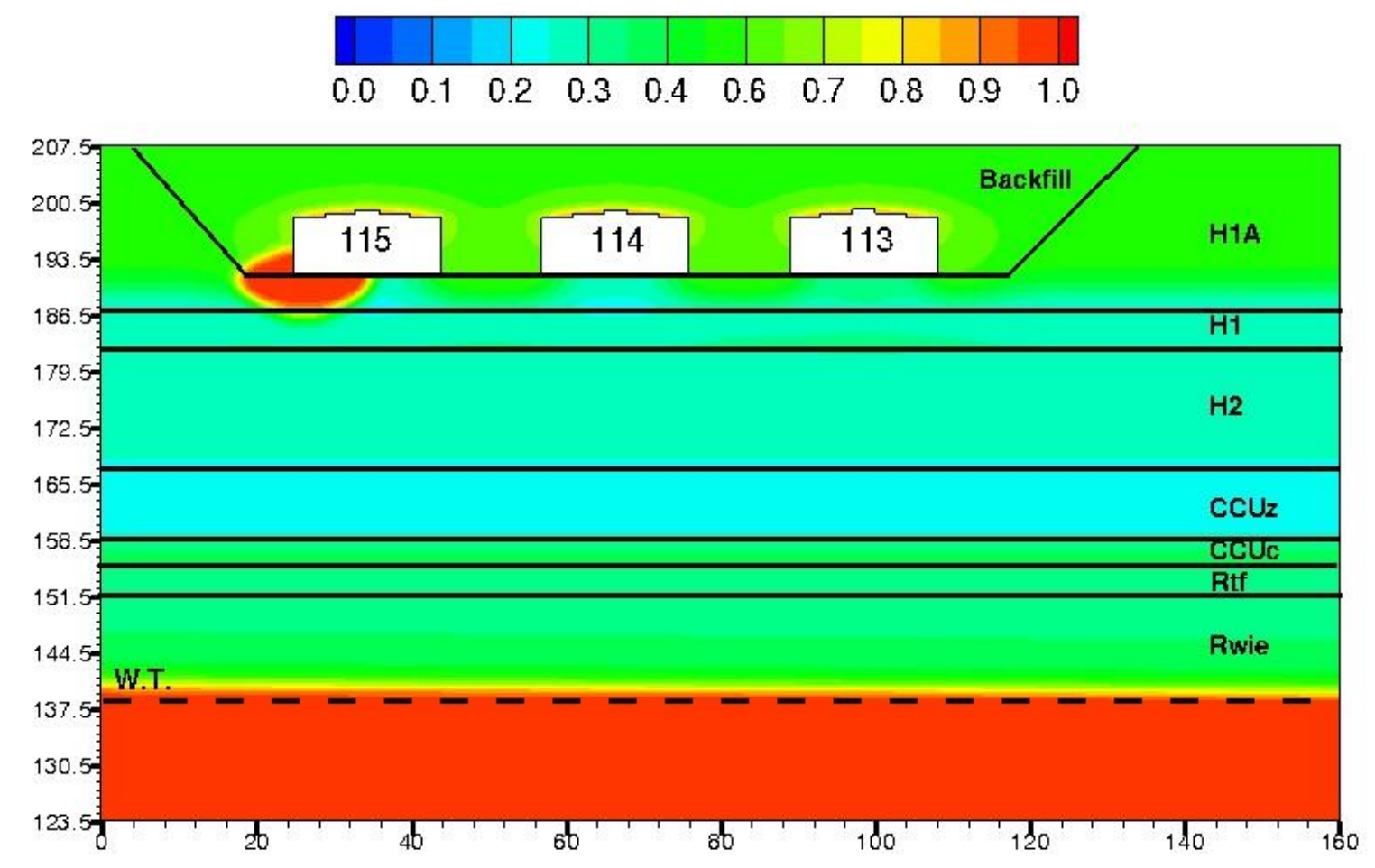

Figure 4.26 Aqueous saturation at the end of the SX-115 leak in 1965 for the Base Case simulation (transect $8 \mathrm{~m}$ south of tank centers).
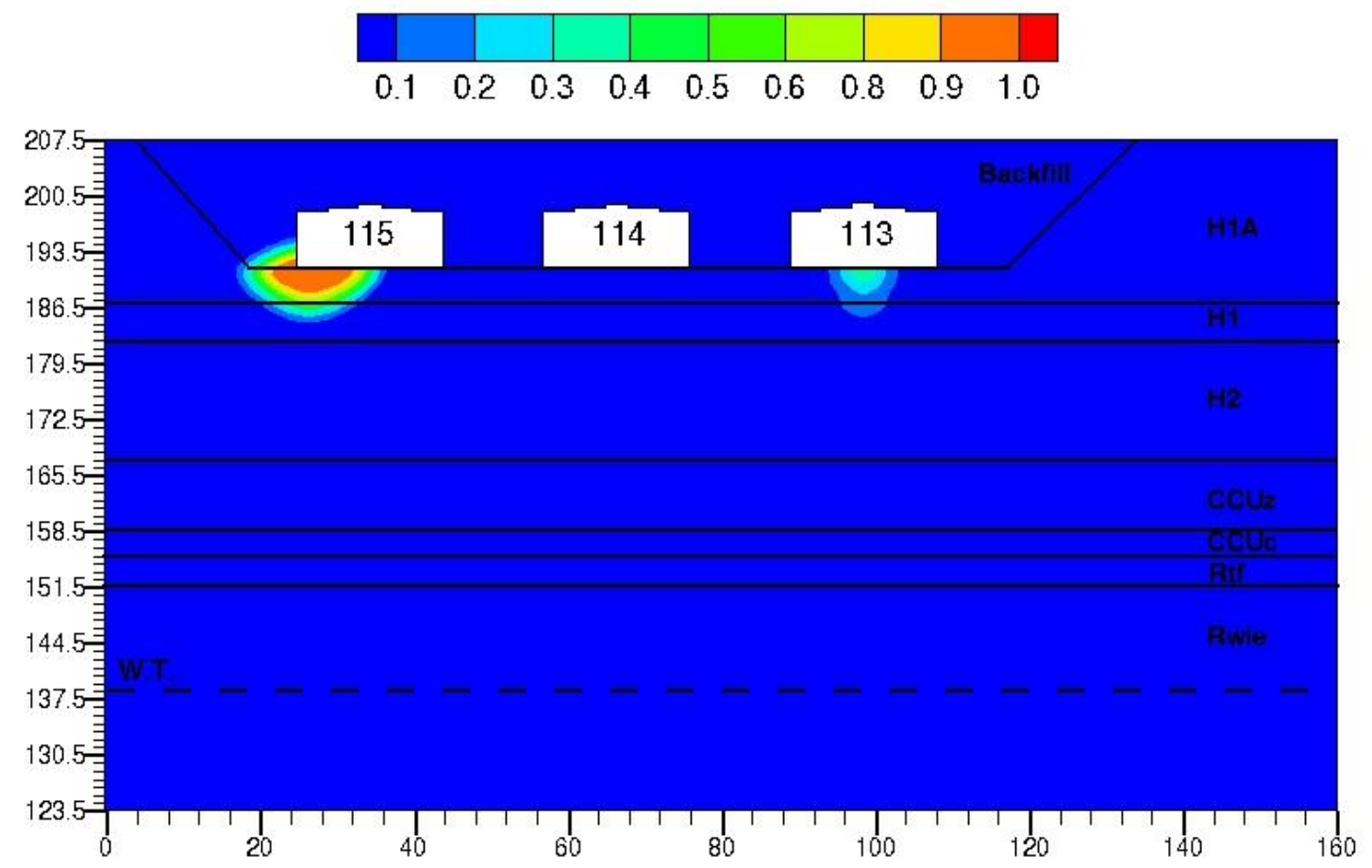

Figure 4.27. Dimensionless Tc-99 concentration at the end of the SX-115 leak in 1967 for the Base Case simulation (transect $8 \mathrm{~m}$ south of tank centers). 

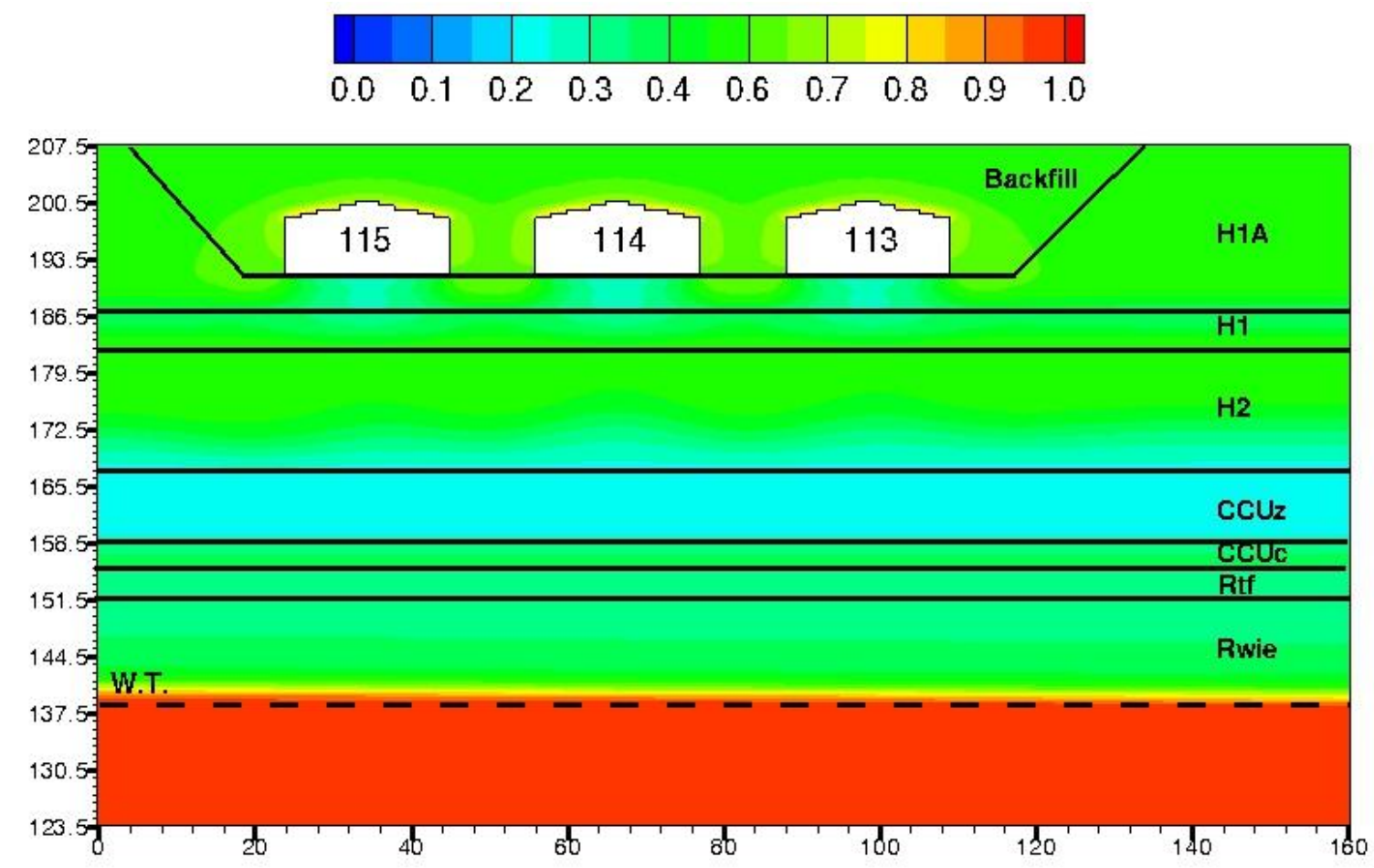

Figure 4.28. Aqueous saturation in 1980 for the Base Case simulation (transect through tank centers).
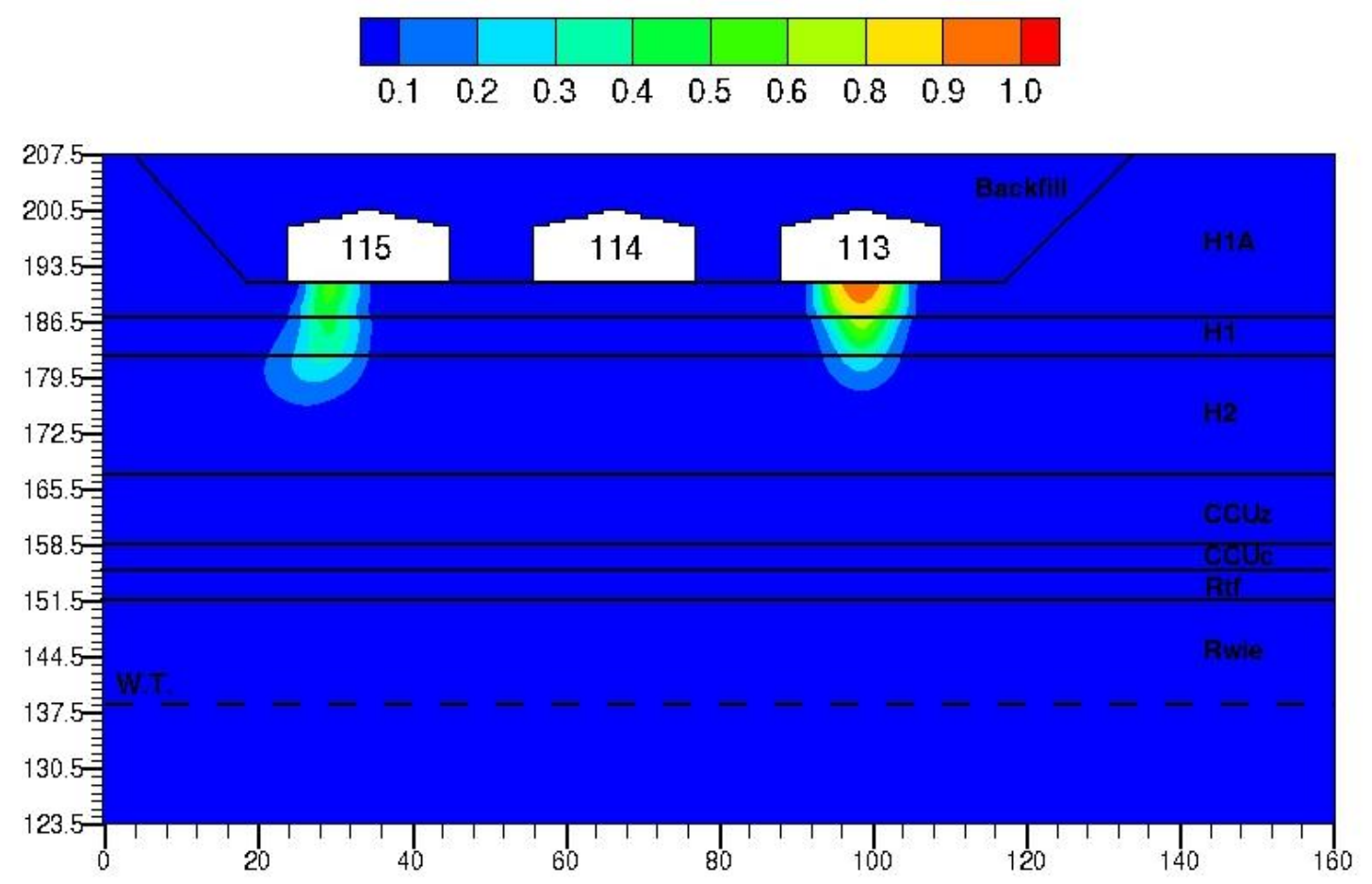

Figure 4.29. Dimensionless Tc-99 concentration in 1980 for the Base Case simulation (transect through tank centers). 

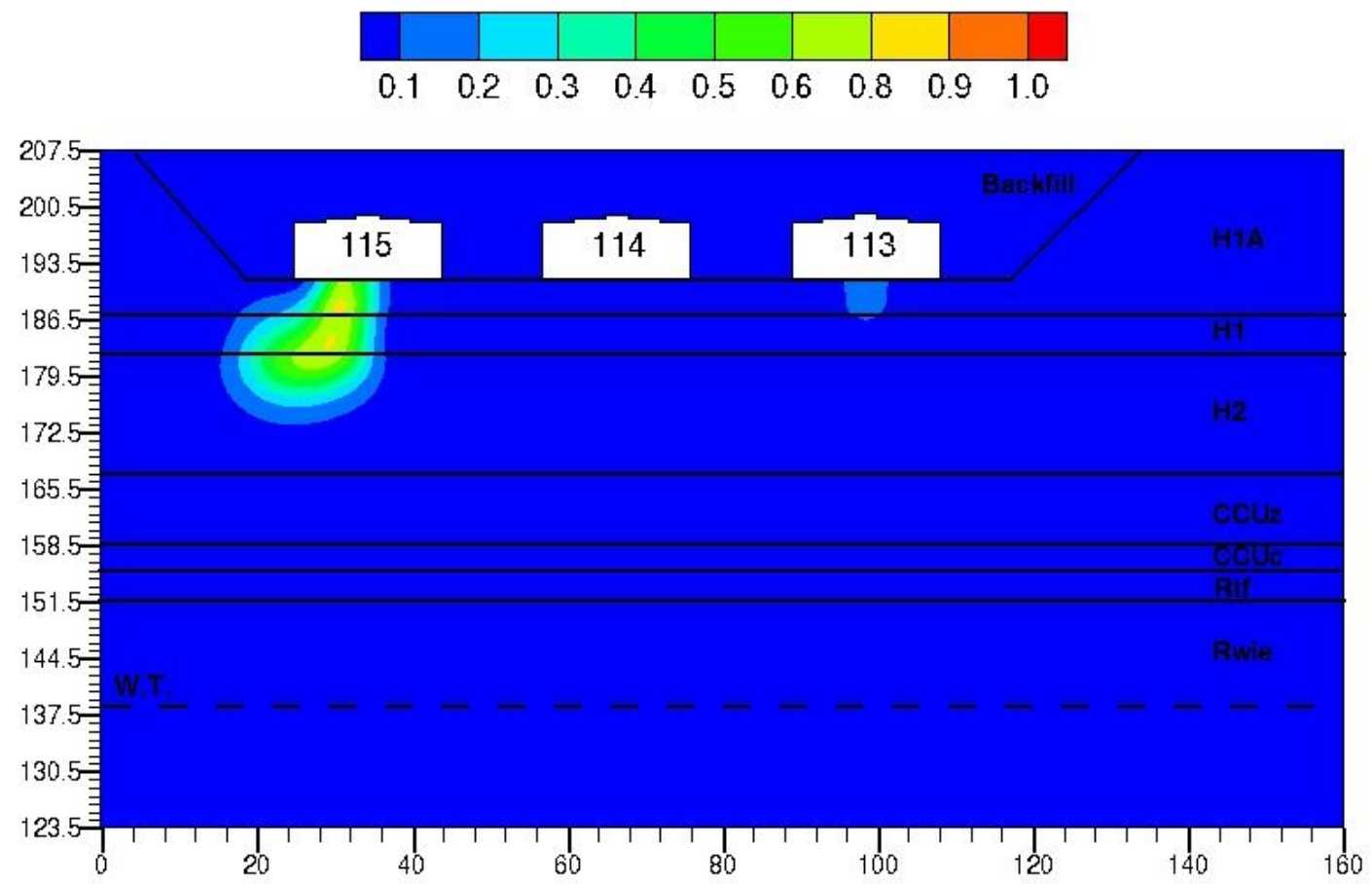

Figure 4.30. Dimensionless Tc-99 concentration in 1980 for the Base Case simulation (transect $8 \mathrm{~m}$ south of tank centers).
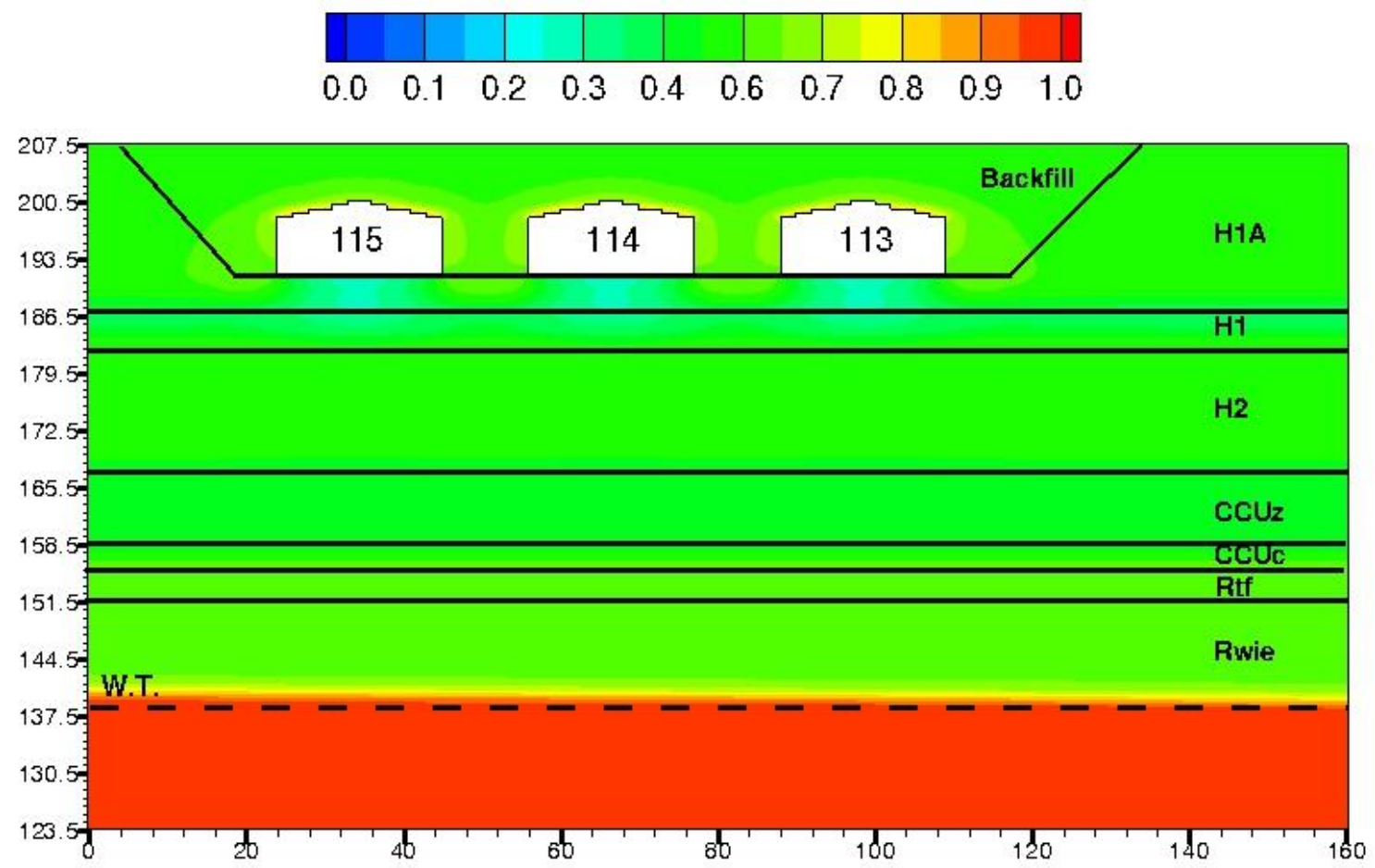

Figure 4.31. Aqueous saturation in 2014 for the Base Case simulation (transect through tank centers). 

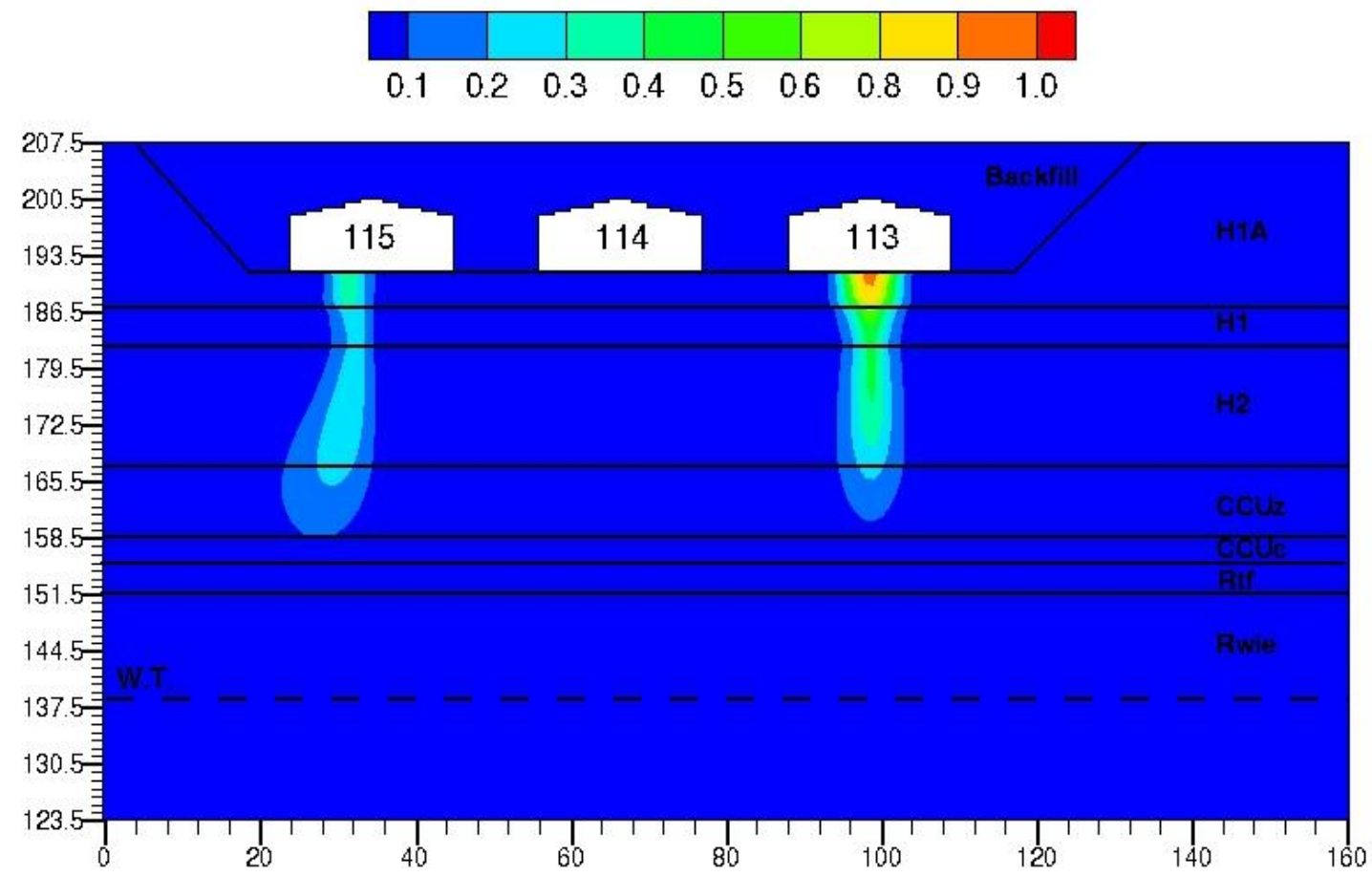

Figure 4.32. Dimensionless Tc-99 concentration in 2014 for the Base Case simulation (transect through tank centers).
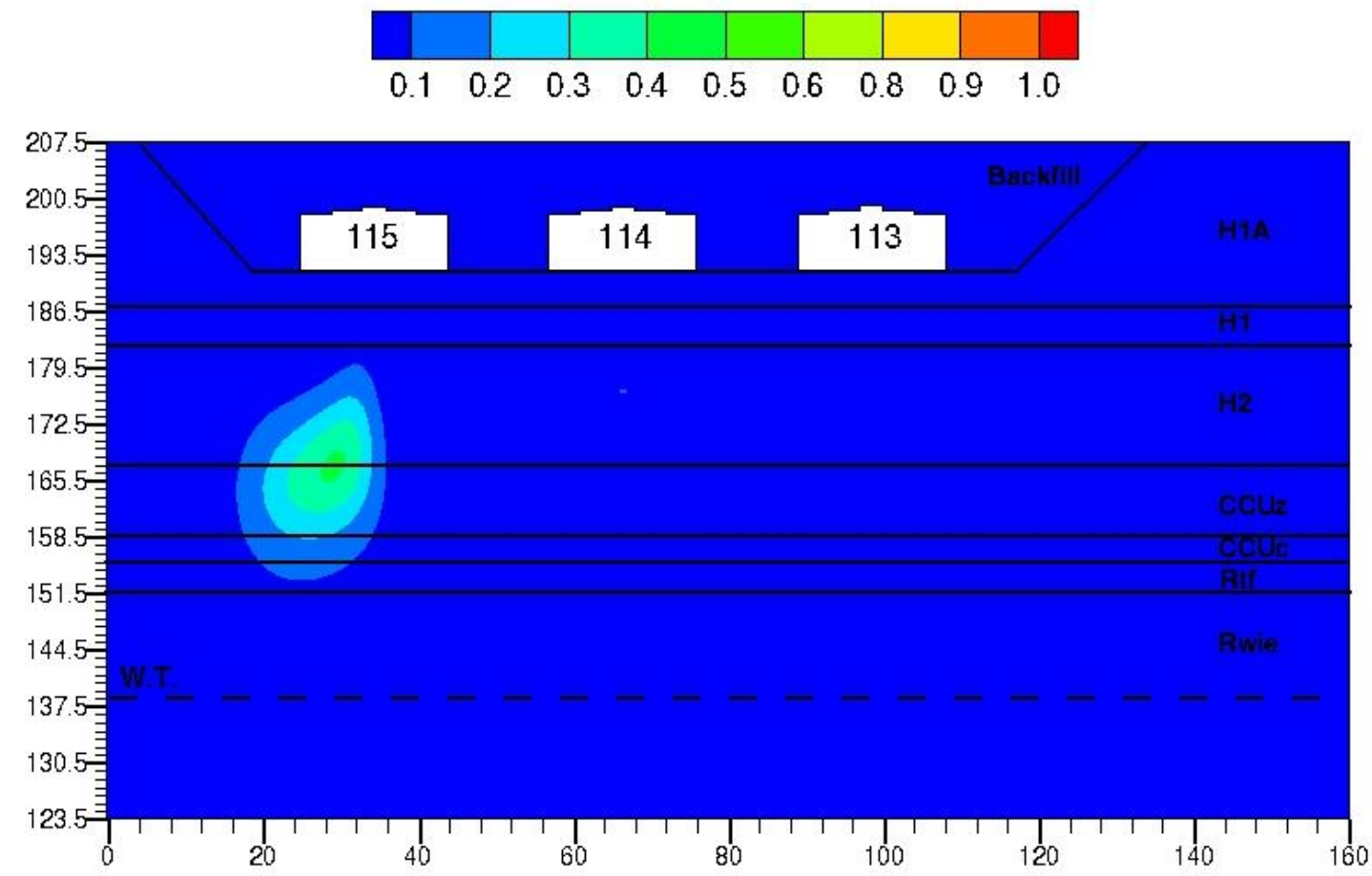

Figure 4.33. Dimensionless Tc-99 concentration in 2014 for the Base Case simulation (transect $8 \mathrm{~m}$ south of tank centers). 


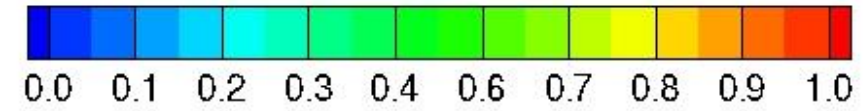

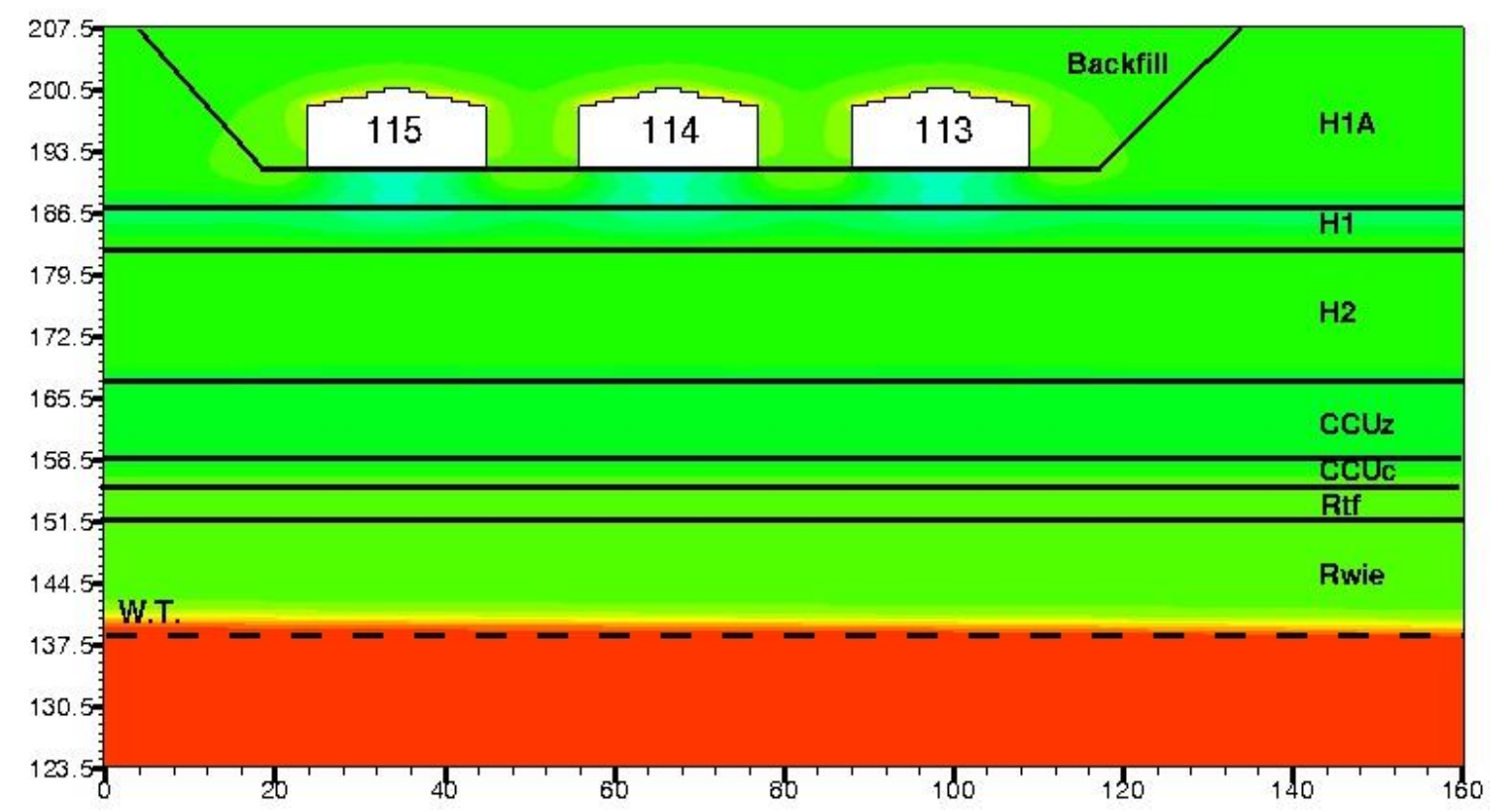

Figure 4.34. Aqueous saturation in 2100 for the Base Case simulation (transect through tank centers).

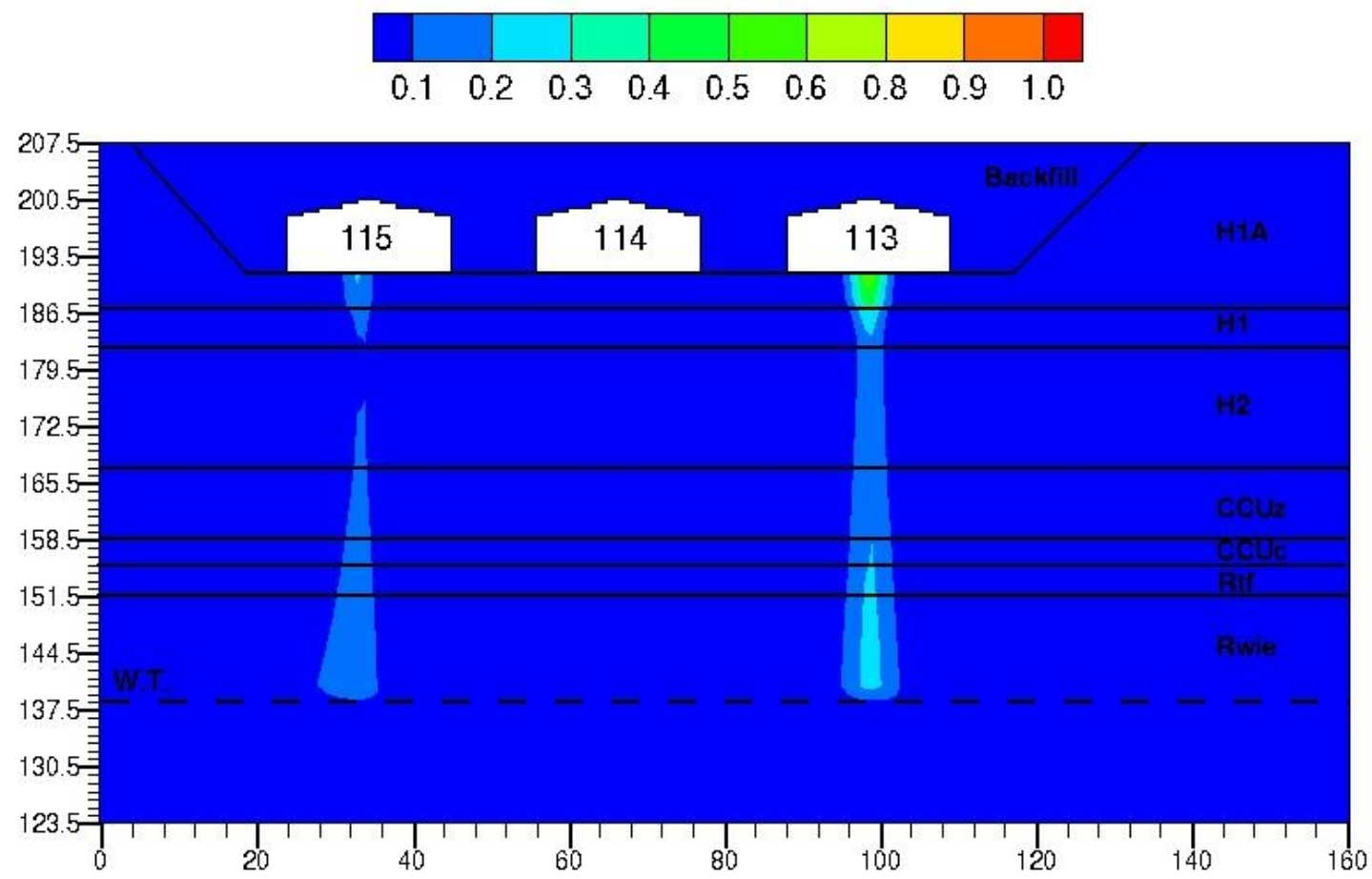

Figure 4.35. Dimensionless Tc-99 concentration in 2100 for the Base Case simulation (transect through tank centers). 

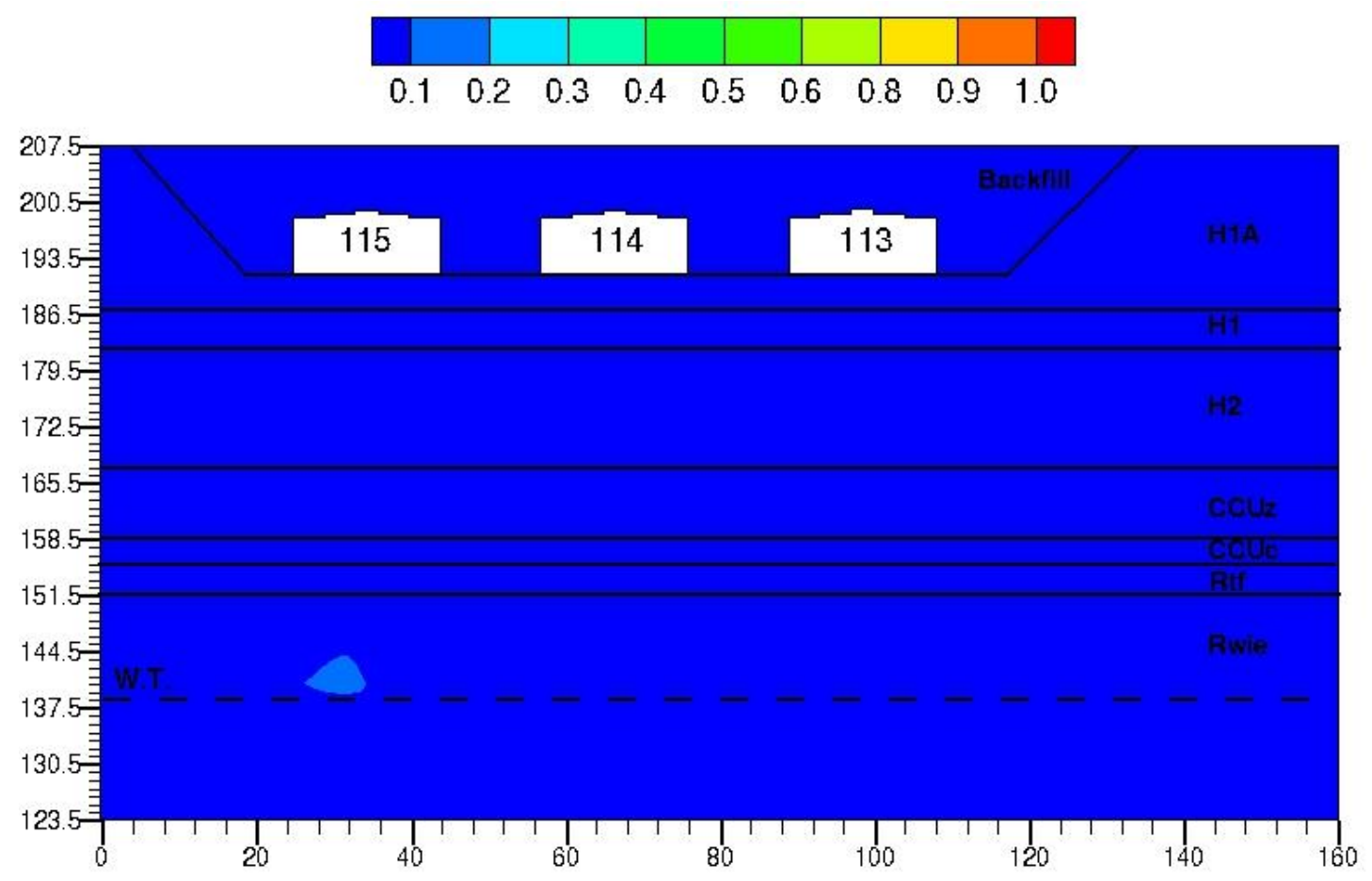

Figure 4.36. Dimensionless Tc-99 concentration in 2100 for the Base Case simulation (transect $8 \mathrm{~m}$ south of tank centers).

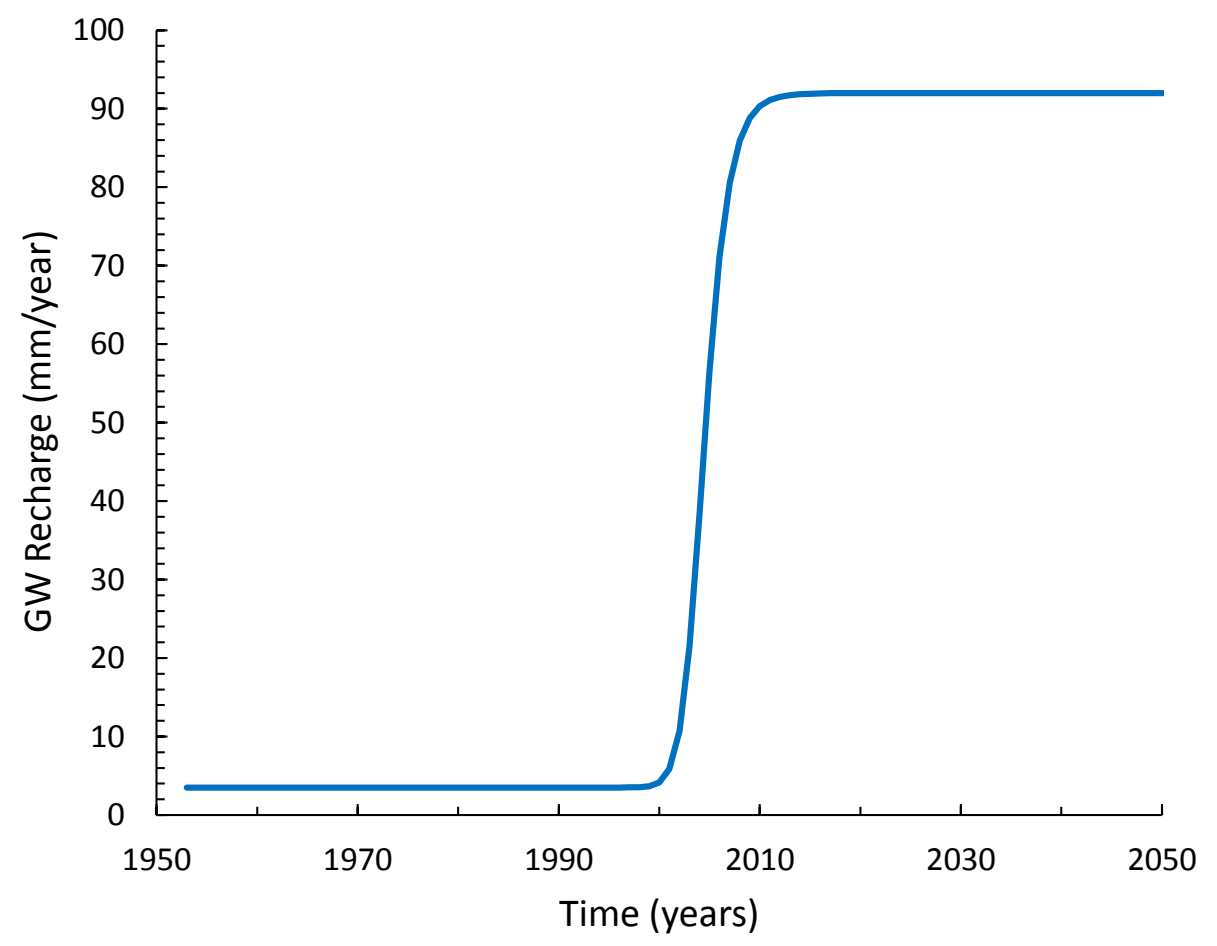

Figure 4.37. Groundwater recharge ( $\mathrm{mm} / \mathrm{yr})$ for the Base Case simulation. 


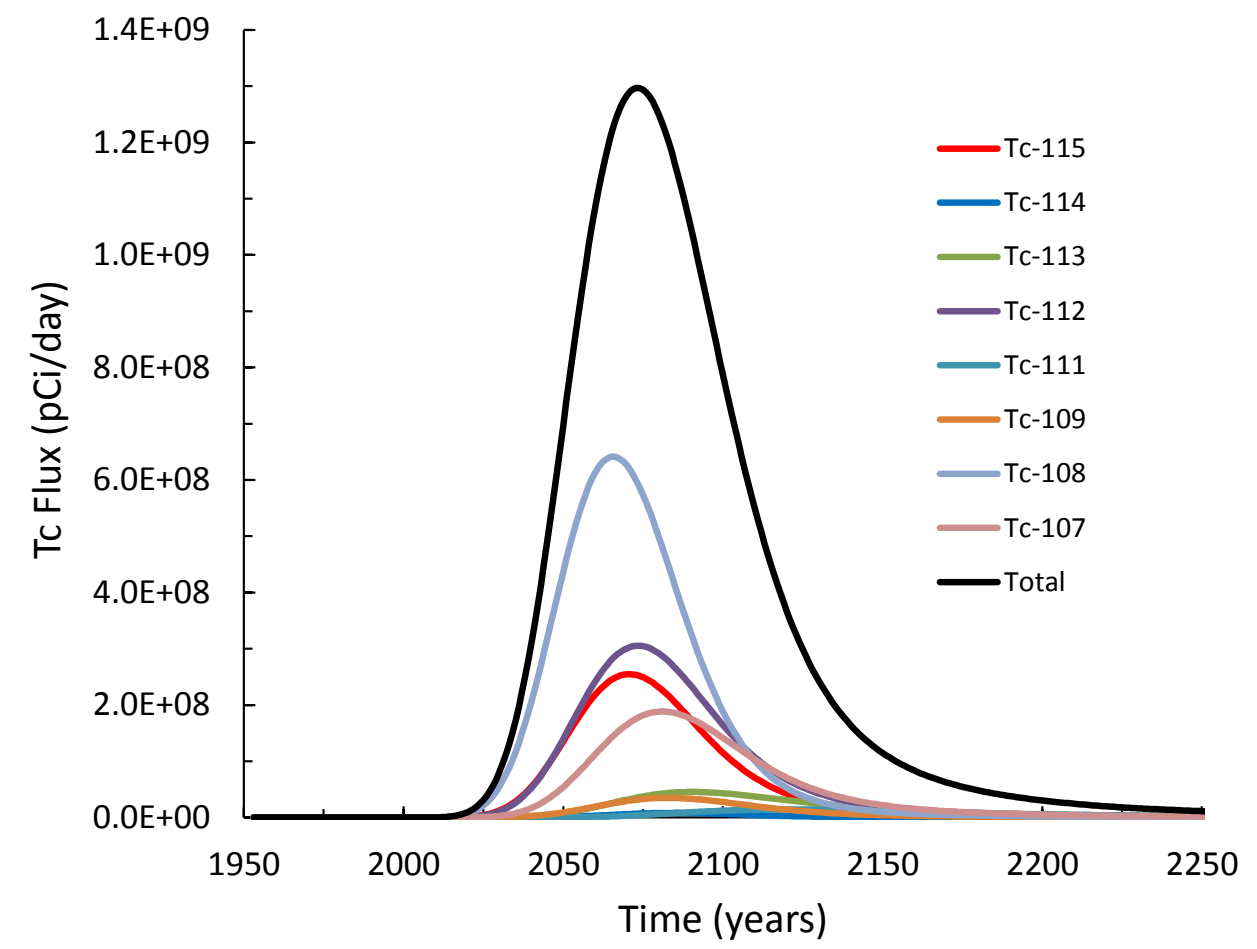

Figure 4.38. Tc-99 mass discharge (pCi/d) into groundwater for the Base Case simulation. The legend shows the SX tank numbers.

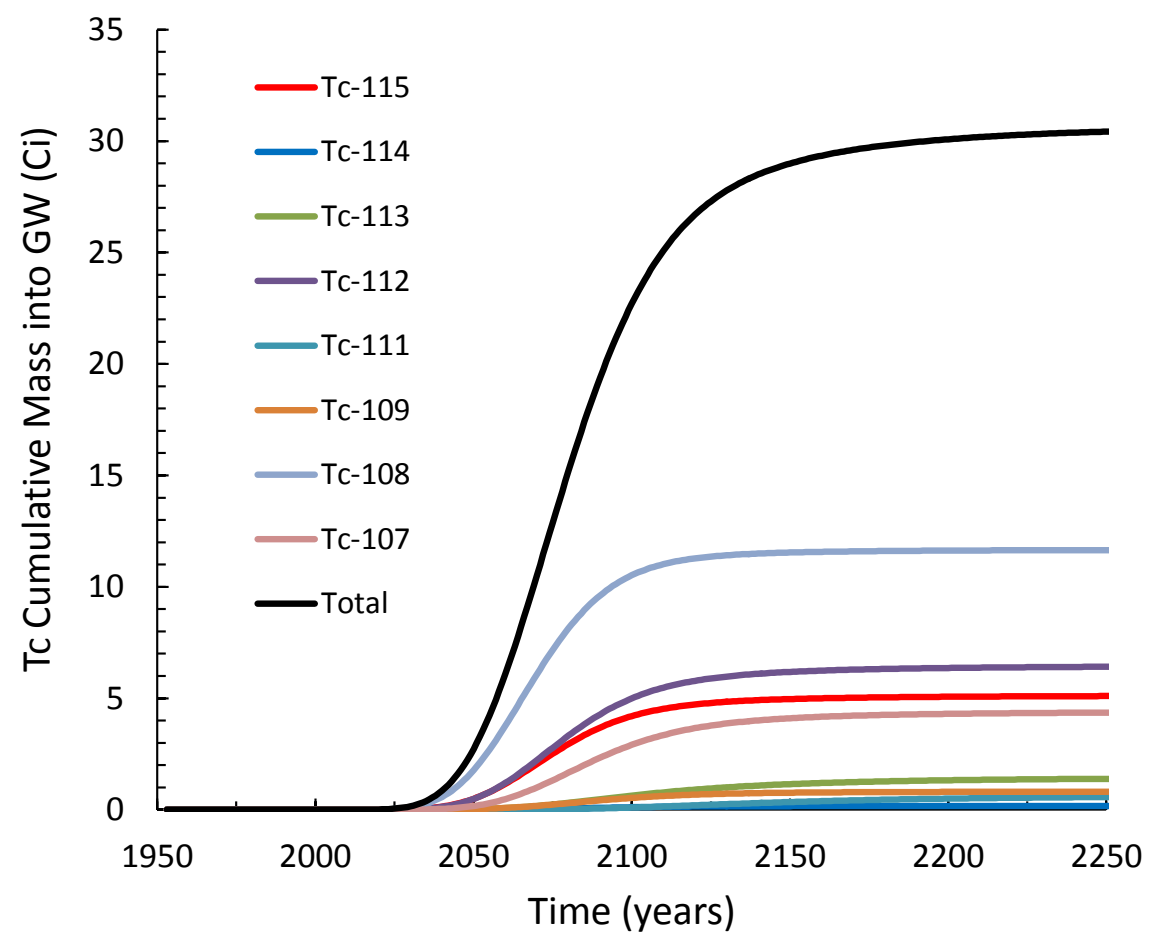

Figure 4.39. Tc-99 cumulative mass discharge (Ci) into groundwater for the Base Case simulation. 


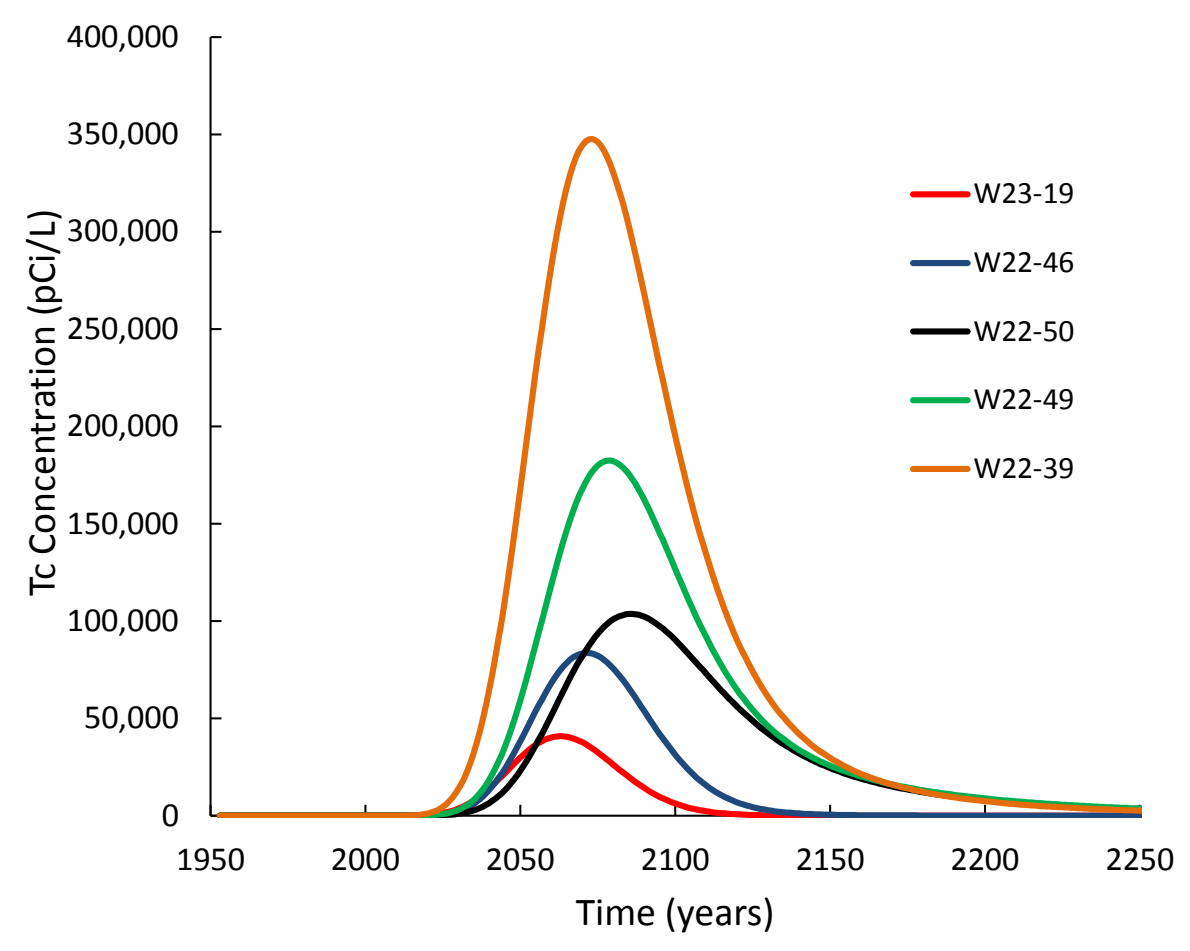

Figure 4.40. Tc-99 well concentrations for the Base Case simulation.

\subsubsection{Effects of Suspected Water Line Leak}

As shown in the previous section, the Base Case simulation clearly overestimates contaminant arrival times (i.e., predicts a slower arrival than has been observed) at the W22-50 and W22-46 wells. It was suggested by, among others, Johnson and Chou (2002) that a substantial water-line leak, located about 15 $\mathrm{m}$ south of the SX-115 tank, could be responsible for an accelerated contaminant migration to the water table and subsequently to the observation wells. Although no direct evidence of such a leak has been presented, a cottonwood tree is located at the suspected leak site (Figure 3.3) where the water lines were removed in 2001. Scoping simulations were first conducted to investigate the water-line leak rate and duration necessary to alter the predicted contaminant arrival times to be consistent with the well observations. The results of these simulations showed that an order of magnitude leak rate of 1,000 L/d over a 40-year period was needed to obtain a match between field data and numerically obtained arrival times.

Using the 1,000 L/d rate and leak duration from 1961-2001, a Water Line Leak simulation (Table 3.3) was conducted. Water saturation and Tc-99 concentration plots for this simulation are shown in Figure 4.41 through Figure 4.45. The effect of the water-line leak is already visible in 1965 (Figure 4.41) with elevated water saturations in the H1 and upper part of the H2. In 1980, after the water-line leak has occurred for 19 years, increases in water saturations are visible over the H2 and CCUs below the SX-115 tank. In 2000 (Figure 4.43) elevated water saturations are observed under the SX-115 tank all the way to the groundwater. In addition, increased water saturations were predicted to occur over the total west-east length of the CCUz unit. The accelerated contaminant movement is illustrated by comparing the 1980 plumes in Figure 4.35 and Figure 4.30 for the Base Case. At this point in time, the plume for the Water Line Leak simulation has migrated to the top of the $\mathrm{CCUz}$, while the Base Case plume has only migrated 
halfway down the $\mathrm{H} 2$ layer. In 2000, the contaminant is clearly moving into the groundwater (Figure 4.45) in the Water Line Leak scenario.

The quantitative aspects of a water-line leak on fluxes into the groundwater are presented in Figure 4.46 through Figure 4.51. As can be seen in Figure 4.46, the 1,000 L/d leak has a large influence on the tank farm averaged groundwater recharge within the model domain used for the $115,114,113$ Sequence model simulations, with a first arrival just after 1970 and a sustained effect until about 2020, although the leak was removed in 2001. The time-integrated area between the two curves equals the total water-line leak volume within $0.001 \%$ and is an indication of the excellent mass balance the STOMP simulator is able to achieve.

Figure 4.47 illustrates that the influence of the water-line leak on contaminant fluxes to groundwater is limited to the SX-115 tank. For the other tanks in this sequence (SX-114 and SX-113) the Tc-99 fluxes to groundwater are not affected. The water-line leak also does not affect the groundwater mass flux originating from the SX-112 tank (a major leaker), which is located north of the SX-115 tank. The local nature of the water-line leak effect is also shown in Figure 4.48 and Figure 4.49, depicting the contaminant mass flux and cumulative mass, respectively, for the Water Line Leak simulation. Compared to the Base Case simulation (Figure 4.38 and Figure 4.39), only the SX-115 curves have shifted about 25 years, while all other curves are unaffected. The changes in groundwater flux behavior for Tc-99 that emanated from the SX-115 tank due to the water-line leak are causing earlier arrival times at the adjacent well W23-19 and the downstream wells W22-46 and W22-50 (Figure 4.50). For these three wells, the water-line leak caused considerable earlier contaminant arrival times that are more consistent with field observations (Figure 2.12, Figure 2.14, and Figure 2.16). The predicted concentrations at the observation wells W22-39 and W22-49 were not affected. To illustrate the sensitivity of the water-line leak configuration to some variables (e.g., reduced line length over which the leak occurred and a reduced leak period; Table 3.3), the mass flux to groundwater for these cases from Tc-99 originating from the SX-115 tank is shown in Figure 4.51. The figure shows that reducing the leak length has minimal influence on the mass flux profile. Reducing the leak period from 40 to 20 years (1981-2001 vs. 1961-2001) does have an effect on the predicted mass flux profile to groundwater, causing a delay in the mass flux. After 1980, the contaminant plume size has grown considerably and the associated concentrations have reduced to a level where added water from a local source has a limited effect on the contaminant mass flux to groundwater. The results in Figure 4.51 suggest that the local water-line leak at the site, which was removed in 2001, must have been releasing water well before 1980 to cause the mass fluxes that best correspond to the observed Tc-99 concentrations at wells. 

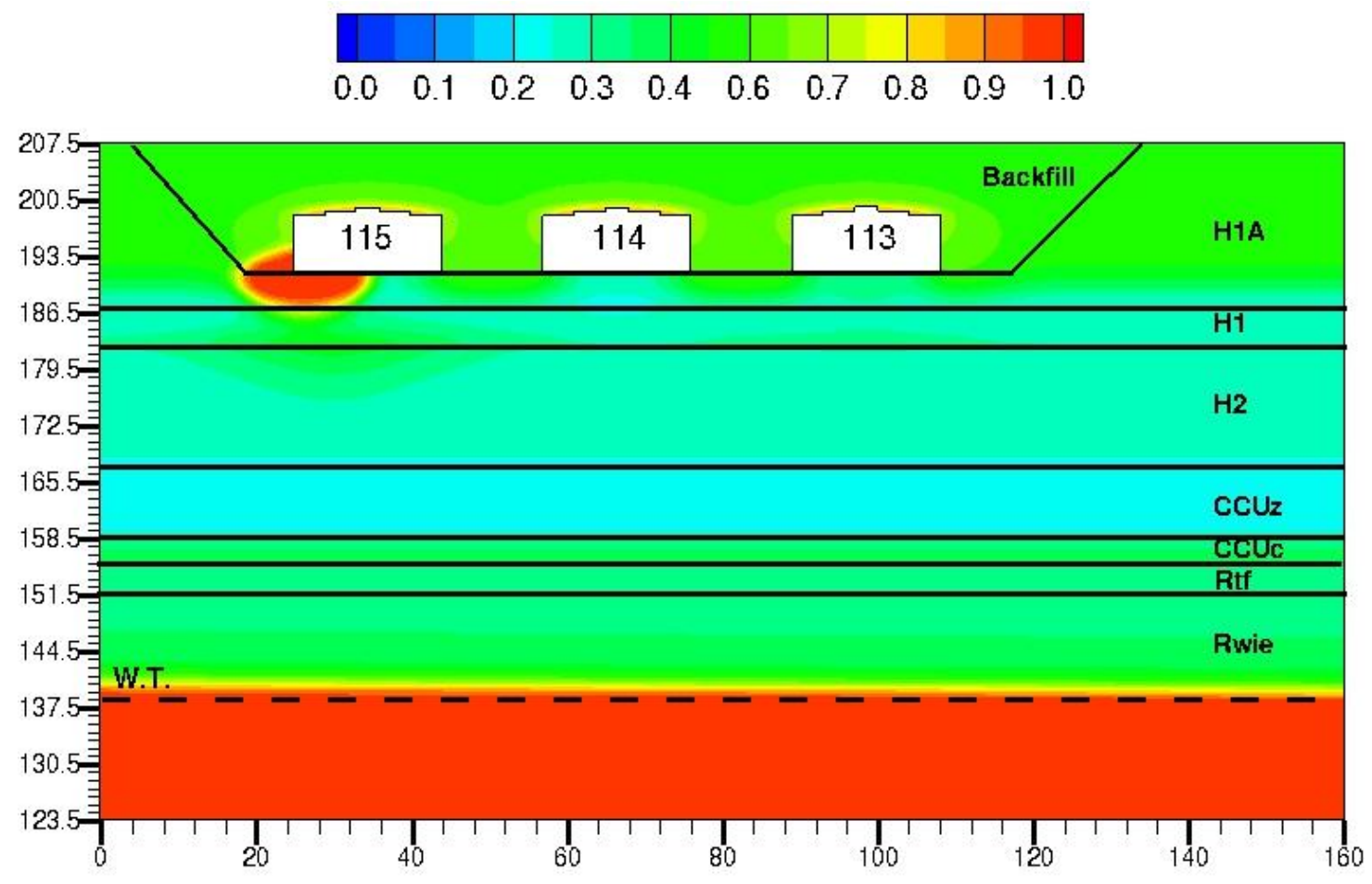

Figure 4.41. Aqueous saturation at the end of the SX-115 leak in 1965 for the Water Line Leak simulation (transect $8 \mathrm{~m}$ south of tank centers).
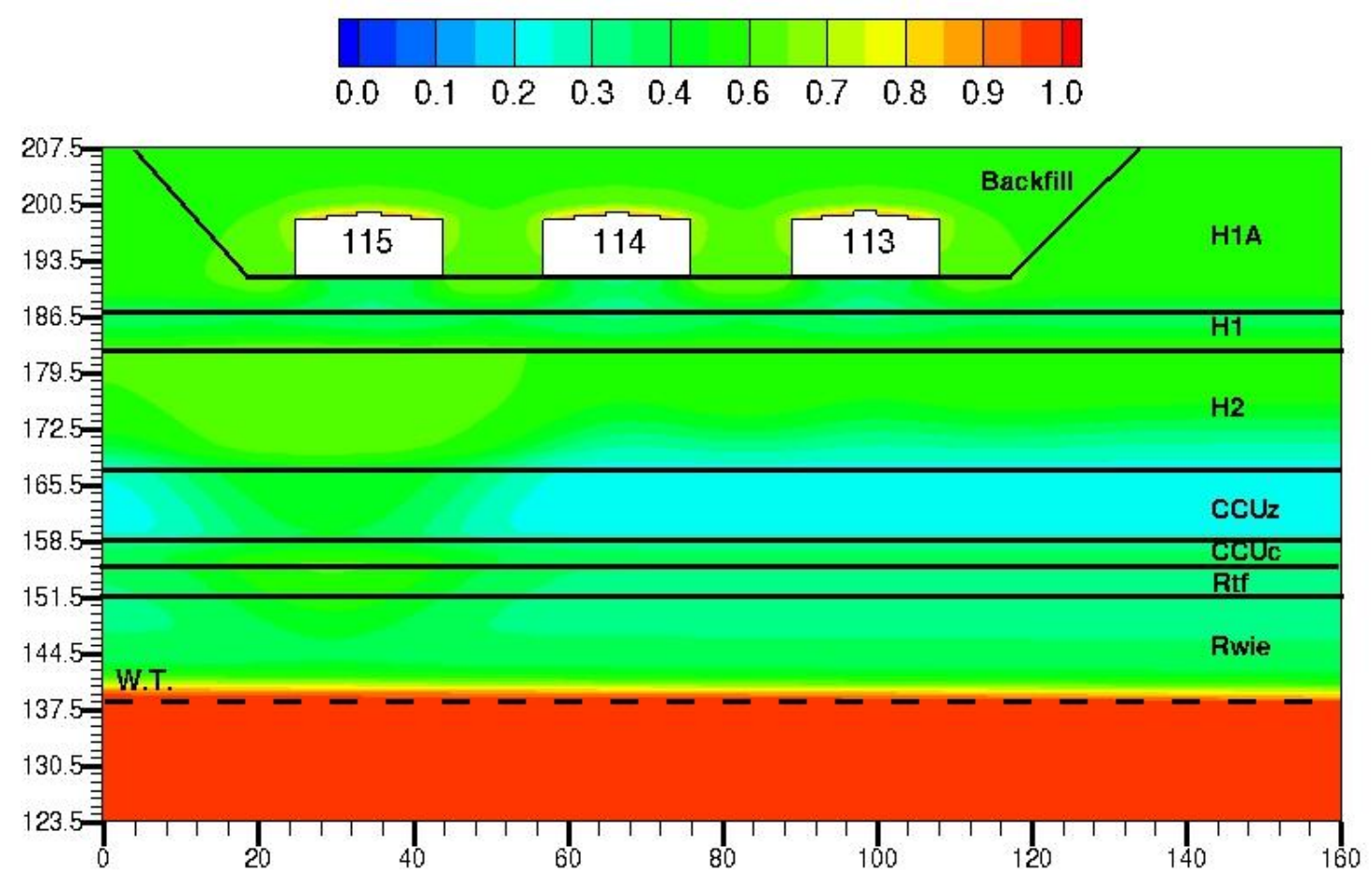

Figure 4.42. Aqueous saturation in 1980 for the Water Line Leak simulation (transect $8 \mathrm{~m}$ south of tank centers). 

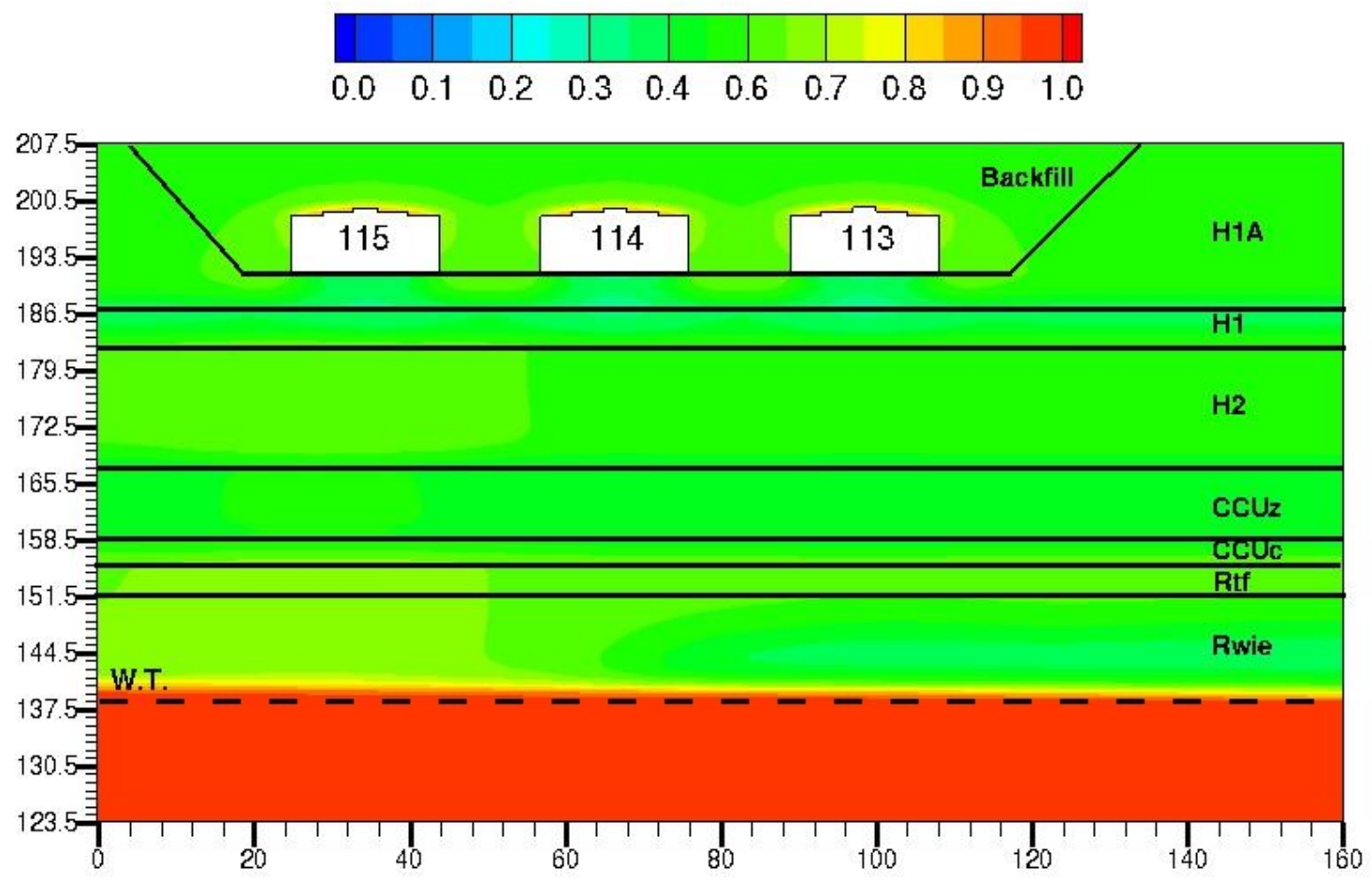

Figure 4.43. Aqueous saturation in 2000 for the Water Line Leak simulation (transect $8 \mathrm{~m}$ south of tank centers).
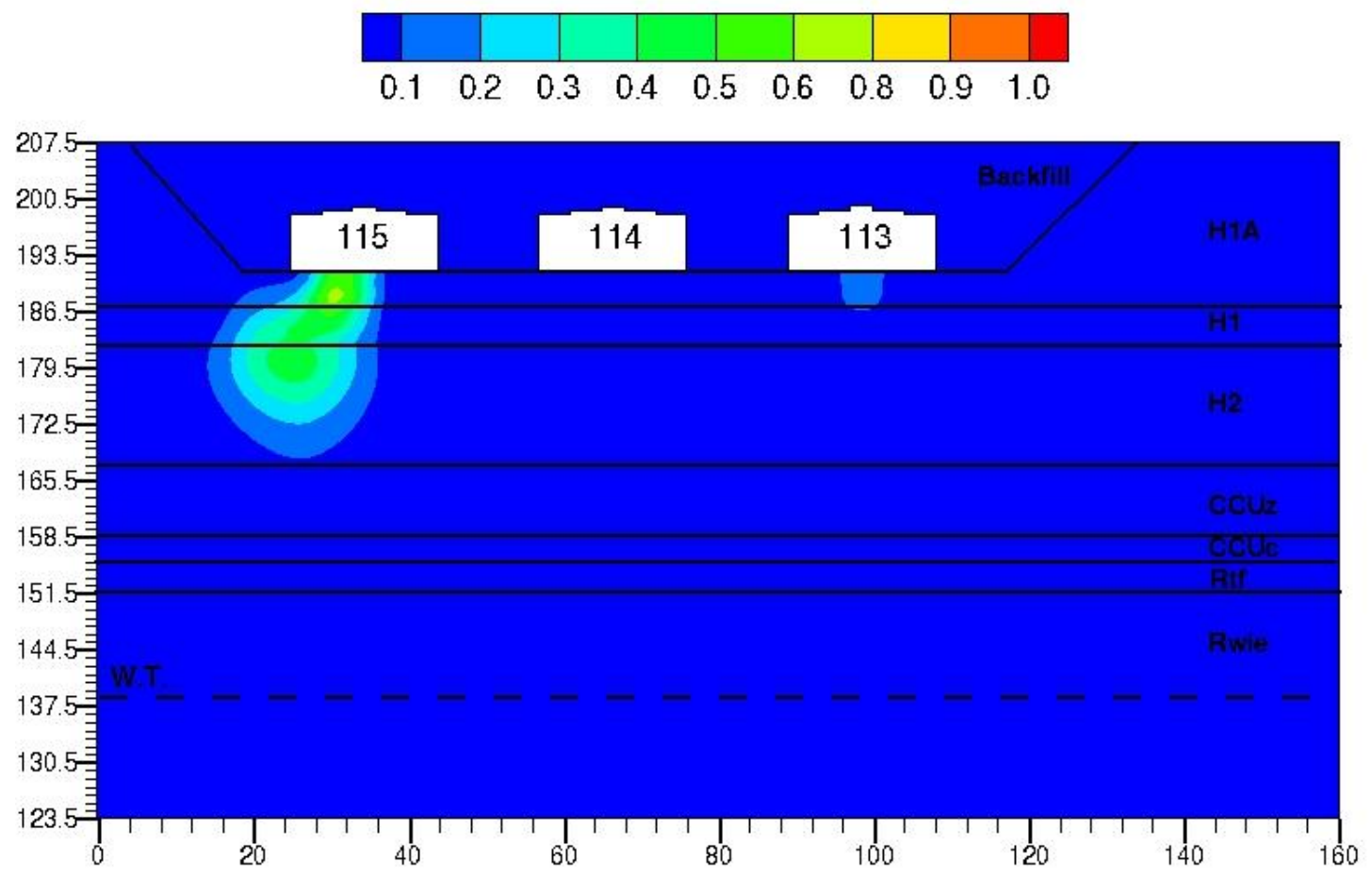

Figure 4.44. Dimensionless Tc-99 concentration in 1980 for the Water Line Leak simulation (transect 8 $\mathrm{m}$ south of tank centers). 


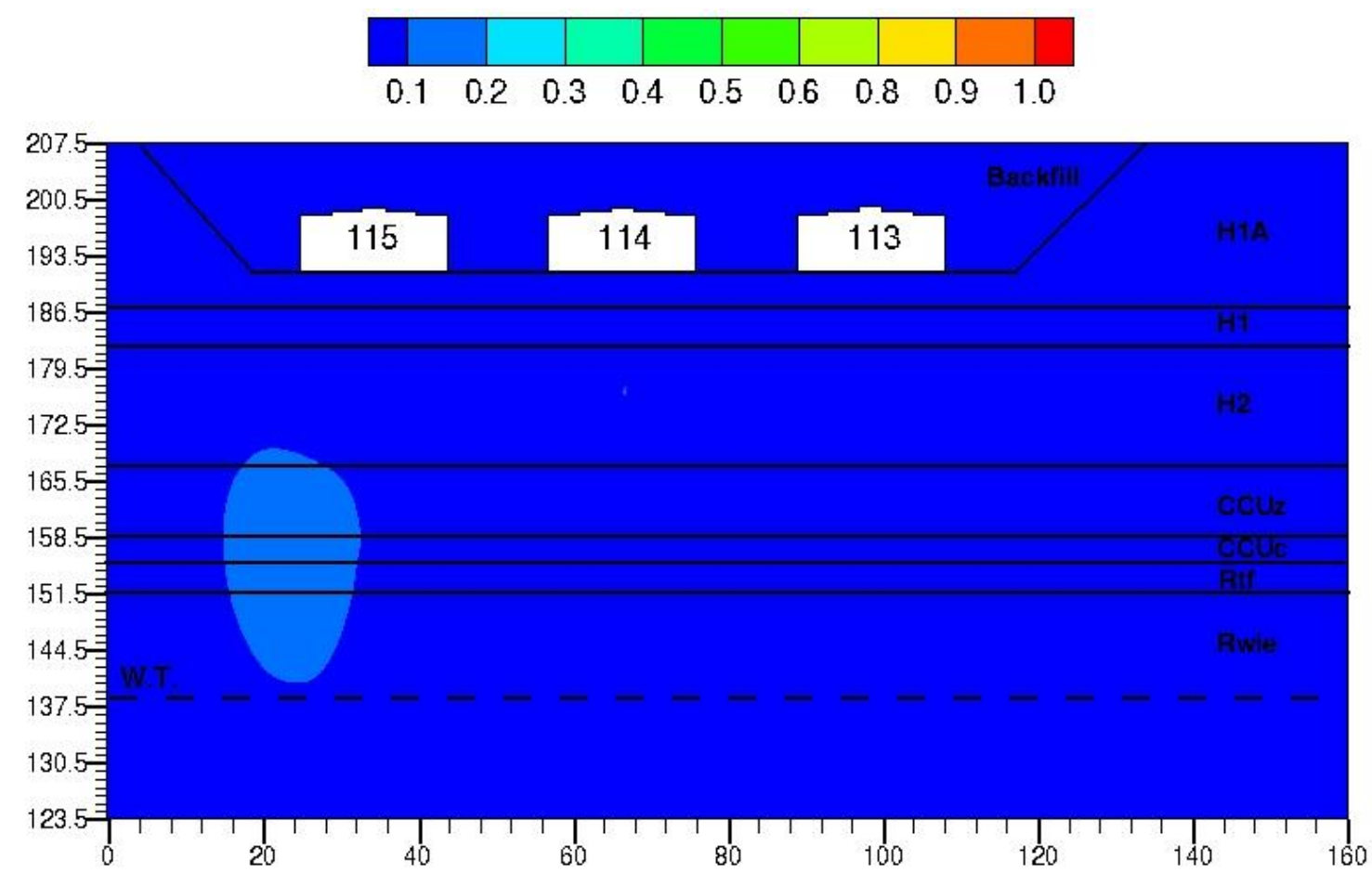

Figure 4.45. Dimensionless Tc-99 concentration in 2000 for the Water Line Leak simulation (transect 8 m south of tank centers).

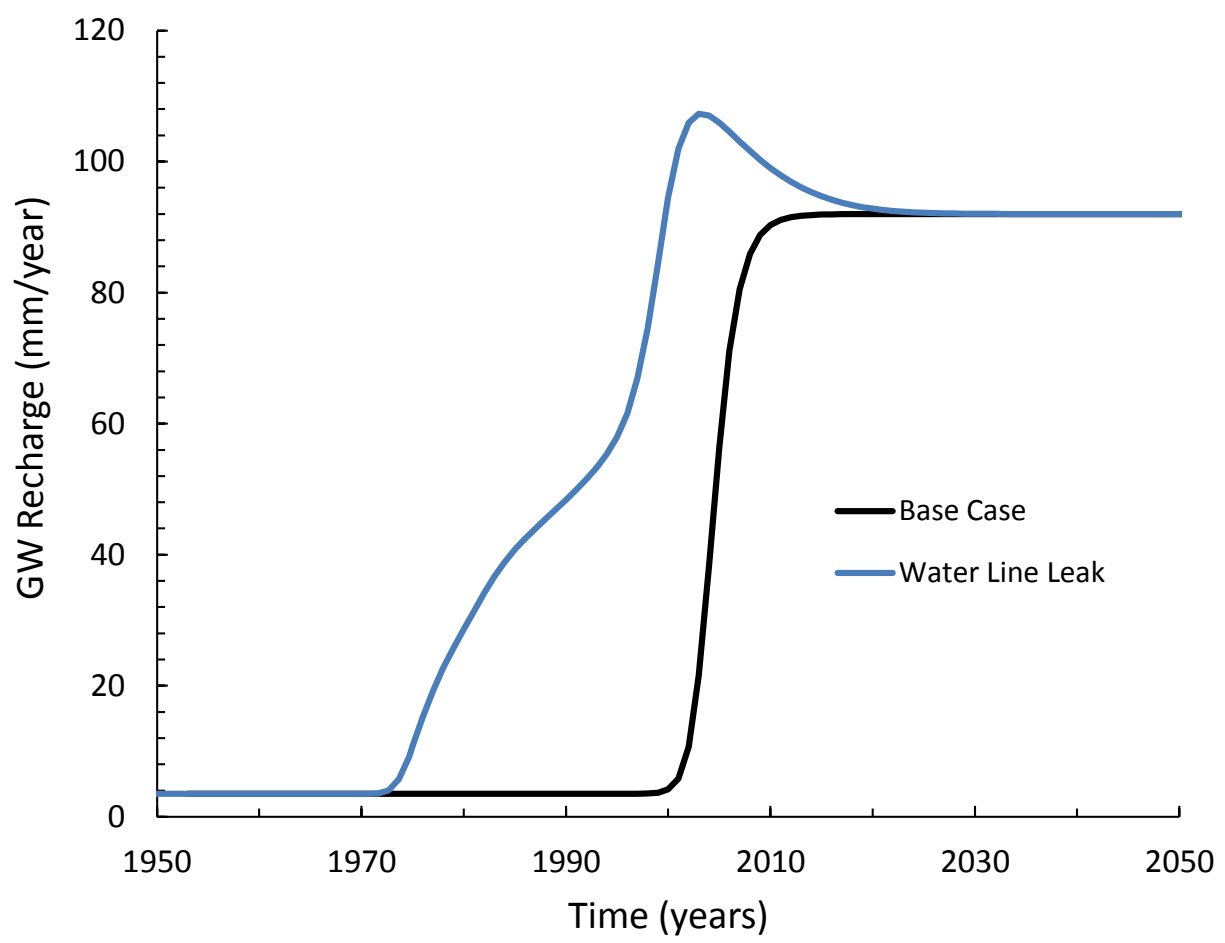

Figure 4.46. Groundwater recharge ( $\mathrm{mm} / \mathrm{yr})$ for the Base Case and Water Line Leak simulation. 


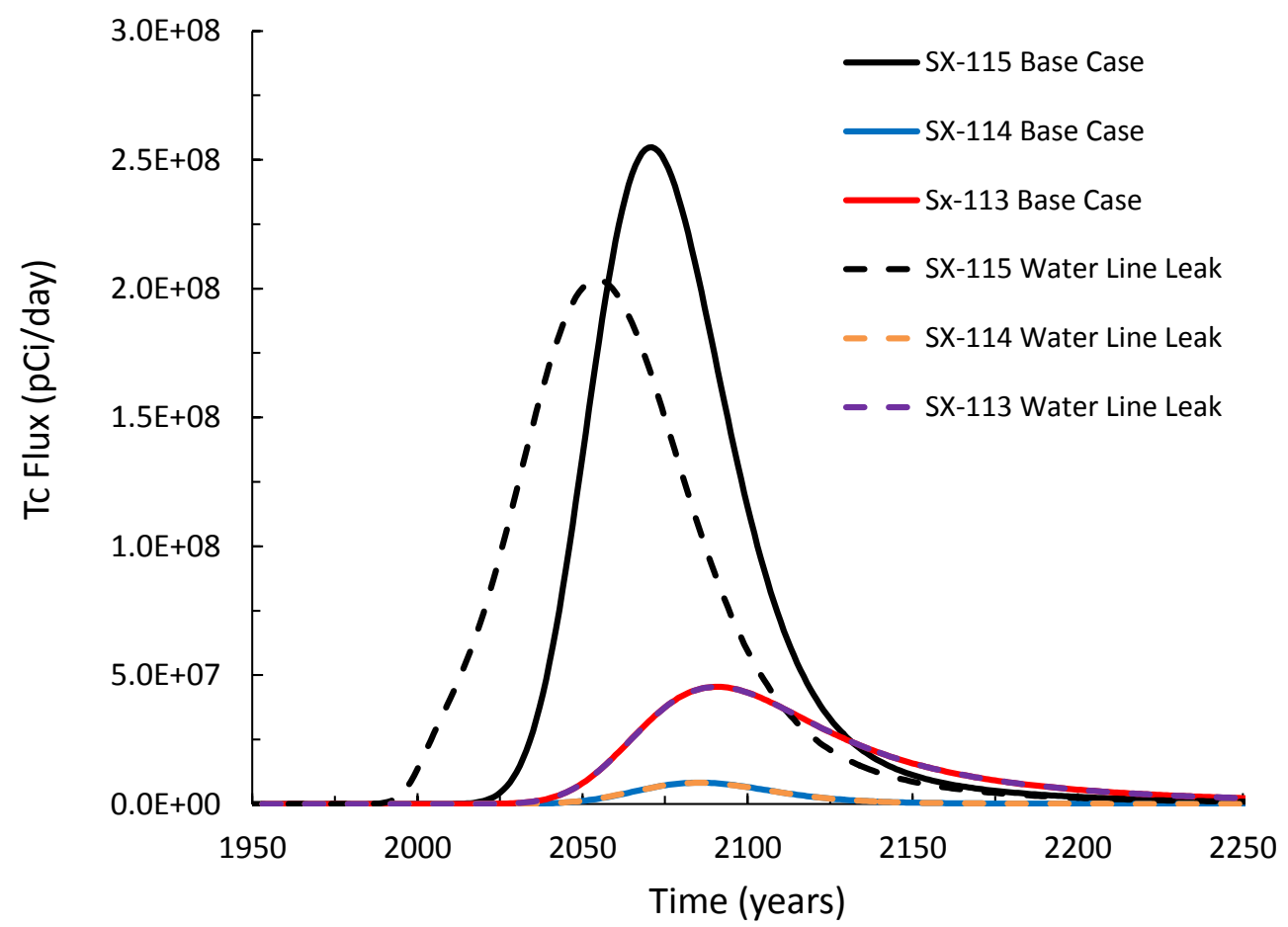

Figure 4.47. Comparison of Tc-99 mass discharge (pCi/d) into groundwater for the Base Case and Water Line Leak simulation.

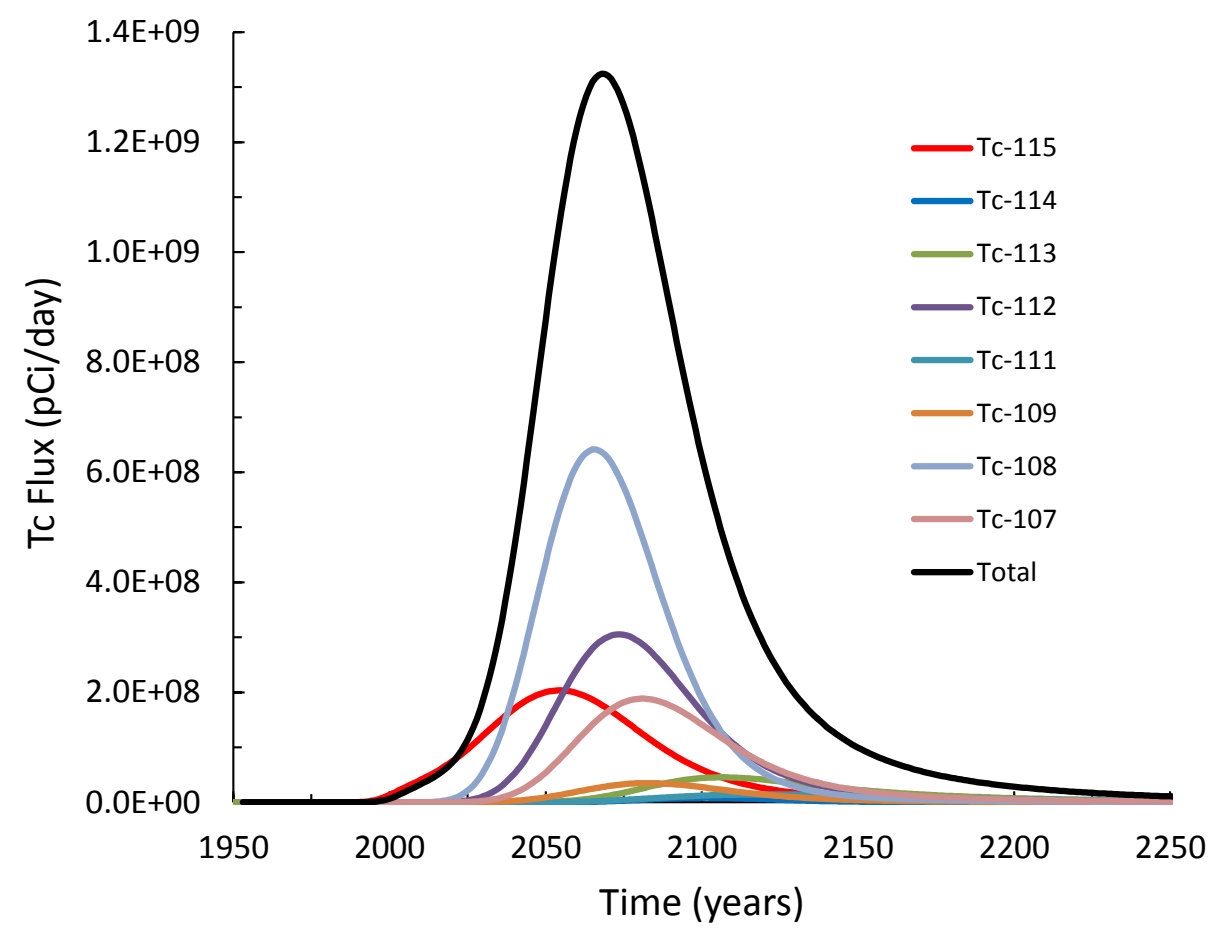

Figure 4.48. Tc-99 mass discharge (pCi/d) into groundwater for the Water Line Leak simulation. 


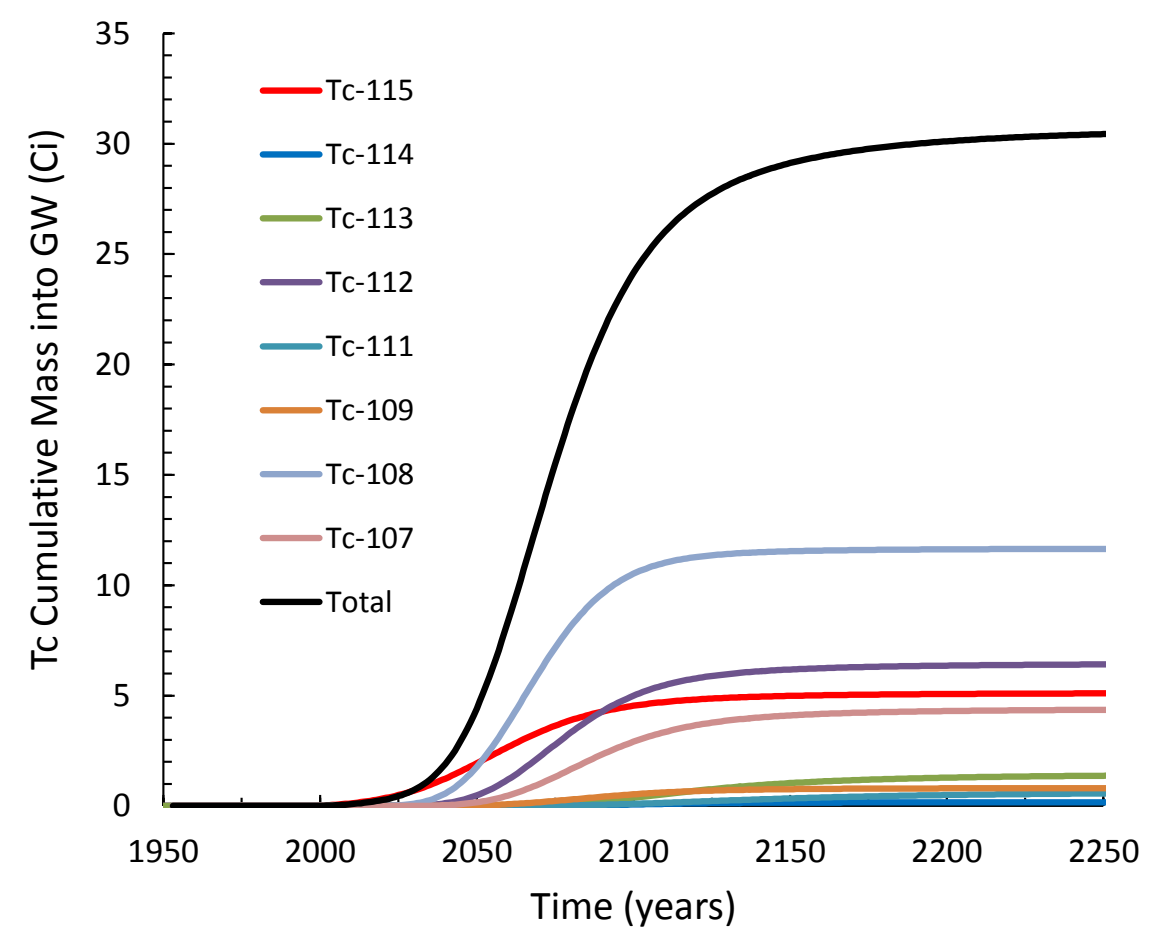

Figure 4.49. Tc-99 cumulative mass discharge (Ci) into groundwater for the Water Line Leak simulation.

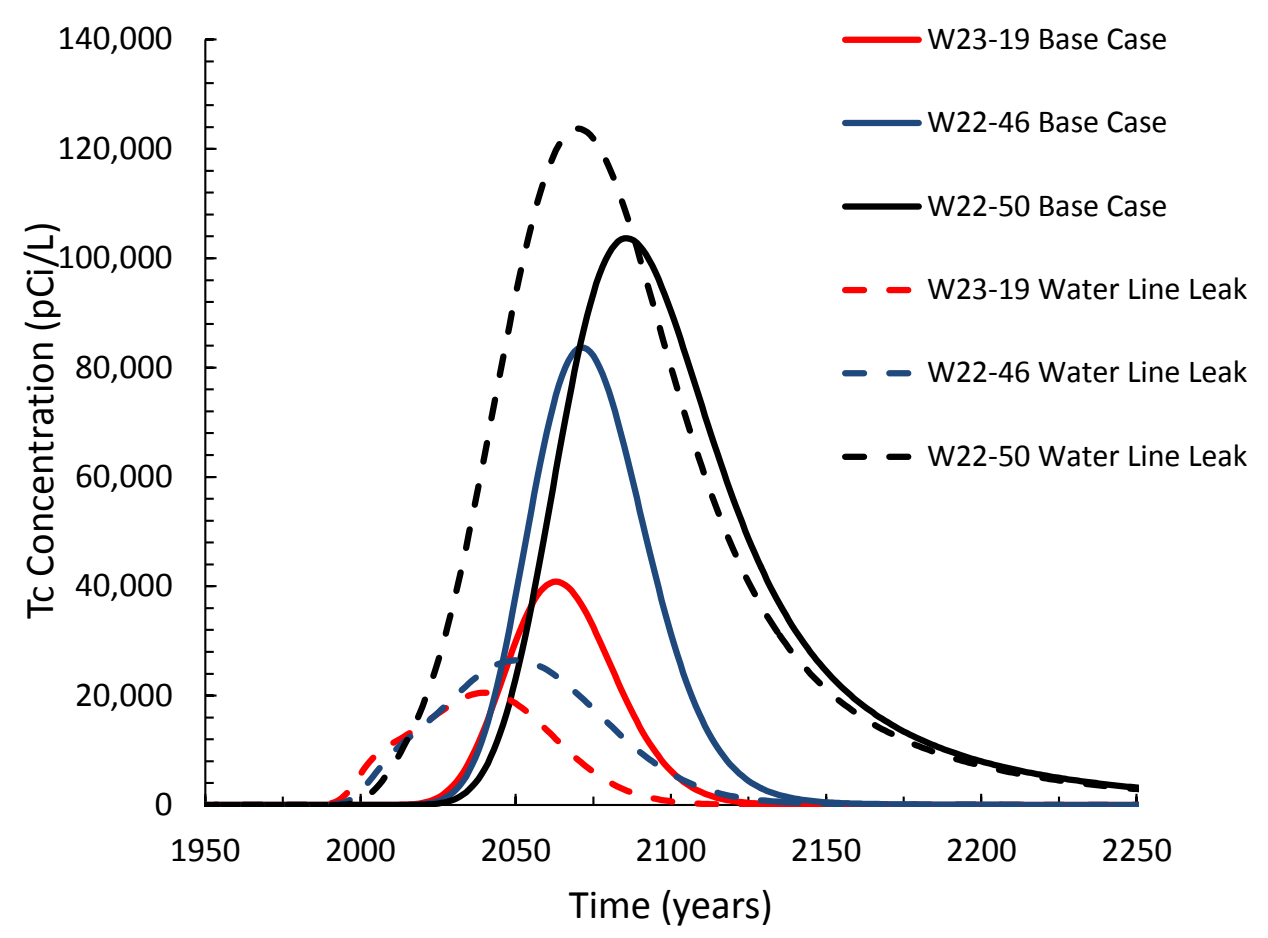

Figure 4.50. Comparison of Tc-99 well concentrations for the Base Case and Water Line Leak simulation. 


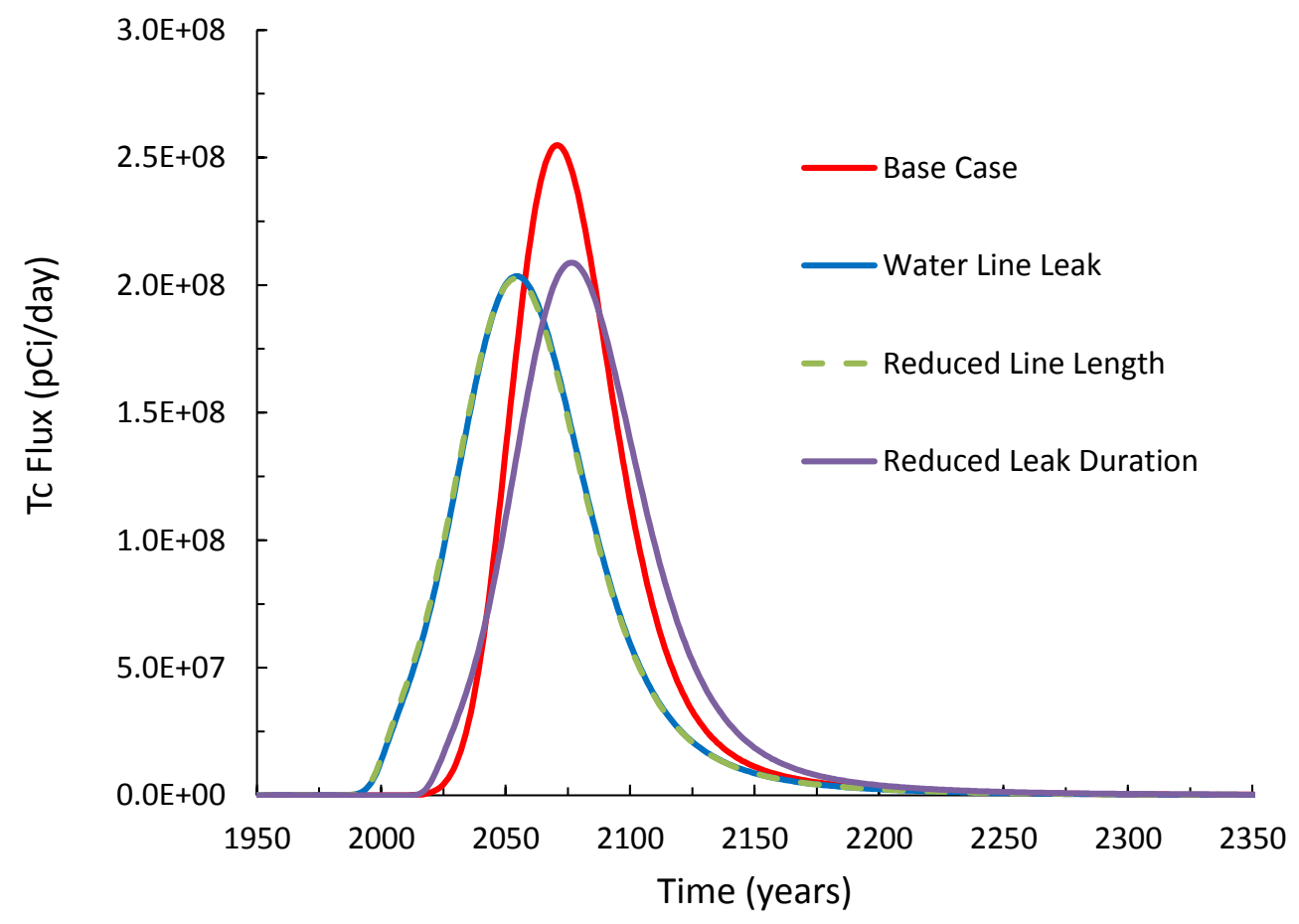

Figure 4.51. SX-115 Tc-99 mass discharge (pCi/d) into groundwater for the three Water Line Leak simulations and the Base Case.

\subsubsection{Effects of Barrier Emplacement}

The previous section illustrated that a water-line leak south of the SX-115 tank can be used to explain the observed arrival of Tc-99 in downstream groundwater monitoring wells. A simulation was then completed combining the water-line leak with emplacement of a barrier in 2020. The Water Line Leak with Barrier simulation results are illustrated with predicted water-saturation levels in year 2100 (Figure 4.52) and the associated contaminant plume (Figure 4.53). Figure 4.52 shows that considerable water drainage has occurred throughout the domain between 2020 and 2100. Because of the lower recharge rate after 2020, contaminant migration has decreased considerably compared to the Base Case (Figure 4.35).

Mass fluxes to groundwater are shown in Figure 4.54 and Figure 4.55, with the time scale on the xaxis being the only difference between the plots. Figure 4.54 provides a detailed view of the mass fluxes at earlier times and Figure 4.55 demonstrates the flux tailing that occurs at later time due to the emplaced barrier and related reduction in recharge rate. The mass fluxes shown in Figure 4.54 do not differ from the fluxes shown in Figure 4.48 for the Water Line Leak simulation until about 2040, after which the effects of the reduced recharge rates become apparent. After that time, the mass fluxes decrease with substantial tailing over time (Figure 80). The maximum total mass flux for this simulation is about three times smaller (Figure 4.54 than for the Water Line Leak simulation (Figure 4.55). The cumulative mass to groundwater plots (Figure 4.56 and Figure 4.57) show that because of the emplaced barrier, mass removal from the vadose zone is considerably slower than for the Water Line Leak simulation without a barrier (Figure 4.50). With a barrier, the predicted mass discharge to the groundwater is only $65 \%$ by 2250 and $82 \%$ by 3000 . Figure 4.58 and Figure 4.59 show that the well concentrations are not affected 
until approximately 2050. After that, similar slow decreases are predicted, following the trends in the mass flux to groundwater behavior.

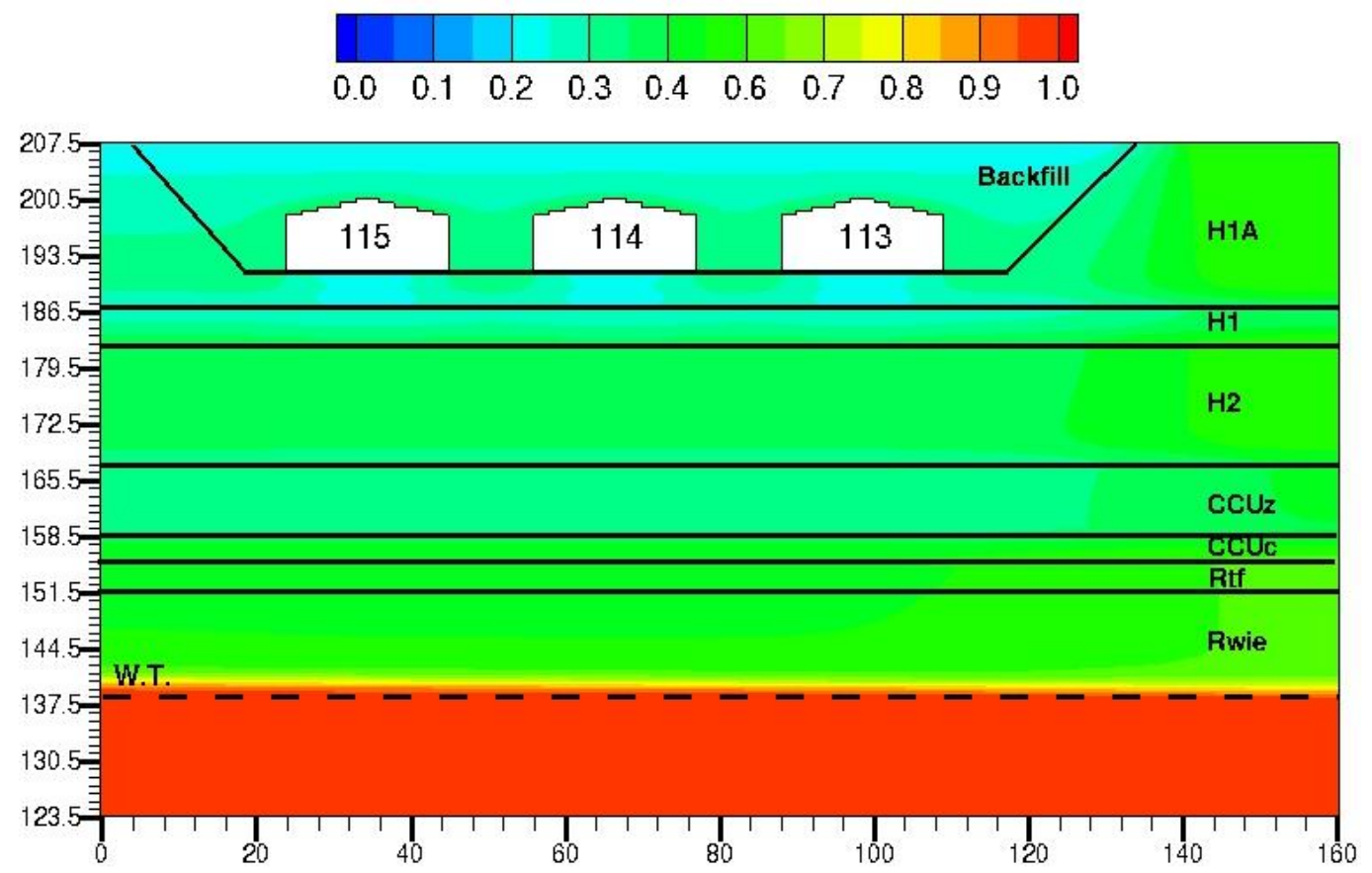

Figure 4.52. Aqueous saturation in 2100 for the Water Line Leak with Barrier simulation (transect through tank centers).
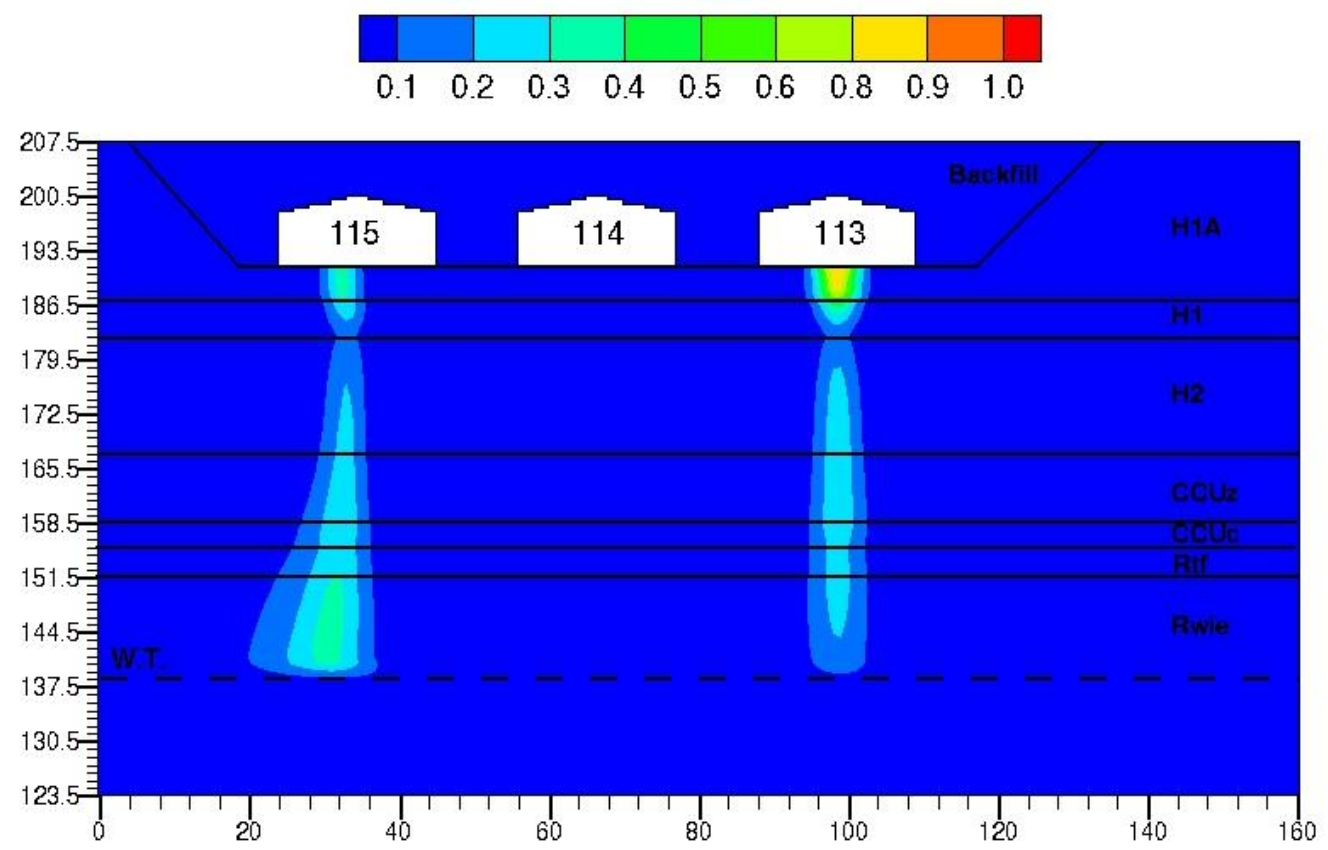

Figure 4.53. Dimensionless Tc-99 concentration in 2100 for the Water Line Leak with Barrier simulation (transect through tank centers). 


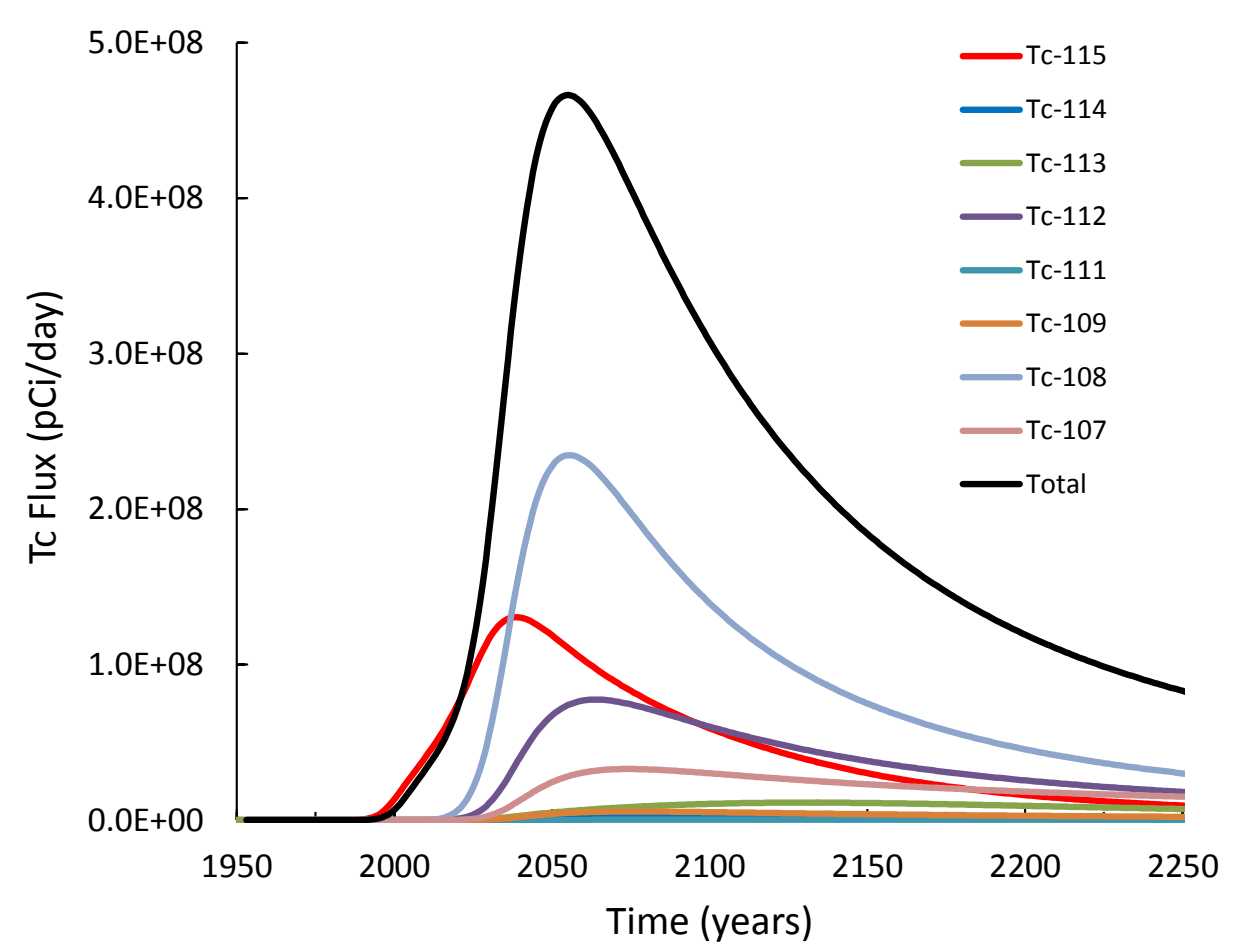

Figure 4.54. Tc-99 mass discharge (pCi/d) for the Water Line Leak with Barrier simulation for 1953-2250.

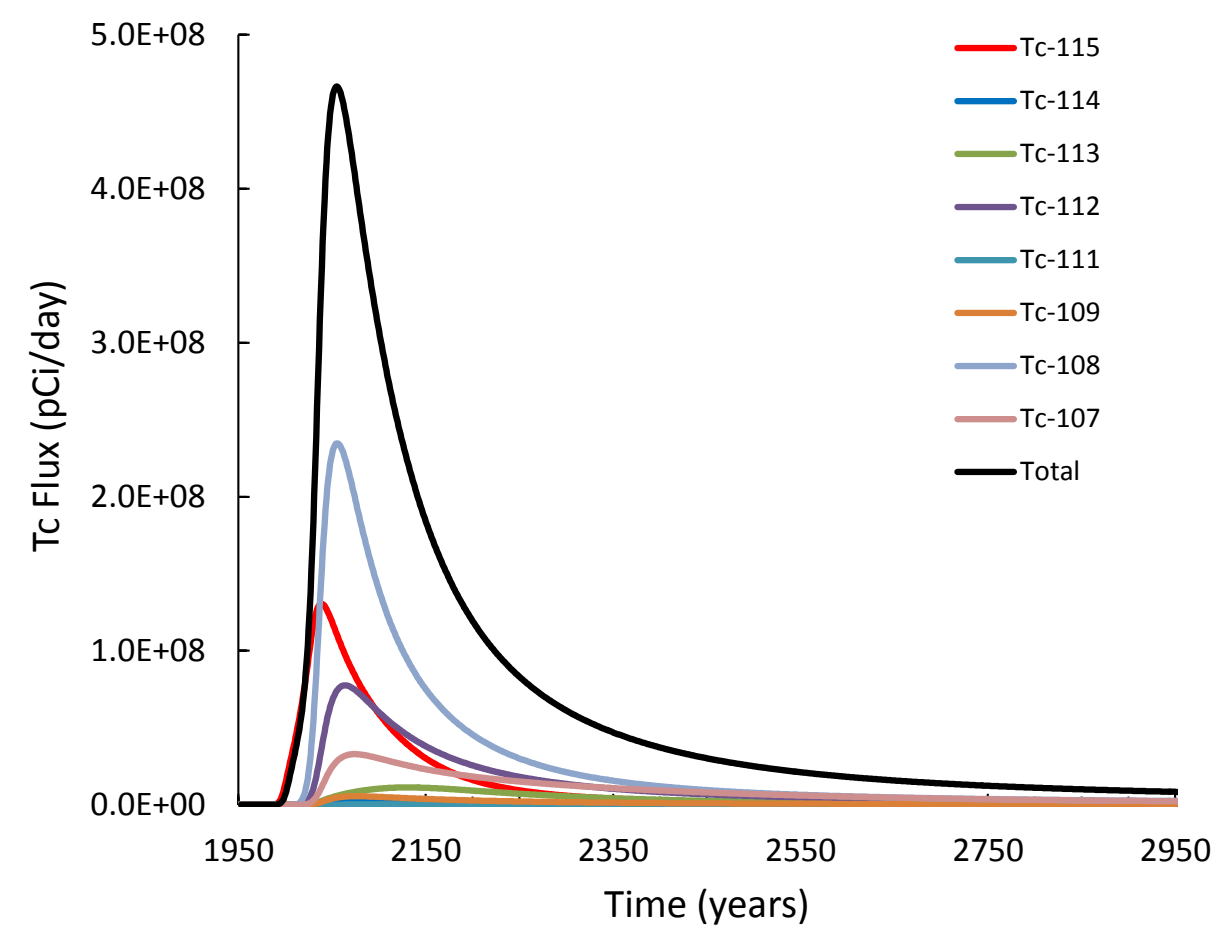

Figure 4.55. Tc-99 mass discharge ( $\mathrm{pCi} / \mathrm{d})$ for the Water Line Leak with Barrier simulation for 1953-2950. 


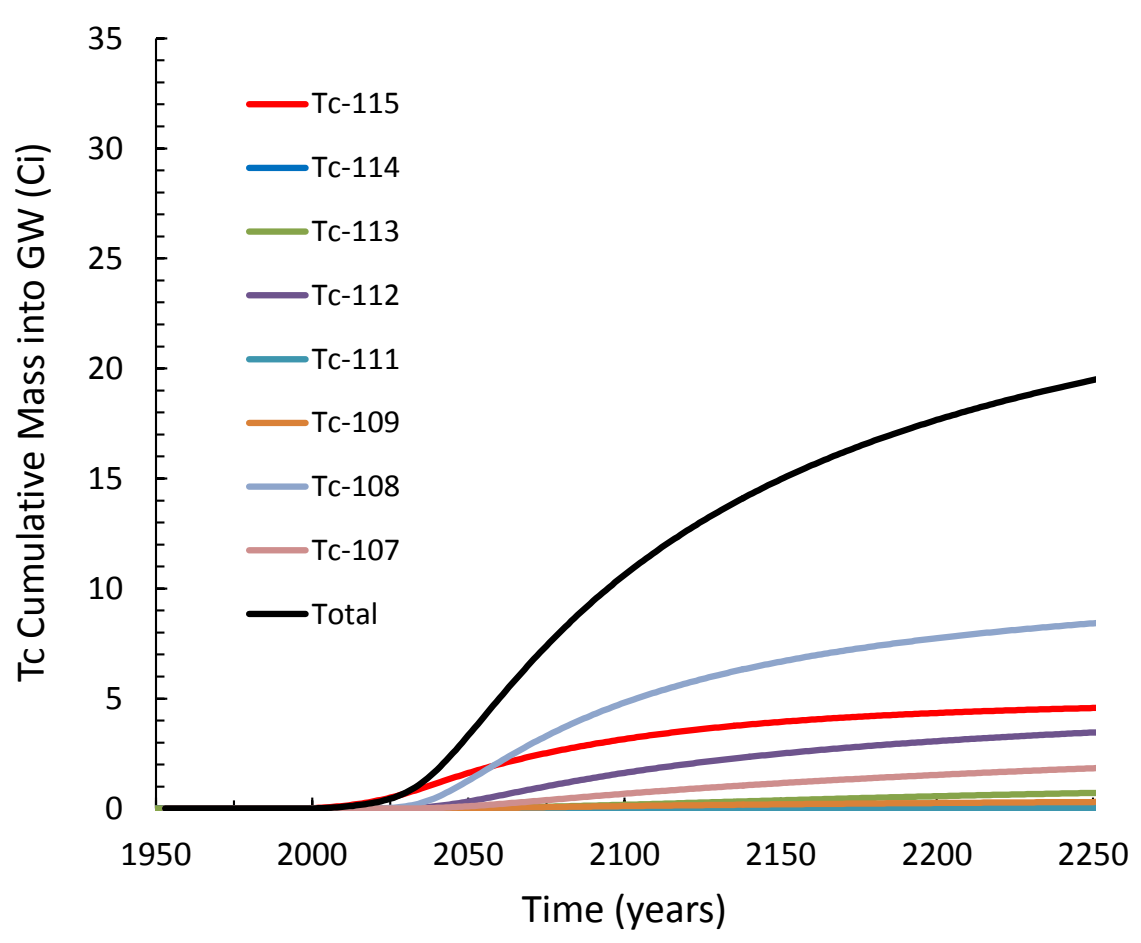

Figure 4.56. Tc-99 cumulative mass discharge (Ci) for the Water Line Leak with Barrier simulation for 1953-2250.

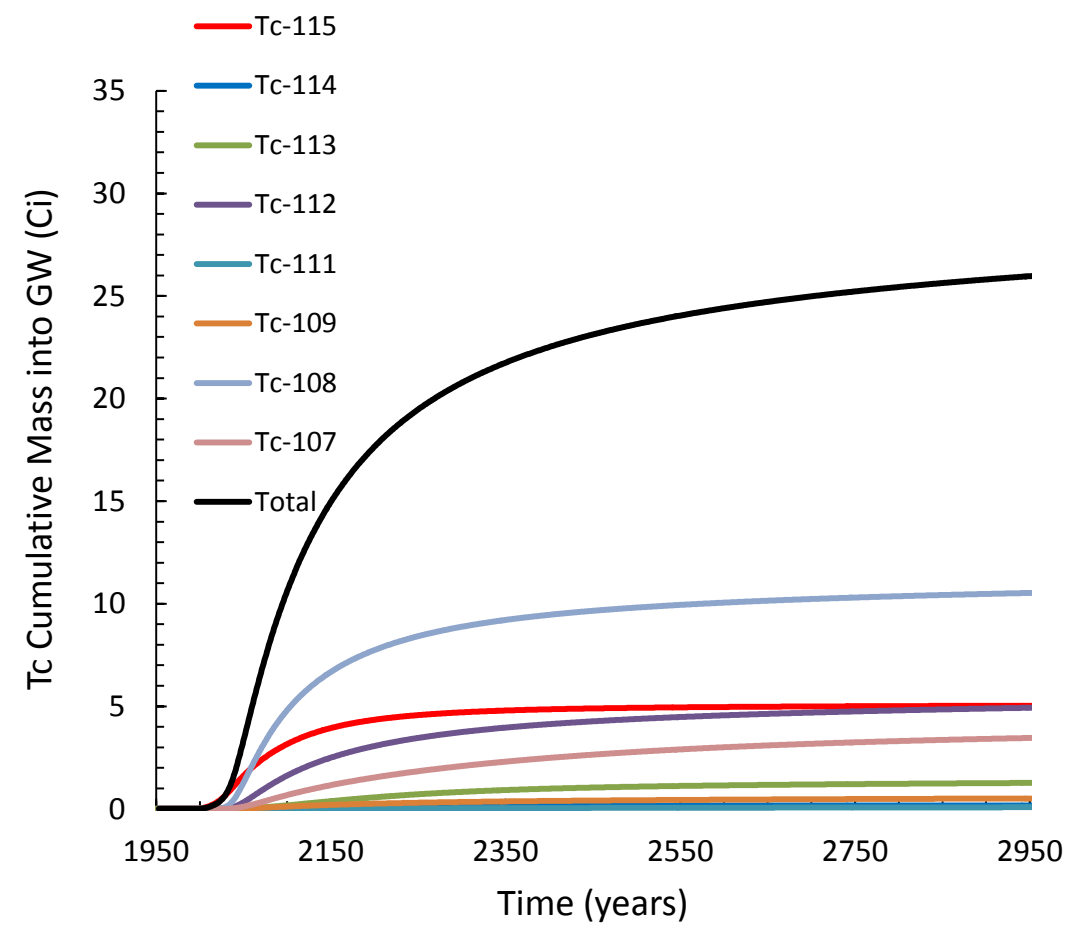

Figure 4.57. Tc-99 cumulative mass discharge (Ci) for the Water Line Leak with Barrier simulation for 1953-2950. 


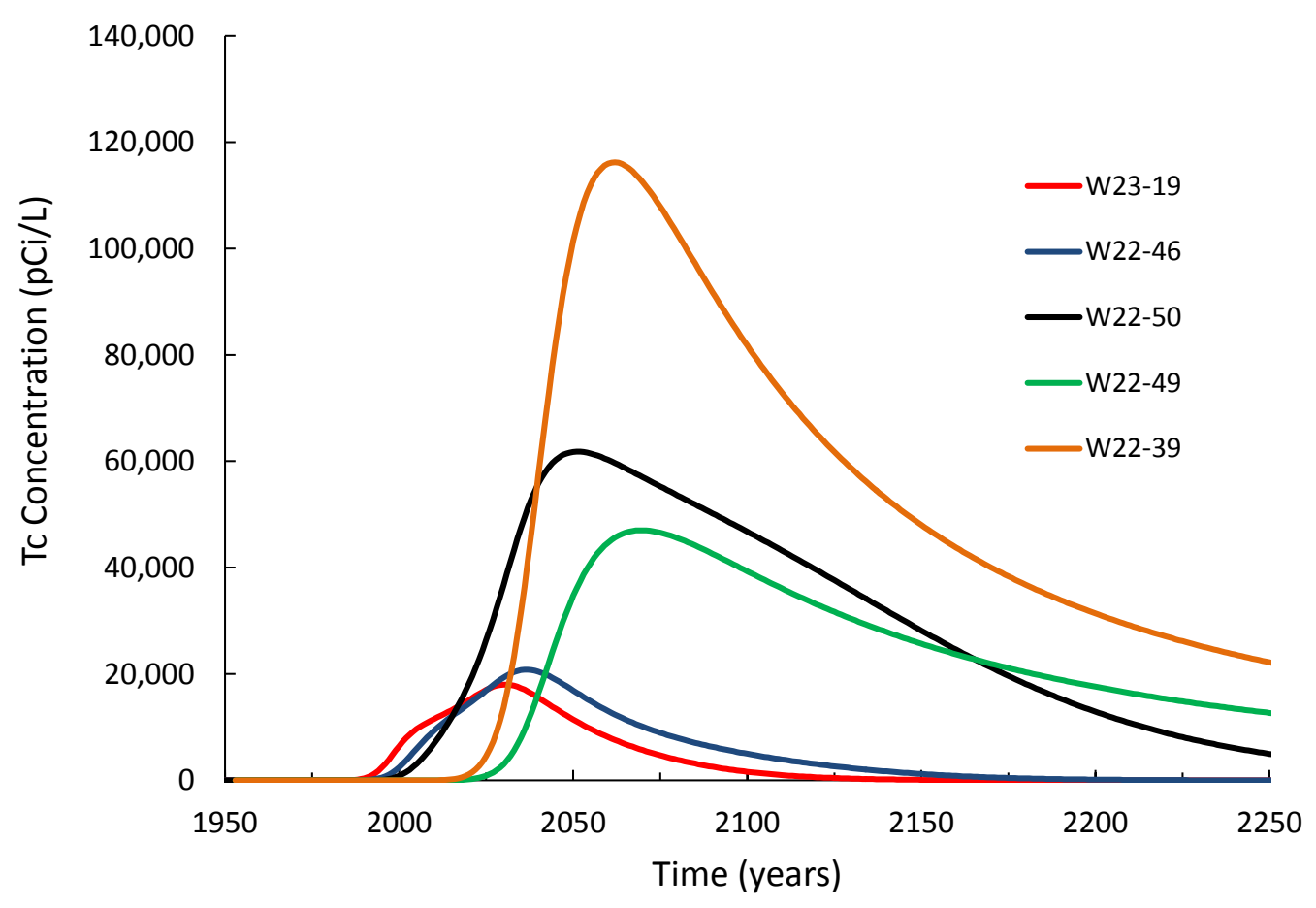

Figure 4.58. Tc-99 well concentrations for the Water Line Leak with Barrier simulation for 1953-2250.

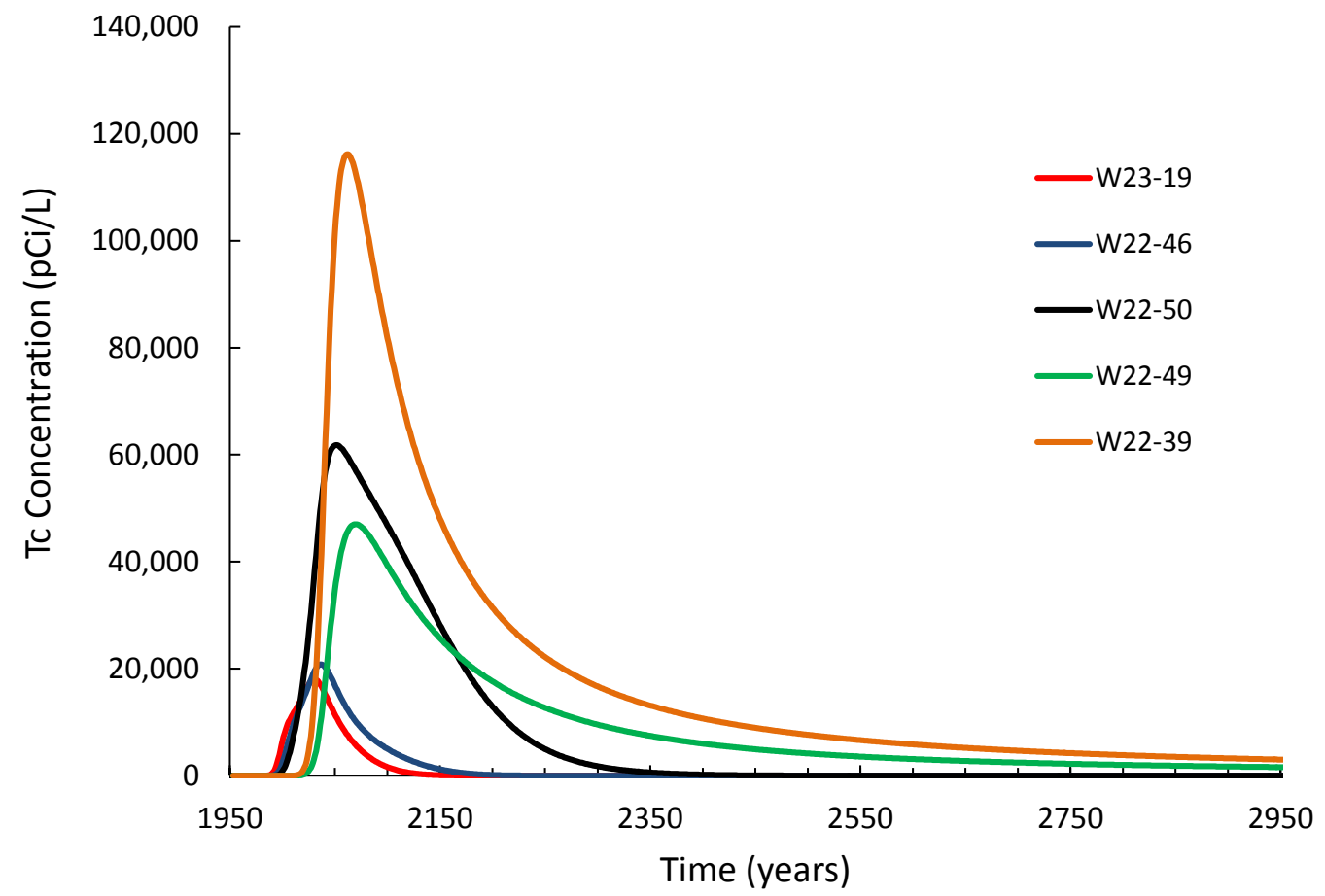

Figure 4.59. Tc-99 well concentrations for the Water Line Leak with Barrier simulation for 1953-2950. 


\subsubsection{Effects of Lower Permeability in the Cold Creek Unit}

The scoping simulations for the SX-108 tank (Section 4.1) showed that a reduction of the CCU permeability by a factor 100 had only a limited effect on mass transfer to the groundwater. An SX Tank Farm simulation (Reduced CCU Ksat; Table 3.3) was conducted to confirm this behavior for the scale of the whole site where eight tanks have leaked in the past, and to investigate whether reduced CCU permeability would cause a consolidation of vadose zone contaminant plumes emanating from adjacent wells.

Figure 4.60 illustrates the increased initial water-saturation levels in the CCU compared to the Base Case (Figure 4.21). Because the water-saturation levels above these units are only slightly affected by the reduced CCU permeability, the water saturation and contaminant plumes after the SX-115 leak (Figure 4.61 and Figure 4.62) do not differ much from what was observed for the Base Case (Figure 4.26 and Figure 4.27). Even in 1980, the difference between the results of this simulation (Figure 4.63 and Figure 4.64) and the Base Case simulation (Figure 4.28 and Figure 4.30) is minimal. Only when the contaminant approaches the wetter CCU (Figure 4.65) does some delay in the transport occur, as can be seen by comparing Figure 4.66 for this simulation and Figure 58 for the Base Case. The differences between the plumes generated with this simulation and the Base Case always remain small, even after most of the contaminant has migrated through the CCU. For instance, the plumes shown in Figure 4.67 and Figure 4.68 at both transects for this simulation in 2100 are similar to the Base Case plumes at the same time (Figure 4.35 and Figure 4.36). As for the Base Case and other simulations described in this chapter, no plume consolidation occurred in the vadose zone. All plumes from the various tanks traveled through the vadose zone without any mixing with plumes from adjacent tanks.

The Tc-99 mass transport to groundwater was somewhat delayed, compared to the Base Case simulation, for all tanks. As an example, the comparison for the SX-115-114-113 sequence is shown in Figure 4.69. For the Tc-99 originating from the SX-115 tank, the first arrival of the contaminant occurred about at the same time for both simulation, but the Reduced CCU Ksat simulation predicts a delayed peak arrival of the mass flux of about 12 years. Of all the tanks with major leaks (SX-115, SX-112, SX-108 and SX-107), the mass flux delay for this tank was the largest. The temporal behavior of the mass fluxes is reflected in the breakthrough at the wells (Figure 4.70). Although the early arrival of the contaminant is not affected by the lower CCU permeability, the predicted times for the maximum well concentrations are between 10 and 15 years later than for the Base Case. 

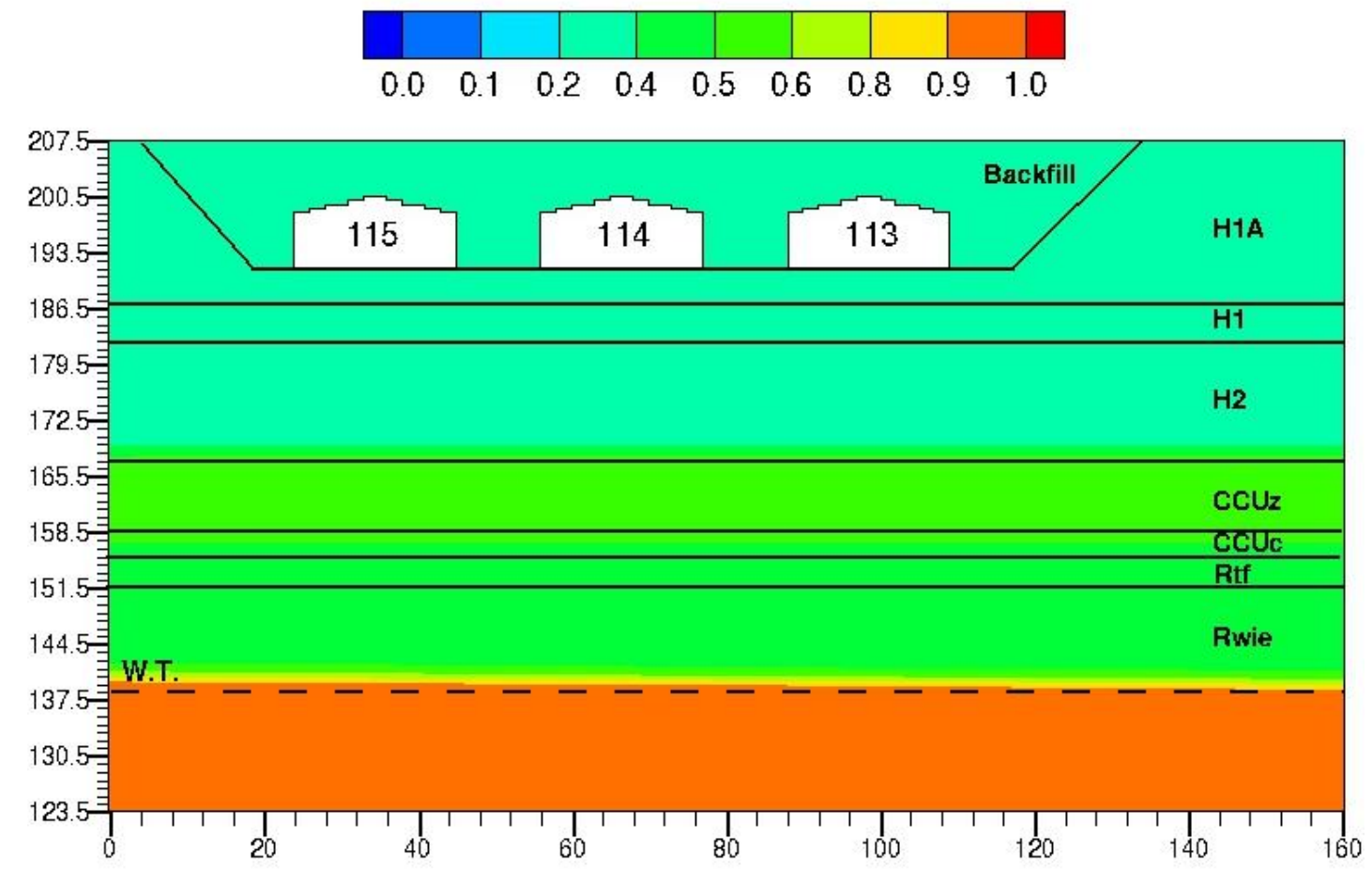

Figure 4.60. Aqueous saturation in 1953 for the Reduced CCU Ksat simulation (transect through tank centers).
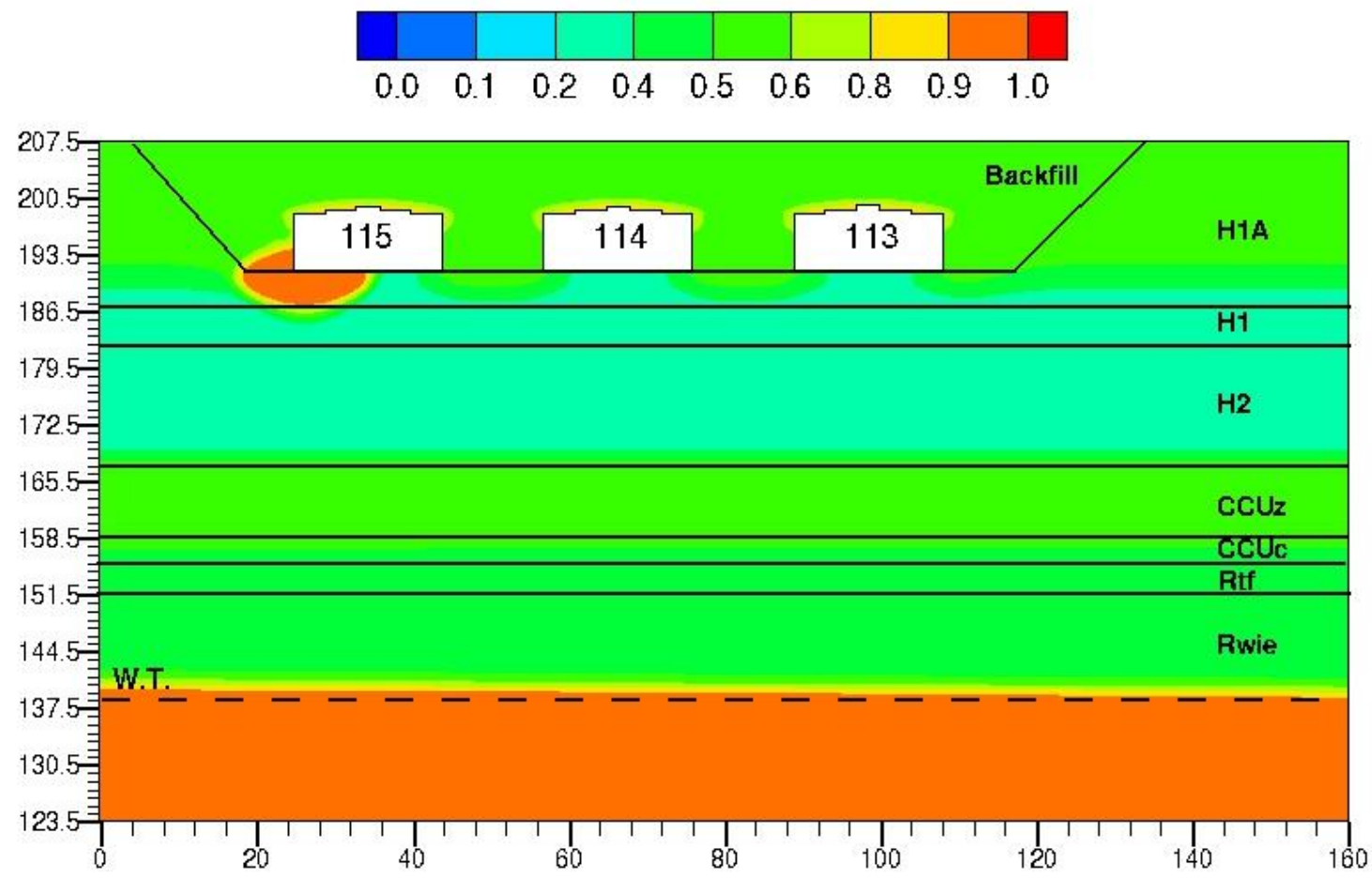

Figure 4.61. Aqueous saturation at the end of the SX-115 leak in 1965 for the Reduced CCU Ksat simulation (transect $8 \mathrm{~m}$ south of tank centers). 

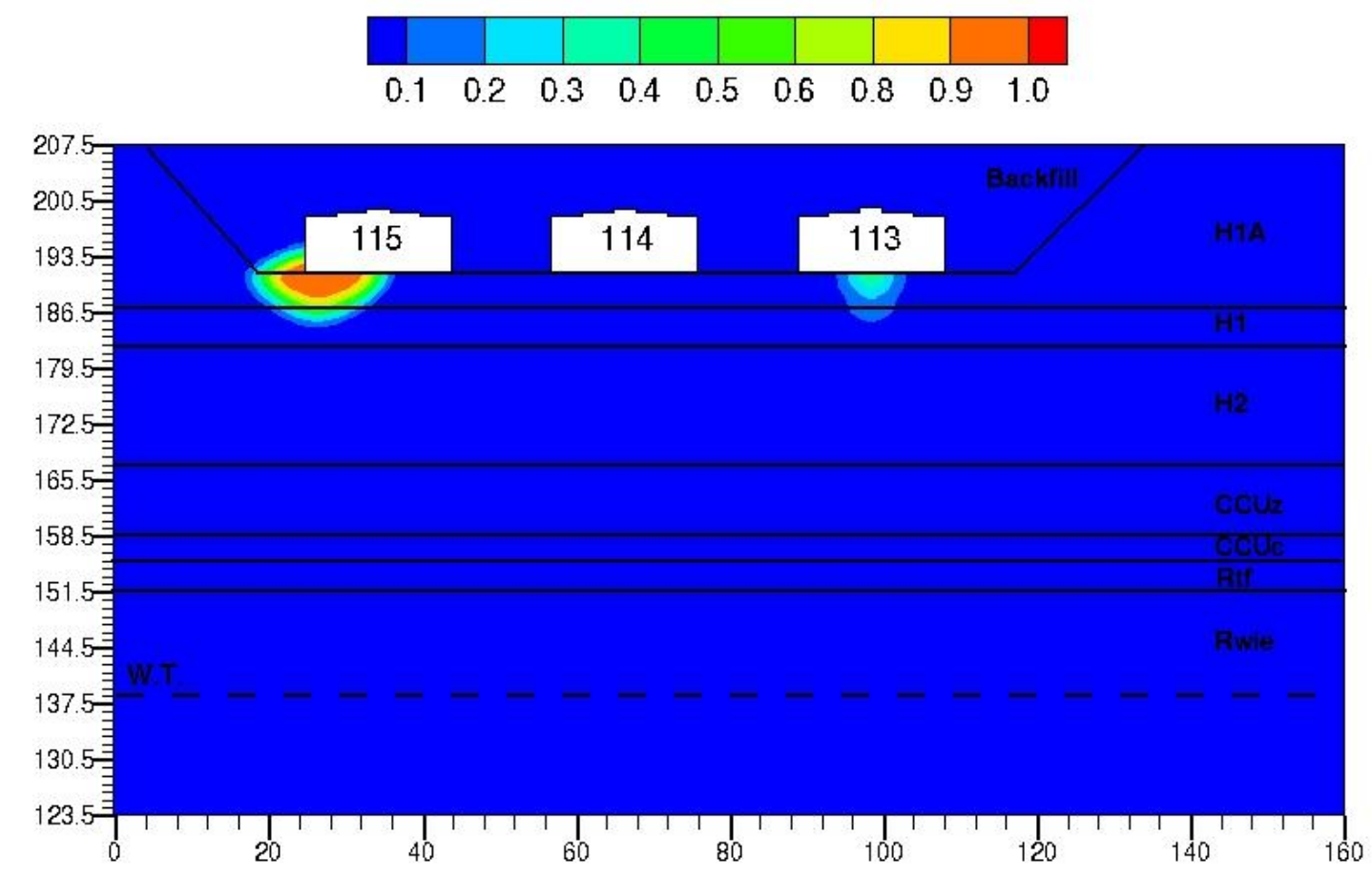

Figure 4.62. Dimensionless Tc-99 concentration at the end of the SX-115 leak in 1965 for the Reduced CCU Ksat simulation (transect $8 \mathrm{~m}$ south of tank centers).

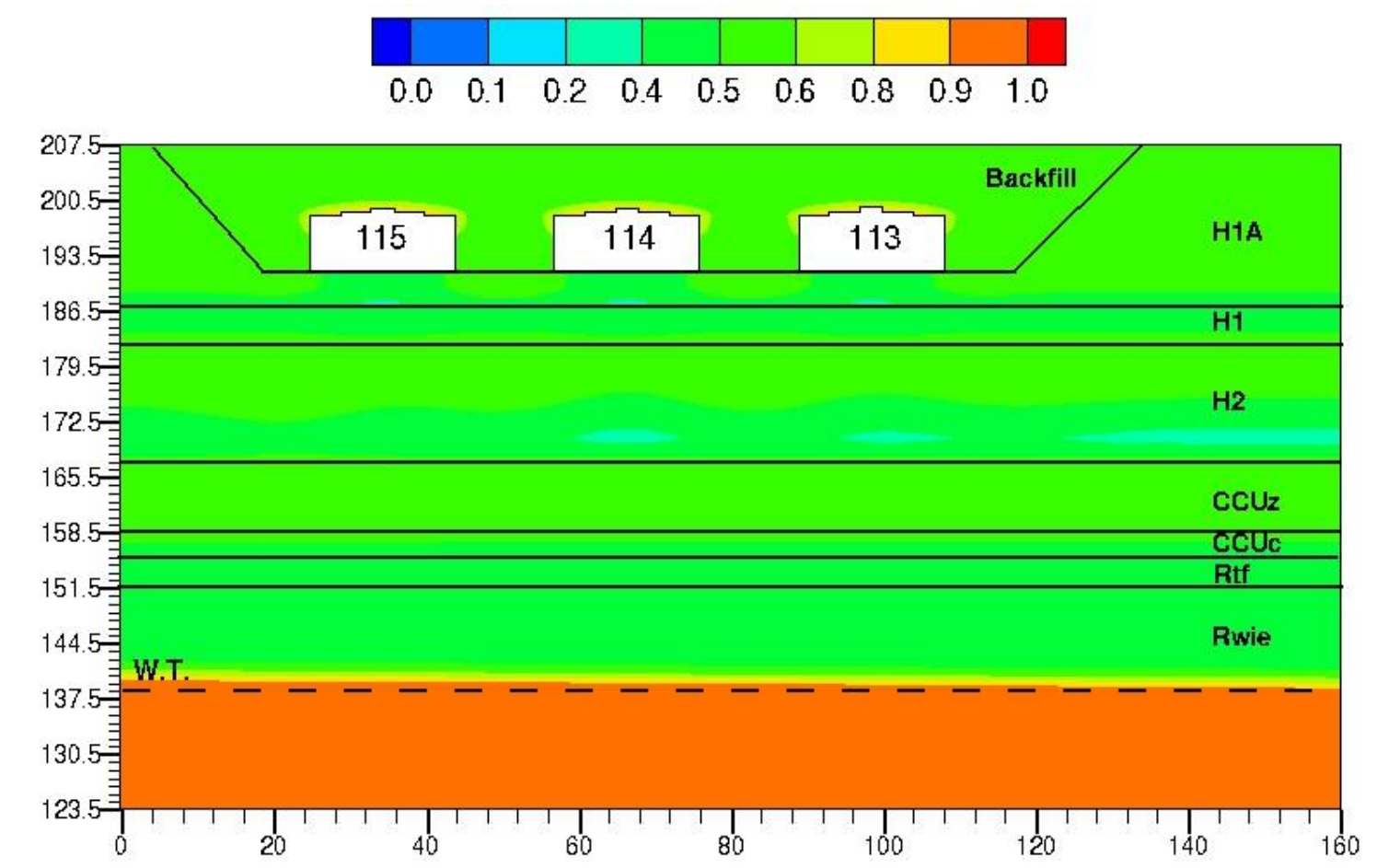

Figure 4.63. Aqueous saturation in 1980 for the Reduced CCU Ksat simulation (transect $8 \mathrm{~m}$ south of tank centers). 


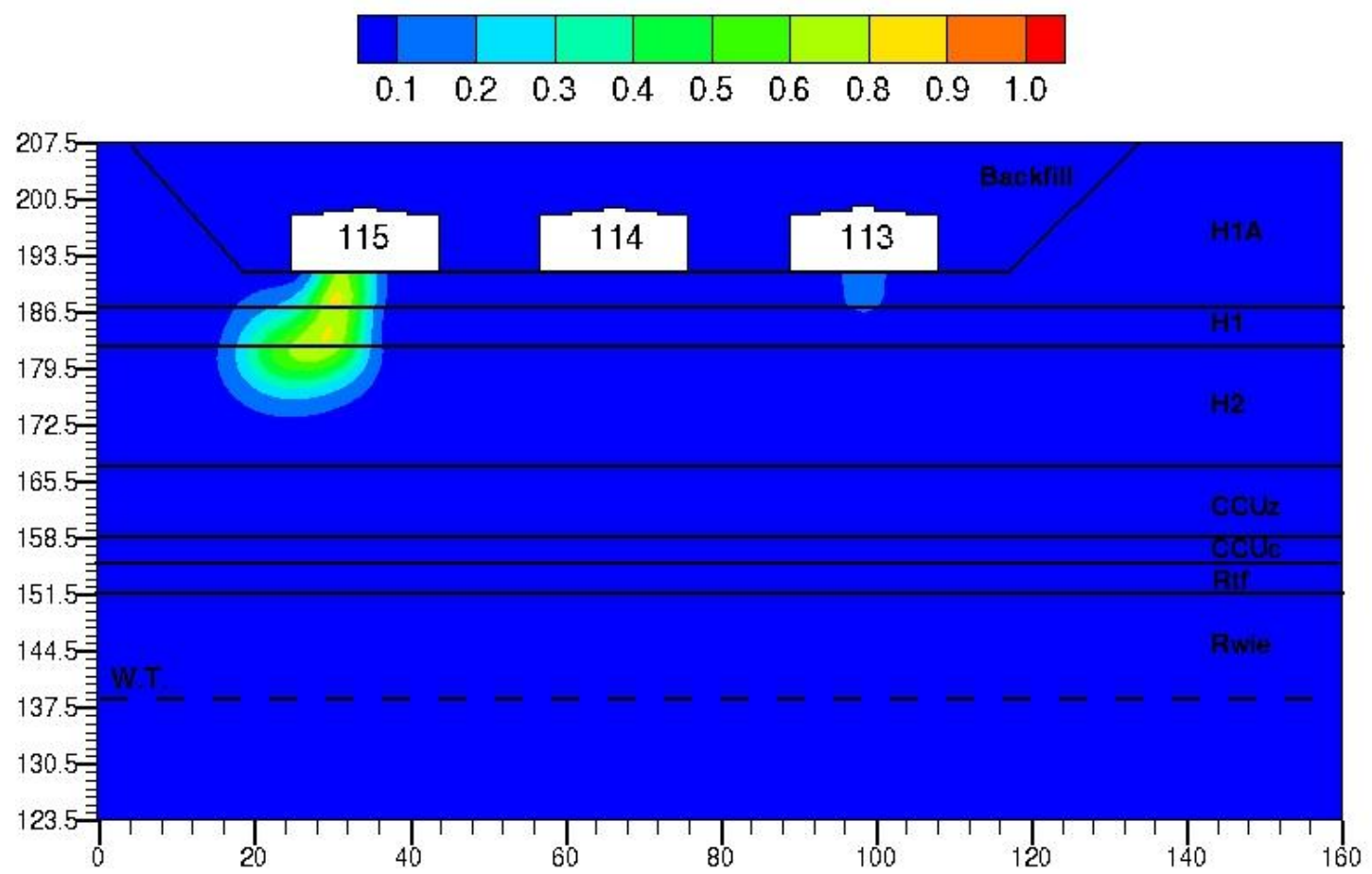

Figure 4.64. Dimensionless Tc-99 concentration in 1980 for the Reduced CCU Ksat simulation (transect $8 \mathrm{~m}$ south of tank centers).
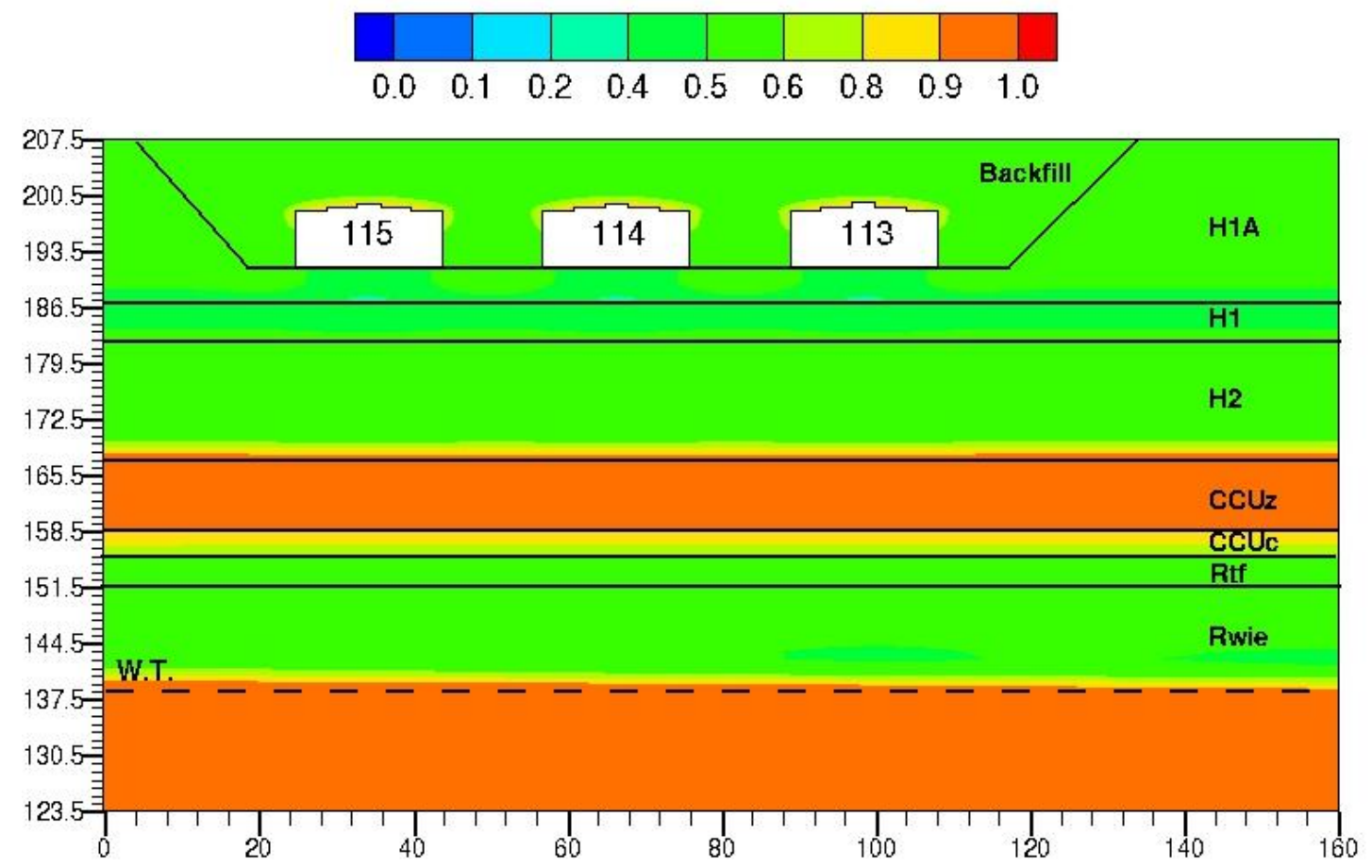

Figure 4.65. Aqueous saturation in 2014 for the Reduced CCU Ksat simulation (transect $8 \mathrm{~m}$ south of tank centers). 

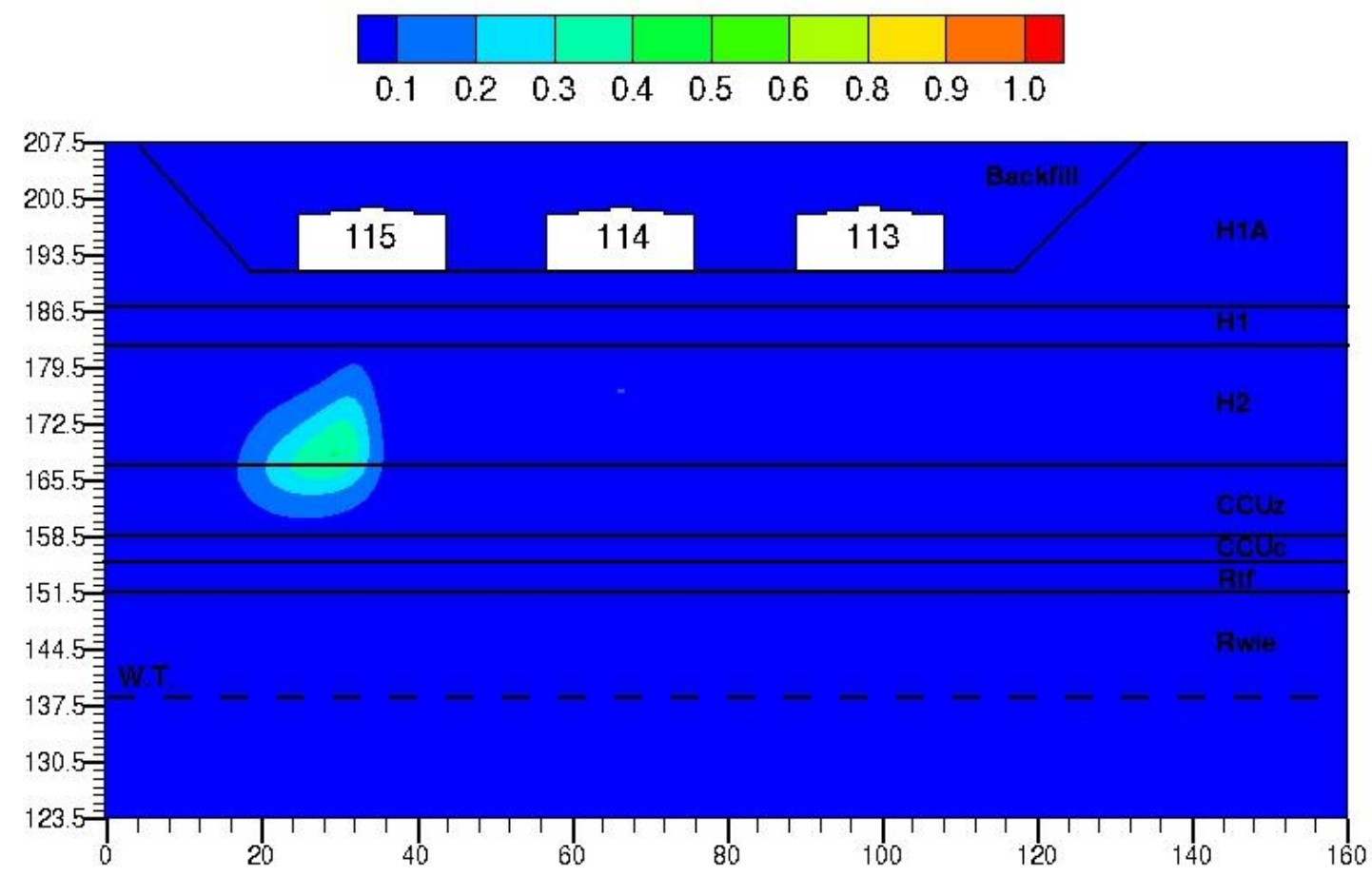

Figure 4.66. Dimensionless Tc-99 concentration in 2014 for the Reduced CCU Ksat simulation (transect $8 \mathrm{~m}$ south of tank centers).
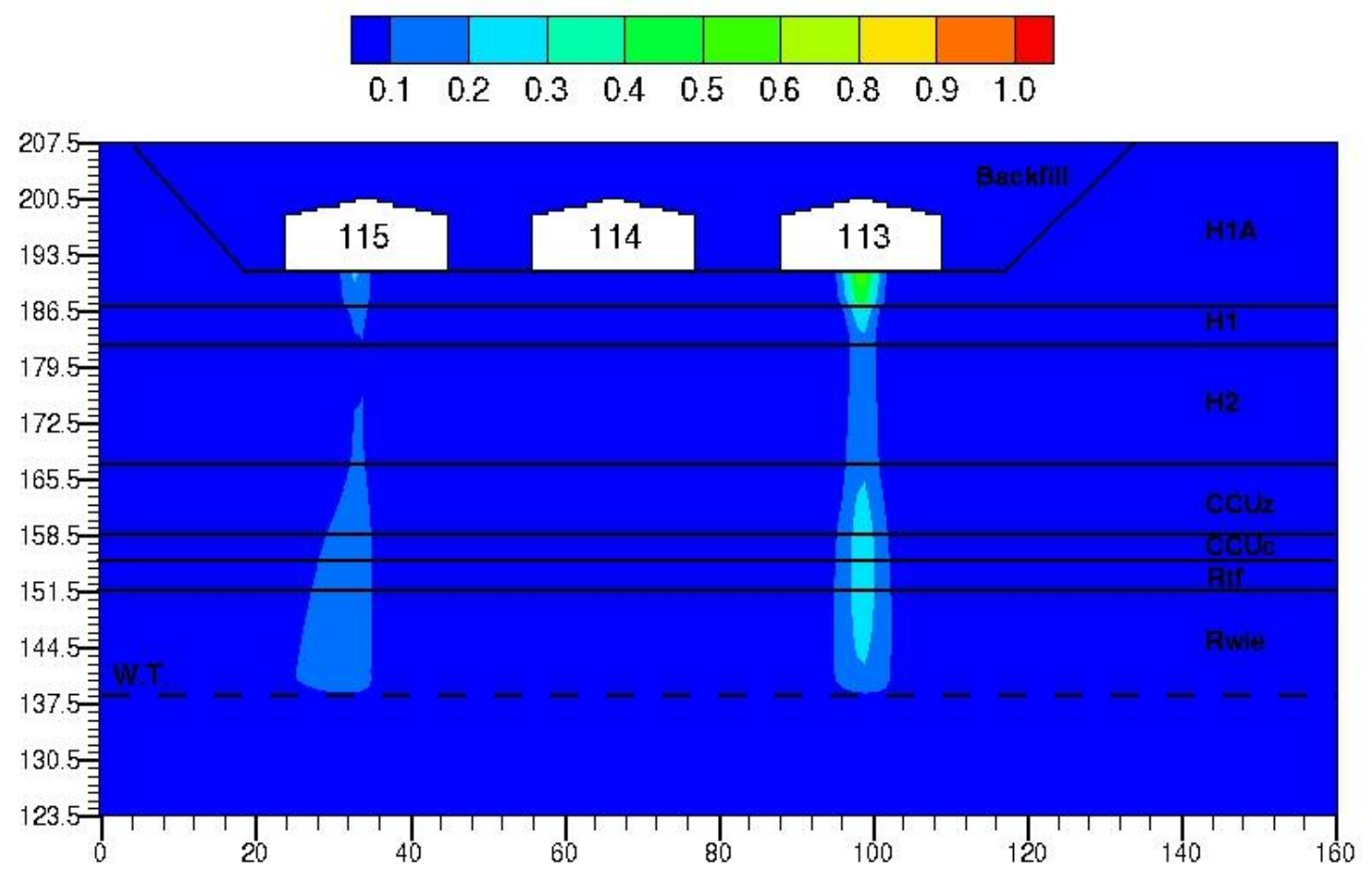

Figure 4.67. Dimensionless Tc-99 concentration in 2100 for the Reduced CCU Ksat simulation (transect through tank centers). 

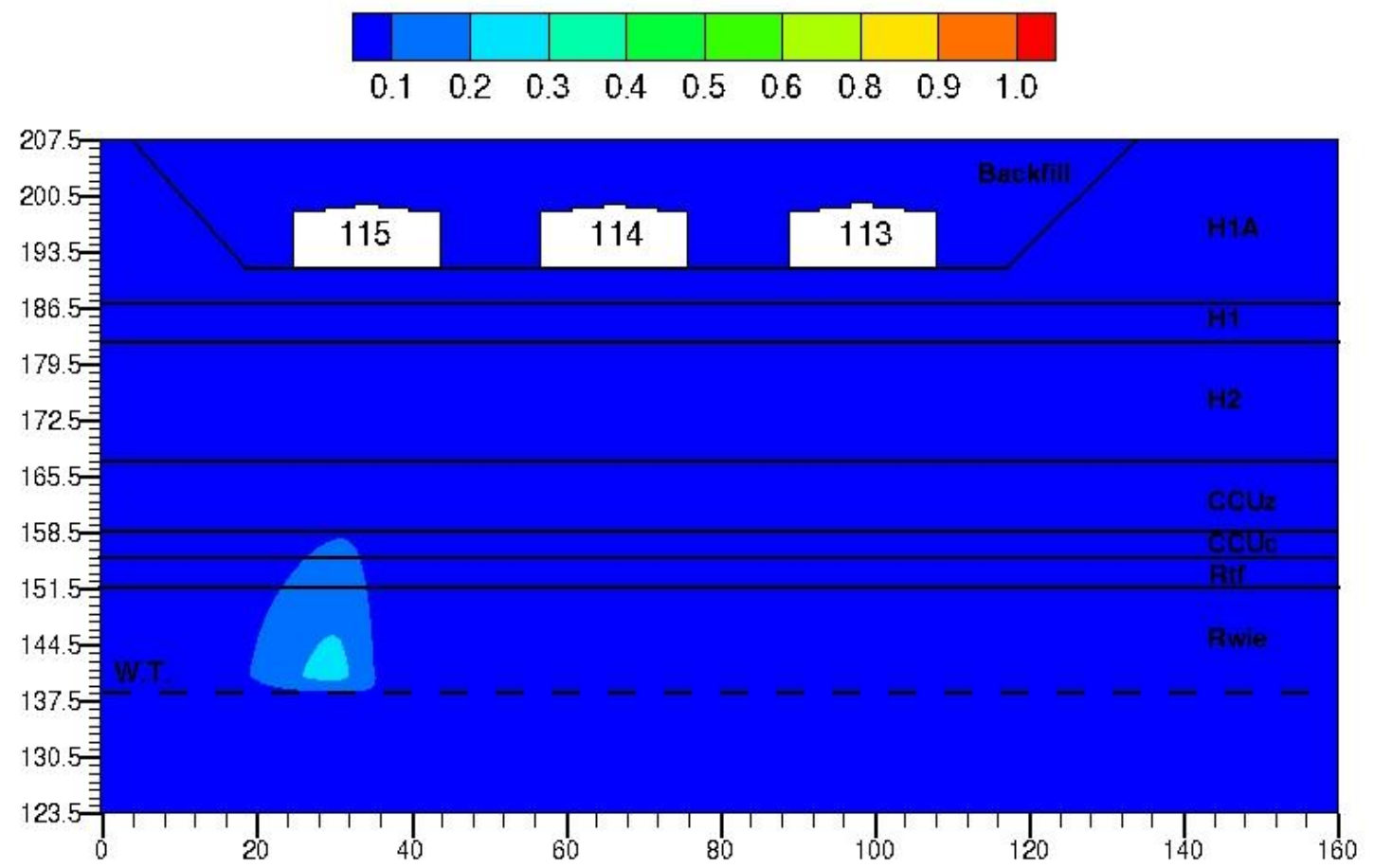

Figure 4.68. Dimensionless Tc-99 concentration in 2100 for the Reduced CCU Ksat simulation (transect $8 \mathrm{~m}$ south of tank centers).

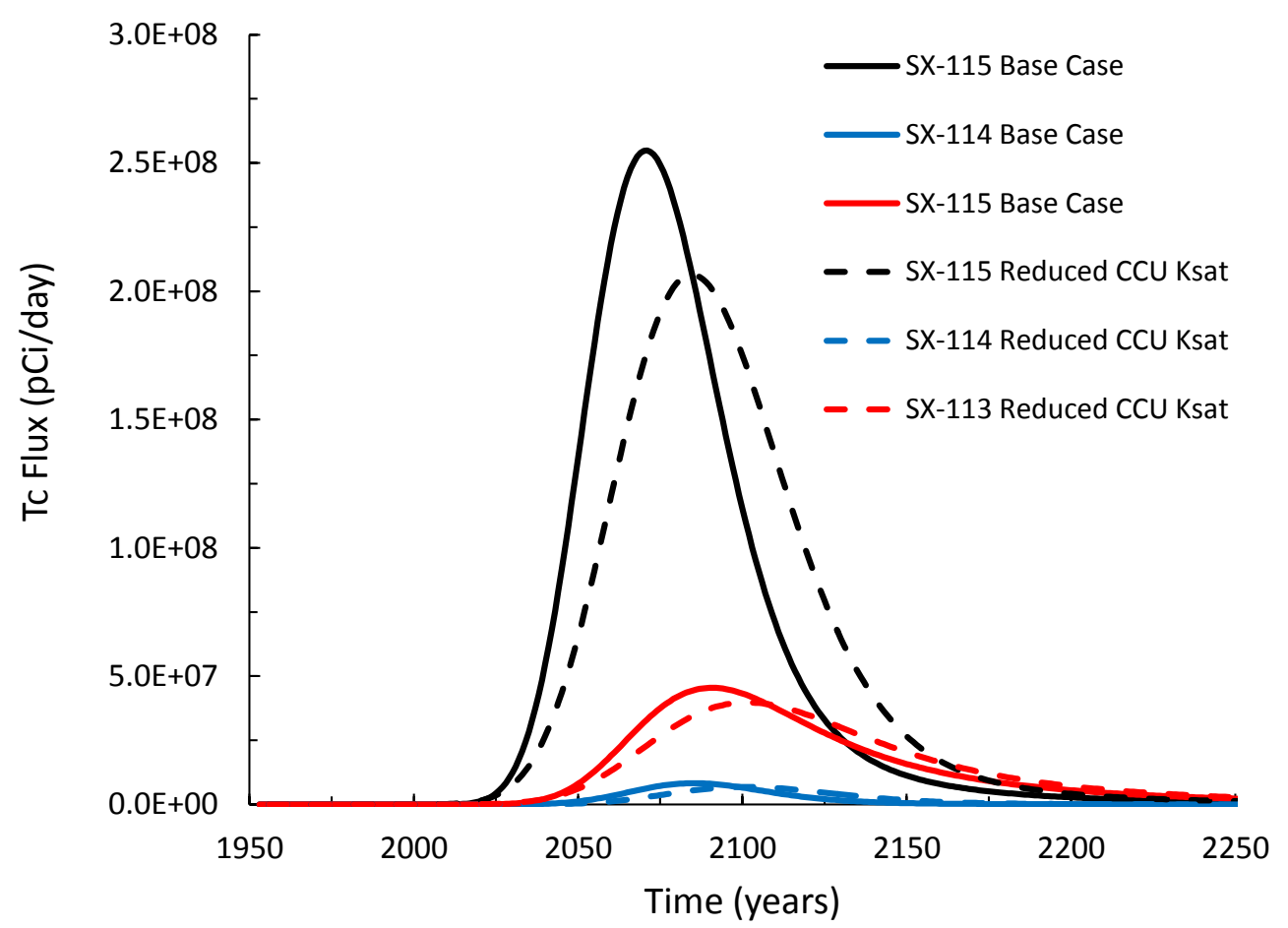

Figure 4.69. Comparison of Tc-99 mass discharge (pCi/d) into groundwater for Base Case and Reduced CCU Ksat simulation. 


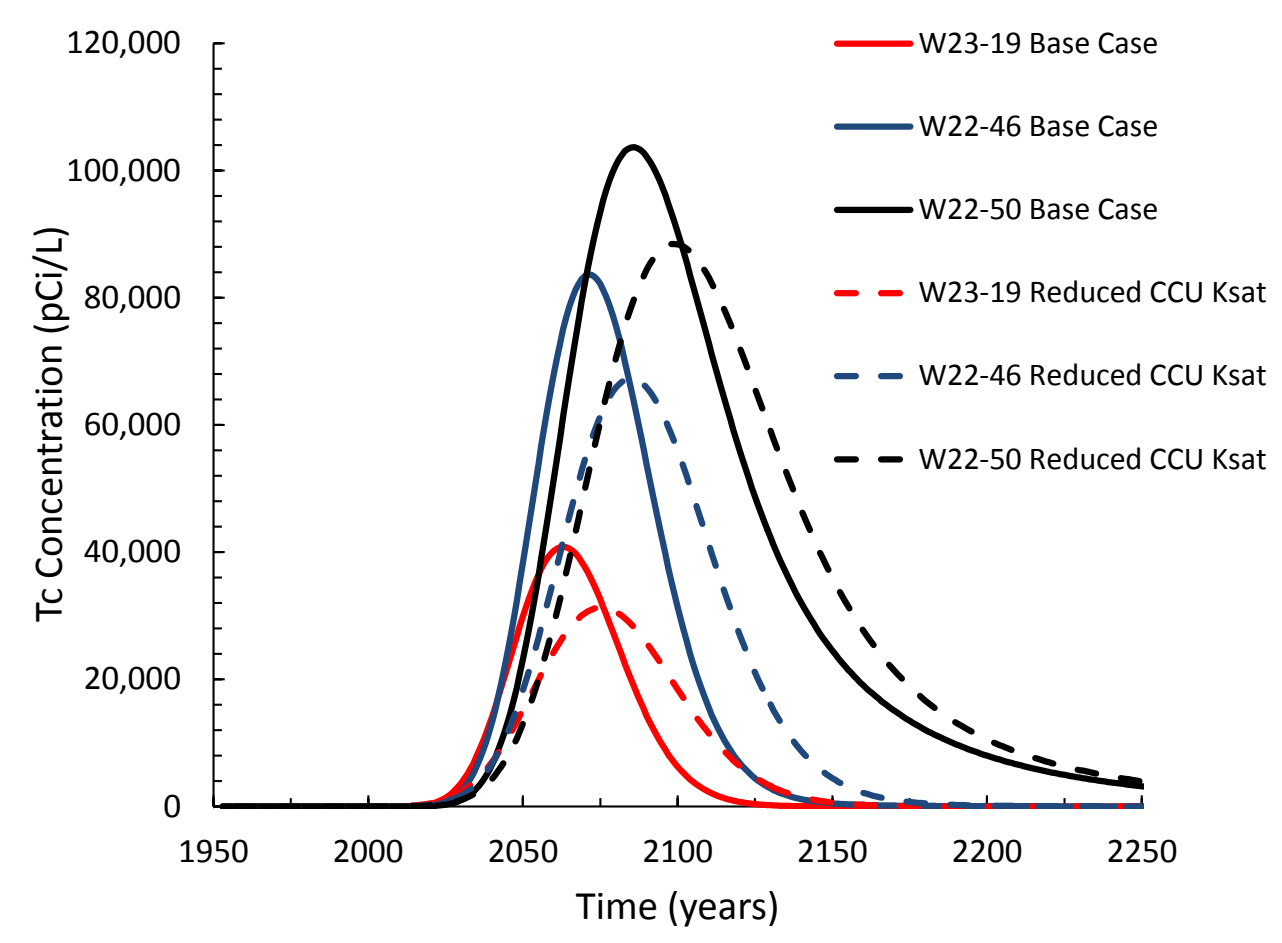

Figure 4.70. Comparison of Tc-99 well concentrations for Base Case and Reduced CCU Ksat simulation.

\subsubsection{Effects of Tank Leak Rates and Duration}

The local SX-108 simulations revealed that the leak duration and leak volumes had a minimal effect on the mass flux to groundwater. SX Tank Farm simulations were conducted to investigate the potential for compounding of individual plumes into large ones as a result of a reduction of the leak duration (Reduced Leak Duration simulation; Table 3.3) or the leakage of larger volumes (Increased Leak Volume). For both of these simulations, the differences between them and the Base Case were small, as was also seen for the SX-108 scoping simulations. The parameter modifications did not lead to compounding plumes. Examples of the limited influence of the imposed changes are presented in Figure 4.71 and Figure 4.72 for the predicted well concentrations. 


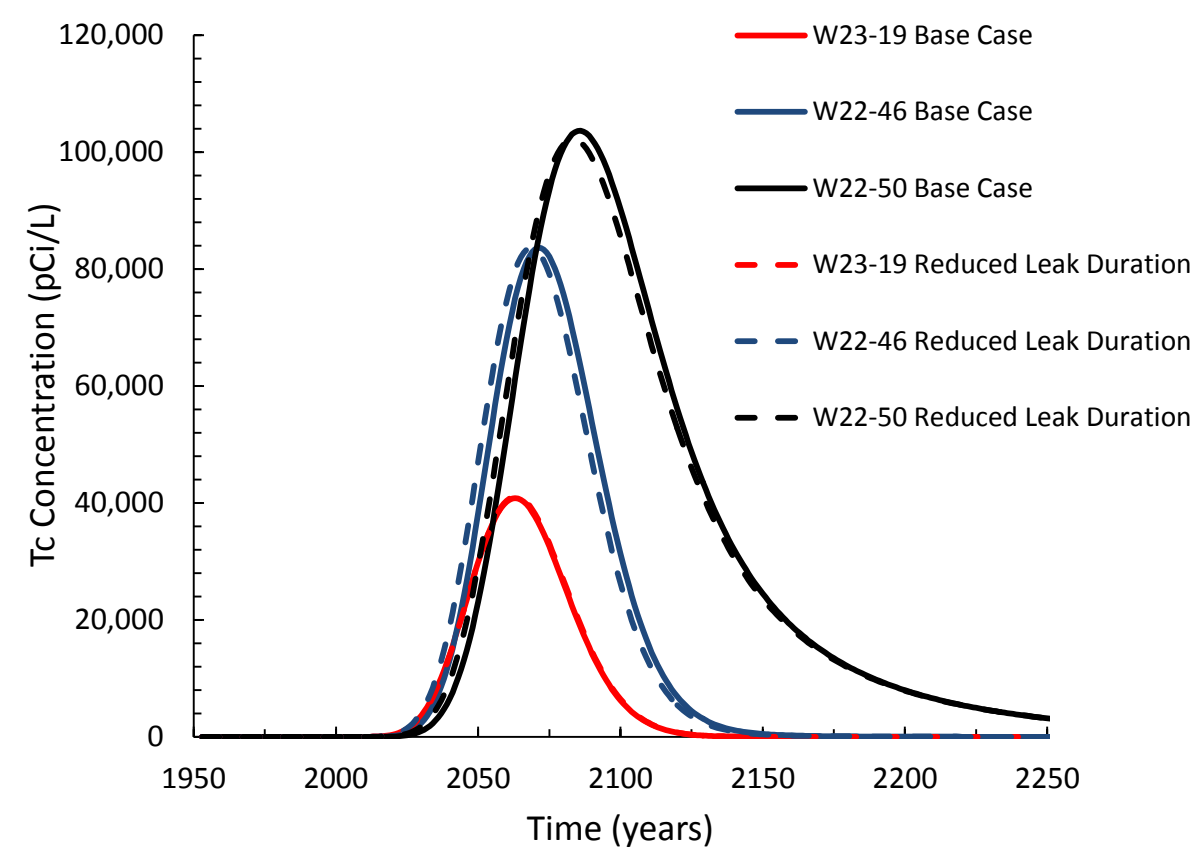

Figure 4.71. Comparison of Tc-99 well concentrations for Base Case and Reduced Leak Duration simulation.

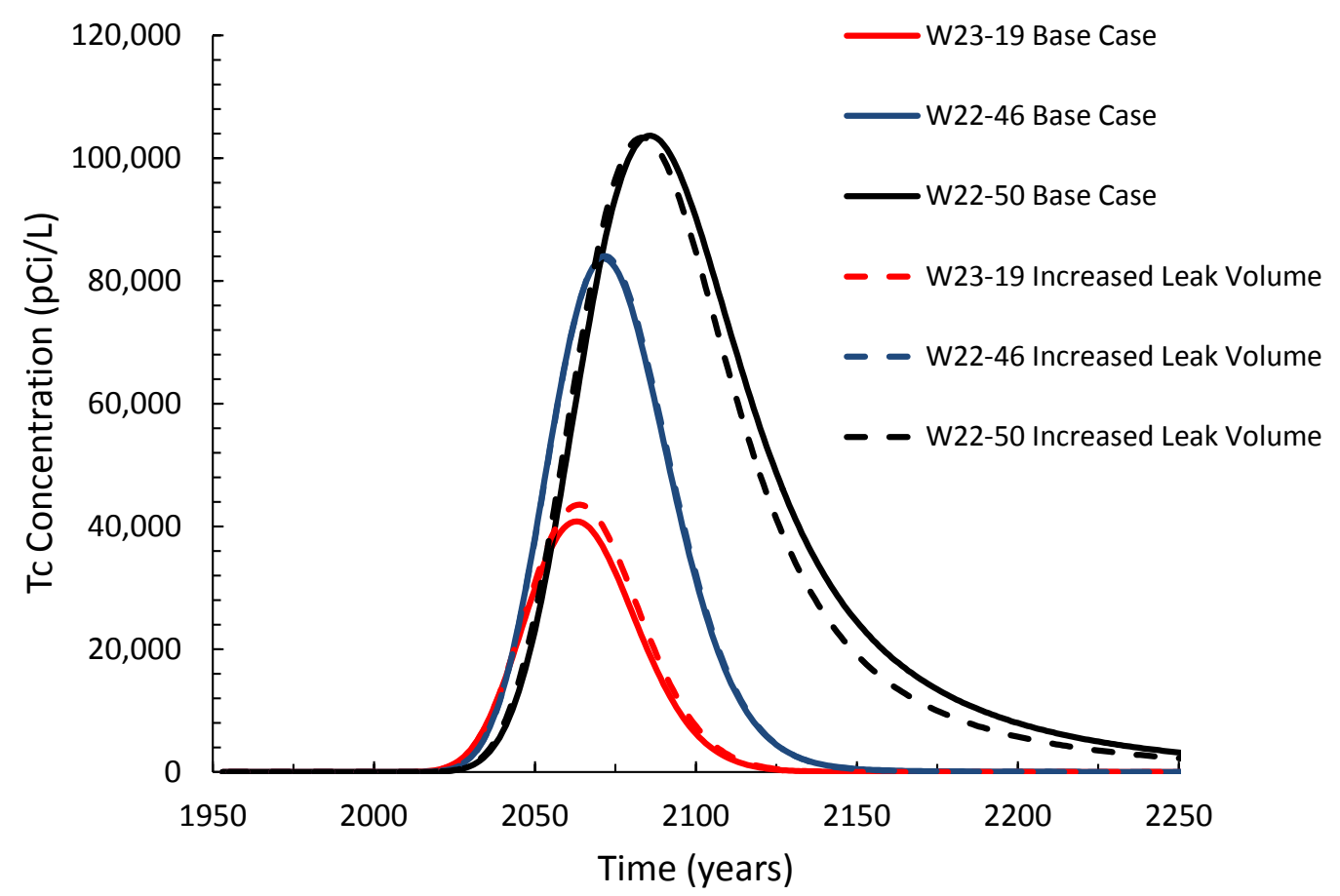

Figure 4.72. Comparison of Tc-99 well concentrations for Base Case and Increased Leak Volume simulation. 


\subsection{Cesium Transport}

All simulations listed in

Table 3.2 and Table 3.3 were also conducted with Cs-137 as the contaminant. The transport behavior of this contaminant is vastly different than that of Tc-99 because of its short half-life of 30 years and its ability to sorb to sediments. Serne et al. (2008a) found that the cesium partitioning coefficients $\left(\mathrm{K}_{\mathrm{d}}\right)$ for all of the tested Hanford sediments would be moderate $(4-40 \mathrm{~mL} / \mathrm{g})$ for very high ionic strength $(7.4 \mathrm{M}$ sodium nitrate), but neutral $\mathrm{pH}$, solutions, and would increase slightly for more moderate ionic strength (4 M sodium nitrate) solutions, especially for Ringold sediments. They also found that the cesium $\mathrm{K}_{\mathrm{d}}$ for low ionic strength, Hanford groundwater solutions, was very high, exceeding $50,000 \mathrm{~mL} / \mathrm{g}$ for some finegrained CCU sediments. These values are consistent with the best estimate cesium $\mathrm{K}_{\mathrm{d}}$ values of $4-10$ $\mathrm{mL} / \mathrm{g}$ identified by Last et al. (2009) for sediments affected by very high salt/very basic waste and 480$2,000 \mathrm{~mL} / \mathrm{g}$ for uncontaminated sediments. Based on the work by Serne et al (2008a) and Last et al. (2009) it was decided to use a $\mathrm{K}_{\mathrm{d}}$ value of $4 \mathrm{~mL} / \mathrm{g}$ for all sediments to predict conservative transport (i.e., more mobile) behavior of Cs-137.

For all simulations (Figure 4.73 through Figure 4.76), it was observed that the Cs-137 would not migrate deeper into the soil profile than the upper part of the $\mathrm{H} 2$ due to the imposed retardation, and that the vast majority would have been decayed by the year 2100 . No Cs-137 at all migrated to the groundwater for all considered conditions.

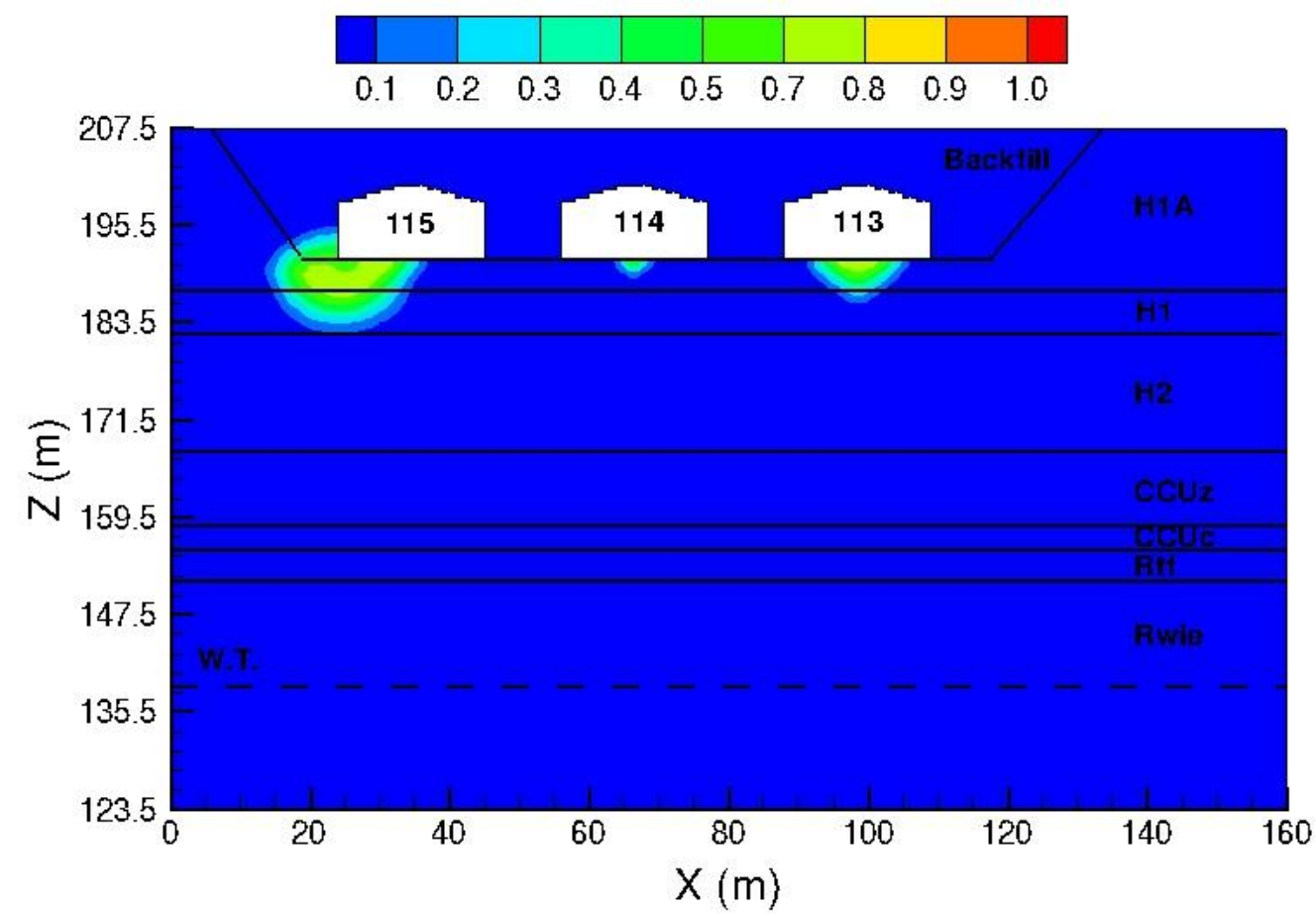

Figure 4.73. Dimensionless Cs-137 concentration at the end of the 1965 SX-115 leak. 


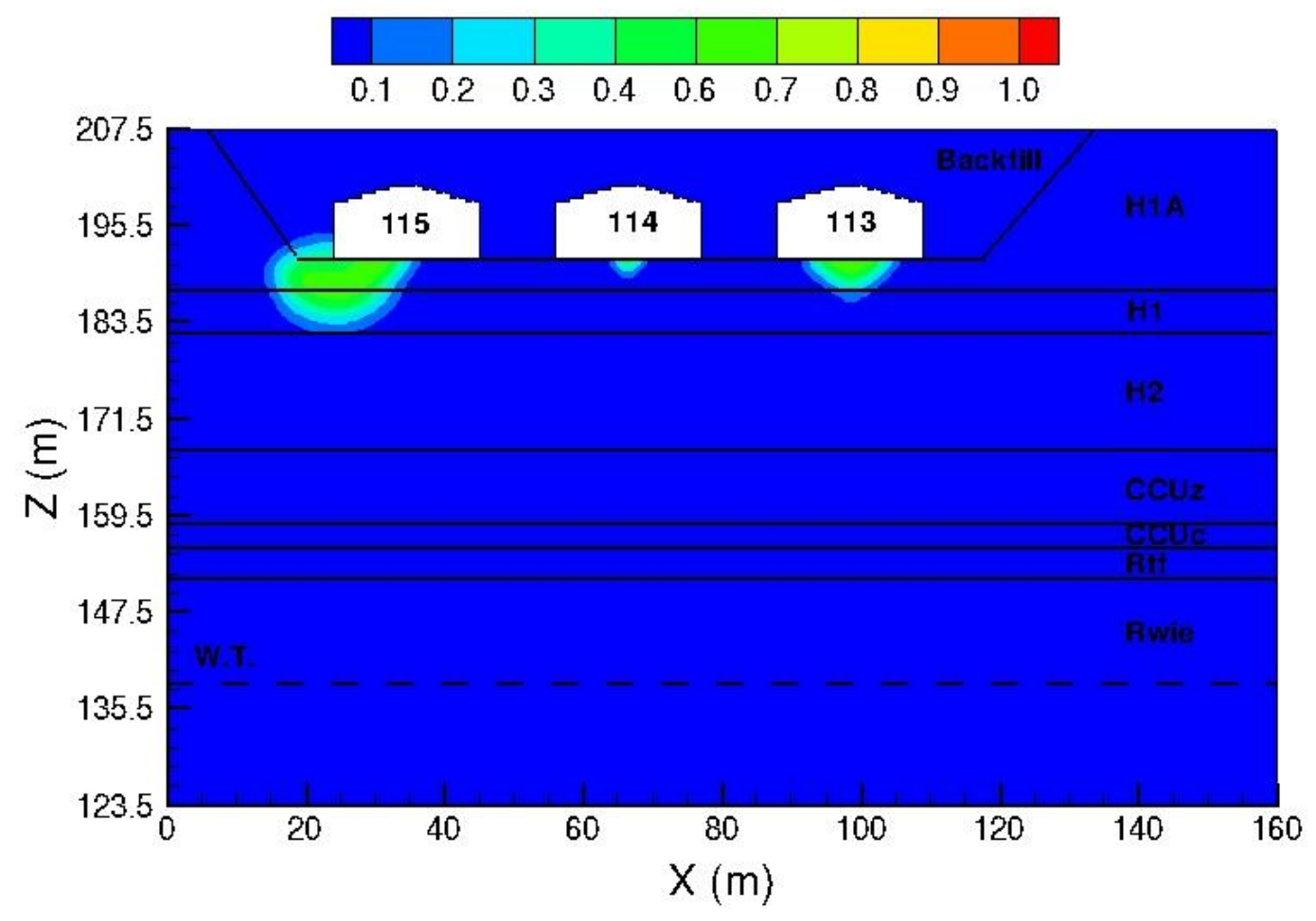

Figure 4.74. Dimensionless Cs-137 concentration in 1980.

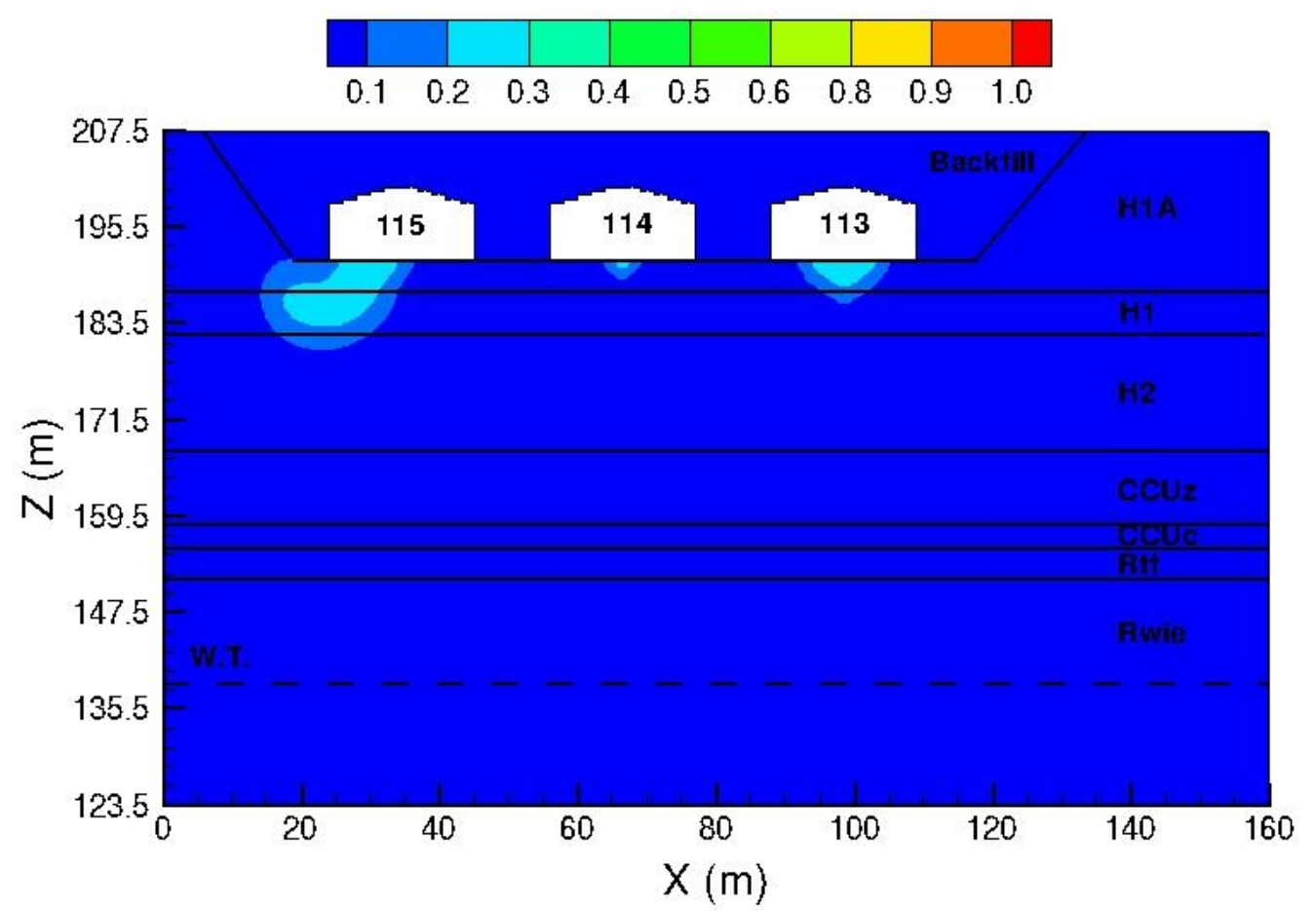

Figure 4.75. Dimensionless Cs-137 concentration in 2014 . 


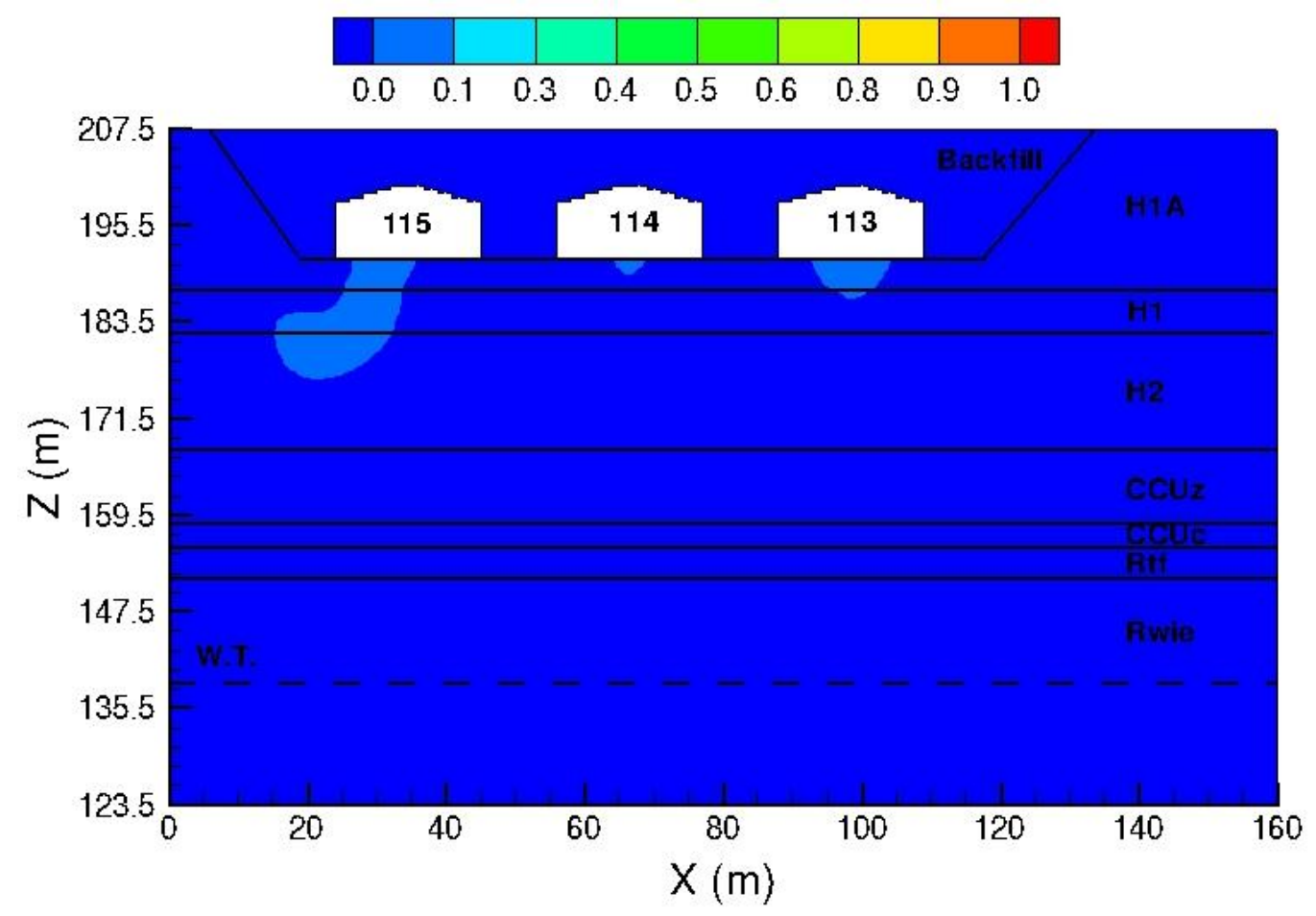

Figure 4.76. Dimensionless Cs-137 concentration in 2100 . 



\subsection{Conclusions}

At the DOE Hanford Site, contaminants were discharged to the subsurface through engineered waste sites in the Hanford Central Plateau. Additional waste was released through waste storage tank leaks. Much of the contaminant inventory is still present within the unsaturated vadose zone sediments. The nature and extent of future groundwater contaminant plumes and the growth or decline of current groundwater plumes beneath the Hanford Central Plateau are a function of the contaminant flux from the vadose zone to the groundwater. In general, contaminant transport is slow through the vadose zone and it is difficult to directly measure contaminant flux in the vadose zone. Predictive analysis, supported by site characterization and monitoring data, was applied using a structured approach based on the framework of Truex and Carroll (2013) to estimate the future contaminant flux to groundwater in support of remediation decisions for the vadose zone and groundwater. The SX Tank Farm was used as a case study because of the existing contaminant inventory in the vadose zone, observations of elevated moisture content in portions of the vadose zone, presence of a limited-extent groundwater plume, and the relatively large amount and wide variety of data available for the site. Although the SX Tank Farm case study is most representative of conditions at tank farm sites, the study has elements that are also relevant to other types of disposal sites in the Hanford Central Plateau.

A structured approach to estimating future contaminant flux to the groundwater was applied. This approach centers on using a systems-based, conceptual model to guide the study. The approach is initiated by considering the environmental and engineering setting of the site, gathering available data and information as is typically done for a tradition conceptual site model. An important part of this step is considering the lines of evidence provided by different types of data and any limitations for use of the data. The conceptual model is then refined by evaluating key elements of the environmental setting, while also considering potential controlling features and processes and relevant boundary conditions in the context of water and contaminant flux through the vadose zone. This refinement takes place as an integrated evaluation of data, unsaturated flow phenomena, and predictive analyses to investigate the role of different driving forces for contaminant flux at the site. Sensitivity analyses are conducted as part of this investigation to help assess the importance of different elements within the range of certainty of the data. Refinement also includes comparing the results of predictive analyses to available characterization and monitoring data. The refinement process identifies a range of contaminant flux conditions that reasonably bound the variation in data and provide an estimate for future contaminant flux to groundwater. Results for contaminant flux estimates can then be explained in terms of the conceptual model and the key controlling features and processes. This approach also provides a means to investigate how types of mitigation strategies - in this example, use of a surface infiltration barrier-may impact the future contaminant flux.

For the SX Tank Farm case study, the following conclusions were reached based on the contaminant flux analysis. These conclusions provide the technical foundation for supporting estimates of contaminant flux at the site. Key elements of the refined conceptual model for the SX Tank Farm are summarized in Figure 5.1.

- The leak volumes were small with respect to attenuation of advective flow in the vadose zone and do not drive long-term flux. The change in surface recharge following tank farm construction imposed a much larger hydraulic driving force on the vadose zone than the tank leaks. 
- Even though massive amounts of water were discharged at sites in the vicinity of the SX Tank Farm (e.g., 216-U Pond), these discharges did not significantly impact water and contaminant flow beneath the SX Tank Farm and do not need to be considered in setting the boundary conditions for SX Tank Farm subsurface flow and transport analyses.

- The imposed recharge change in 1953, with an estimated impact of changing the surface recharge from about $3.5 \mathrm{~mm} / \mathrm{yr}$ to about $92 \mathrm{~mm} / \mathrm{yr}$, propagated changes in the vadose zone flow conditions. Changes in the surface recharge resulted in changes in the water flux into the groundwater about 50 years after the surface change occurred such that current conditions in the vadose zone are at a steadystate condition with respect to the imposed $92-\mathrm{mm} / \mathrm{yr}$ recharge rate. This recharge rate controls the water flux throughout the vadose zone beneath the SX Tank Farm regardless of subsurface sediment properties, unless there is a localized source of higher water inflow (e.g., a water-line leak).

- In the presence of a water-line leak, localized conditions can be created that intersect vadose zone contamination and accelerate contaminant transport into the groundwater. The Tc-99 plume at the south end of the SX Tank Farms cannot be explained without imposing a localized water-line leak near the SX-115 tank. When a leak is simulated, the Tc-99 plume and contaminant arrival times at downstream wells can be reasonably replicated. It appears that the water-line leak adjacent to the SX115 tank has created the only accelerated contaminant flux condition at the SX Tank Farm. The other contaminant plumes would be expected to develop based on recharge-driven flux.

- While contaminants released from the tanks were initially advectively transported due to the leak, vadose zone processes quickly dissipated these conditions and the increased recharge rate became the controlling factor for water flux toward the groundwater. Unsaturated flow properties and the increased relative importance of molecular contaminant diffusion delay the contaminant flux compared to the water flux. Thus, in the absence of localized water-line leaks enhancing advective transport, while the increased recharge front is estimated to have reached the water table at present, the contamination front from leaks is expected to occur in the future.

- The contaminant flux profile is related to the decrease in contaminant concentration caused by vadose zone flow and transport processes, contaminant-specific sorption, and decay properties (which are significant for Cs-137), and the recharge-driven water flux. Because the radioactive decay of Cs-137 is relatively fast, even with moderate sorption to sediments, Cs-137 is predicted to decay before being discharged to the groundwater. In contrast, Tc-99 has a long half-life and minimal sorption and is predicted to enter the groundwater.

- Because leak volumes are relatively small and recharge controls the water flux through the vadose zone, contaminant plumes from individual tanks are not expected to co-mingle significantly in the vadose zone.

- Because recharge controls the contaminant flux conditions, a surface infiltration barrier can reduce the future contaminant flux to groundwater. However, it takes time for the effects of a barrier to propagate in the vadose zone and impact the water and associated contaminant flux to the groundwater. Although emplacement of a barrier will reduce the magnitude of future contaminant fluxes, these fluxes may result in groundwater concentrations exceeding standards over much longer periods. 


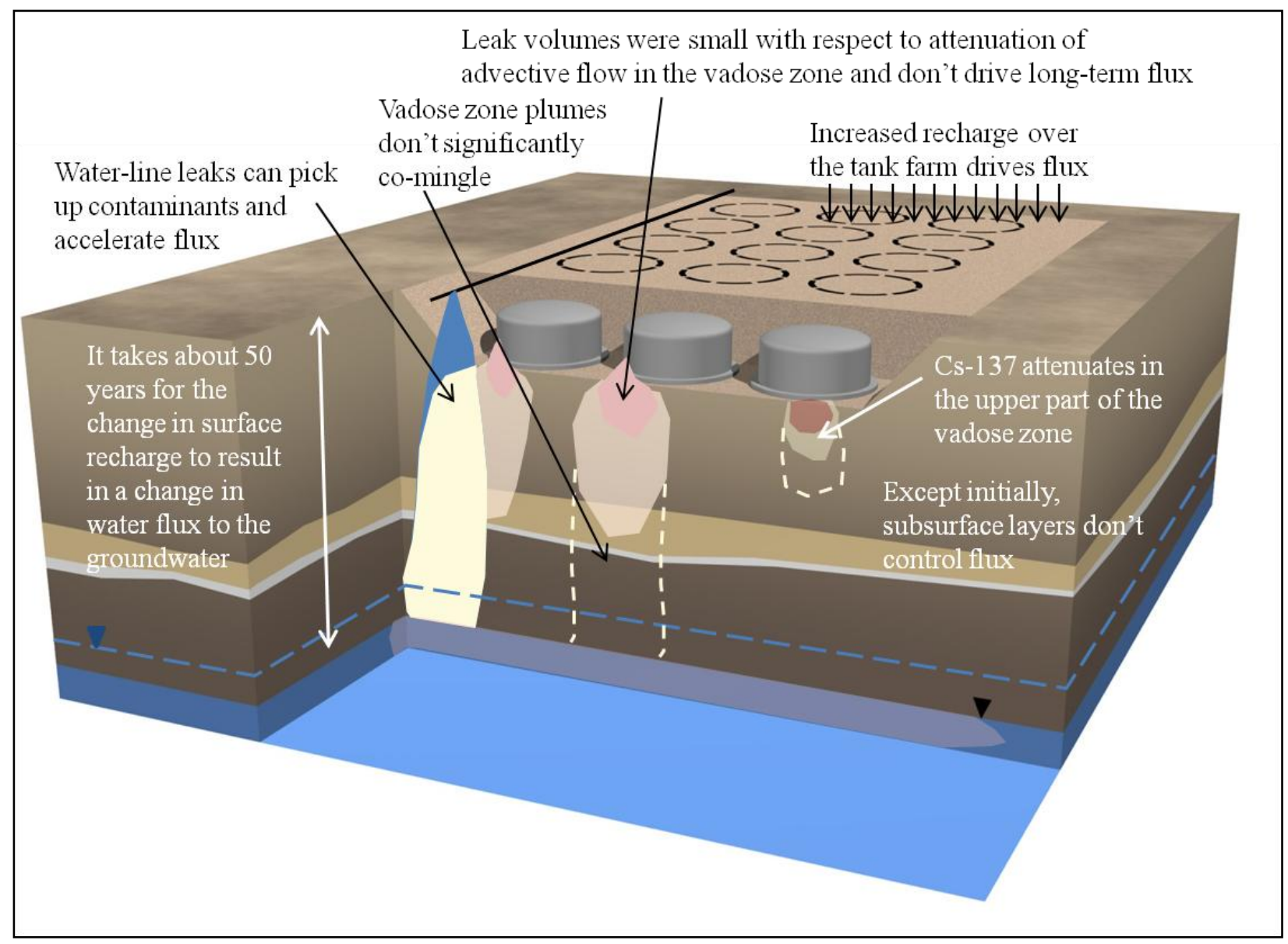

Figure 5.1. Synthesized conceptual model for the SX Tank Farm showing key conclusions related to future contaminant flux estimates.

Based on the contaminant flux analyses in the study, in the absence of any mitigation measures, the Tc-99 flux to groundwater from the SX-115 tank is expected to increase over the next 40 years before it starts to decline. Groundwater contamination from other tank leaks is expected to occur over the next 10-20 years with a peak contaminant flux in 60-100 years (depending on the individual tank leak). Installation of a surface infiltration barrier can delay the initial contaminant flux and decrease the magnitude of the peak flux, causing a lower overall contaminant flux over a much longer period of time. The magnitude and duration of contaminant flux are both important aspects in evaluating remediation alternatives.

The analysis presented herein was conducted as a case study using SX Tank Farm data. The intent is to provide 1) an example of a structured approach to estimating future contaminant flux to groundwater and 2) a technical foundation for the flux estimates. Key portions of the SX Tank Farm and associated water and contaminant sources (i.e., Tc-99 and Cs-137) were examined, but the analysis was not comprehensive for all SX Tank Farm contaminants. While the structured approach to estimating future contaminant flux is transferrable to other tank farms and waste disposal sites, specific conclusions with respect to contaminant flux at the SX Tank Farms are not necessarily applicable at other sites. 
The contaminant flux analysis is important to provide input to remediation decisions, and also to focus characterization. For instance, only a few elements were shown to control the contaminant flux at the SX Tank Farm. Additional information about non-controlling features will not improve these estimates. Thus, characterization can be focused on gathering information that decreases uncertainty in these flux estimates, if needed to support a remedy decision, or on aspects related to evaluation and implementation of remediation alternatives. For the SX Tank Farm, the future contaminant flux estimates are fairly well bounded by the available information. This type of study may also be useful in communicating and discussing remediation decisions by demonstrating that uncertainty in some parameters (e.g., leak volumes and duration, detailed hydraulic property distributions) do not significantly impact the estimates of future contaminant flux. 


\subsection{Quality Assurance}

The Pacific Northwest National Laboratory (PNNL) Quality Assurance (QA) Program is based upon the requirements defined in DOE Order 414.1D, Quality Assurance and 10 CFR 830, Energy/Nuclear Safety Management, Subpart A - Quality Assurance Requirements (a.k.a. the Quality Rule). PNNL has chosen to implement the following consensus standards in a graded approach:

- ASME NQA-1-2000, Quality Assurance Requirements for Nuclear Facility Applications, Part 1, Requirements for Quality Assurance Programs for Nuclear Facilities.

- ASME NQA-1-2000, Part II, Subpart 2.7, Quality Assurance Requirements for Computer Software for Nuclear Facility Applications, including problem reporting and corrective action.

- ASME NQA-1-2000, Part IV, Subpart 4.2, Guidance on Graded Application of Quality Assurance (QA) for Nuclear-Related Research and Development.

The procedures necessary to implement the requirements are documented through PNNL's "How Do I...? (HDI) system, a system for managing the delivery of laboratory-level policies, requirements and procedures.

The DVZ-AFRI Quality Assurance Plan (Meier 2014) is the minimum applicable QA document for all Deep Vadose Zone-Applied Field Research Initiative (DVZ-AFRI) projects. This QA Plan also conforms to the QA requirements of DOE Order 414.1D, Quality Assurance, and 10 CFR 830, Subpart A, Quality Assurance Requirements. The DVZ-AFRI is subject to the Price Anderson Amendments Act (PAAA 2005). The implementation of the DVZ-AFRI QA program is graded in accordance with NQA-12000, Part IV, Subpart 4.2, Guidance on Graded Application of Quality Assurance (QA) for NuclearRelated Research and Development.

The work for this report was performed under the technology level of Applied Research. Applied Research consists of research tasks that acquire data and documentation necessary to ensure satisfactory reproducibility of results. The emphasis during this stage of a research task is on achieving adequate documentation and controls necessary to be able to reproduce results. 



\subsection{References}

10 CFR 830, Subpart A, 2001 - “Quality Assurance Requirements.” U.S. Code of Federal Regulations.

Anderson, F.J. 2001. Engineering Report, Single-Shell Tank Farms, Interim Measures to Limit Infiltration Through the Vadose Zone. RPP-5002, Rev. 1, CH2M HILL Hanford Group, Inc., Richland, Washington.

ASME. 2001. Quality Assurance Requirements for Nuclear Facility Applications. NQA-1-2000, American Society of Mechanical Engineers, New York.

CHPRC. 2014. Hanford Site Groundwater Monitoring Report For 2013. DOE/RL-2014-32, Revision 0, CH2MHill Plateau Remediation Company, Richland, Washington.

Corbin, R.A., B.C. Simpson, M.J. Anderson, W.F. Danielson, III, J.G. Field, T.E. Jones, and C.T. Kincaid. 2005. Hanford Soil Inventory Model, Rev. 1. RPP-26744, Rev. 0, CH2MHill Hanford Group, Inc., Richland, Washington.

DOE. 2005. Technical Guidance Document for Tank Closure Environmental Impact Statement Vadose Zone and Groundwater Revised Analyses, Final Rev. 0, March 25, 2005. U.S. Department of Energy, Richland, Washington. Available at: http://www.hanford.gov/files.cfm/TCEISVadose.pdf.

DOE. 2011, as amended. Quality Assurance. DOE Order 414.1D, Washington, D.C.

DOE/RL 2012. Final Tank Closure and Waste Management Environmental Impact Statement for the Hanford Site, Richland, Washington. DOE/EIS-0391, U.S. Department of Energy, Richland Operations Office, Richland, Washington.

DOE/RL. 2013. Hanford Site Groundwater Monitoring Report for 2012. DOE/RL-2013-22, U.S. Department of Energy, Richland Operations Office, Richland, Washington.

EPA/Ecology/DOE. 2012. Record of Decision, For Interim Remedial Action, Hanford 200 Area Superfund Site, 200-UP-1 Operable Unit. 12-AMRP-0171, U.S. Environmental Protection Agency, Washington State Department of Ecology, and U.S. Department of Energy, Richland, Washington. Available at: http://pdw.hanford.gov/arpir/index.cfm/docDetail?accession=0091413 or http://www.epa.gov/region10/pdf/sites/hanford/200/Hanford 200 Area_Interim ROD Remedial_Action_0912.pdf; accessed on September 18, 2014).

Fayer, M.J., and J.M. Keller. 2007. Recharge Data Package for Hanford Single-Shell Tank Waste Management Areas. PNNL-16688, Pacific Northwest National Laboratory, Richland, Washington.

Fayer, M.J., A.L. Ward, and V.L. Freedman. 2010. Technical Basis for Evaluating Surface Barriers to Protect Groundwater from Deep Vadose Zone Contamination. PNNL-18661, Pacific Northwest National Laboratory, Richland, Washington. 
Girardot, C.L., and D.G. Harlow. 2014. Hanford Single-Shell Tank Leak Causes and Locations - 241-SX Farm. RPP-RPT-54910, Rev. 0., Washington River Protection Solutions, Richland, Washington.

Hartman, M.J. 2000. Hanford Site Groundwater Monitoring: Setting, Sources, and Methods. PNNL13080, Pacific Northwest National Laboratory, Richland, Washington.

Johnson, V.G., and C.J. Chou. 2002. Groundwater Quality Assessment Report for Waste Management Area S-SX (April 2000 through December 2001). PNNL-13801, Pacific Northwest National Laboratory, Richland, Washington.

Johnson, M.E., and J.G. Field. 2010. Hanford SX-Farm Leak Assessments Report. RPP-ENV-39658, Rev. 0, Washington River Protection Solutions, Richland, Washington.

Johnson, T.C., and D.M. Wellman. 2013. Re-inversion of Surface Electrical Resistivity Tomography Data from the Hanford Site B-Complex. PNNL-22520, Pacific Northwest National Laboratory, Richland, Washington.

Last, G.V., E.J. Freeman, K.J. Cantrell, M.J. Fayer, G.W. Gee, W.E. Nichols, B.N. Bjornstad, and D.G. Horton. 2006a. Vadose Zone Hydrogeology Data Package for the 2004 Composite Analysis. PNNL-14702 Rev. 1, Pacific Northwest National Laboratory, Richland, Washington.

Last, G.V., W.E. Nichols, and C.T. Kincaid. 2006b. Geographic and Operational Site Parameters List (GOSPL) for Hanford Assessments. PNNL-14725, Pacific Northwest National Laboratory, Richland, Washington.

Last, G.V., P.D. Thorne, J.A. Horner, K.R. Parker, B.N. Bjornstad, D.C. Lanigan, and B.A. Williams. 2009. Hydrogeology of the Hanford Site Central Plateau - A Status Report for the 200 West Area. PNNL-17913, Rev. 1, Pacific Northwest National Laboratory, Richland, Washington.

Levitt, M., and C. Henderson. 2009. Surface Geophysical Exploration of the SX Tank Farm at the Hanford Site. RPP-RPT-42513, Rev. 0, Washington River Protection Solutions, Richland, Washington.

Meier, K.M. 2014. Deep Vadose Zone Applied Field Research Initiative Quality Assurance Plan. QA-DVZ-AFRI-001, Rev. 1, Pacific Northwest National Laboratory, Richland, Washington.

Mualem, Y. 1976. "A New Model for Predicting the Hydraulic Conductivity of Unsaturated Porous Media." Water Resources Research, 12:513-522.

PAAA. 2005. Price-Anderson Amendments Act. Energy Policy Act of 2005. Title VI—Nuclear Matters, Subtitle A-Price-Anderson Act Amendments, Section 601 et. seq. Public Law 109-58, as amended. 42 USC 15801 et seq.

Serne, R.J., G.V. Last, H.T. Schaef, D.C. Lanigan, C.W. Lindenmeier, C.C. Ainsworth, R.E. Clayton, V.L. Legore, M.J. O'Hara, C.F. Brown, R.D. Orr, I.V. Kutnyakov, T.C. Wilson, K.B. Wagnon, B.A. Williams, and D.S. Burke. 2008a. Characterization of Vadose Zone Sediment: Borehole 41-09-39 in the S-SX Waste Management Area. PNNL-13757-3, Pacific Northwest National Laboratory, Richland, Washington. 
Serne, R.J., G.V. Last, H.T. Schaef, D.C. Lanigan, C.W. Lindenmeier, C.C. Ainsworth, R.E. Clayton, V.L. Legore, M.J. O'Hara, C.F. Brown, R.D. Orr, I.V. Kutnyakov, T.C. Wilson, K.B. Wagnon, B.A. Williams, and D.S. Burke. 2008b. Characterization of Vadose Zone Sediment: Slant Borehole SX-108 in the S-SX Waste Management Area. PNNL 13757-4, Rev. 1, Pacific Northwest National Laboratory, Richland, Washington.

Truex, M.J., and K.C. Carroll. 2013. Remedy Evaluation Framework for Inorganic, Non-Volatile Contaminants in the Vadose Zone. PNNL-21815, Pacific Northwest National Laboratory, Richland, Washington.

Truex, M.J., M. Oostrom, T.W. Wietsma, G.V. Last, and D.C. Lanigan. 2013. Pore-Water Extraction Scale-Up Study for the SX Tank Farm. PNNL-21882, Pacific Northwest National Laboratory, Richland, Washington.

van Genuchten, M.Th. 1980. "A Closed Form Equation for Predicting the Hydraulic Conductivity of Unsaturated Soils.” Soil Science Society of America J., 44(5):892-898.

White, M.D., and M. Oostrom. 2006. STOMP - Subsurface Transport Over Multiple Phases, Version 4.0 - User's Guide. PNNL-15782, Pacific Northwest National Laboratory, Richland, Washington.

Williams, J.C. 2001. Historical Vadose Zone Contamination From S and SX Tank Farm Operations. HNF-SD-WM-ER-560, Rev. 1, Fluor Federal Services, Richland, Washington.

Wood, M.I., V.G. Johnson, S.P. Reidel, and T.E. Jones. 1999. Subsurface Conditions Description for the S-SX Waste Management Area. HNF-4936, Lockheed Martin Hanford Corporation, Richland, Washington.

Zhang, Z.F., V.L. Freedman, S.R. Waichler, and S.K. Wurstner. 2005. 2005 Closure Assessments for SSX Tank Farms: Numerical Simulations. PNNL-15399, Pacific Northwest National Laboratory, Richland, Washington. 



\section{Appendix A}

SX Tank Farm Operational Background Information 



\section{Appendix A}

\section{SX Tank Farm Operational Background Information}

\section{A.1 Operational History}

The SX tanks began receiving high-level waste from REDOX in 1954 and continued to receive waste until REDOX was shut down in 1967 (Williams 2001). By early 1955 the first four tanks (241-SX-101, 102, -103, and -104) were full (Williams 2001). Tank space quickly became an issue and efforts were made to recover tank space in the SX Tank Farm through waste transfers to other tank farms in 1958 and during the mid-1960s, and volume reduction efforts (from the uranium recovery and in-plant [REDOX] concentration programs) (Williams 2001).

REDOX high-level waste was highly concentrated and led to self-boiling within the tanks. Vapors (from the boiling action) were routed through headers to tank 241-SX-106 and then to condensers (in buildings 241-SX-401 and -402). Non-condensables were vented to the atmosphere through filters (Anderson 2001). Condensate was either discarded to the 216-S-21 crib or returned to the waste tanks to maintain the desired liquid level (Anderson 2001) and ensure an even boiling rate (Williams 2001). Condenser cooling water was discharged to the 216-U-10 Pond. Two large tanks (2901-SX-1 and -2) of emergency cooling water were located outside the tank farm in case of condenser failure (Williams 2001). Condensate and cooling water from the 241-SX-401 and -402 condenser buildings were discharged to the 216-S-21 crib and 216-U-10 Pond, respectively, from November 1954 to December 1970, when a new ventilation system was installed and the 241-SX-401 and -402 condensers were shut down (Williams 2001). The new SX Tank Farm exhauster is still in operation (Willams 2001).

Airlift circulators within the tanks, were operated to promote mixing of the tank supernatant. Steam condensate from the air compressor house (241-SX-701) used to support the in-tank airlift circulators was routed to the 216-SX-2 crib, which operated from 1952 to 1965, when it was abandoned because of poor infiltration. The steam condensate was then routed to an open pit south of the SX Tank Farm (200-W236), via the 200-W-235-PL pipeline.

By November 1973, an evaporator-crystallizer, (242-S) was placed in operation to remove water from the tanks, converting aqueous salt wastes from the 241-S and -SX tanks to salt slurry that was returned to the tanks for storage (Anderson 2001). Interstitial liquid was removed from the tanks by saltwell jet pumping and sent to the evaporator-crystallizer. Evaporator bottoms were sent back to the tanks for storage. Process condensate from the 242-S evaporator was discharged to the 216-S-25 crib. By November 1980, all liquid waste in the S/SX Tank Farms had been reduced to saltcake, the tanks had been taken out of service, and the 242-S evaporator had been shut down (Williams 2001). The tanks, diversion boxes, etc. have undergone stabilization and isolation (Anderson 2001; Williams 2001).

\section{A.2 Unplanned Releases}

"Numerous tank waste leaks have occurred in the single-shell tank (SST) farms through overfilling of tanks or through leaks in ancillary equipment (e.g., piping) during transfers of waste from one tank to 
another. This characterization program" (i.e., the Field Investigation Report for Waste Management Area S-SX) "has shown how important the effects of anthropomorphic type leaks from tank infrastructure have been in the migration history of tank leaks" (CHPRC 2002 |RPP-7884|).

Inadvertent and unplanned releases during operation of the 241-SX Tank Farm (like other SST farms) contributed contamination to "the soil above, around, and below the SSTs" (Anderson 2001). Ten of the 15 tanks in the SX Tank Farm were officially designated as leakers (Williams 2001). Eight of the tanks are believed to have released liquids to the subsurface and a groundwater plume appears to originate near the site's southern perimeter (Johnson and Field 2010; CHPRC 2014). Williams (2001) and Johnson and Field (2010) listed a number of these releases, summarized in Table A.1.

Table A.1. Unplanned waste and water releases and pipeline failures (after Williams 2001; Johnson and Field 2010).

\begin{tabular}{|c|c|c|c|}
\hline Date & WIDS ID & Description & $\begin{array}{l}\text { Volume } \\
\text { Released }\end{array}$ \\
\hline 1955, September & $?$ & $\begin{array}{l}\text { Airlift circulator for tank } 241-S X-101 \text { was taken out of } \\
\text { service following the release of contamination at grade } \\
\text { level. }\end{array}$ & Unknown. \\
\hline 1957, June & UPR-200-W-96 & $\begin{array}{l}\text { The nine air-cooled condensers above the } 241-\mathrm{SX} \text { tank } \\
\text { developed leaks that led to surface contamination. }\end{array}$ & Unknown. \\
\hline 1958, July 21 & UPR-200W-49 & $\begin{array}{l}\text { The ground between the } 241-\mathrm{SX}-111 \text { and } 241-\mathrm{SX}-113 \\
\text { tanks was contaminated with levels up to } 6 \mathrm{rad} / \mathrm{h} \text {. A } \\
460-\mathrm{m}^{2} \text { area of contamination was found just outside the } \\
\text { southeast corner of the } 241-\mathrm{SX} \text { attributed to wind spread } \\
\text { of the farm contaminants }\end{array}$ & Unknown. \\
\hline 1958, August 25 & UPR-200-W-50 & $8,000-\mathrm{m}^{2}$ area contaminated east of 241-SX (airborne) & Unknown. \\
\hline 1958, October & $?$ & $\begin{array}{l}\text { Plugged line and pipeline leak in } 241-\mathrm{SX} \text { and } 241-\mathrm{TX} \\
\text { Tank Farm: Of the two available lines for pumping non- } \\
\text { boiling waste from the } 241-\mathrm{SX} \text { to the } 241-\mathrm{TX} \text { Tank Farm, } \\
\text { one was found to be plugged, the other to have a leak. }\end{array}$ & Unknown. \\
\hline $\begin{array}{l}\text { 1959, November } \\
12\end{array}$ & $\begin{array}{l}\text { Included in } \\
\text { UPR-200-W-144 } \\
\text { and } \\
\text { UPR-W-200-94 }\end{array}$ & $\begin{array}{l}\text { A significant leak was detected in a diversion valve } \\
\text { located in the valve pit near the } 112 \text {-SX boiling waste } \\
\text { tank, with an estimated maximum of } 25,000 \text { gallons of } \\
\text { condensate containing } 80 \text { to } 100 \text { curies of cesium } \\
\text { discharged to ground. }{ }^{\text {(a) }}\end{array}$ & $<94,600 \mathrm{~L}^{(\mathrm{a})}$ \\
\hline 1961, July 11 & $?$ & $\begin{array}{l}\text { A } 10 \times 20 \mathrm{ft} \text { area around pump pit was contaminated to } 5 \\
\mathrm{rad} / \mathrm{h} \text { including } 3 \mathrm{rad} / \mathrm{h} 3 \mathrm{ft} \text { above the ground while } \\
\text { removing SX pump and elephant trunk for burial. }\end{array}$ & Unknown \\
\hline $\begin{array}{l}\text { 1962, December } \\
3\end{array}$ & $?$ & $\begin{array}{l}\text { A bad leak developed at the isolation valve in the } \\
\text { condensate return system between the } 241-S X-101 \text { and - } \\
102 \text { Tanks. }\end{array}$ & Unknown \\
\hline 1962 & UPR-200-W-141 & Tank 241-SX-108 leaked. & $\begin{array}{l}\sim 9,000 \mathrm{~L} \\
(189,000- \\
379,000 \mathrm{~L})^{(\mathrm{a})}\end{array}$ \\
\hline 1962 & UPR-200-W-145 & Tank 241-SX-113, reclassified as "confirmed" leaker & $\begin{array}{l}\sim 56,800 \mathrm{~L}^{(\mathrm{c})} \\
(56,800 \mathrm{~L})^{(\mathrm{a})}\end{array}$ \\
\hline 1964 & UPR-200-W-140 & Tank 241-SX-107 leaked & $\begin{array}{l}\sim 19,000 \mathrm{~L} \\
(22,700 \mathrm{~L})^{(\mathrm{a})}\end{array}$ \\
\hline
\end{tabular}


Table A.1. (contd)

\begin{tabular}{|c|c|c|c|}
\hline \multicolumn{4}{|c|}{ Table A.1. (contd) } \\
\hline Date & WIDS ID & Description & $\begin{array}{l}\text { Volume } \\
\text { Released }\end{array}$ \\
\hline 1965, March 19 & $?$ & $\begin{array}{l}\text { A leak was discovered outside the pump pit, while } \\
\text { pumping 103-SX to 101-TX. Tried to replace the } \\
\text { valve but found out it so "hot" Maintenance could not get } \\
\text { to it, so a new line was installed from 102-SX pump pit } \\
\text { into } 103-S X \text { pump pit. }\end{array}$ & Unknown \\
\hline 1965 & UPR-200-W-142 & Tank 241-SX-109 leaked & $\begin{array}{l}\sim 19,000 \mathrm{~L} \\
(3,800 \mathrm{~L})^{(\mathrm{a})}\end{array}$ \\
\hline 1965 & UPR-200-W-146 & Tank 241-SX-115 leaked & $\begin{array}{l}\sim 189,000 \mathrm{~L} \\
(193,000 \mathrm{~L})^{(\mathrm{a})}\end{array}$ \\
\hline $\begin{array}{l}1965, \text { November } \\
18\end{array}$ & $?$ & $\begin{array}{l}\text { A leak developed at the } 102-\mathrm{SX} \text { transfer valve. } \\
\text { Approximately } 4,000 \text { gal of radioactive wastes were lost } \\
\text { to the ground. }{ }^{\text {(a) }}\end{array}$ & $\sim 15,000 \mathrm{~L}^{(\mathrm{a})}$ \\
\hline 1966, May & $\begin{array}{l}\text { Included in UPR- } \\
200-\mathrm{W}-96\end{array}$ & $\begin{array}{l}\text { The } 102-103-S X \text { transfer valves have been leaking. } \\
\text { The leakage has caused the surrounding dirt to harden } \\
\text { and become highly radioactive. Excavated dirt placed in } \\
\text { a "sluff trench."(a) }\end{array}$ & Unknown \\
\hline 1969, January 24 & UPR0200-W-109 & Underground line break east of SX Tank Farm & Unknown \\
\hline 1969 & UPR-200-W-144 & Tank 241-SX-112 leaked & $\begin{array}{l}\sim 114,000 \mathrm{~L} \\
(102,000 \mathrm{~L})^{(\mathrm{a})}\end{array}$ \\
\hline 1972 & None & Tank 241-SX-114 assumed leak & $<7,600 \mathrm{~L}^{(\mathrm{a})}$ \\
\hline 1974 & UPR-200-W-143 & Tank 241-SX-111 leaked & $\begin{array}{l}\sim 7,600 \mathrm{~L} \\
(10,600 \mathrm{~L})^{(\mathrm{a})}\end{array}$ \\
\hline 1976 & None & Tank 241-SX-110, assumed leak & $\begin{array}{l}\sim 20,800 \mathrm{~L}^{(\mathrm{c})} \\
(0, \text { leak } \\
\text { unlikely })^{(\mathrm{a})}\end{array}$ \\
\hline 1978 , October 24 & UPR-200-W-80 & $\begin{array}{l}\text { Surface contamination from } 241-\mathrm{SX} \text { spread to the } 244-\mathrm{S} \\
\text { receiver tank construction site }\end{array}$ & \\
\hline 1979, January 2 & UPR-200-W-81 & $\begin{array}{l}\text { Contamination (from airborne) detected between } 241-S \\
\text { and } 241-S X\end{array}$ & \\
\hline September 1980 & UPR-200-W-114 & Surface contamination discovered east of $241-\mathrm{SX}$. & \\
\hline 1985 & UPR-200-W-165 & Contamination had migrated from $241-\mathrm{S},-\mathrm{SX}$, and $-\mathrm{SY}$. & \\
\hline 1978 & None & Tank 241-SX-104, assumed leak & $\begin{array}{l}\sim 22,700 \mathrm{~L}^{(\mathrm{b})} \\
(0, \text { leak } \\
\text { unlikely })^{(\mathrm{a})}\end{array}$ \\
\hline 1996, September & NA & $\begin{array}{l}\text { A 14-in. water line ruptured in the vicinity of the } 241-\mathrm{S} \\
\text { and } 241-S Y \text { Tank Farms. Within } 2 \text { hours, 555,000 } \\
\text { gallons spilled on to the ground surface. }{ }^{(\text {) }}\end{array}$ & $2,082,000 \mathrm{~L}$ \\
\hline \multicolumn{4}{|c|}{ (a) Johnson and Field (2010) } \\
\hline \multicolumn{4}{|c|}{ (b) Naiknimbalkar (2006) } \\
\hline \multicolumn{4}{|c|}{ (c) Rogers (2010) } \\
\hline \multicolumn{4}{|c|}{ (d) Anderson (2001) } \\
\hline
\end{tabular}




\section{A.3 Inventory of Unplanned Releases}

An inventory of the masses of key constituents believed to have been released from the major tank leaks is provided in Table A.2.

Table A.2. Volumes and masses released from the SX tanks.

\begin{tabular}{|c|c|c|c|c|c|c|c|c|}
\hline & $\begin{array}{l}5 \\
0 \\
\dot{x} \\
0 \\
\frac{1}{d} \\
\text { à }\end{array}$ & $\begin{array}{l}\infty \\
0 \\
\dot{1} \\
\dot{x} \\
\sim 1 \\
\frac{1}{ \pm}\end{array}$ & $\begin{array}{l}8 \\
0 \\
\dot{x} \\
0 \\
\frac{1}{7} \\
\text { d }\end{array}$ & $\begin{array}{l}\exists \\
\bar{z} \\
\dot{x} \\
\text { a } \\
\frac{1}{\dot{d}}\end{array}$ & $\begin{array}{l}\stackrel{N}{J} \\
\frac{1}{x} \\
0 \\
\frac{1}{d} \\
\stackrel{d}{d}\end{array}$ & $\begin{array}{l}m \\
z \\
\dot{x} \\
u \\
\frac{1}{d}\end{array}$ & 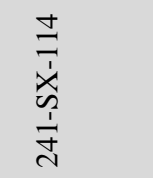 & 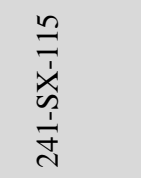 \\
\hline $\begin{array}{l}\text { Total } \\
\text { Volume } \\
\text { Release } \\
(\mathrm{ML}) \\
\end{array}$ & 0.023 & 0.132 & 0.008 & 0.011 & 0.105 & 0.058 & 0.008 & 0.198 \\
\hline \multicolumn{9}{|c|}{ Mass Released (kg) } \\
\hline $\mathrm{Na}$ & $1.19 \mathrm{E}+04$ & $2.86 \mathrm{E}+04$ & $1.88 \mathrm{E}+03$ & $1.54 \mathrm{E}+03$ & $1.57 \mathrm{E}+04$ & $6.97 \mathrm{E}+03$ & $1.25 \mathrm{E}+02$ & $1.68 \mathrm{E}+04$ \\
\hline $\mathrm{NO}_{3}$ & $9.98 \mathrm{E}+03$ & $2.40 \mathrm{E}+04$ & $1.57 \mathrm{E}+03$ & $1.29 \mathrm{E}+03$ & $1.32 \mathrm{E}+04$ & $7.60 \mathrm{E}+03$ & $1.03 E+02$ & $1.61 \mathrm{E}+04$ \\
\hline $\mathrm{NO}_{2}$ & $4.80 \mathrm{E}+03$ & $1.15 \mathrm{E}+04$ & $7.57 \mathrm{E}+02$ & $6.23 \mathrm{E}+02$ & $6.35 \mathrm{E}+03$ & $1.93 \mathrm{E}+03$ & $5.04 \mathrm{E}+01$ & $0.00 \mathrm{E}+00$ \\
\hline $\mathrm{PO}_{4}$ & $2.38 \mathrm{E}+00$ & $5.74 \mathrm{E}+00$ & $3.76 \mathrm{E}-01$ & $3.09 \mathrm{E}-01$ & $3.16 \mathrm{E}+00$ & $0.00 \mathrm{E}+00$ & $7.26 \mathrm{E}-01$ & $7.92 \mathrm{E}-02$ \\
\hline $\mathrm{SO}_{4}$ & $2.45 \mathrm{E}+02$ & $5.90 \mathrm{E}+02$ & $3.87 \mathrm{E}+01$ & $3.18 \mathrm{E}+01$ & $3.25 \mathrm{E}+02$ & $1.01 \mathrm{E}+02$ & $1.03 \mathrm{E}+01$ & $2.96 \mathrm{E}+02$ \\
\hline $\mathrm{F}$ & $1.84 \mathrm{E}-01$ & 4.42E-01 & 2.90E-02 & $2.38 \mathrm{E}-02$ & $2.43 \mathrm{E}-01$ & 4.93E-05 & $5.06 \mathrm{E}-02$ & $6.23 \mathrm{E}-03$ \\
\hline $\mathbf{U}$ & $1.43 E+00$ & $3.43 \mathrm{E}+00$ & 2.25E-01 & 1.85E-01 & $1.89 \mathrm{E}+00$ & $1.69 \mathrm{E}+00$ & 3.94E-02 & $6.60 \mathrm{E}+00$ \\
\hline $\mathrm{Cr}$ & $1.32 \mathrm{E}+02$ & $3.18 \mathrm{E}+02$ & $2.09 \mathrm{E}+01$ & $1.72 \mathrm{E}+01$ & $1.75 \mathrm{E}+02$ & $1.57 \mathrm{E}+02$ & $2.02 E+00$ & $2.68 \mathrm{E}+02$ \\
\hline \multicolumn{9}{|c|}{ Activity Released (Ci) } \\
\hline${ }^{60} \mathrm{Co}$ & $2.16 \mathrm{E}-01$ & $5.20 \mathrm{E}-01$ & $3.41 \mathrm{E}-02$ & 2.81E-02 & $2.86 \mathrm{E}-01$ & $3.08 \mathrm{E}-02$ & 7.79E-03 & $1.02 \mathrm{E}+00$ \\
\hline${ }^{129} \mathbf{I}$ & 7.52E-03 & $1.81 \mathrm{E}-02$ & $1.19 \mathrm{E}-03$ & $9.76 \mathrm{E}-04$ & $9.95 \mathrm{E}-03$ & $2.31 \mathrm{E}-03$ & $1.11 \mathrm{E}-04$ & $7.96 \mathrm{E}-03$ \\
\hline${ }^{99} \mathrm{Tc}$ & $4.87 \mathrm{E}+00$ & $1.17 \mathrm{E}+01$ & $7.68 \mathrm{E}-01$ & $6.32 \mathrm{E}-01$ & $6.45 \mathrm{E}+00$ & $1.44 \mathrm{E}+00$ & $1.63 \mathrm{E}-01$ & $5.12 \mathrm{E}+00$ \\
\hline${ }^{3} \mathrm{H}$ & $1.97 \mathrm{E}+00$ & $4.74 \mathrm{E}+00$ & $3.11 \mathrm{E}-01$ & $2.55 \mathrm{E}-01$ & $2.61 \mathrm{E}+00$ & 8.69E-01 & $2.01 \mathrm{E}-02$ & $2.50 \mathrm{E}+01$ \\
\hline${ }^{238} \mathrm{Pu}$ & $9.11 \mathrm{E}-03$ & 2.19E-02 & $1.43 \mathrm{E}-03$ & $1.18 \mathrm{E}-03$ & $1.20 \mathrm{E}-02$ & $5.28 \mathrm{E}-03$ & $2.89 \mathrm{E}-04$ & $3.71 \mathrm{E}-02$ \\
\hline${ }^{239} \mathrm{Pu}$ & 2.33E-01 & $5.62 \mathrm{E}-01$ & $3.69 \mathrm{E}-02$ & $3.03 \mathrm{E}-02$ & $3.09 \mathrm{E}-01$ & $2.78 \mathrm{E}-01$ & $6.44 \mathrm{E}-03$ & $1.08 \mathrm{E}+00$ \\
\hline${ }^{137} \mathrm{Cs}$ & $1.16 \mathrm{E}+04$ & $2.79 \mathrm{E}+04$ & $1.84 \mathrm{E}+03$ & $1.46 \mathrm{E}+00$ & $1.53 \mathrm{E}+04$ & $3.26 \mathrm{E}+03$ & $1.05 \mathrm{E}+03$ & $1.34 \mathrm{E}+03$ \\
\hline $\begin{array}{l}\text { Notes: } \\
\text { Cobalt- } 6 \\
\text { The five } \\
\mathrm{ML}=\mathrm{m}\end{array}$ & $\begin{array}{l}\text { volume a } \\
\text { ritium, an } \\
\text { entially n } \\
\text { (million) }\end{array}$ & $\begin{array}{l}\text { inventory } \\
{ }^{37} \mathrm{Cs} \text { activit } \\
\text { ile contam } \\
\mathrm{rs}\end{array}$ & $\begin{array}{l}\text { mates for } \\
\text { decay con } \\
\text { nts of con }\end{array}$ & $\begin{array}{l}\text { tanks com } \\
\text { ted to } 9 / 30 \\
\text { are in bo }\end{array}$ & $\begin{array}{l}\text { om Johns } \\
10 . \\
\text { ype. }\end{array}$ & and Field & & \\
\hline
\end{tabular}

\section{A.4 Adjacent Liquid Waste Disposal Facilities}

A number of liquid waste disposal facilities are located adjacent to the 241-SX Tank Farm. An evaluation of high-volume liquid waste disposal facilities within about $1 \mathrm{~km}$ of the 241-SX Tank Farm identified 17 facilities with total discharges exceeding 100,000 $\mathrm{m}^{3}$ (1e+8 L) (see Table A.3, and Figure 2.1). 
Table A.3. Major liquid effluent discharges in the vicinity of the 241-SX Tank Farm (after Last et al. 2006; and Corbin et al. 2005).

\begin{tabular}{lccrrr}
\hline $\begin{array}{c}\text { WIDS Site } \\
\text { Code }\end{array}$ & Site Type & $\begin{array}{c}\text { Operational Start } \\
\text { Date }\end{array}$ & $\begin{array}{c}\text { Operational Start } \\
\text { Date }\end{array}$ & $\begin{array}{r}\text { Total Volume } \\
\left(\mathrm{m}^{3}\right)\end{array}$ & $\begin{array}{r}\text { Average Annual } \\
\text { Discharge }\left(\mathrm{m}^{3} / \mathrm{yr}\right)\end{array}$ \\
\hline $216-U-10$ & Pond & 1944 & 1985 & 163600000 & 3990244 \\
$216-S-16 P$ & Pond & 1957 & 1975 & 40720000 & 2262222 \\
$216-S-17$ & Pond & 1951 & 1954 & 6437000 & 2145667 \\
$216-S-6$ & Crib & 1954 & 1972 & 4471000 & 248389 \\
$216-Z-20$ & Crib & 1981 & 1995 & 4303000 & 307357 \\
$216-S-5$ & Crib & 1954 & 1957 & 4102000 & 1367333 \\
$216-S-11$ & Pond & 1954 & 1965 & 3621000 & 329182 \\
$216-U-14$ & Ditch & 1944 & 1995 & 3084000 & 60471 \\
$216-S-19$ & Pond & 1952 & 1984 & 798200 & 24944 \\
$216-S-10 P$ & Pond & 1952 & 1984 & 736200 & 23006 \\
$216-U-17$ & Crib & 1988 & 1994 & 565200 & 94200 \\
$216-U-16$ & Crib & 1984 & 1987 & 409000 & 136333 \\
$216-S-7$ & Crib & 1956 & 1965 & 389900 & 43322 \\
$216-U-8$ & Crib & 1952 & 1960 & 378500 & 47313 \\
$216-S-25$ & Crib & 1973 & 1992 & 288100 & 15163 \\
$216-Z-12$ & Crib & 1959 & 1973 & 281100 & 20079 \\
$216-S-26$ & Crib & 1984 & 1995 & 200000 & 18182 \\
\hline
\end{tabular}

\section{A.5 References}

Anderson, F.J. 2001. Engineering Report, Single-Shell Tank Farms, Interim Measures to Limit Infiltration Through the Vadose Zone. RPP-5002, Rev. 1, CH2M HILL Hanford Group, Richland, Washington.

CHPRC. 2014. Hanford Site Groundwater Monitoring Report for 2013. DOE/RL-2014-32, Revision 0, CH2M HILL Plateau Remediation Company, Richland, Washington

Corbin, R.A., B.C. Simpson, M.J. Anderson, W.F. Danielson III, J.G. Field, T.E. Jones, and C.T. Kincaid. 2005. Hanford Soil Inventory Model, Rev. 1. RPP-26744, Rev. 0, CH2MHill Hanford Group, Richland, Washington.

Johnson, M.E., and J.G. Field. 2010. Hanford SX-Farm Leak Assessments Report. RPP_ENV-39658, Rev. 0, Washington River Protection Solutions, Richland, Washington.

Last, G.V., E.J. Freeman, K.J. Cantrell, M.J. Fayer, G.W. Gee, W.E. Nichols, B.N. Bjornstad, and D.G. Horton. 2006. Vadose Zone Hydrogeology Data Package for the 2004 Composite Analysis. PNNL-14702, Rev. 1, Pacific Northwest National Laboratory, Richland, Washington.

Naiknimbalkar, A.N. 2006. Waste Tank Summary Report for Month Ending June 30, 2006. HNF-EP-0182, Rev. 219, CH2MHill Hanford Group, Richland, Washington. 
Rogers, M.J. 2010. Waste Tank Summary Report for Month Ending December 31, 2009. HNF-EP-0182, Rev. 261, Washington River Protection Solutions, Richland, Washington.

Williams, J.C. 2001. Historical Vadose Zone Contamination from S and SX Tank Farm Operations. HNF-SD-WM-ER-560, Revision 1, Fluor Federal Services, Richland, Washington. 


\section{Appendix B}

\section{SX Tank Leak Source Term Estimates}





\section{Appendix B}

\section{SX Tank Leak Source Term Estimates}

The purpose of this study was to assemble tank leak source term estimates including the release rates, durations, and locations of leaks from eight high-level waste (HLW) single-shell tanks (SSTs) in the SX Tank Farm: 241-SX-107, -108, -109, -111, -112, -113, -114, and -115. This information is based primarily on the analysis of waste loss events by Johnson and Field (2010), and location/cause analyses conducted by Girardot and Harlow (2014). Figure B.1 illustrates the configuration of the designated leakers within the SX Tank Farm and their associated laterals and drywells. 


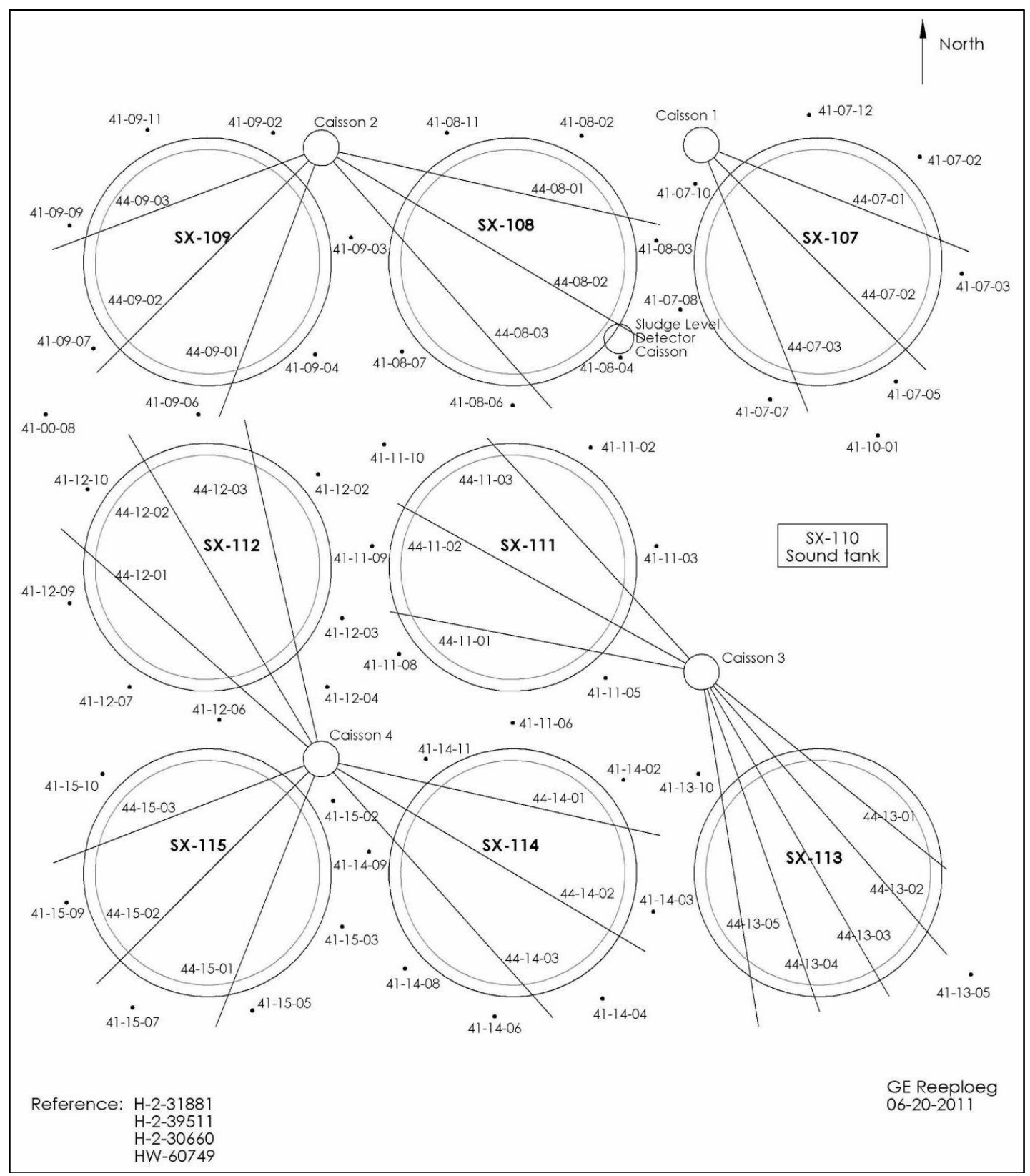

Figure B.1. SX Tank Farm designated leakers and associate laterals and drywells (from Girardot and Harlow 2014).

The poorly documented nature of tank leaks from the SX Tank Farm SSTs, the complicated operations history of inputs and exports of fluids to the SSTs, and complexities/uncertainties in monitoring data make it difficult to obtain good estimates of the timing and duration of the leaks, their release volumes, contaminant inventories, and the location of the leaks. However, these source term parameters are needed to support numerical simulation of the leaks, thus, we have made a concerted effort to review available information to make our best estimates. 
Table B.1 summarizes the key source term parameters for tank leaks associated with each of the SX tanks. A synopsis of key information about leaks/releases from each individual tank and interpreted source term parameters (e.g., location, release rate, etc.) are described in the following sections. Contaminant inventories for each of the tank waste leases was taken from the draft report Preliminary Conceptual Site Model Report for 200-DV-1 Operable Unit Waste Sites in the S Complex Area (CH2MHILL 2011). The total release volumes cited in that report vary slightly from those cited by Johnson and Field (2010) and/or Girardot and Harlow (2014). This may vary the estimated concentrations, but not the estimated total mass of each constituent.

Table B.1. Summary of key tank leak source term estimates.

\begin{tabular}{|c|c|c|c|c|c|}
\hline $\begin{array}{c}\text { Leak Event } \\
\text { Totals }\end{array}$ & Duration (days) & Volume (gal) & Volume (L) & $\begin{array}{c}\text { Release Rate } \\
(\mathrm{L} / \mathrm{d})\end{array}$ & $\begin{array}{c}{ }^{137} \mathrm{Cs} \text { Inventory }(\mathrm{Ci}, \\
\text { decay corrected to } \\
9 / 30 / 2010)\end{array}$ \\
\hline \multirow[t]{3}{*}{ SX-107 } & 60 (min.) & 3,400 (min.) & 12,900 (min.) & 33 (min.) & $5.40+3(\min )$ \\
\hline & 365 (best) & 6,400 (best) & 24,200 (best) & 66 (best) & $1.16 \mathrm{E}+04$ (best) \\
\hline & 395 (max.) & $23,000(\max )$ & $78,100(\max )$ & 1,300 (max.) & $2.86 \mathrm{E}+4(\max )$ \\
\hline \multirow[t]{3}{*}{ SX-108 } & 487 (min.) & 50,700 (min.) & 192,000 (min.) & 122 (min.) & $6.35 \mathrm{E}+3(\mathrm{~min})$ \\
\hline & 1190 (best) & 76,100 (best) & 288,000 (best) & 242 (best) & $2.79 \mathrm{E}+04$ (best) \\
\hline & 1580 (max.) & $102,000(\max )$ & $384,000(\max )$ & 788 (max.) & 8.89E+4 (max) \\
\hline \multirow[t]{3}{*}{ SX-109 } & 60 (min.) & 310 (min.) & 1,200 (min.) & 2.3 (min.) & $4.90 \mathrm{E}+2(\min )$ \\
\hline & 487 (best) & 1,000 (best) & 3,800 (best) & 7.8 (best) & $1.84 \mathrm{E}+03$ (best) \\
\hline & 516 (max.) & $<10,000(\max )$ & $<37,900(\max )$ & 632 (max.) & $9.59 \mathrm{E}+3(\max )$ \\
\hline \multirow[t]{3}{*}{ SX-111 } & 27 (min.) & 500 (min.) & 1,900 (min.) & 44 (min.) & $1.59 \mathrm{E}-1$ (min) \\
\hline & 27 (best) & 2,800 (best) & 11,000 (best) & 100 (best) & $1.46 \mathrm{E}+00$ (best) \\
\hline & 43 (max.) & $2,800(\max )$ & $11,000(\max )$ & 100 (max.) & $1.83 \mathrm{E}+3(\max )$ \\
\hline \multirow[t]{3}{*}{ SX-112 } & 16 (min.) & 1,000 (min.) & 3,790 (min.) & 62.1 (min.) & $2.07 \mathrm{E}+1(\mathrm{~min})$ \\
\hline & 16 (best) & 27,000 (best) & 102,000 (best) & 6,380 (best) & $1.53 \mathrm{E}+4$ (best) \\
\hline & 426 (max.) & $44,000(\max )$ & 167,000 (max.) & 6,380 (max.) & $1.70 \mathrm{E}+5(\max )$ \\
\hline \multirow[t]{3}{*}{ SX-113 } & 5 (min.) & 15,000 (min.) & 56,800 (min.) & 1,620 (min.) & $7.29 \mathrm{E}+0(\mathrm{~min})$ \\
\hline & 12 (best) & 15,000 (best) & 56,800 (best) & 4,730 (best) & $3.30 \mathrm{E}+3$ (best) \\
\hline & 40 (max.) & $65,000(\max )$ & 208,000 (max.) & 30,300 (max.) & $1.23 \mathrm{E}+4(\max )$ \\
\hline \multirow[t]{3}{*}{ SX-114 } & 14 (min.) & 43 (min.) & 163 (min.) & 1.36 (min.) & 0 (min.) \\
\hline & 52 (best) & $<2,000$ (best) & $<7,570$ (best) & $>146$ (best) & $1.05 \mathrm{E}+03$ (best) \\
\hline & 120 (max.) & 2,000 (max.) & 7,570 (max.) & 540 (max.) & $1.05 \mathrm{E}+03(\max )$ \\
\hline \multirow[t]{3}{*}{ SX-115 } & 6 (min.) & 50,000 (min.) & 189,000 (min.) & 15,750 (min.) & $8.53 \mathrm{E}+3(\mathrm{~min})$ \\
\hline & 12 (best) & 51,000 (best) & 193,000 (best) & 16,080 (best ) & $1.34 \mathrm{E}+04$ (best) \\
\hline & 12 (max.) & $52,300(\max )$ & $198,000(\max )$ & 33,000 (max.) & $1.46 \mathrm{E}+4(\max )$ \\
\hline
\end{tabular}

The ensuing sections of this appendix present leak information for all of the tanks listed in Table B.1. 


\section{B.1 Tank 241-SX-107 Waste Loss Event (after Johnson and Field 2010 and Girardot and Harlow 2014)}

\section{B.1.1 Leak Chronology}

- March 9, 1964 - The first indications of a leak, when radioactivity was detected in lateral No. 1 (44-07-01), about $15 \mathrm{ft}$. (4.6 m) from the outer edge of the tank. Waste additions were stopped.

- In June 1964 a "possible leak in the 107-SX underground storage tank" was identified and radioactivity continued to increase in lateral No. 1, peaking in August 1964.

- No significant increases were observed in October 1964 and no material losses were observed.

- In October 1965 an increase in radioactivity was again recorded in lateral No. 1. Radioactivity remained stable through June 1966.

- In March 1968, a possible leak was again identified due to radioactivity increases in the laterals and drywells, and supernate was pumped from the tank.

- In September 1968, new evidence of a leak was observed in the laterals (radioactivity detected in lateral 44-07-02 and increased in lateral 44-07-03) and drywells (41-07-05 and 41-07-07). Tank 241SX-107 was declared at leaker and was removed from service. Additional supernate was pumped from the tank, and on December 19, 1968, it was connected to an exhauster to aid in air cooling of the tank and drying of sludge.

- December 1968 - Photographs revealed bent piping, confirming the presence of a bulged tank liner.

- March 1969 - Radioactivity increased in drywell 41-07-07.

- June 1969 - The bulged liner evidently relaxed back to its normal configuration.

- September 1973 - Low-level radioactivity was detected in drywell 41-10-01, indicating spread of the August 1968 leak.

- January 1975 - Radioactivity was reported in drywell 41-07-08.

- November 1976 - Radioactivity increased significantly in drywell 41-07-08, interpreted as either a new leak site or from migration of leak detected in March 1964.

- October 1979 - Tank SX-107 was deemed interim stabilized.

\section{B.1.2 Estimated Release Events and Durations}

Girardot and Harlow (2014) suggested that there were two or three different leak events. The leak chronology above suggests that there may have been as many as four potential leak events; however, only two of these appear to have been significant. Estimated volumes from each individual release event are unavailable. 
- March - August 1964: This event is assumed to have had a duration of 6 months. The leak duration could have been as short as a month or less, starting in early March and ending in late March when waste additions were stopped. However, the duration is unlikely to be much longer than about 7 months, because radioactivity peaked in August 1964 and no significant increases were observed in October 1964).

- October 1965: This event is assumed to have released an insignificant volume.

- March - September 1968: This event is assumed to have had a duration of 6 months. The leak could have lasted as little as one month, seeing as how they pumped waste out of the tank in March 1968, however, it is unlikely that the duration was more than about 6 months because they removed even more waste in September 1968).

- January - November 1976: This event is assumed to have released an insignificant volume.

\section{B.1.3 Estimated Total Release Volume and Average Release Rates}

Johnson and Field (2010) provide the best estimate for the total leak volume at 6,000 to 6,400 gal (22,700-24,200 L). Johnson and Field (2010) based the 6,400 gal (24,200 L) estimate on an interpreted inventory of ${ }^{137} \mathrm{Cs}$ (from kriging analyses of vadose zone data) of 13,400 Ci (decayed to January 2001) and an estimated ${ }^{137} \mathrm{Cs}$ concentration of $2.7 \mathrm{Ci} / \mathrm{gal}$ for REDOX tank waste at the time of the leak. Note that this volume is similar to the volume of 6,350 gal estimated by Knepp (2002). However, volume estimates range from a low of $<5,000 \mathrm{gal}$ (Rogers 2014) to a high of 15,000 gal (as reported by Fields and Jones 2004).

- Assuming a total volume of 6,400 gal (24,000 L) and a total duration of 12 months, would yield an average release rate of $17.5 \mathrm{gal} /$ day $(66 \mathrm{~L} /$ day $)$ for each of the two primary release events.

\section{B.1.4 Location}

Girardot and Harlow (2014) concluded that tank SX-107 leaked in either two or three locations (Figure B.2), and the tank leaks are believed to have originated at or near the bottom of the tank.

- March - August 1964: This leak is assumed to have been under the northern portion of the tanks, site A (State Plane E 566833, N 134243 - estimated from Qmap).

- March - September 1968: This leak is assumed to have been along the south edge of the tank close to borehole 41-07-07 (299-W23-77), site B (State Plane E 566833, N 134228 - estimated from Qmap).

- Figure B.2. Possible SX-107 Tank Leak Locations (from Girardot and Harlow 2014). 


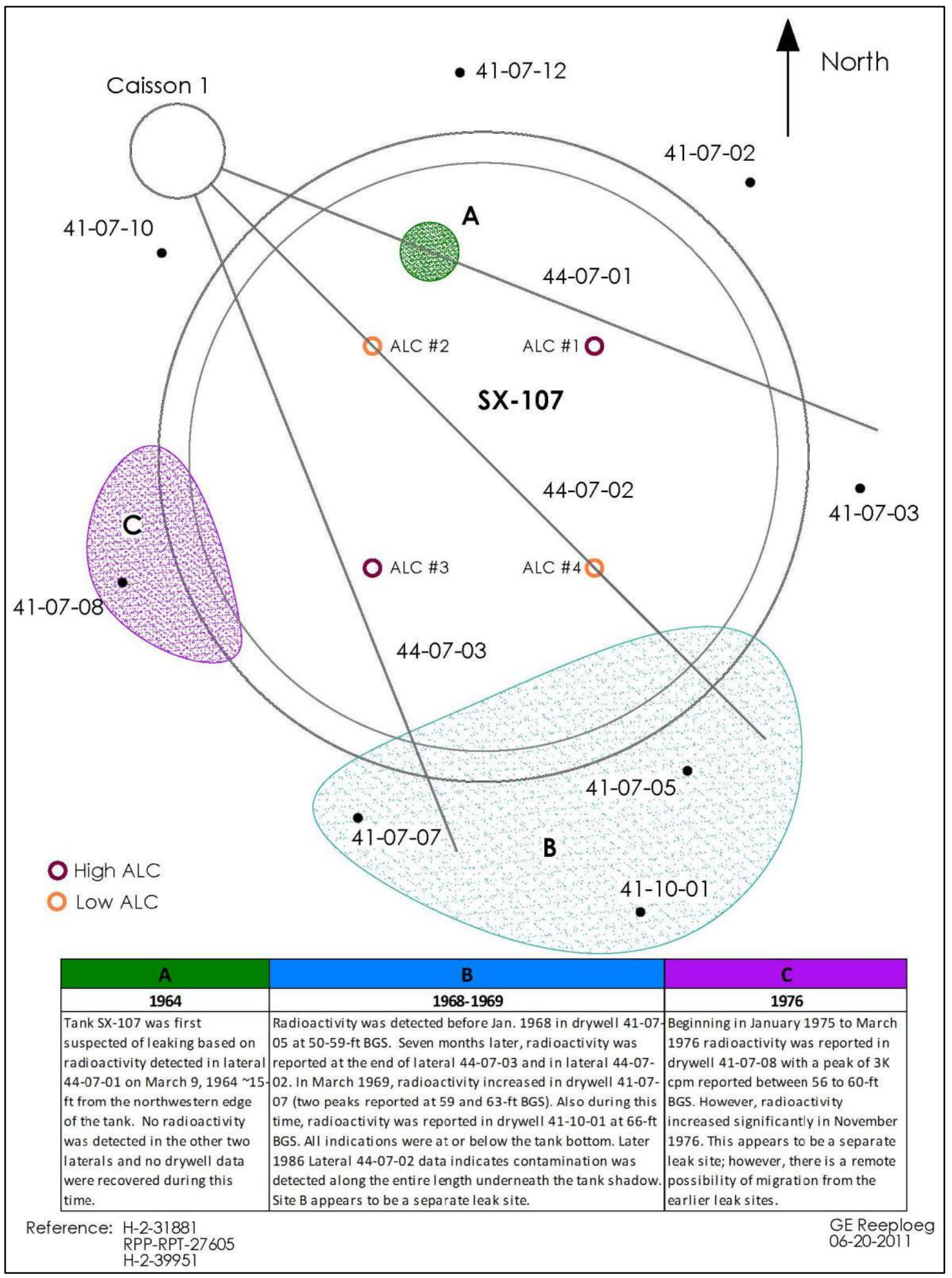

Figure B.2. Possible SX-107 tank leak locations (from Girardot and Harlow 2014). 


\section{B.1.5 Inventory}

Johnson and Field (2010, p. 5-27) stated that the estimated the ${ }^{137}$ Cs inventory of the SX-107 tank leaks was 13,400 $\mathrm{Ci}$ (decayed to January 2001) based on kriging analyses of vadose zone data (presumably as reported by Jones et al. (2000). Later in the same paragraph, they indicate that the revised ${ }^{137} \mathrm{Cs}$ inventory is $14,500 \mathrm{Ci}$. This value can be reproduced by decay correcting the estimated 17,100 Ci (decay corrected to January 1994, as cited by Knepp [2002, Table 3.3], and Jones et al. [2000, Table 3]) to January 2001. Johnson and Field (2010) recommended calculation of the inventory for all analytes, by multiplying the ratio of the revised ${ }^{137} \mathrm{Cs}$ inventory $(14,500 \mathrm{Ci}$, decay corrected to January 2001) and the Soil Inventory Model (SIM) ${ }^{137}$ Cs inventory (17,900 Ci, decay corrected to January 2001) by the SIM inventory for the selected analyte. CH2MHILL (2011), used this approach to estimate the inventories as shown in Table B.2 (decay corrected to 9/30/2010), which are taken here as the best estimate. However, other kriging estimates, reported by Knepp (2002), and Jones et al. (2000) suggest that the ${ }^{137} \mathrm{Cs}$ inventory in the vadose zone could range from 5,400 to 28,600 $\mathrm{Ci}$ (decay corrected to 9/30/2010).

Johnson and Field (2010) noted that because of the large amount of caustic makeup and cooling water added to maintain the waste temperature and $\mathrm{pH}$, the leak volume may have been larger, and this would change the concentrations, but not the total inventory.

Table B.2. Estimated inventory for SX-107 tank release, based on a release volume of 23,000 liters (from CH2MHILL 2011, Draft, Table 3.4).

\begin{tabular}{|c|c|c|}
\hline Constituent & $\begin{array}{c}\text { Minimum and Best Estimate } \\
\text { Mass Released }(\mathrm{kg})\end{array}$ & $\begin{array}{l}\text { SIM (Corbin et al. 2005) } \\
\text { Mass Released (kg) }\end{array}$ \\
\hline $\mathrm{Na}$ & $1.19 \mathrm{E}+04$ & $1.47 \mathrm{E}+04(\mathrm{SD}=1.78 \mathrm{E}+03)$ \\
\hline $\mathrm{NO}_{3}$ & $9.98 \mathrm{E}+03$ & $1.23 \mathrm{E}+04(\mathrm{SD}=1.49 \mathrm{E}+03)$ \\
\hline $\mathrm{NO}_{2}$ & $4.80 \mathrm{E}+03$ & $5.93 \mathrm{E}+03(\mathrm{SD}=7.2 \mathrm{E}+02)$ \\
\hline $\mathrm{PO}_{4}$ & $2.38 \mathrm{E}+00$ & $2.94 \mathrm{E}+00(\mathrm{SD}=3.54 \mathrm{E}-01)$ \\
\hline $\mathrm{SO}_{4}$ & $2.45 \mathrm{E}+02$ & 3.0.E $+02(\mathrm{SD}=3.69 \mathrm{E}+01)$ \\
\hline $\mathrm{F}$ & $1.84 \mathrm{E}-01$ & $2.27 \mathrm{E}-01(\mathrm{SD}=2.75 \mathrm{E}-20)$ \\
\hline $\mathbf{U}$ & $1.43 E+00$ & $1.76 \mathrm{E}+00(\mathrm{SD}=2.09 \mathrm{E}+00)$ \\
\hline $\mathbf{C r}$ & $1.32 \mathrm{E}+02$ & $1.63 \mathrm{E}+02(\mathrm{SD}=1.98 \mathrm{E}+01)$ \\
\hline Constituent & Activity Released (Ci) & Activity Released (Ci) ${ }^{(\mathrm{a})}$ \\
\hline${ }^{60} \mathrm{Co}$ & $2.16 \mathrm{E}-01$ & $9.61 \mathrm{E}-01(\mathrm{SD}=1.00 \mathrm{E}+00)$ \\
\hline${ }^{129} \mathbf{I}$ & $7.52 \mathrm{E}-03$ & $9.28 \mathrm{E}-03(\mathrm{SD}=8.39 \mathrm{E}-03)$ \\
\hline${ }^{99} \mathrm{Tc}$ & $4.87 \mathrm{E}+00$ & $6.02 \mathrm{E}+00(\mathrm{SD}=5.48 \mathrm{E}+01)$ \\
\hline${ }^{3} \mathrm{H}$ & $1.97 \mathrm{E}+00$ & $4.21 \mathrm{E}+00(\mathrm{SD}=4.03 \mathrm{E}+00)$ \\
\hline${ }^{238} \mathrm{Pu}$ & $9.11 \mathrm{E}-03$ & $1.12 \mathrm{E}-02(\mathrm{SD}=2.89 \mathrm{E}-02)$ \\
\hline${ }^{239} \mathrm{Pu}$ & 2.33E-01 & $2.88 \mathrm{E}-01(\mathrm{SD}=3.47 \mathrm{E}-01)$ \\
\hline${ }^{137} \mathrm{Cs}$ & $1.16 \mathrm{E}+04$ & $1.79 \mathrm{E}+04(\mathrm{SD}=1.66 \mathrm{E}+04)$ \\
\hline \multicolumn{3}{|c|}{$\begin{array}{l}\text { Notes: The volume and inventory estimates for SX tanks come from Johnson and Field (2010) } \\
\text { Cobalt- } 60 \text {, tritium, and }{ }^{137} \mathrm{Cs} \text { activities decay corrected to } 9 / 30 / 2010 \text {. } \\
\text { The five potentially mobile contaminants of concern are in bold type. } \\
\text { (a) Mean value rounded to } 3 \text { digits, and decay corrected to 1/1/2001. } \\
\text { SD = Standard Deviation. }\end{array}$} \\
\hline
\end{tabular}




\section{B.1.6 Summary}

Table B.3 summarizes the key source term parameters for leaks from tank SX-107.

Table B.3. Key source term parameters for leaks from Tank SX-107.

\begin{tabular}{|c|c|c|c|c|c|}
\hline Leak Event & Duration (days) & Volume (gal) & Volume (L) & $\begin{array}{c}\text { Release Rate } \\
\text { (L/d) }\end{array}$ & $\begin{array}{c}{ }^{137} \mathrm{Cs} \text { Inventory }(\mathrm{Ci}, \\
\text { decay corrected to } \\
9 / 30 / 2010)\end{array}$ \\
\hline \multirow{3}{*}{$\begin{array}{l}\text { March - August } \\
1964\end{array}$} & $30(\min )$ & -- & -- & -- & -- \\
\hline & 182 (best est.) & & & & \\
\hline & $213(\max )$ & & & & \\
\hline \multirow{5}{*}{$\begin{array}{l}\text { March - Sept. } \\
1968\end{array}$} & $30(\min )$ & -- & -- & -- & -- \\
\hline & $\begin{array}{c}182 \text { (best est., } \\
\text { and } \max \text { ) }\end{array}$ & & & & \\
\hline & 60 (min.) & 3,400 (min.) & 12,900 (min.) & 33 (min.) & $5.40+3(\mathrm{~min})$ \\
\hline & 365 (best est.) & 6,400 (best est.) & 24,200 (best est.) & 66 (best est.) & $1.16 \mathrm{E}+04$ (best est.) \\
\hline & 395 (max.) & 23,000 (max) & $78,100(\max )$ & 1,300 (max.) & $2.86 \mathrm{E}+4(\max )$ \\
\hline
\end{tabular}

\section{B.2 Tank 241-SX-108 Waste Loss Event (after Johnson and Field 2010 and Girardot and Harlow 2014 )}

\section{B.2.1 Leak Chronology}

- December 11, 1962 - The first indications of a leak occurred when minor amounts of radiation were detected in laterals no. 1 and no. 2 (44-08-01 and 44-08-02). However, further monitoring detected no radiation increase, and the tank was thought to have self-sealed, so it was kept in service. Note that Girardot and Harlow (2014) reported that reanalysis indicated that the leak may have started as early as May 1959.

- July 1964 - Radioactivity in laterals no. 1 and 2 started to increase.

- In August 1964 - A steady increase in radiation was detected in two of the laterals and radioactivity was present in dry well 41-08-11. Radioactivity continued to increase in the laterals and drywell through November 1964. The tank was identified as a confirmed leaker.

- March 1965 - Drywell 41-08-02 showed a peak in radioactivity at 52 ft bgs.

- By mid-1965 - Increased radioactivity was reported for all three laterals. Five test wells were added and soil samples were obtained to define the affected area and the amount of leakage up through mid1965 was estimated to be $2,400 \mathrm{gal}(9,000 \mathrm{~L})$.

- November 1965 -The tank was isolated from the tank farm condensation system and fitted with its own condenser to return condensate back to the tank.

- By December 1965 - With no loss of liquid level detected in the tank, the leak was thought to have self-sealed again. 
- March 1966 - High radiation levels were detected in lateral no. 3 (44-08-03), indicating the plume had spread and moved toward the south.

- January 1967 - Supernatant was transferred out of the tank.

- By February 1967 - A liquid level drop of about 24 in. had been observed, suggesting that 48,300 to 66,100 gal $(183,000-250,000 \mathrm{~L})$ may have leaked from the tank.

- By March 1967 - Persistent activity in the laterals led to the conclusion that leak was again active, the tank was confirmed to be a leaker and was taken out of service. The liquid contents were pumped out, leaving the sludge and some supernate in the tank. An induced ventilation system was added to remove heat and evaporate the supernate.

- In September 1967 - The bottom liner of the tank was determined to be bulged upward, and a month later it was found to have bulged about $2.5 \mathrm{ft}$ in the northwest quadrant of the tank.

- By December 1967 the volume estimated to have been lost from tank SX-108 was 0 to 33,000 gal (0 $125,000 \mathrm{~L})$.

- By December 1968 - An exploratory sludge level detector caisson was installed along the tank wall to the footings and encountered high radiation levels under the footing.

- Early 1968 - In-tank photos taken in early 1968 showed a liquid level drop of about 24 in., with an effective liquid level decrease estimated at 12 in. due to substantial uncertainty.

- From 1973 through July 1987 - Radioactivity levels generally increased in all laterals, but then decreased in April 1989. Activity levels in the dry wells showed only slight changes except for drywell 41-08-07, which showed increases in 1989, suggesting continued southward movement of the plume.

- August 1979 - The tank was administratively stabilized.

\section{B.2.2 Estimated Release Events, Volumes, and Average Release Rate}

- November - December 1962. Assumed duration 1 month, minor (de minimis) volume.

- July 1964 - June 1965. Assumed duration of 10 months, 2,400 gal. $(9,000$ L) = 7.9 gal/d (29.9 L/d). Note that there is virtually no disagreement/variability in the volume of this release. However, the leak duration could have been as short as about 3 months, starting in July and ending in November 1964. The duration is unlikely to have been any longer than about 16 months, since the tank was thought to have self-sealed by December 1965. Thus, release rates could range from as much as 26.3 gal/d to as little as $4.9 \mathrm{gal} / \mathrm{d}(100-18.5 \mathrm{~L} / \mathrm{d})$.

- March 1966 - March 1967. Johnson and Field (2010) estimated the volume of this release at 48,300-66,100 gal. (183,000-250,000 L), yielding an average of 57,200 gal (217,000 L). A best estimate for the duration of the leak is 12 months, however, the duration could have been as short as about 2 months (February and March 1967) or as long as about 12 months (bumping up against the 
next leak event). The release rate for this event is estimated to have ranged from 132-1,080 gal/d (501-4,100 L/d), with a best estimate of $157 \mathrm{gal} / \mathrm{d}(595 \mathrm{~L} / \mathrm{d})$.

- March 1967 - August 1968. Johnson and Field (2010) estimated the volume of this release at 0-33,000 gal (0-125,000 L), yielding an average of 16,500 gal $(62,500 \mathrm{~L})$. The leak is assumed to have occurred over a duration of 17 months, however, it could have been as short as about 11 months (March 1967 to December 1967), or as long as 24 months (March 1967 to March 1969; Girardot and Harlow 2014). The release rate is estimated to have been from 0-63.9 gal/d (0-241.9 L/d).

- By December 1968. Possible seepage through concrete cracks, with only minor (de minimis) volume.

Johnson and Field (2010, p. 5-64) estimated the total release volume at 50,700 to 101,500 gal $(192,000-384,000 \mathrm{~L})$ yielding an average of about 76,100 gal $(288,000 \mathrm{~L})$.

\section{B.2.3 Location}

The tank leak is believed to have originated at or near the bottom of the tank. Girardot and Harlow (2014) noted two to four possible leak locations (Figure B.3).

- The first and second leak events (November-December 1962, and July 1964-June 1965) are believed to have occurred along the northwest edge of the 241-SX-108 Tank (State Plane E 566796, N 134243 - estimated from Qmap).

- The third and fourth leak events (March 1966 to March 1967, and March 1967 to August 1968) are thought to have occurred along the west edge of the tank (State Plane E 566794, N 134233 estimated from Qmap).

\section{B.2.4 Inventory}

Best estimate of the total volume released was 50,700 to 101,500 gal (192,000-384,000 L) (Johnson and Field 2010). Johnson and Field (2010) also suggested a best estimate ${ }^{137} \mathrm{Cs}$ inventory of 34,900 Ci, which CH2MHill [2011] adjusted to 27,900 Ci (decay corrected to September 30, 2010). However, the ${ }^{137} \mathrm{Cs}$ inventory could have ranged from 6,350 to 88,900 Ci (decay corrected to September 30, 2010). Johnson and Fields (2010) suggested that the inventories for other analytes, should be calculated by multiplying the SIM inventories by the ratio of 34,900/41,800 $=0.835$, to account for volume and sample differences. This was apparently done by CH2MHill (2011), yielding the total best estimate inventory shown in Table B.4. 
Table B.4. Estimated inventory for SX-108 tank release, based on a release volume of 132,000 liters (from CH2MHill 2011, Draft, Table 3.4).

\begin{tabular}{ccc}
\hline Constituent & Mass Released $(\mathrm{kg})$ & $\begin{array}{c}\text { SIM (Corbin et al. 2005) } \\
\text { Mass Released }(\mathrm{kg})\end{array}$ \\
\hline $\mathrm{Na}$ & $2.86 \mathrm{E}+04$ & $3.43 \mathrm{E}+4(\mathrm{SD}=4.14 \mathrm{E}+3)$ \\
$\mathrm{NO}_{\mathbf{3}}$ & $\mathbf{2 . 4 0 E}+\mathbf{0 4}$ & $\mathbf{2 . 8 7 E + 4}(\mathbf{S D}=\mathbf{3 . 4 8 E}+\mathbf{3})$ \\
$\mathrm{NO}_{2}$ & $1.15 \mathrm{E}+04$ & $1.38 \mathrm{E}+4(\mathrm{SD}=1.67 \mathrm{E}+3)$ \\
$\mathrm{PO}_{4}$ & $5.74 \mathrm{E}+00$ & $6.87 \mathrm{E}+0(\mathrm{SD}=8.34 \mathrm{E}-1)$ \\
$\mathrm{SO}_{4}$ & $5.90 \mathrm{E}+02$ & $7.07 \mathrm{E}+2(\mathrm{SD}=8.56 \mathrm{E}+1)$ \\
$\mathrm{F}$ & $4.42 \mathrm{E}-01$ & $5.29 \mathrm{E}-1(\mathrm{SD}=6.40 \mathrm{E}-2)$ \\
$\mathbf{U}$ & $\mathbf{3 . 4 3 E}+\mathbf{0 0}$ & $\mathbf{4 . 1 0 E}+\mathbf{0}(\mathbf{S D}=\mathbf{4 . 8 7 E}+\mathbf{0})$ \\
$\mathbf{C r}$ & $\mathbf{3 . 1 8 E + 0 2}$ & $\mathbf{3 . 8 1 E}+\mathbf{2}(\mathbf{S D}=\mathbf{4 . 6 2 E}+\mathbf{1})$ \\
\hline $\mathrm{Constituent}$ & Activity Released $(\mathrm{Ci})$ & Activity Released $(\mathrm{Ci})$ \\
\hline${ }^{60} \mathrm{Co}$ & $5.20 \mathrm{E}-01$ & $2.24 \mathrm{E}+0(\mathrm{SD}=2.34 \mathrm{E}+0)$ \\
${ }^{129} \mathbf{I}$ & $\mathbf{1 . 8 1 E}-\mathbf{0 2}$ & $\mathbf{2 . 1 7 E}-\mathbf{2}(\mathbf{S D}=\mathbf{1 . 9 6 E}-\mathbf{2})$ \\
${ }^{99} \mathbf{T c}$ & $\mathbf{1 . 1 7 E}+\mathbf{0 1}$ & $\mathbf{1 . 4 0 E}+\mathbf{1}(\mathbf{S D}=\mathbf{1 . 2 8 E}+\mathbf{0})$ \\
${ }^{3} \mathrm{H}$ & $4.74 \mathrm{E}+00$ & $9.82 \mathrm{E}+0(\mathrm{SD}=9.42 \mathrm{E}+0)$ \\
${ }^{238} \mathrm{Pu}$ & $2.19 \mathrm{E}-02$ & $2.63 \mathrm{E}-2(\mathrm{SD}=6.74 \mathrm{E}-2)$ \\
${ }^{239} \mathrm{Pu}$ & $5.62 \mathrm{E}-01$ & $6.73 \mathrm{E}-1(\mathrm{SD}=8.09 \mathrm{E}-1)$ \\
${ }^{137} \mathrm{Cs}$ & $2.79 \mathrm{E}+04$ & $4.18 \mathrm{E}+4(\mathrm{SD}=3.89 \mathrm{E}+4)$ \\
\hline
\end{tabular}

Notes: The volume and inventory estimates for SX tanks come from Johnson and Field (2010).

Cobalt-60, tritium, and ${ }^{137} \mathrm{Cs}$ activities decay corrected to 9/30/2010.

The five potentially mobile contaminants of concern are in bold type.

(a) Mean value rounded to 3 digits, and decay corrected to 1/1/2001.

$\mathrm{SD}=$ Standard Deviation.

\section{B.2.5 Summary}

Table B.5 summarizes the key source term parameters for principal tank leak events associated with tank SX-108.

Table B.5. Key source term parameters for leaks from tank SX-108.

\begin{tabular}{|c|c|c|c|c|c|}
\hline Leak Event & Duration (days) & Volume (gal) & Volume (L) & $\begin{array}{c}\text { Average } \\
\text { Release Rate } \\
\text { (L/d) }\end{array}$ & $\begin{array}{c}{ }^{137} \text { Cs Inventory } \\
\text { (Ci, decay } \\
\text { corrected to } \\
9 / 30 / 2010)\end{array}$ \\
\hline \multirow{3}{*}{$\begin{array}{l}\text { July } 1964- \\
\text { June } 1965\end{array}$} & 91 (min.) & \multirow{3}{*}{ 2,400 (best) } & \multirow{3}{*}{9,000 (best). } & 18.5 (min.) & \\
\hline & 304 (best) & & & 26.3 (best) & $6.22 \mathrm{E}+3$ (best) \\
\hline & 487 (max.) & & & 100 (max.) & \\
\hline March 1966 - & 61 (min) & 48,300 (min.) & 183,000 (min.) & 501 (min.) & \multirow{3}{*}{--} \\
\hline \multirow[t]{2}{*}{ March 1967} & 365 (best) & 57,200 (ave./best) & 217,000 (ave./best) & 595 (ave./best) & \\
\hline & $365(\max )$ & 66,100 (max.) & 250,000 (max.) & 4,100 (max.) & \\
\hline March 1967 - & 335 (min.) & 0 (min.) & 0 (min.) & 0 (min.) & \multirow{3}{*}{--} \\
\hline \multirow[t]{2}{*}{ August 1968} & 517 (best) & 16,500 (ave./best) & 62,500 (ave./best) & 120 (best) & \\
\hline & 730 (max.) & 33,000 (max.) & 125,000 (max.) & $373(\max )$ & \\
\hline \multirow[t]{3}{*}{ Totals } & 487 (min.) & 50,700 (min.) & 192,000 (min.) & 122 (min.) & $6.35 \mathrm{E}+3(\mathrm{~min})$ \\
\hline & 1190 (best) & 76,100 (best) & 288,000 (best) & 242 (best) & $2.79 \mathrm{E}+04$ (best) \\
\hline & 1580 (max.) & $102,000(\max )$ & $384,000(\max )$ & 788 (max.) & $8.89 \mathrm{E}+4(\max )$ \\
\hline
\end{tabular}




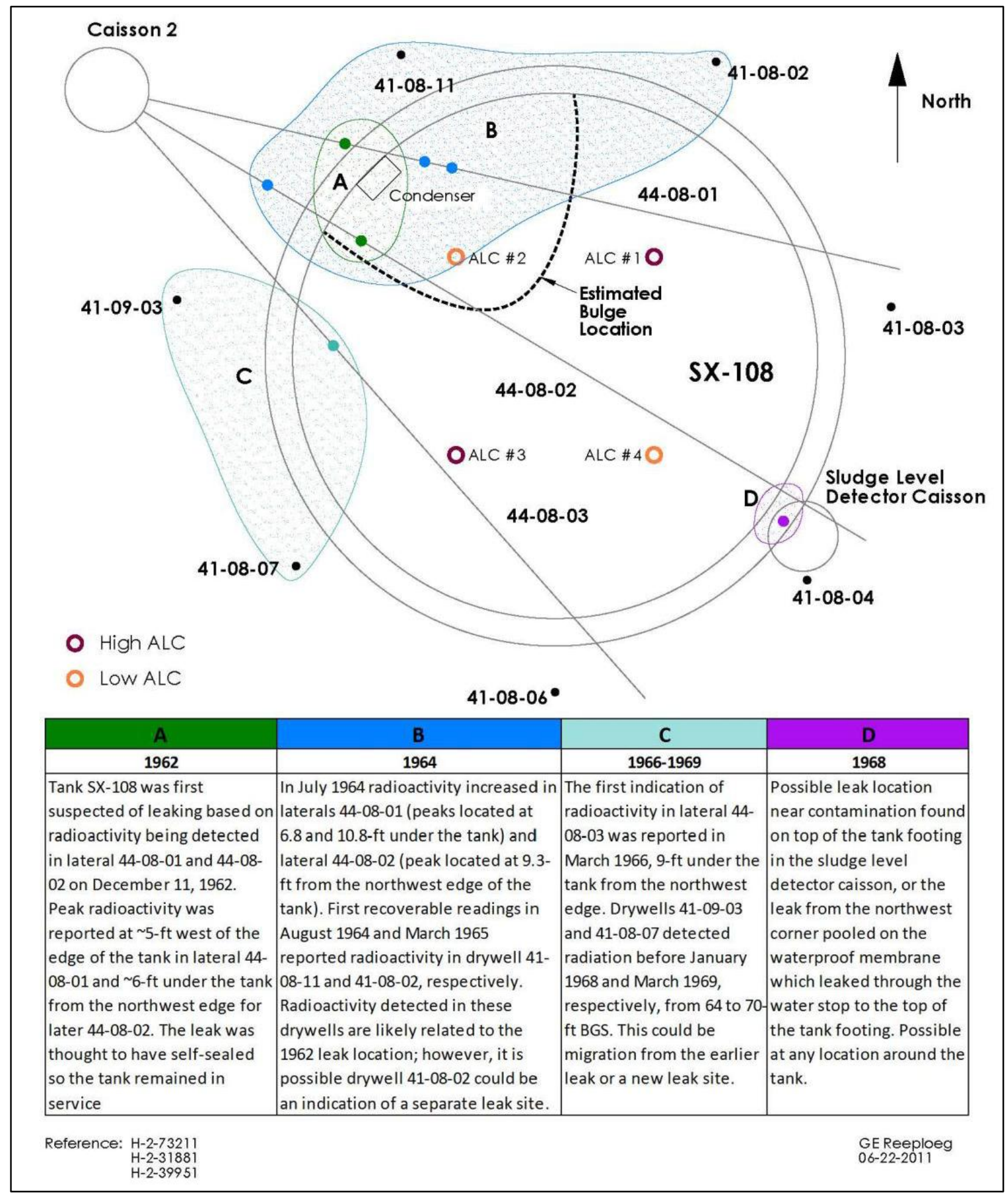

Figure B.3. Possible SX-108 tank leak locations (from Girardot and Harlow 2014). 


\section{B.3 Tank 241-SX-109 Waste Loss Event (after Johnson and Field 2010 and Girardot and Harlow 2014)}

\section{B.3.1 Leak Chronology}

- January 1965 - Radiation was first detected in lateral no. 3 (44-09-03) and dry well 41-09-02 below the bottom of the tank, in the northwest quadrant.

- February 20, $1965-5,000 \mathrm{cpm}$ radioactivity was detected in lateral no. 3. The tank was suspected of leaking and declared a confirmed leaker, but liquid was not immediately removed from the tank, because there was a shortage of storage space for HLW, and the leak was thought to have self-sealed.

- March 31, 1965 - 14,100 cpm radioactivity was detected in lateral no. 2, indicating either spreading of leaked waste or a new leak site from tank SX-109. The radioactivity detected in laterals no. 2 and 3 continued to increase and $200 \mathrm{cpm}$ radioactivity was detected in lateral no. 1 on April 29, 1965.

- After May 1965 - No additional waste transfer or water additions were made and the tank waste was allowed to slowly evaporate.

- May 1965 through June 1966 - Radioactivity in all three laterals continued to increase.

- The tank was kept in service to store supernate and sludge because there was a shortage of storage space and the leak was thought to have self-sealed.

- July 1, 1969 - 3 ft. of liquid ( 99,800 gal) was pumped from tank SX-109.

- July 8, 1969 - An additional 3-ft of liquid ( 99 kgal) was pumped from the tank.

- July 14, 1969 - Photographs confirmed the existence of a previously identified bulge in the bottom liner based on the presence of bent and tilted instrument piping.

- July 16, 1969 - Approximately 34,000 gal of condensate was pumped into tank SX-109 to cover and cool the sludge until a separate air-cooling system could be installed.

- In the fourth quarter of calendar year (CY) 1971 - Approximately 55,000 gal of supernate was transferred from tank SX-109 and the residual supernate allowed to evaporate.

- September 1972 - Drywell readings showed significant increases in radiation at levels below the tank bottom. Radioactivity continued to slowly increase in lateral 44-09-02 with new peaks recorded on January 2, 1973, and September 28, 1973.

- Between 1965 and 1973 - An average liquid level decrease of 4 in./yr was calculated based on liquid level decreases. A portion of the liquid level decrease can be attributed to evaporation, however, based on estimated evaporation rates of $2.5 \mathrm{in}$./yr or more, an estimated 33,000 gal of waste may have leaked to the soil.

- From 1980 through 1988 - The waste leaked from tank SX-109 may have spread based on increased radioactivity detected in drywells. 
- January 1992 - Tank SX-109 was declared interim stabilized based on May 1986 in-tank photographs.

\section{B.3.2 Estimated Release Events and Durations}

Girardot and Harlow (2014) suggested that there may have been three or four leak events at one or two locations. The leak chronology above suggests two primary leak events in close succession and a third potential leak event. Estimated volumes from each individual release event are unavailable.

- January to February 1965. This leak event is suspected to have occurred over a 1 or 2-month period, after which the leak was believed to have self-sealed.

- March 1965 - June 1966. The same leak appears to have reopened (perhaps off and on) for a period of up to 15 months, after which the leak was again assumed to have self-sealed.

- September 1972 to September 1973. Another leak may have occurred in a new location, or migration was detected from an earlier/different leak. In any case, the assumed release volume is low (de minimis).

\section{B.3.3 Estimated Total Release Volume and Average Release Rates}

Johnson and Field (2010) estimated the total leak volume at 1,000 gal (3,800 L), while CH2MHill (2011) estimated the total release volume at 2,100 gal $(8,000 \mathrm{~L})$. These are fairly consistent with Rogers (2014) estimate of $<10,000$ gal $(37,900 \mathrm{~L})$. However, Jones et al. (2000) suggest the total leak volume may have been as low as $310 \mathrm{gal}(1,200 \mathrm{~L})$.

- Assuming a total duration of 16 months, and a best estimate volume of 1,000 gal (3,800 L) would yield an average release rate of about $2 \mathrm{gal} / \mathrm{d}(7.6 \mathrm{~L} / \mathrm{d})$.

\section{B.3.4 Location}

Girardot and Harlow (2014) found that the tank SX-109 liner leaked at or near the bottom of the tank in one location with the possibility of a second location or migration from the first (Figure B.4).

- The primary tank leak is believed to have originated near the bottom of the tank along the outer edge of the tank bottom liner potentially on the northeast-east side of the tank (State Plane $\mathbf{E} \mathbf{5 6 6 7 8 3}, \mathbf{N}$ 134240 - estimated from Qmap). 


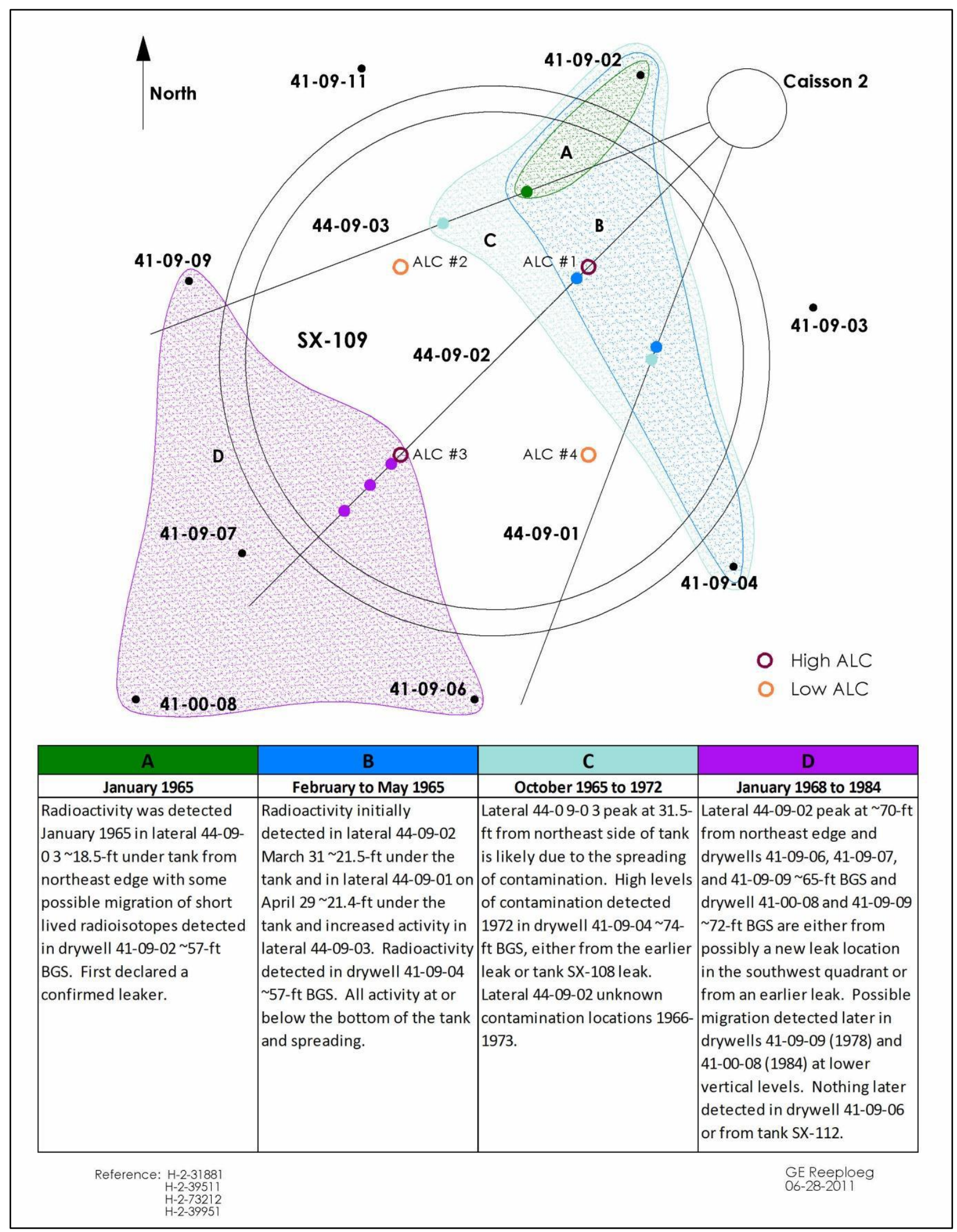

Figure B.4. Tank SX-109 possible radial leak locations (from Girardot and Harlow). 


\section{B.3.5 Inventory}

Johnson and Field (2010) estimated the total ${ }^{137} \mathrm{Cs}$ release inventory to be 2,300 Ci, which CH2MHILL (2011) decay corrected to September 30, 2010, yielding 1,840 Ci. This is consistent with the SIM estimate by Corbin et al. (2005), who also suggested that the ${ }^{137} \mathrm{Cs}$ inventory could have been as high as 9,590 Ci (decay corrected to September 30, 2010). Johnson and Field (2010) recommended calculation of the inventory for all analytes, by multiplying the ratio of the revised ${ }^{137} \mathrm{Cs}$ inventory $(2,300 \mathrm{Ci}$, decay corrected to January 2001) and the SIM ${ }^{137}$ Cs inventory (2,400 Ci, decay corrected to January 2001) by the SIM inventory for the selected analyte. CH2MHILL (2011) used this approach to estimate the inventories shown in Table B.6 (decay corrected to 9/30/2010), which are taken here as the best estimate.

Johnson and Field (2010) further noted that the leak volume may have been larger than their estimated 1,000 gal $(3,800 \mathrm{~L})$, and that an unknown transfer line or water losses may have also resulted in a larger distribution of waste leaked to the soil. This would change the concentrations, but not the total inventory.

Table B.6. Estimated inventory based on a release volume of 8,000 liters (from CH2MHill 2011, Draft, Table 3.4).

\begin{tabular}{|c|c|c|}
\hline \multirow[b]{2}{*}{ Constituent } & \multirow[b]{2}{*}{ Mass Released (kg) } & \multirow{2}{*}{$\begin{array}{l}\text { SIM (Corbin et al. 2005) } \\
\text { Mass Released }(\mathrm{kg})^{(\mathrm{a})}\end{array}$} \\
\hline & & \\
\hline $\mathrm{Na}$ & $1.88 \mathrm{E}+03$ & $1.96 \mathrm{E}+3(\mathrm{SD}=2.37 \mathrm{E}+2)$ \\
\hline $\mathrm{NO}_{3}$ & $1.57 \mathrm{E}+03$ & $1.64 \mathrm{E}+3(\mathrm{SD}=1.99 \mathrm{E}+2)$ \\
\hline $\mathrm{NO}_{2}$ & $7.57 \mathrm{E}+02$ & $7.90 \mathrm{E}+2(\mathrm{SD}=9.52 \mathrm{E}+1)$ \\
\hline $\mathrm{PO}_{4}$ & $3.76 \mathrm{E}-01$ & $3.93 \mathrm{E}-1(\mathrm{SD}=4.73 \mathrm{E}-2)$ \\
\hline $\mathrm{SO}_{4}$ & $3.87 \mathrm{E}+01$ & $4.04 \mathrm{E}+1(\mathrm{SD}=4.86 \mathrm{E}+0)$ \\
\hline $\mathrm{F}$ & $2.90 \mathrm{E}-02$ & $3.02 \mathrm{E}-2(\mathrm{SD}=3.65 \mathrm{E}-3)$ \\
\hline $\mathbf{U}$ & 2.25E-01 & 2.35E-1 $(\mathrm{SD}=2.79 \mathrm{E}-1)$ \\
\hline $\mathrm{Cr}$ & $2.09 E+01$ & $2.18 \mathrm{E}+1(\mathrm{SD}=2.63 \mathrm{E}+0)$ \\
\hline Constituent & Activity Released (Ci) & Activity Released (Ci) $^{(\mathrm{a})}$ \\
\hline${ }^{60} \mathrm{Co}$ & $3.41 \mathrm{E}-02$ & $1.28 \mathrm{E}-1(\mathrm{SD}=1.34 \mathrm{E}-1)$ \\
\hline${ }^{129} \mathrm{I}$ & 1.19E-03 & $1.24 \mathrm{E}-3(\mathrm{SD}=1.12 \mathrm{E}-3)$ \\
\hline${ }^{99} \mathrm{Tc}$ & 7.68E-01 & 8.02E-1 $(\mathrm{SD}=7.29 \mathrm{E}-1)$ \\
\hline${ }^{3} \mathrm{H}$ & $3.11 \mathrm{E}-01$ & $5.61 \mathrm{E}-1(\mathrm{SD}=5.37 \mathrm{E}-1)$ \\
\hline${ }^{238} \mathrm{Pu}$ & $1.43 \mathrm{E}-03$ & $1.50 \mathrm{E}-3(\mathrm{SD}=3.81 \mathrm{E}-3)$ \\
\hline${ }^{239} \mathrm{Pu}$ & $3.69 \mathrm{E}-02$ & $3.85 \mathrm{E}-2(\mathrm{SD}=4.64 \mathrm{E}-2)$ \\
\hline${ }^{137} \mathrm{Cs}$ & $1.84 \mathrm{E}+03$ & $2.39 \mathrm{E}+3(\mathrm{SD}=2.22 \mathrm{E}+3)$ \\
\hline \multicolumn{3}{|c|}{$\begin{array}{l}\text { Notes: The volume and inventory estimates for SX tanks come from Johnson and Field } \\
\text { (2010). } \\
\text { Cobalt-60, tritium, and }{ }^{137} \text { Cs activities decay corrected to 9/30/2010. } \\
\text { The five potentially mobile contaminants of concern are in bold type. } \\
\text { (a) Mean value rounded to } 3 \text { digits, and decay corrected to 1/1/2001. } \\
\text { SD = Standard Deviation. }\end{array}$} \\
\hline
\end{tabular}




\section{B.3.6 Summary}

Table B.7 summarizes the key source term parameters for principal leak events for tank SX-109.

Table B.7. Key source term parameters for leaks from tank SX-109.

\begin{tabular}{|c|c|c|c|c|c|}
\hline Leak Event & Duration (days) & Volume (gal) & Volume (L) & $\begin{array}{c}\text { Release Rate } \\
(\mathrm{L} / \mathrm{d})\end{array}$ & $\begin{array}{c}{ }^{137} \mathrm{Cs} \text { Inventory }(\mathrm{Ci}, \\
\text { decay corrected to } \\
9 / 30 / 2010)\end{array}$ \\
\hline Jan. - Feb. 1965 & $\begin{array}{c}30 \text { (min) } \\
30 \text { (best est.) } \\
60 \text { (max) }\end{array}$ & -- & -- & -- & -- \\
\hline $\begin{array}{l}\text { Mar. } 1965 \text { - June } \\
1966\end{array}$ & $\begin{array}{c}30 \text { (min) } \\
456 \text { (best est.) } \\
456 \text { (max) }\end{array}$ & -- & -- & -- & -- \\
\hline Totals & $\begin{array}{c}60 \text { (min.) } \\
487 \text { (best est.) } \\
516 \text { (max.) }\end{array}$ & $\begin{array}{c}310 \text { (min.) } \\
1,000 \text { (best est.) } \\
<10,000(\max )\end{array}$ & $\begin{array}{c}1,200 \text { (min.) } \\
3,800 \text { (best est.) } \\
<37,900 \text { (max) }\end{array}$ & $\begin{array}{c}2.3 \text { (min.) } \\
7.8 \text { (best est.) } \\
632 \text { (max.) }\end{array}$ & $\begin{array}{c}4.90 \mathrm{E}+2(\min ) \\
1.84 \mathrm{E}+03 \text { (best est.) } \\
9.59 \mathrm{E}+3(\max )\end{array}$ \\
\hline
\end{tabular}

\section{B.4 Tank 241-SX-111 Waste Loss Event (after Johnson and Field 2010 and Girardot and Harlow 2014)}

\section{B.4.1 Leak Chronology}

- April 30, 1974 - Radioactivity first detected in lateral \#2 (44-11-02), below the bottom of the tank $\sim 23 \mathrm{ft}$ from the southeast edge.

- May 4, 1974 - It was determined that SX-111 was leaking (based on liquid level decline and an increase in radiation in lateral \#2 (44-11-02) during April 19 through May 4, 1974), and waste was transferred out of the tank. The average tank leak rate was estimated at an average of $103.6 \mathrm{gal} / \mathrm{d}$ from April 7 to May 4, 1974 (suggesting a tank leak volume of 2,800 gal; however, there was considerable uncertainty in this estimate). Assuming the leak volume to be 2,000 gal, the inventories of ${ }^{137} \mathrm{Cs},{ }^{90} \mathrm{Sr}$, and plutonium leaked in May 1974 were estimated to be 2,400 Ci, $0.27 \mathrm{Ci}$, and $0.03 \mathrm{~g}$, respectively.

- May 20, 1974 - A saltwell was installed and 1,300 gal of liquid were pumped from the tank before the pump lost suction.

- October 7, 1974 - Gamma activity in lateral \#2 reached its peak at a distance of $~ 120$ to $125 \mathrm{ft}$ from the entrance of the lateral. Gamma activity then began to decline.

- March 3, 1977 - Radioactivity from the April 1974 leak apparently moved west to a location of $\sim 30 \mathrm{ft}$ from the southeast edge of the tank in lateral 44-11-02. 
- Pumping of the interstitial liquid from the saltwell was periodically attempted until January 1979, when the tank was declared interim stabilized.

\section{B.4.2 Estimated Release Events and Average Release Rate}

- April 7 - May 4, 1974 (assumed duration of 27 days).

Johnson and Field (2010) list the best estimated leak volume as 2,800 gal (11,000 L). Note however, that Rogers (2014) list the total leak volume as 500 to 2,000 gal (1,900-7,600 L).

Assuming a total duration of 27 days would yield an average release rate of 104 gal/d (394 L/d). However, if the leak continued until liquid was pumped from the tank (May 20) the duration could have been as much as 43 days. Assuming the total volume was 2,800 gal, this would yield a release rate of $65 \mathrm{gal} / \mathrm{d}(250 \mathrm{~L} / \mathrm{d})$.

\section{B.4.3 Location}

The tank leak is believed to have originated at or near the bottom of the tank near the center of the tank near the middle of lateral \#2 (44-11-02) (Figure B.5) (State Plane E 566858, N 134191 - estimated from Qmap). 


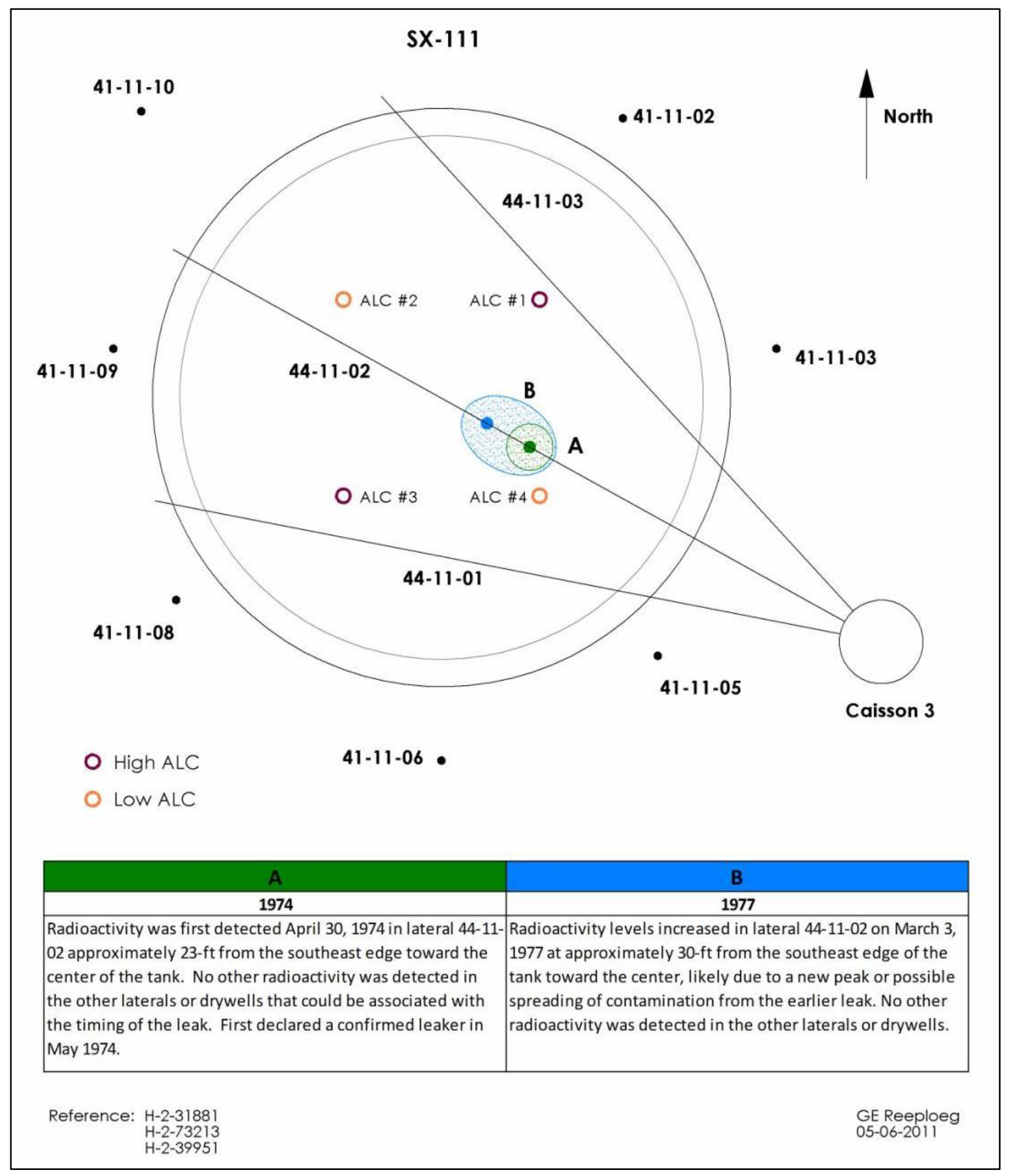

Figure B.5. Tank SX-111 possible leak locations. 


\section{B.4.4 Inventory}

The total leak volume is estimated to have been 2,800 gal $(11,000 \mathrm{~L})$, with a total inventory shown in Table B.8. Johnson and Field (2010) suggested that because SIM assumed a 1958 leak date versus 1974 and should have used the R-Saltcake waste type (RSLTCK), the SIM inventory estimates should be multiplied by about 0.55 .

Table B.8. Estimated inventory based on a release volume of 11,000 liters (from CH2MHill 2011, Draft, Table 3.4).

\begin{tabular}{|c|c|c|}
\hline Constituent & Mass Released (kg) & $\begin{array}{l}\text { SIM (Corbin et al. 2005) } \\
\text { Mass Released (kg) }{ }^{(\mathrm{a})}\end{array}$ \\
\hline $\mathrm{Na}$ & $1.54 \mathrm{E}+03$ & $1.75 \mathrm{E}+2(\mathrm{SD}=6.32 \mathrm{E}+1)$ \\
\hline $\mathrm{NO}_{3}$ & $1.29 \mathrm{E}+03$ & $1.44 \mathrm{E}+2(\mathrm{SD}=5.12 \mathrm{E}+1)$ \\
\hline $\mathrm{NO}_{2}$ & $6.23 \mathrm{E}+02$ & $7.05 \mathrm{E}+1(\mathrm{SD}=2.63 \mathrm{E}+1)$ \\
\hline $\mathrm{PO}_{4}$ & $3.09 \mathrm{E}-01$ & $1.02 \mathrm{E}+0(\mathrm{SD}=4.04 \mathrm{E}-1)$ \\
\hline $\mathrm{SO}_{4}$ & $3.18 \mathrm{E}+01$ & $1.44 \mathrm{E}+1(\mathrm{SD}=5.97 \mathrm{E}+0)$ \\
\hline $\mathrm{F}$ & $2.38 \mathrm{E}-02$ & $7.07 \mathrm{E}+2(\mathrm{SD}=2.43 \mathrm{E}+2)$ \\
\hline $\mathbf{U}$ & 1.85E-01 & $5.50 \mathrm{E}-2(\mathrm{SD}=5.66 \mathrm{E}-2)$ \\
\hline $\mathrm{Cr}$ & $1.72 \mathrm{E}+01$ & $2.82 \mathrm{E}+0(\mathrm{SD}=1.08 \mathrm{E}+0)$ \\
\hline Constituent & Activity Released (Ci) & Activity Released (Ci) \\
\hline${ }^{60} \mathrm{Co}$ & $2.81 \mathrm{E}-02$ & $3.92 \mathrm{E}-02(\mathrm{SD}=4.34 \mathrm{E}-02)$ \\
\hline${ }^{129} \mathrm{I}$ & 9.76E-04 & $1.56 \mathrm{E}-04(\mathrm{SD}=1.52 \mathrm{E}-04)$ \\
\hline${ }^{99} \mathrm{Tc}$ & 6.32E-01 & $2.28 \mathrm{E}-01(\mathrm{SD}=2.55 \mathrm{E}-01)$ \\
\hline${ }^{3} \mathrm{H}$ & $2.55 \mathrm{E}-01$ & $4.86 \mathrm{E}-02(\mathrm{SD}=3.68 \mathrm{E}-02)$ \\
\hline${ }^{238} \mathrm{Pu}$ & $1.18 \mathrm{E}-03$ & 4.04E-04 (SD = 7.05E-04) \\
\hline${ }^{239} \mathrm{Pu}$ & $3.03 \mathrm{E}-02$ & $9.00 \mathrm{E}-03(\mathrm{SD}=1.19 \mathrm{E}-02)$ \\
\hline${ }^{137} \mathrm{Cs}$ & $1.46 \mathrm{E}+00$ & $5.26 \mathrm{E}+01(\mathrm{SD}=3.29 \mathrm{E}+01)$ \\
\hline
\end{tabular}

Notes: The volume and inventory estimates for SX tanks come from Johnson and Field (2010).

Cobalt-60, tritium, and ${ }^{137} \mathrm{Cs}$ activities decay corrected to 9/30/2010.

The five potentially mobile contaminants of concern are in bold type.

(a) Mean value rounded to 3 digits, and decay corrected to 1/1/2001.

$\mathrm{SD}=$ Standard Deviation.

\section{B.4.5 Summary}

Table B.9 summarizes the key source term parameters for the primary leak event from tank SX-111.

Table B.9. Key source term parameters for leaks from tank SX-111.

\begin{tabular}{cccccc}
\hline & & & & & \\
& & & ${ }^{137} \mathrm{Cs}$ Inventory (Ci, \\
Release Rate & corrected to \\
Leak Event & Duration (days) & Volume (gal) & Volume (L) & (L/30/2010) \\
\hline April 7 - May 4, & 27 (min.) & 500 (min.) & 1,900 (min.) & 44 (min.) & $1.59 \mathrm{E}-1$ (min) \\
1974 (Totals) & 27 (best est.) & 2,800 (best est.) & 11,000 (best est.) & 100 (best est.) & $1.46 \mathrm{E}+00$ (best est.) \\
& 43 (max.) & 2,800 (max) & 11,000 (max) & 100 (max.) & $1.83 \mathrm{E}+3$ (max) \\
\hline
\end{tabular}




\section{B.5 Tank 241-SX-112 Waste Loss Event (after Johnson and Field 2010 and Girardot and Harlow 2014)}

\section{B.5.1 Leak Chronology}

- October 1958-September 1959 - Agnew and Corbin (1998), suggested that the first unaccounted volume loss first occurred in October 1958 with several additional months having unaccounted losses as well. They suggested a leak of around $1,600 \mathrm{gal} / \mathrm{mo}$ over 12 months for a total leak volume of 19,000 gal.

- Mid-January 1969 - A gradual liquid level decrease was first observed. Based on the liquid level measurements, it was estimated that up to 27,000 gal of supernatant liquid containing about 40,000 curies of ${ }^{137} \mathrm{Cs}$ may have leaked from the tank.

- January 16,1969 - Supernate was transferred out of the tank, reducing the liquid level from $20 \mathrm{ft}$ to 8 $\mathrm{ft}$.

- January 19, 1969 - Liquid levels were holding steady, but radiation readings in the leak detection laterals began rising sharply, apparently as a result of the migration of activity from the initial leak.

- January 21-22, 1969 - Liquid level dropped slightly.

- More waste was pumped from tank, reducing liquid levels to $4 \mathrm{ft}$, and leaving an estimated 82,000 gal of supernate and 39,000 gal of sludge in the tank. Photographs inside the tank indicated a raised liner.

- The tank was connected to a sludge cooler, and evaporation of water from the waste was allowed to occur.

- January 27- February 9, 1969 - Liquid level holding steady.

- February 1969 - The rate of rise of the radiation readings in the lateral dramatically decreased and it was believed that no additional leakage was occurring.

- Radioactivity first appeared in drywells 41-12-02 and 41-12-03 prior to March 1969 from $71 \mathrm{ft}$ bgs and 60 to $65 \mathrm{ft}$ bgs, respectively. Drywell 41-12-02 had lower levels of radioactivity compared to drywell 41-12-03.

- July 1974 - Photographs inside the tank show an apparent crack in the sidewall of the tank above the fourth stiffer ring (about 16-ft level).

- October 11, 1974 - Radioactivity was first detected in lateral \#1 (44-12-01) at $16.4 \mathrm{ft}$ bgs.

- By July 1979 - No supernate remained and the tank was deemed stabilized.

- 1983 - Radioactivity levels increased in lateral \#1 (44-12-01) at 21.4 ft from southeast edge. 


\section{B.5.2 Estimated Release Events, Volumes, and Average Release Rate}

- October 1958 - September 1959. Agnew and Corban (1998) assumed a duration for this leak of 12 months with an average release rate of 1,600 gal/mo [53 gal/d] for a release volume of 19,000 gal. However, no other reference recognizes this leak event, so, this is considered a maximum, and the best estimate and minimum are taken to be 0 gal.

- January 1 - January 16, 1969 (assumed duration of 16 days). Johnson and Field (2010) estimate the leak volume at 27,000 gal $(102,000 \mathrm{~L})$. Assuming a total duration of 16 days would yield an average release rate of 1,690 gal/d (6,390 L/d). Agnew and Corbin (1998) suggested a leak volume of 25,000 gal and a duration of 2 months, yielding a leak rate of 13,000 gal/mo (427 gal/d). However, this duration is considered a maximum. The duration is unlikely to have lasted after January 16, when the tank was pumped. Field and Jones (2004) estimated a nominal leak volume of only 1,000 gal, which we take here as the minimum.

- October 11, 1974 - A possible new leak location (with de minimis volume), or possibly from migration of the earlier leak.

- June 1983 - Likely possible spreading of radioactivity, or possibly a new leak (with de minimis volume).

Johnson and Field (2010, p. 5-64) estimated the total release volume to be up to 27,000 gal with a

${ }^{137}$ Cs inventory of 19,200 (decayed to January 1, 2001). However, Rogers (2014) estimated the total release volume at 30,000 gal, while Agnew and Corbin (1998) estimated the total release at 44,000 gal, and Field and Jones (2004) estimated it at only 1,000 gal.

\section{B.5.3 Location}

Girardot and Harlow (2014) found that tank SX-112 leaked at or near the bottom of the tank in either two or three locations (Figure B.6).

- The primary tank leak (January 1969) was found to have originated beneath the eastern portion of the tank above laterals \#2 and \#3 (State Plane E 566860, N 134185 - estimated from Qmap). 


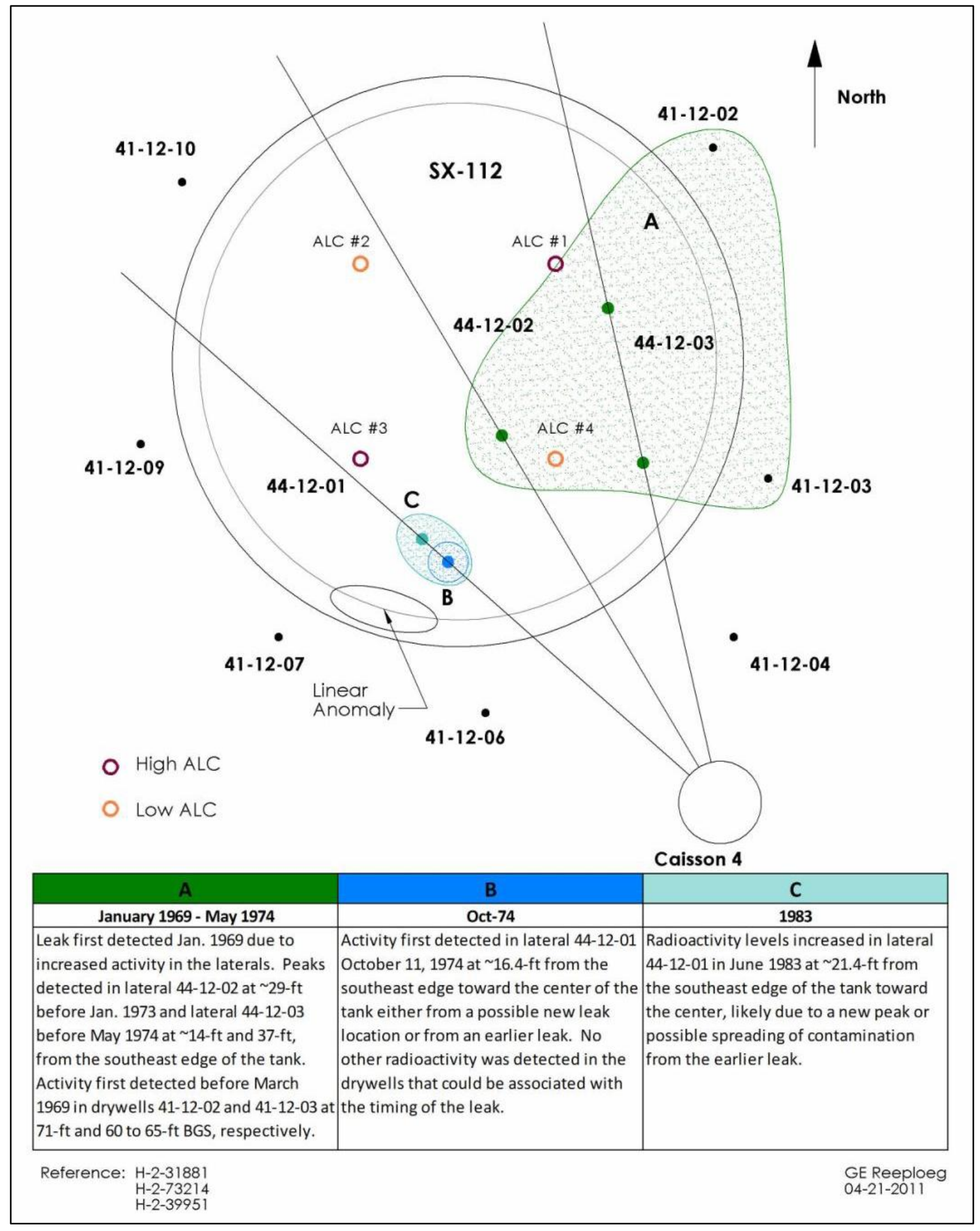

Figure B.5. Tanks SX-112 possible leak locations (from Girardot and Harlow 2014). 


\section{B.5.4 Inventory}

The best estimate of the total volume released is 27,000 gal (102,000 L) (Johnson and Field 2010). Johnson and Field (2010) also suggested a best estimate ${ }^{137} \mathrm{Cs}$ inventory of 19,200 Ci (decay corrected to January 1, 2001), which CH2MHill (2011) adjusted to 15,300 Ci (decay corrected to September 30, 2010). However, Agnew and Corbin (1998) suggest the ${ }^{137} \mathrm{Cs}$ inventory could have been as high as 96,200 to $250,000 \mathrm{Ci}$ (decay corrected to January 1, 1994, or 65,500 to $170,000 \mathrm{Ci}$, decay corrected to 9/1/2010). Jones et al. (2000) estimated the ${ }^{137}$ Cs inventory in the vadose zone based on kriging (by Montana State University, MSU) to be 20.7 to $109 \mathrm{Ci}$ (decay corrected to 1/1/94).

Johnson and Fields (2010) suggested that the inventories for other analytes, should be calculated by multiplying the SIM inventories (Corbin et al. 2005) by the ratio of $19,200 / 1,190=16.1$, to account for volume and sample differences. This was supposedly done by CH2MHill (2011), yielding the total best estimate inventory shown in Table B.10; however, Corbin et al. (2005, Appendix C) do not provide inventory estimates for the SX-112 tank leak.

Table B.10. Estimated inventory from the 241-SX-112 waste release event, based on a release volume of 105,000 liters (from CH2MHill 2011, Draft, Table 3.4).

\begin{tabular}{cc}
\hline Constituent & Mass Released $(\mathrm{kg})$ \\
\hline $\mathrm{Na}$ & $1.57 \mathrm{E}+04$ \\
$\mathrm{NO}_{3}$ & $\mathbf{1 . 3 2 E}+\mathbf{0 4}$ \\
$\mathrm{NO}_{2}$ & $6.35 \mathrm{E}+03$ \\
$\mathrm{PO}_{4}$ & $3.16 \mathrm{E}+00$ \\
$\mathrm{SO}_{4}$ & $3.25 \mathrm{E}+02$ \\
$\mathrm{~F}$ & $2.43 \mathrm{E}-01$ \\
$\mathbf{U}$ & $\mathbf{1 . 8 9 E}+\mathbf{0 0}$ \\
$\mathbf{C r}$ & $\mathbf{1 . 7 5 E + 0 2}$ \\
\hline${ }_{\mathrm{Constituent}}$ & Activity Released $(\mathrm{Ci})$ \\
\hline${ }^{60} \mathrm{Co}$ & $2.86 \mathrm{E}-01$ \\
${ }^{129} \mathbf{I}$ & $\mathbf{9 . 9 5 E - 0 3}$ \\
${ }^{99} \mathbf{T c}$ & $\mathbf{6 . 4 5 E}+00$ \\
${ }^{3} \mathrm{H}$ & $2.61 \mathrm{E}+00$ \\
${ }^{238} \mathrm{Pu}$ & $1.20 \mathrm{E}-02$ \\
${ }^{239} \mathrm{Pu}$ & $3.09 \mathrm{E}-01$ \\
${ }^{137} \mathrm{Cs}$ & $1.53 \mathrm{E}+04$ \\
\hline
\end{tabular}

Notes: The volume and inventory estimates for SX tanks come from Johnson and Field (2010).

Cobalt-60, tritium, and ${ }^{137} \mathrm{Cs}$ activities decay corrected to 9/30/2010.

The five potentially mobile contaminants of concern are in bold type.

\section{B.5.5 Summary}

Table B.11 summarizes the key source term parameters for principal leak events from tank SX-112. 
Table B.11. Key source term parameters for principal leaks from tank SX-112.

\begin{tabular}{|c|c|c|c|c|c|}
\hline $\begin{array}{l}\text { Leak } \\
\text { Event }\end{array}$ & $\begin{array}{c}\text { Duration } \\
\text { (days) }\end{array}$ & Volume (gal) & Volume (L) & $\begin{array}{c}\text { Average } \\
\text { Release Rate } \\
(\mathrm{L} / \mathrm{d})\end{array}$ & $\begin{array}{c}{ }^{137} \text { Cs Inventory } \\
\text { (Ci, decay } \\
\text { corrected to } \\
9 / 30 / 2010 \text { ) }\end{array}$ \\
\hline \multirow{3}{*}{$\begin{array}{l}\text { Oct. } 1958 \text { - } \\
\text { Sept. } 1959\end{array}$} & 0 (min.) & 0 (min.) & 0 (min.) & 0 (min.) & 0 (min.) \\
\hline & 0 (best) & 0 (best) & 0 (best) & 0 (best) & 0 (best) \\
\hline & 365 (max.) & 19,000 (max.) & 71,900 (max.) & 200 (max.) & -- \\
\hline \multirow{3}{*}{$\begin{array}{l}\text { January } 1- \\
\text { January 16, } \\
1969\end{array}$} & 16 (min) & 1,000 (min.) & 3,790 (min.) & 62.1 (min.) & \multirow{3}{*}{--} \\
\hline & 16 (best) & 27,000 (best) & 102,000 (best) & 6,380 (best) & \\
\hline & $61(\max )$ & 27,000 (max.) & 102,000 (max.) & 6,380 (max.) & \\
\hline \multirow[t]{3}{*}{ Totals } & 16 (min.) & 1,000 (min.) & 3,790 (min.) & 62.1 (min.) & $2.07 \mathrm{E}+1(\mathrm{~min})$ \\
\hline & 16 (best) & 27,000 (best) & 102,000 (best) & 6,380 (best) & $1.53 \mathrm{E}+4$ (best) \\
\hline & 426 (max.) & $44,000(\max )$ & 167,000 (max.) & 6,380 (max.) & $1.70 \mathrm{E}+5(\max )$ \\
\hline
\end{tabular}

\section{B.6 Tank 241-SX-113 Waste Loss Event (after Johnson and Field 2010 and Girardot and Harlow 2014)}

\section{B.6.1 Leak Chronology}

- February 19, 1958 - The 24-in. vapor header butterfly valve (to the exhaust ventilation system) was opened to tank SX-113.

- February 20,1958 - Tank SX-113 began receiving 202-S REDOX HLW. There is no record that the tank contained any liquid waste or water prior to receiving REDOX HLW. This is important because the tank was first connected to the exhaust ventilation system before receiving any waste. If the exhaust ventilation system exerted vacuum of 2.4-in. water gauge or higher, deflection of the tank bottom would occur because no liquid was present in the tank.

- The concentration of radionuclides was sufficient to promote self-boiling of this waste.

- Operations personnel observed, "... that the volume received in the tank exceeded slightly the volume sent."

- April 7, 1958 - The airlift circulators were turned on.

- Continuous self-boiling commenced about April 22, 1958.

- May 28, 1958 - Attempts to install an experimental, replaceable airlift circulator encountered an obstruction. Subsequent soundings "indicated the steel lining of the tank to be elevated to a height greater than four feet above its original position." Extensive evaluation of material balances and temperature data indicated the presence of liquid between the concrete supporting structure and the steel liner as the most likely cause of the displacement. 
- By June 2, 1958 - Approximately 483,000 gal of REDOX HLW had been received and further waste receipt terminated.

- Between June 11 and June 18, 1958 - The liner returned to its original position, but the integrity of the tank liner was in doubt. However, extensive leak checks, dry well checks, and tank electrode readings indicated no leakage. Well points driven to a depth of $50 \mathrm{ft}$ on the northwest side of the tank and to a depth of $24 \mathrm{ft}$ by the tank fill line found no evidence of ground contamination.

- Painstaking calculations showed that approximately 40,000 gal of waste remained unaccounted for. This is consistent with the theory that the bulge was caused by liquid (under the bottom of the liner), which subsequently escaped to the soil through a fault in the concrete, thus, allowing the steel plate to resume its normal position.

- July 22, 1958 - The airlift circulators were shut off to enable removal of the tank contents.

- Between July 23 and July 25, 1958 - The tank contents were pumped to another SX farm tank, due to concerns about the stresses suffered by the liner.

- August 1958 - Sixteen days after emptying the tank, the bottom again started to rise, reaching 40 in. above normal within the next 15 days. The liner returned to approximately normal position near the end of the month.

- It was believed that the bulged liner was likely the result of water contained in the grout and concrete tank shell that vaporized to steam as a result of the elevated waste temperatures.

- December 1959 - Drilling of five horizontal laterals under SX-113 was completed and no soil contamination was encountered.

- January 1959 - Monitoring of the laterals found no anomalous radiation indicating that the tank integrity was intact.

- August 2, 1962 - No radiation was detected during monitoring of the laterals under the tank.

- October 10, 1962 through October 29, 1962 - Leak testing of the 113-SX tank was conducted. A total of 65,000 gal of salt waste solution was transferred into tank SX-113. Liquid level measurements conducted between October 11, 1962 and October 29, 1962 indicated a volume decrease of $\sim 2,800$ gal. However, evidence that the tank did or did not leak was considered to be inconclusive.

- October 30, 1962 through November 2, 1962 - An additional 143,000 gal of waste was transferred into tank SX-113, filling the tank to the 80 -in. level or 204,000 gal.

- November 2 through November 7, 1962 - A leak was indicated when the liquid level decreased 2-9/16 in. (7,000 gal) in 5 days (November 2, 1962 through November 7, 1962).

- November 13, 1962 - A leak was confirmed by monitoring the horizontal laterals under the tank. The peak activity detected was $\sim 7,500 \mathrm{cpm}$ gamma in the central lateral no. 3 . 
- November 13, 1962 - The leak test was terminated and remaining liquid was transferred back out of the tank on November 14 and 15, 1962, except for a heel of about 10,000 gal.

- Calculations show that approximately 15,000 gal of solution containing 7,800 $\mathrm{Ci}$ of gamma activity $\left(>99 \%{ }^{137} \mathrm{Cs}\right.$ ) were lost to the ground. The major portion of the leakage occurred after November 2 , 1962, at a rate of 1200-1400 gpd when the tank liquid level was increased from approximately 30 in. to $80 \mathrm{in.}$

- 1972 - 45 tons of diatomaceous earth was added to the tank to absorb and immobilize the liquid waste heel.

- 1978 - The tank was declared interim stabilized/partially isolated.

\section{B.6.2 Estimated Release Events and Average Release Rate}

- May 28, 1958 - June 2, 1958. An estimated 40,000 gal (151,000 L) was thought to have potentially been lost at a rate of 12,000 to 15,000 gal/d for about 5 days (Johnson and Field 2010, p.5-122). However, extensive leak integrity testing indicated that the tanks integrity was intact, and the apparent loss of liquid was attributed to collapse of the bulging liner. Thus, the best estimate is that no waste was loss during this event.

- November 2 - November 14, 1962. A total estimated leak volume of 15,000 gal (56,800 L), with an assumed total duration of 12 days would yield an average release rate of $1,250 \mathrm{gal} / \mathrm{d}(4,730 \mathrm{~L} / \mathrm{d})$. However, the duration of this leak could have ranged from a minimum of about 5 days (November 2 to November 7) to a maximum of about 35 days (October 10 to November 14).

\section{B.6.3 Location}

- Girardot and Harlow (2014) found that the tank leaked at or near the bottom of the tank in one or possibly two locations (Figure B.7). They also found that the leak may have started in the central portion of the tank above lateral \#3 (State Plane E 566837, N 134176 - estimated from Qmap). 


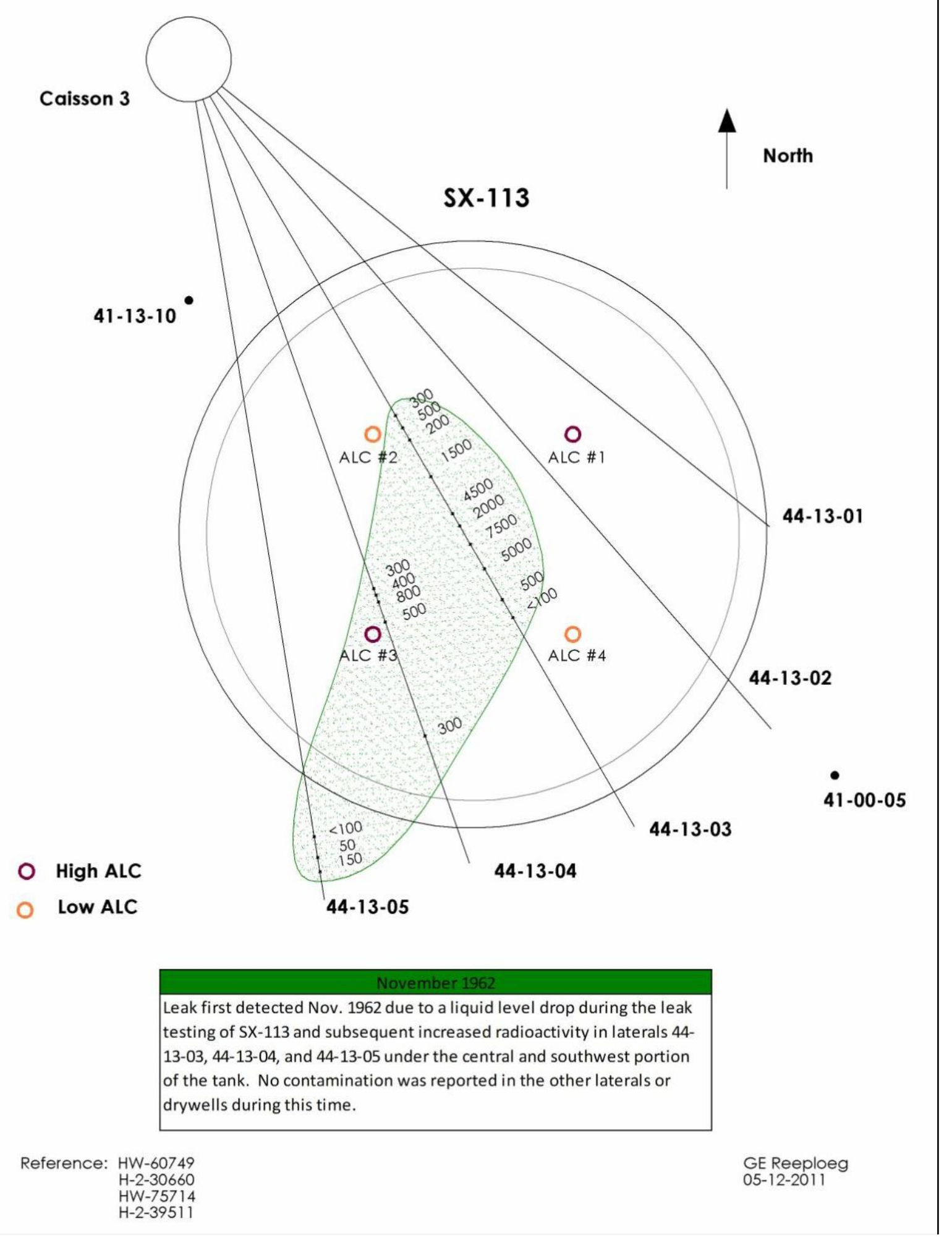

Figure B.6. Tank SX-113 possible leak locations (from Girardot and Harlow 2014). 


\section{B.6.4 Inventory}

The best estimate total leak volume is 15,000 gal $(56,800 \mathrm{~L})$, with a best estimate total ${ }^{137} \mathrm{Cs}$ inventory of $4,080 \mathrm{Ci}$ (decay corrected to January 1, 2001, or 3,226 Ci (decay corrected to September 30, 2010) as shown in Table B.7. Johnson and Fields (2010) suggested that the inventories for other analytes could be estimated by multiplying the SIM inventories by the ratio of 0.96 , to account for volume and sample differences. This was supposedly done by CH2MHill (2011), yielding the total best estimate inventory shown in Table B.12.

Table B.12. Estimated inventory from the 241-SX-113 waste release event, based on a release volume of 58,000 liters (from CH2MHill 2011, Draft, Table 3.4).

\begin{tabular}{|c|c|c|}
\hline Constituent & Mass Released (kg) & $\begin{array}{l}\text { SIM (Corbin et al. 2005) } \\
\text { Mass Released (kg) }\end{array}$ \\
\hline $\mathrm{Na}$ & $6.97 \mathrm{E}+03$ & $7.23 \mathrm{E}+03(\mathrm{SD}=1.03 \mathrm{E}+03)$ \\
\hline $\mathrm{NO}_{3}$ & $7.60 \mathrm{E}+03$ & $7.87 \mathrm{E}+03(\mathrm{SD}+1.12 \mathrm{E}+03)$ \\
\hline $\mathrm{NO}_{2}$ & $1.93 \mathrm{E}+03$ & $2.00 \mathrm{E}+03(\mathrm{SD}=2.84 \mathrm{E}+02)$ \\
\hline $\mathrm{PO}_{4}$ & $0.00 \mathrm{E}+00$ & $0.00 \mathrm{E}+00(\mathrm{SD}=0.00 \mathrm{E}+00)$ \\
\hline $\mathrm{SO}_{4}$ & $1.01 \mathrm{E}+02$ & $1.04 \mathrm{E}+02(\mathrm{SD}=1.49 \mathrm{E}+01)$ \\
\hline $\mathrm{F}$ & $4.93 \mathrm{E}-05$ & $5.11 \mathrm{E}-05(\mathrm{SD}=1.36 \mathrm{E}-05)$ \\
\hline $\mathbf{U}$ & $1.69 \mathrm{E}+00$ & $1.75 \mathrm{E}+00(\mathrm{SD}=1.41 \mathrm{E}+00)$ \\
\hline $\mathrm{Cr}$ & $1.57 \mathrm{E}+02$ & $1.62 \mathrm{E}+02(\mathrm{SD}=2.31 \mathrm{E}+01)$ \\
\hline Constituent & Activity Released (Ci) & Activity Released $(\mathrm{Ci})^{(\mathrm{a})}$ \\
\hline${ }^{60} \mathrm{Co}$ & $3.08 \mathrm{E}-02$ & $1.15 \mathrm{E}-01(\mathrm{SD}=7.18 \mathrm{E}-02)$ \\
\hline${ }^{129} \mathbf{I}$ & 2.31E-03 & $2.39 \mathrm{E}-03(\mathrm{SD}=1.40 \mathrm{E}-03)$ \\
\hline${ }^{99} \mathrm{Tc}$ & $1.44 \mathrm{E}+00$ & $1.49 \mathrm{E}+00(\mathrm{SD}=8.43 \mathrm{E}-01)$ \\
\hline${ }^{3} \mathrm{H}$ & 8.69E-01 & $1.56 \mathrm{E}+00(\mathrm{SD}=9.20 \mathrm{E}-01)$ \\
\hline${ }^{238} \mathrm{Pu}$ & $5.28 \mathrm{E}-03$ & $5.47 \mathrm{E}-03(\mathrm{SD}=6.44 \mathrm{E}-03)$ \\
\hline${ }^{239} \mathrm{Pu}$ & $2.78 \mathrm{E}-01$ & $2.88 \mathrm{E}-01(\mathrm{SD}=2.10 \mathrm{E}-01)$ \\
\hline${ }^{137} \mathrm{Cs}$ & $3.26 \mathrm{E}+03$ & $4.23 \mathrm{E}+03(\mathrm{SD}=2.42 \mathrm{E}+03)$ \\
\hline
\end{tabular}

Notes: The volume and inventory estimates for SX tanks come from Johnson and Field (2010).

Cobalt-60, tritium, and ${ }^{137} \mathrm{Cs}$ activities decay corrected to 9/30/2010.

The five potentially mobile contaminants of concern are in bold type.

(a) Mean value rounded to 3 digits, and decay corrected to 1/1/2001.

$\mathrm{SD}=$ Standard Deviation .

\section{B.6.5 Summary}

Table B.13 summarized the key source term parameters for principal leaks associated with tank SX113. 
Table B.13. Key source term parameters for principal leaks from tanks SX-113.

\begin{tabular}{|c|c|c|c|c|c|}
\hline Leak Event & $\begin{array}{c}\text { Duration } \\
\text { (days) }\end{array}$ & Volume (gal) & Volume (L) & $\begin{array}{c}\text { Average } \\
\text { Release Rate } \\
\text { (L/d) }\end{array}$ & $\begin{array}{c}{ }^{137} \text { Cs Inventory } \\
\text { (Ci, decay } \\
\text { corrected to } \\
9 / 30 / 2010)\end{array}$ \\
\hline \multirow{3}{*}{$\begin{array}{l}\text { May } 28- \\
\text { June } 2,1958\end{array}$} & 0 (min.) & 0 (min.) & 0 (min.) & 0 (min.) & 0 (min.) \\
\hline & 0 (best) & 0 (best) & 0 (best) & 0 (best) & 0 (best) \\
\hline & 5 (max.) & 40,000 (max.) & 151,000 (max.) & 30,300 (max.) & -- \\
\hline \multirow{3}{*}{$\begin{array}{l}\text { Nov. } 2 \text { - 14, } \\
1962\end{array}$} & $5(\min )$ & 15,000 (min.) & 56,800 (min.) & 1,620 (min.) & $7.29 \mathrm{E}+0(\mathrm{~min})$ \\
\hline & 12 (best) & 15,000 (best) & 56,800 (best) & 4,730 (best) & $3.30 \mathrm{E}+3$ (best) \\
\hline & $35(\max )$ & 15,000 (max.) & 56,800 (max.) & 11,200 (max.) & $1.23 \mathrm{E}+4(\max )$ \\
\hline \multirow[t]{3}{*}{ Totals } & 5 (min.) & 15,000 (min.) & 56,800 (min.) & 1,620 (min.) & $7.29 \mathrm{E}+0$ (min) \\
\hline & 12 (best) & 15,000 (best) & 56,800 (best) & 4,730 (best) & $3.30 \mathrm{E}+3$ (best) \\
\hline & 40 (max.) & $65,000(\max )$ & 208,000 (max.) & 30,300 (max.) & $1.23 \mathrm{E}+4(\max )$ \\
\hline
\end{tabular}

\section{B.7 Tank 241-SX-114 Waste Loss Event (after Johnson and Field 2010 and Girardot and Harlow 2014)}

\section{B.7.1 Leak Chronology}

- August 1958 - Tank SX-114 experienced a pressurization event that resulted in a maximum reported pressure of 71 in. of water ( 2.6 psi) and steam escaping from two risers. While measures were taken at the time to reduce the tank temperature and pressure, damage to the concrete tank shell may have resulted. Structural failure of the concrete tank wall approximately $18 \mathrm{ft}$ above the bottom is reported to occur if the pressure inside the tank exceeds 140 in. of water (5.2 psi) when the tank is full.

Complete failure of the concrete tank wall in August 1958 is unlikely to have occurred given that the tank pressure was only $50 \%$ of the maximum allowable, but cracks may have occurred in the concrete wall. Furthermore, the thermal coefficient of expansion for the carbon steel liner and concrete tank shell are different. Temperature excursions in the waste could lead to crushing and cracking of the concrete tank shell. This could result in a leak pathway out of the tank.

- February 1964 - Gamma activity was first reported in lateral \#3 (44-14-03) at 550 cps, however daily checking revealed no change by the end of the month.

- First quarter, through April 1972 - Received waste bringing the tank level up to 29 ft (200,000 gal of sludge and 737,000 gal of supernate for a total waste volume of 937,000 gal).

- July 10, 1972 - First indication of a leak was detected in dry well 41-14-06 (299-W23-87) at $34 \mathrm{ft} \mathrm{bgs}$ ( 16 ft above tank bottom).

- August 21, 1972 - a second radiation peak was detected in drywell 41-14-06 at 51 ft bgs, about $3 \mathrm{ft}$ above the tank bottom and continued to increase through August 31, 1972, but it did not reach the same activity level as the radiation peak $34 \mathrm{ft}$ bgs. This activity was thought to be likely associated 
with surface water transporting radioactivity down through the soil column resulting in accumulation of soil moisture at the base of the tank farm excavation.

- August and September 1972 - The waste level in tank SX-114 was lowered to $15.1 \mathrm{ft}$ above the tank bottom based on the belief that a leak had developed above the 16-ft waste height (i.e., 508,600 gal).

- October 20, 1972 - Radioactivity was first detected in drywell 41-14-04 at 3,250 cps, $57 \mathrm{ft}$ bgs.

- September 1973 - Radioactivity was detected in drywell 41-14-09 at $580 \mathrm{cps}, 60 \mathrm{ft}$ bgs.

- All remaining supernate was transferred from tank SX-114 to tanks 241-T-101 and 241-T-102, lowering the waste height to that of the sludge ( $6.8 \mathrm{ft}$ above tank bottom or 204,000 gal) in the fourth quarter of CY 1972.

- May 14, 1974 - Radioactivity was first detected in lateral \#3 (44-14-03) at the end of the lateral outside the tank shadow.

- October 11, 1974 - Contamination was detected at the end of lateral \#3 (44-14-03) at a maximum of 19 cps. Note that the end of the lateral is in the general vicinity of drywell 41-14-06.

- 1975 - The tank was removed from service.

- July 1979 - The tank was designated as interim stabilized.

- Mid-1981 - A slight increase in gamma activity was detected in drywell 41-14-06 at $51 \mathrm{ft}$ bgs. However, a separate tank leak or contamination source at the base of SX-114 (51 ft bgs) is unlikely because SST SX-114 contained little, if any, free liquid at that time. Instead, it is most likely the result of water infiltration and increased soil moisture causing migration of contamination from some other location toward drywell 41-14-06. Gamma activity observed in drywell 41-14-06 at $51 \mathrm{ft}$ bgs probably represents contamination that accumulated at the base of the backfill in the tank farm excavation. The surface of the excavation would have been compacted to some degree by vehicles and heavy equipment during tank construction, and may act as a retarding layer for downward migration.

- Tank SX-114, ancillary equipment, or piping appear to be the only possible contamination sources. However, there are no known leaks associated with pipelines in the vicinity of tank SX-114. Therefore, it is unlikely that waste loss from a pipeline could have contributed to the gamma activity detected in drywell 41-14-06 in August 1972.

\section{B.7.2 Estimated Release Events and Average Release Rate}

July 10 - August 31, 1972. Johnson and Field (2010) estimated a total leak volume of $<2,000$ gal $(7,570 \mathrm{~L})$. With an estimated duration of about 52 days that would yield an average release rate of 38 gal/day (144 L/day). However, the duration could have been as short as a couple of weeks (14 days), or perhaps as long as 4 months (120 days, April to August 1972). 


\section{B.7.3 Location}

Girardot and Harlow (2014) found that the tank SX-114 liner possibly leaked in the sidewall above the 16-ft waste level and near the bottom of the tank at possibly two locations (Figure B.8).

- The primary tank leak is believed to have originated at about $34 \mathrm{ft}$ bgrs ( $16 \mathrm{ft}$ above the tank bottom) along the southern side of the tank near drywell 41-14-06 (State Plane E 566803, N 134163 estimated from Qmap). 


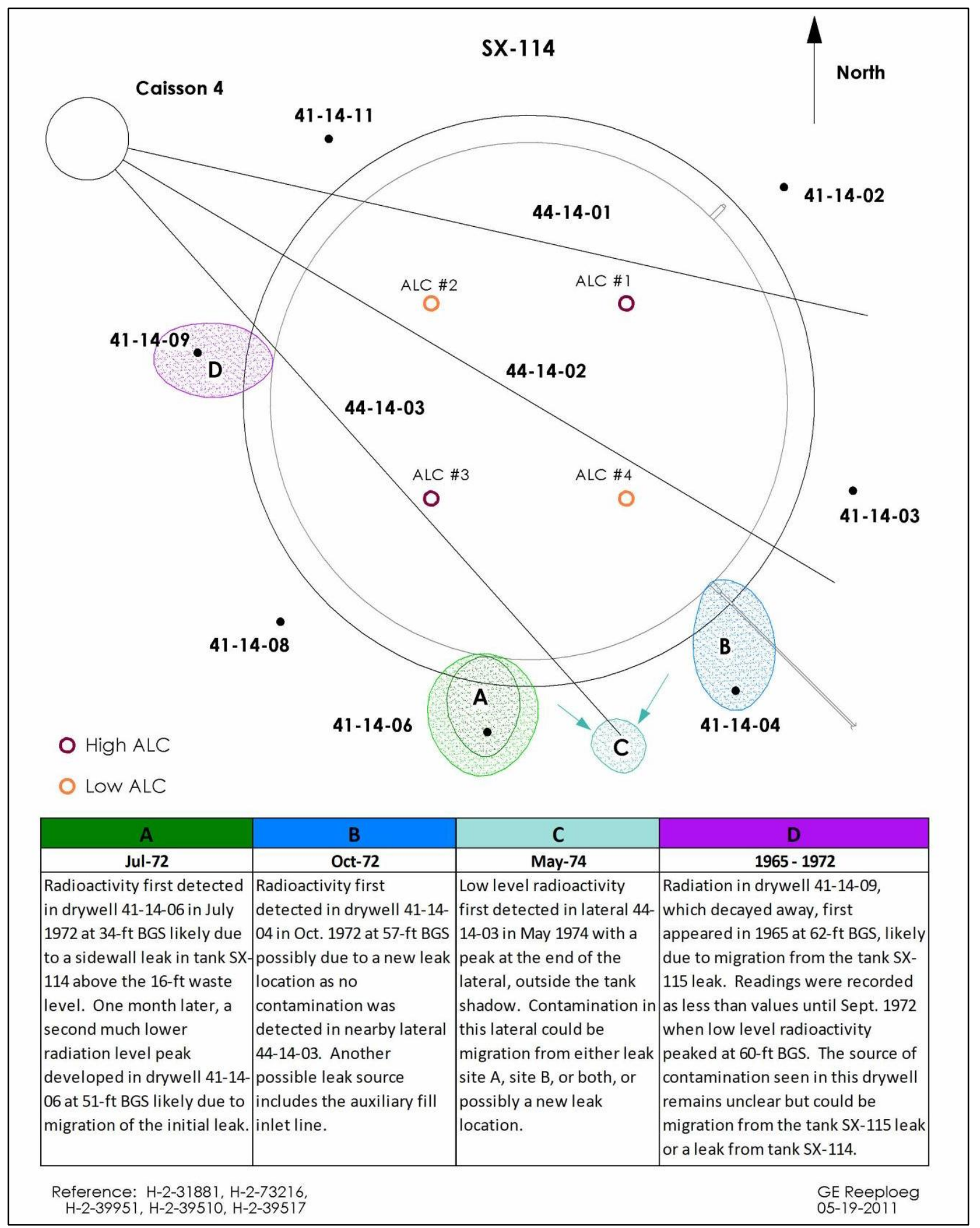

Figure B.7. Tanks SX-114 possible leak locations (from Girardot and Harlow 2014). 


\section{B.7.4 Inventory}

Johnson and Field (2010) estimated the total leak volume is estimated at $<2,000$ gal $(7,570 \mathrm{~L})$, with a total ${ }^{137} \mathrm{Cs}$ inventory of $1.05 \mathrm{E}+03 \mathrm{Ci}$ (decay corrected to September 30, 2010) as shown in Table B.14.

Table B.14. Estimated inventory from the 241-SX-114 waste release event, based on a release volume of 8,000 liters (from CH2MHill 2011, Draft, Table 3.4).

\begin{tabular}{cc}
\hline Constituent & Mass Released $(\mathrm{kg})$ \\
\hline $\mathrm{Na}$ & $1.25 \mathrm{E}+02$ \\
$\mathrm{NO}_{\mathbf{3}}$ & $\mathbf{1 . 0 3 E + 0 2}$ \\
$\mathrm{NO}_{2}$ & $5.04 \mathrm{E}+01$ \\
$\mathrm{PO}_{4}$ & $7.26 \mathrm{E}-01$ \\
$\mathrm{SO}_{4}$ & $1.03 \mathrm{E}+01$ \\
$\mathrm{~F}$ & $5.06 \mathrm{E}-02$ \\
$\mathbf{U}$ & $\mathbf{3 . 9 4 E - 0 2}$ \\
$\mathbf{C r}$ & $\mathbf{2 . 0 2 E + 0 0}$ \\
\hline Constituent & Activity Released $(\mathrm{Ci})$ \\
\hline${ }^{60} \mathrm{Co}$ & $7.79 \mathrm{E}-03$ \\
${ }^{\mathbf{1 2 9}} \mathbf{I}$ & $\mathbf{1 . 1 1 E - 0 4}$ \\
${ }^{99} \mathbf{T c}$ & $\mathbf{1 . 6 3 E - 0 1}$ \\
${ }^{3} \mathrm{H}$ & $2.01 \mathrm{E}-02$ \\
${ }^{238} \mathrm{Pu}$ & $2.89 \mathrm{E}-04$ \\
${ }^{239} \mathrm{Pu}$ & $6.44 \mathrm{E}-03$ \\
${ }^{137} \mathrm{Cs}$ & $1.05 \mathrm{E}+03$ \\
\hline Notes: & The volume and inventory estimates for SX tanks come from \\
RPP-ENV-39658. & \\
Cobalt-60, tritium, and ${ }^{137}$ Cs activities decay corrected to 9/30/2010. \\
The five potentially mobile contaminants of concern are in bold type. \\
\hline
\end{tabular}

\section{B.7.5 Summary}

Table B.15 summarizes the key source term parameters for leaks from tank SX-114.

Table B.15. Key source term parameters for leaks from tank SX-114.

\begin{tabular}{lccccc}
\hline & & & & & \\
Average & & $\begin{array}{c}{ }^{137} \text { Cs Inventory } \\
\text { (Ci, decay } \\
\text { Release Rate } \\
\text { (L/d) }\end{array}$ & $\begin{array}{c}\text { correct to } \\
9 / 30 / 2010)\end{array}$ \\
\hline Leak Event & $\begin{array}{c}\text { Duration } \\
\text { (days) }\end{array}$ & Volume (gal) & Volume (L) & 1.36 (min.) & 0 (min.) \\
Auly $10-$ & 14 (min.) & 43 (min.) & 163 (min.) & $>146$ (best) & $1.05 \mathrm{E}+03$ (best) \\
1972 (Total) & 52 (best) & $<2,000$ (best) & $<7,570$ (best) & 540 (max.) & $\begin{array}{c}1.05 \mathrm{E}+03 \\
\text { (max.) }\end{array}$ \\
\hline
\end{tabular}




\section{B.8 Tank 241-SX-115 Waste Loss Event (after Johnson and Field 2010 and Girardot and Harlow 2014 |)}

\section{B.8.1 Leak Chronology}

- December 12, 1963 - A scan of lateral no. 2 indicated slightly elevated radiation peaks between 60 and $98 \mathrm{cpm}$. However there was no reported liquid level decline associated with the activity detected in lateral no. 2; and no estimate of the waste loss made — any waste loss in 1963 is likely to have been small.

- February 24-March 2, 1965 - The tank was determined to be leaking sodium nitrate waste to the ground, based on an observed liquid level decrease of about 16 in. and gamma activity detected in the laterals. It contained $\sim 111,000$ gal ( 47.7 in.) of waste at the time this leak was discovered. A fairly large single or series of openings led to an assumed initial leak rate of $5.2 \mathrm{gal} / \mathrm{min}$.

- March 3, 1965 - 52,349 gal of remaining pumpable sodium nitrate waste transferred out of the tank.

- March 2 to March 8, 1965 - The liquid level continued to decrease but at a reduced rate. It is unclear why there was a change in the liquid level rate of decrease. For unknown reasons the opening(s) may have partially closed resulting in a slower rate of leakage $(0.6 \mathrm{gal} / \mathrm{min})$.

- March 9, 1965 - The remaining waste was pumped from tank SX-115, leaving an 8 1/2-in. heel.

- June 1966 - adioactivity was first detected in lateral 44-15-02 at 14.2 to $26.2 \mathrm{ft}$ from the northeast edge of the tank.

- January 1973 - Radioactivity at much higher levels was first detected in January 1973 in lateral 44$15-03$ at $7.6 \mathrm{ft}$ from the northeast edge. However, it is likely radioactivity reported in lateral 44-15-03 was present in 1966 as indicated by Raymond and Shdo (1966); but that earlier data were not recovered.

- October 1978 - The tank was declared interim stabilized.

- June-July 1981 - Core samples were taken of the tank haunch, wall, and footings; encountering contamination in the bottom $6 \mathrm{ft}$ of core from the wall, reaching a max of 1,600 $\mathrm{mR}$ in the footing.

\section{B.8.2 Estimated Release Volume:}

Johnson and Fields (2010) found the best estimate total leak volume from SX-115 to be 51,000 gal (193,000 L) based on measured liquid level decreases. However, Fields and Jones (2004) and Rogers (2014) both cite a total release volume of 50,000 gal (189,000 L), while CH2MHill (2011) used an estimated a total release volume of 198,000 L (52,300 gal). 


\section{B.8.3 Estimated Release Events, Duration, and Release Rates}

- February 24 - March 8, 1965 (assumed duration of 12 days - however, Girarodt and Harlow [2014] suggest that most of the liquid level decrease may have happened over a period of 6 days, see Figure B.9).

- Assuming a total estimated leak volume of 51,000 gal (193,000 L) and a total duration of 12 days would yield an average release rate of 4,250 gal/d $(16,100 \mathrm{~L} / \mathrm{d})$, or about $3 \mathrm{gal} / \mathrm{min}$. However, liquid level decreases (Girarodt and Harlow 2014, Figure 11.2) suggest that the tank leaked at a rate of about $5.2 \mathrm{gal} / \mathrm{min}$ for the first 6 days $(44,900 \mathrm{gal})$ and $0.6 \mathrm{gal} / \mathrm{min}$ for the next 6 days $(5,180 \mathrm{gal})$.

\section{B.8.4 Leak Location}

Girarodt and Harlow (2014, p. 11-32) found that the leak likely occurred at or near the bottom of the tank and identified three possible leak site locations (Figure B.9), suggesting simultaneous ruptures as the tank bottom deformed and pulled away from the sidewalls. State Plane coordinates for these locations are E 566779, N 134183; E 566785, N 134177; and E 566766, N 134165 - estimated from Qmap. 


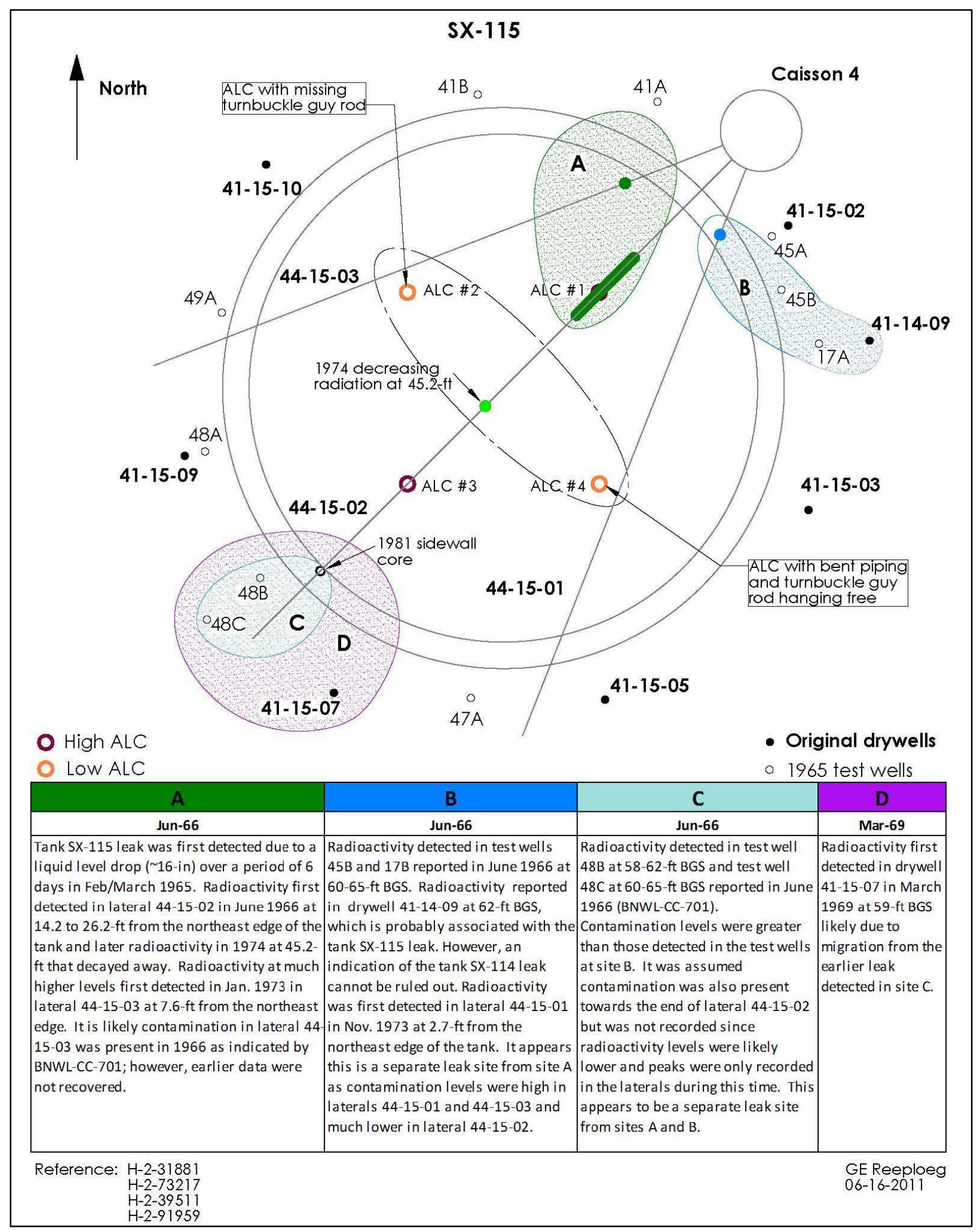

Figure B.8. Tank SX-115 possible leak locations (from Girarodt and Harlow 2014). 


\section{B.8.5 Inventory}

Johnson and Fields (2010) concluded that the best estimate ${ }^{137}$ Cs inventory for the SX-115 tank leak was $16,800 \mathrm{Ci}$ (decay corrected to January 1, 2001). This equates to an inventory of about 13,100 Ci (decay corrected to September 30, 2010). This compares to an estimate of $\sim 11,900 \mathrm{Ci}$ (decay corrected to September 30, 2010) modified from Kincaid et al.( 2006) and 12,800 Ci (decay corrected to September 30, 2010) modified from Jones et al. (2000). Johnson and Fields (2010) cite Raymond and Shdo (1966) as estimating a ${ }^{137} \mathrm{Cs}$ inventory of $8,530 \mathrm{Ci}$ (decay corrected to 9/30/2010) based on soil data compared to 14,600 Ci (decay corrected to 9/30/2010) estimated from liquid level decreases and a tank waste sample concentration. Note, that $\mathrm{CH} 2 \mathrm{MHill}$ (2011) reported an inventory of 1,340 $\mathrm{Ci}$ (decay, corrected to September 30, 2010); this is an order of magnitude different and is most likely an error that was corrected in Table B.16.

Johnson and Fields (2010) suggested that the inventories for other analytes should be calculated by multiplying the SIM inventories by a ratio of 1.13 to account for volume and sample differences. This was apparently done by CH2MHill (2010), yielding the total best estimate inventory shown in Table B.16.

Table B.16. Estimated inventory from the 241-SX-115 waste release event, based on a release volume of 198,000 liters (52,300 gal) (from CH2MHill 2011, Draft, Table 3.4, and Appendix C of Corbin et al. 2005).

\begin{tabular}{|c|c|c|}
\hline Constituent & $\begin{array}{l}\text { SCW-50280 (draft) } \\
\text { Mass Released (kg) }\end{array}$ & $\begin{array}{l}\text { SIM (Corbin et al. 2005) } \\
\text { Mass Released (kg) }\end{array}$ \\
\hline $\mathrm{Na}$ & $1.68 \mathrm{E}+04$ & $1.49 \mathrm{E}+4(\mathrm{SD}=7.90 \mathrm{E}+2)$ \\
\hline $\mathrm{NO}_{3}$ & $1.61 E+04$ & $1.43 \mathrm{E}+4(\mathrm{SD}=7.27 \mathrm{E}+2)$ \\
\hline $\mathrm{NO}_{2}$ & $0.00 \mathrm{E}+00$ & $6.04 \mathrm{E}+3(\mathrm{SD}=3.33 \mathrm{E}+2)$ \\
\hline $\mathrm{PO}_{4}$ & 7.92E-02 & $7.01 \mathrm{E}-2(\mathrm{SD}=8.47 \mathrm{E}-3)$ \\
\hline $\mathrm{SO}_{4}$ & $2.96 \mathrm{E}+02$ & $2.62 \mathrm{E}+2(\mathrm{SD}=1.49 \mathrm{E}+1)$ \\
\hline $\mathrm{F}$ & $6.23 \mathrm{E}-03$ & $5.51 \mathrm{E}-3(\mathrm{SD}=6.56 \mathrm{E}-4)$ \\
\hline $\mathbf{U}$ & $6.60 \mathrm{E}+00$ & $5.84 \mathrm{E}+0(\mathrm{SD}=3.50 \mathrm{E}+0)$ \\
\hline $\mathrm{Cr}$ & $2.68 \mathrm{E}+02$ & $2.37 \mathrm{E}+2(\mathrm{SD}=1.72 \mathrm{E}+1)$ \\
\hline Constituent & Activity Released (Ci) & \\
\hline${ }^{60} \mathrm{Co}$ & $1.02 \mathrm{E}+00$ & $3.26 \mathrm{E}+0(\mathrm{SD}=2.48 \mathrm{E}+0)$ \\
\hline${ }^{129} \mathbf{I}$ & $7.96 \mathrm{E}-03$ & $7.05 \mathrm{E}-3(\mathrm{SD}=5.03 \mathrm{E}-3)$ \\
\hline${ }^{99} \mathrm{Tc}$ & $5.12 \mathrm{E}+00$ & $4.53 \mathrm{E}+0(\mathrm{SD}=3.26 \mathrm{E}+0)$ \\
\hline${ }^{3} \mathrm{H}$ & $2.50 \mathrm{E}+01$ & $3.83 \mathrm{E}+1(\mathrm{SD}=3.11 \mathrm{E}+1)$ \\
\hline${ }^{238} \mathrm{Pu}$ & $3.71 \mathrm{E}-02$ & $3.28 \mathrm{E}-2(\mathrm{SD}=5.35 \mathrm{E}-2)$ \\
\hline${ }^{239} \mathrm{Pu}$ & $1.08 \mathrm{E}+00$ & $9.56 \mathrm{E}-1(\mathrm{SD}=6.45 \mathrm{E}-1)$ \\
\hline${ }^{137} \mathrm{Cs}$ & 1.34E+03 1.34E+4* $(\sim 1.15 \mathrm{E}+4)$ & $1.49 \mathrm{E}+4(\mathrm{SD}=1.13 \mathrm{E}+4)$ \\
\hline
\end{tabular}

Notes: The volume and inventory estimates from SGW-50280 are reportedly from RPP-ENV-39658.

Cobalt-60, tritium, and ${ }^{137}$ Cs activities decay corrected to 9/30/2010.

The five potentially mobile contaminants of concern are in bold type.

(a) Mean value rounded to 3 digits, and decay corrected to January 1. 2001.

$\mathrm{SD}=$ Standard Deviation

* Corrected for consistency with Johnson and Fields (2010). Note, multiply SIM mean by $1.13=1.68 \mathrm{E}+4$ (decay correcting to $9 / 30 / 2010=\sim 1.15 \mathrm{E}+4$ ) 


\section{B.8.6 Summary}

Table B.17 summarizes the key source term parameters for principal leaks from tank SX-115.

Table B.17. Key source term parameters for leaks associated with tank SX-115.

\begin{tabular}{|c|c|c|c|c|c|}
\hline Leak Event & $\begin{array}{l}\text { Duration } \\
\text { (days) }\end{array}$ & Volume (gal) & Volume (L) & $\begin{array}{l}\text { Release Rate } \\
\text { (L/d) }\end{array}$ & $\begin{array}{c}{ }^{137} \text { Cs Inventory } \\
\text { (Ci, decay } \\
\text { corrected to } \\
9 / 30 / 2010)\end{array}$ \\
\hline $\begin{array}{l}\text { A1. February } \\
24-\text { March 2, } \\
1965\end{array}$ & 6 (best) & 44,900 (best) & 170,000 (best) & 28,300 (best) & -- \\
\hline $\begin{array}{l}\text { A2. March 3- } \\
8,1965\end{array}$ & 6 (best) & 5,180 (best) & 19,600 (best) & 3,270 (best) & -- \\
\hline Totals & $\begin{array}{c}6 \text { (min.) } \\
12 \text { (best) } \\
12 \text { (max.) }\end{array}$ & $\begin{array}{l}50,000 \text { (min.) } \\
51,000 \text { (best) } \\
52,300 \text { (max) }\end{array}$ & $\begin{array}{l}189,000 \text { (min.) } \\
193,000 \text { (best) } \\
198,000 \text { (max) }\end{array}$ & $\begin{array}{c}15,750 \text { (min.) } \\
16,080 \text { (best est.) } \\
33,000 \text { (max.) }\end{array}$ & $\begin{array}{c}8.53 \mathrm{E}+3(\min ) \\
1.34 \mathrm{E}+04 \text { (best) } \\
1.46 \mathrm{E}+4 \text { (max) }\end{array}$ \\
\hline
\end{tabular}

\section{B.8.7 References}

Agnew, S.F., and R.A. Corbin. 1998. Analysis of SX Farm Leak Histories-Historical Leak Model (HLM). LA-UR-96-3537, Los Alamos National Laboratory, Los Alamos, New Mexico.

CH2MHill. 2011. Preliminary Conceptual Site Model Report for 200-DV-1 Operable Unit Waste Sites in the S Complex Area. SGW-50280 (draft), CH2MHILL Plateau Remediation Company, Richland, Washington.

Corbin, R.A., B.C. Simpson, M.J. Anderson, W.F. Danielson III, J.G. Field, T.E. Jones, and C.T. Kincaid. 2005. Hanford Soil Inventory Model, Rev. 1. RPP-26744, Rev. 0, CH2MHill Hanford Group, Richland, Washington.

Field, J.G., and T.E. Jones. 2004. Tank Farm Vadose Zone Contamination: Volume Estimates for Risk Assessments. RPP-23405, Rev. 0, CH2M HILL Hanford Group, Richland, Washington.

Girardot, C.L., and D.G. Harlow. 2014. Hanford Single-Shell Tank Leak Causes and Locations - 241-SX Farm. RPP-RPT-54910, Rev. 0, Washington River Protection Solutions, Richland, Washington.

Kincaid, C.T., P.W. Eslinger, R.L. Aaberg, T.B. Miley, I.C. Nelson, D.L. Strenge, J.C. Evans Jr. 2006. Inventory Data Package for Hanford Assessments. PNNL-15829, Rev. 0, Pacific Northwest National Laboratory, Richland, Washington.

Knepp, A.J. 2002. Field Investigation Report for Waste Management Area S-SX. RPP-7884, Rev. 0, CH2M HILL Hanford Group, Richland, Washington.

Johnson, M.E., and J.G. Field. 2010. Hanford SX-Farm Leak Assessments Report. RPP-ENV-39658, Rev. 0, Washington River Protection Solutions, Richland, Washington. 
Jones, T.E., R.A. Watrous, and G.T. Maclean. 2000. Inventory Estimates for Single-Shell Tank Leaks in $S$ and SX Tank Farms. RPP-6285, Rev. 0, CH2M HILL Hanford Group, Richland, Washington.

Raymond, J.R., and G.E. Shdo. 1966. Characterization of Subsurface Contamination in the SX Tank Farm. BNWL-CC-701, Battelle Northwest, Richland, Washington.

Rogers, M.L. 2014. Waste Tank Summary Report for Month Ending May 31, 2014. HNF-EP-0182, Rev. 317, Washington River Protection Solutions, Richland, Washington. 
PNNL-23737

RPT-DVZ-AFRI-026

\section{Distribution}

No. of

$\underline{\text { Copies }}$

ONSITE

DOE, Richland Operations Office

JG Morse

(PDF)
No. of

Copies

6 Pacific Northwest National Laboratory

$\begin{array}{ll}\text { MJ Truex } & (\mathrm{PDF}) \\ \text { M Oostrom } & (\mathrm{PDF}) \\ \text { GV Last } & \text { (PDF) } \\ \text { CE Strickland } & \text { (PDF) } \\ \text { GD Tartakovsky } & \text { (PDF) } \\ \text { DM Wellman } & \text { (PDF) }\end{array}$






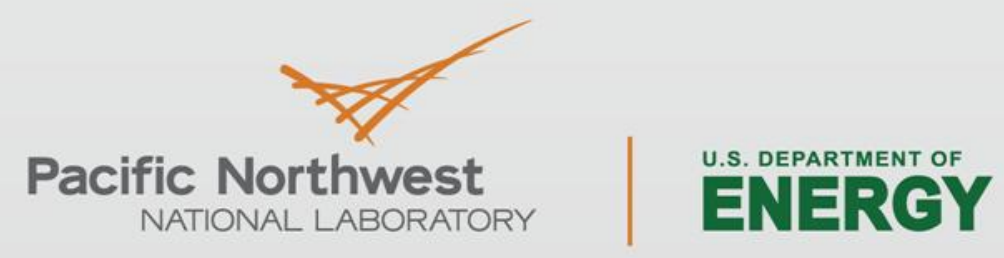

Proudly Operated by Battelle Since 1965

902 Battelle Boulevard

P.O. Box 999

Richland, WA 99352

1-888-375-PNNL (7665)

www.pnnl.gov 